\title{
INVESTIGATION OF SUPERCRITICAL FLUID TECHNOLOGY TO PRODUCE DRY PARTICULATE FORMULATIONS OF ANTIBODY FRAGMENTS
}

Louise Santha SARUP B.Eng. (Hons), MSc.

Thesis submitted for the degree of Doctor of Philosophy

University College London

University of London 
ProQuest Number: U643906

All rights reserved

INFORMATION TO ALL USERS

The quality of this reproduction is dependent upon the quality of the copy submitted.

In the unlikely event that the author did not send a complete manuscript and there are missing pages, these will be noted. Also, if material had to be removed, a note will indicate the deletion.

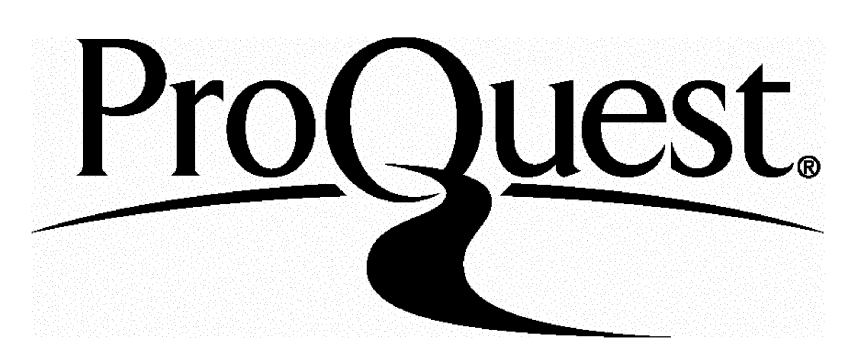

ProQuest U643906

Published by ProQuest LLC(2016). Copyright of the Dissertation is held by the Author.

All rights reserved.

This work is protected against unauthorized copying under Title 17, United States Code. Microform Edition (c) ProQuest LLC.

\author{
ProQuest LLC \\ 789 East Eisenhower Parkway \\ P.O. Box 1346 \\ Ann Arbor, MI 48106-1346
}




\section{ABSTRACT \\ Investigation of Supercritical Fluid Technology to Produce Dry Particulate Formulations of Antibody Fragments}

Micro, submicrometre and ultrafine particles are increasingly in demand as they have a broad application in pharmaceutical delivery and needle-free powder injection. Conventional methods of powder preparation including freeze-drying and spray drying have considerable disadvantages for these applications.

The use of supercritical fluids for materials' processing is one of the efficient and novel approaches used to achieve high purity micron-sized particles in a single step. The technique of Solution Enhanced Dispersion by Supercritical Fluids (SEDS) dramatically reduces or eliminates the problems associated with current, conventional particle-formation and size-reduction processes. SEDS involves the rapid dispersion, mixing and extraction of a protein solution, anti-solvent and supercritical carbon dioxide.

SEDS has been used to produce dry particulate formulations of three antibody fragments (D1.3Fv, 4D5Fab, PEG-4D5Fab) and a whole antibody (CDP850). The aim of this research was to assess affects of the SEDS process on the functionality antibody fragments and antibody.

The results demonstrated that dried formulations of antibody fragments and antibody can be produced using the SEDS process. The level of damage caused during SEDS was found to be dependent on choice solvent and protein. The main cause of activity loss was identified as the presence of both water and solvent during SEDS processing. 


\section{ACKNOWLEDGEMENTS}

First and foremost, I would like to express my gratitude and thanks to Professor Mike Hoare for his invaluable support and guidance throughout the period of this research. I would also like to acknowledge the BBSRC for the generous provision of a CASE award with Bradford Particle Design, which provided the financial support for this project. I am also very grateful to all those members of the Department of Biochemical Engineering, past and present, who assisted in any way with this project, in particular Daniel Bracewell who not only helped with the biosensor work but read this tome almost willingly.

From Bradford Particle Design I wish to thank everyone who helped me, especially Dr Gwyn Humphreys, Professor Peter York and Mr George Townend. I am indebted to the support of Dr Raymond Sloan who gave me untold amounts of help and advice. Special thanks go to Mrs Madge Hollowood who not only helped me with the technical side of my work but also gave me a 'home away from home' whenever I visited Bradford, I am eternally grateful for your love and support.

Finally, I would like to express limitless gratitude, thanks and love to all my friends and family for their encouragement and support during this project. Special thanks go to Stuart for all his help along the way and especially in putting this final thesis together, to Tamara for sharing and understanding the PhD experience with me, we finally made it and to Diccon for making the many cocktails that smoothed the way. I am indebted to my parents for their love, support and understanding along the way. 
Investigation of Supercritical Fluid Technology for Producing Dry Particulate Formulations of Antibody Fragments Acknowledgements

I dedicate this thesis to my parents with thanks for their unfailing love and support

They gave this child more of themselves than that, These became part of that child who went forth everyday, and who now goes, and will always go forth every day.

(Walt Whitman) 


\section{Table of Contents}

Title

Abstract

Acknowledgements

3

Dedication

Table of Contents 5

$\begin{array}{ll}\text { List of Figures } & 9\end{array}$

$\begin{array}{ll}\text { List of Tabies } & 10\end{array}$

1 Introduction -..-12

1.1 Purpose of introduction-...-13

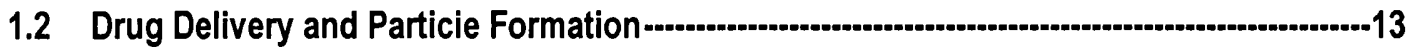

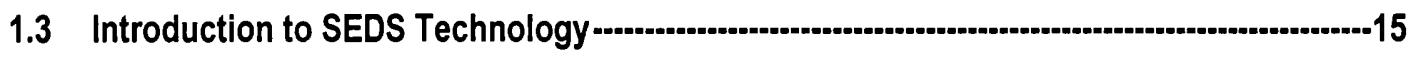

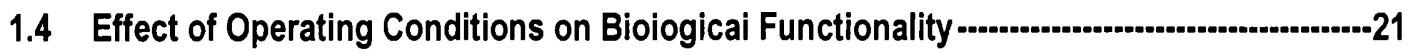

1.4 .1 Temperature---22

$1.4 .2 \mathrm{pH}$-.-22

1.4.3 Chemical Environment -...

1.4.3.1 Oxidation -..-23

1.4.3.2 Deamidation -

1.4.4 Shear Environment - -.

1.4 .5 Interfacial Environment ---

1.4.5.1 Solid-Liquid Interfaces -..- 26

1.4.5.2 Air-Liquid Interfaces -.--27

1.4.5.3 Liquid-Liquid Interfaces -...-27

1.5 Brief Overview of Formulation-..-..-.-28

1.6 Requirements for Drying Proteins

1.7 Drying of Materiais - generai overview-...-...-31

1.7.1 Drying of Foodstuffs

1.7.2 Drying of Pharmaceutical Products ---32

1.7.3 Materials Processing for Particle Formation -

1.7.4 Freeze Drying --...-34

1.7.4.1 Impact of Freeze-Drying on Biological Functionality

1.7.5 Spray-Drying---37

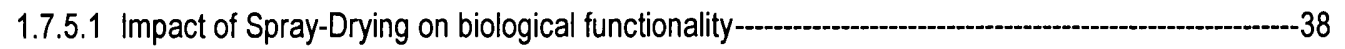

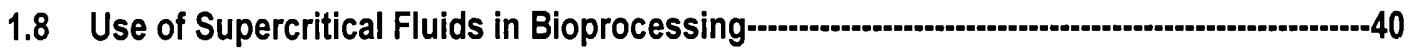


Investigation of Supercritical Fluid Technology to Produce Dry Particulate Formulations of Antibody Fragments

Table of Contents

1.8.1 Phase Diagram for Carbon Dioxide-42

1.8.2 Use for Supercritical Fluids -.-44

1.8.2.1 Chromatography, Extraction and Environmental Applications -...

1.8.3 Use for Drying/Materials Processing -...-47

1.8.3.1 Rapid Expansion of Supercritical Fluid Solutions (RESS)-ב-ב-_-_t

1.8.3.2 Gas Anti-Solvent (GAS) ----48

1.8.3.3 Precipitation with a Compressed Anti-Solvent (PCA)--...-50

1.8.3.4 Particles from gas saturated solution process-

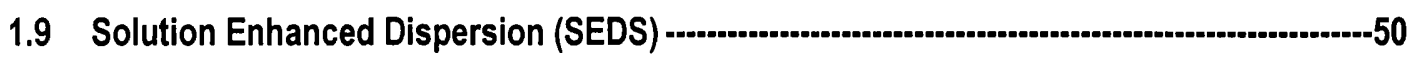

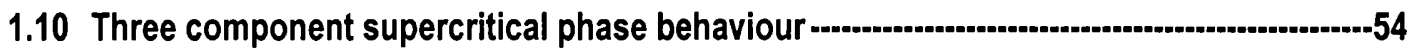

1.11 Antibodies

1.11.1 Structure and Function of Antibodies -

1.11.2 Antibody Production --59

1.11.3 Applications of Antibodies and Antibody Fragments-a

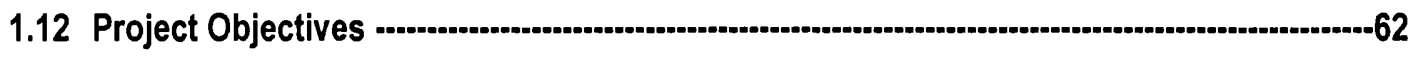

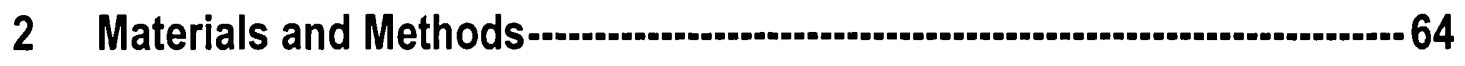

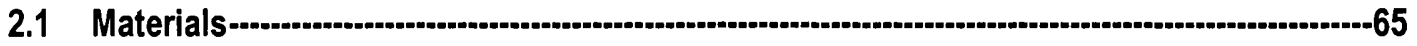

2.2 Purification of D1.3Fv

2.2.1 Affinity Chromatography --66

2.2.2 Sample Dialysis

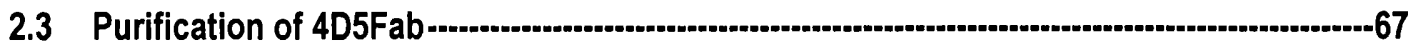

2.3.1 Periplasmic Extraction-

2.3.2 Fluid Protein Liquid Chromatography (FPLC) -

2.3.3 Sample Dialysis ---on

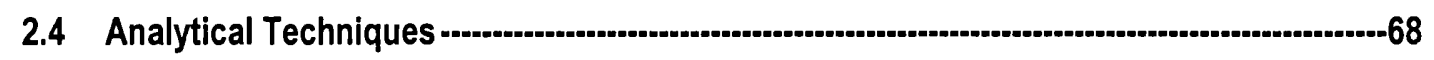

2.4.1 Optical Biosensor- 68

2.4.1.1 Making Biosensor Cuvettes --.-68

2.4.2 4D5Fab and 4D5 PEG-Fab ELISA

2.4.3 CDP850 ELISA

2.4.4 Total Protein Measurements-32

2.5 Experimental Procedures

2.5.1 Temperature Stability Experiments --..-73

2.5.2 Solvent Stability Experiments-o-

2.5.2.1 Initial Solvent Experiments-

2.5.2.2 Modified Solvent Experiments --.-13 
Investigation of Supercritical Fluid Technology to Produce Dry Particulate Formulations of Antibody Fragments Table of Contents

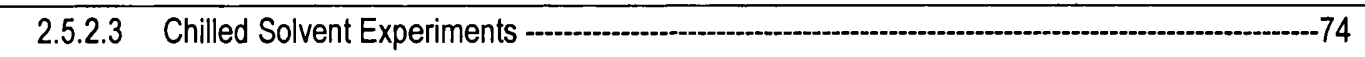

2.5.3 Shear Experiments

2.5 .4 Freeze Drying -

2.5 .5 pHExperiment

2.5 .6 Stability Tests--.- 77

2.5.7 Timed Stability Runs -- 78

2.5.8 SEDS Experiment - 78

2.5.8.1 Different Temperature SEDS-

2.5.8.2 Different Solvent SEDS-81

2.5.8.3 Different Nozzle Configuration SEDS --:-o1

3. Preliminary Stability Studies on D1.3Fv and 4D5Fab

3.1 Introduction -13

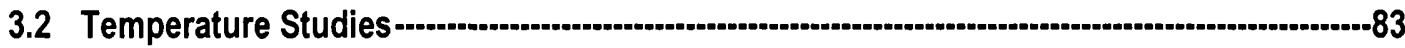

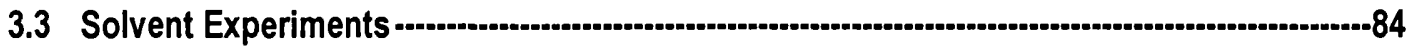

3.4 The Effects of Temperature and Solvent

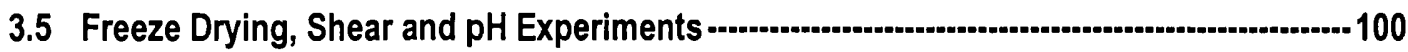

3.5.1 Introduction -ב-100

3.5.2 Shear Experiments----100

3.5.3 pHExperiments

3.5.4 Freeze Drying - 101

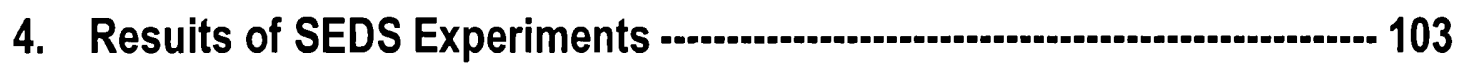

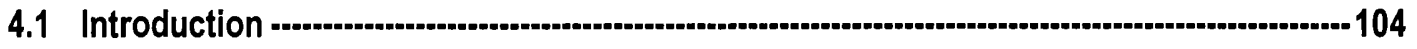

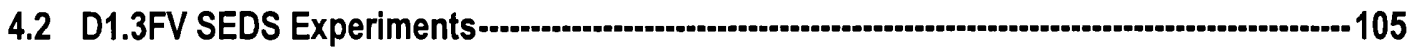

4.3 4D5Fab SEDS Experiments

4.4 CDP850 SEDS Experiments -...-123

4.5 SEDS runs using PEG

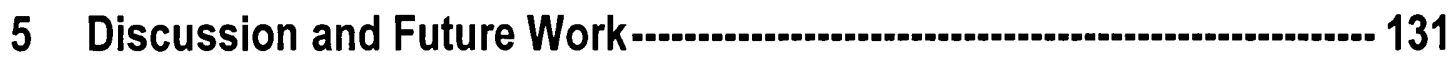

5.1 Introduction - 132

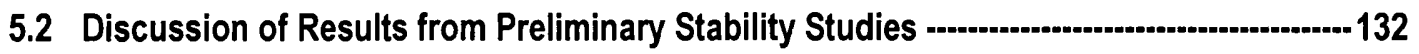

5.2.1 Temperature Experiments--132

5.2 .2 Solvent Experiments- 133

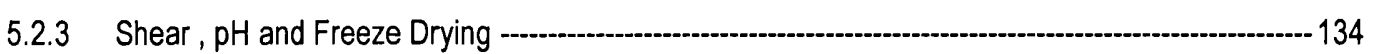




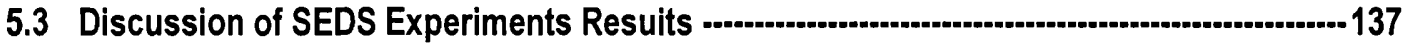

5.3.1 Temperature and Solvent Effects -.-137

5.3.2 Stability Tests

5.3.3 Protein Effect - 141

5.4 Overall Conclusions

5.5 Future Work -

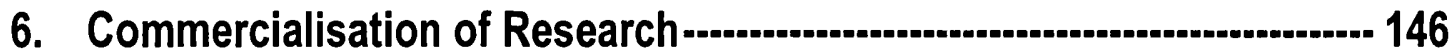

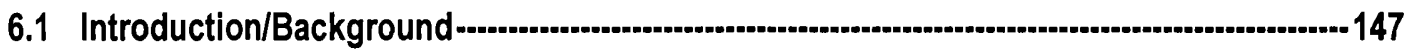

6.2 Evaluation-..-148

6.2.1 Technical Evaluation - 148

6.2.2 Commercial Evaluation - 149

6.2.3 Development Stages - 152

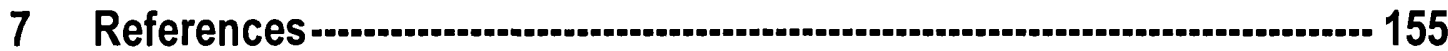

Appendices - substantive minor additions to thesis--.---.---.------.-----169

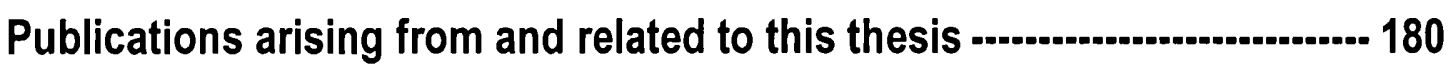




\section{List of Figures}

Figure 1.1 Comparison of SEDS and Conventional Particle Formation--16

Figure 1.2 The SEDS Experimental set up--17

Figure 1.3 Inside the SEDS Oven-18

Figure $1.4 \quad$ Nozzle Attachment to SEDS Drying Chamber---_.--19

Figure 1.5 SEDS Nozzles--.-20

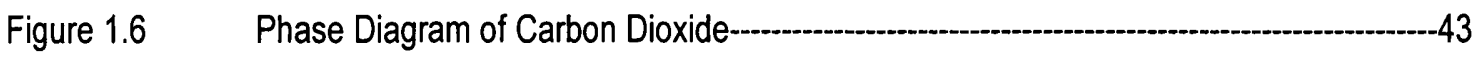

Figure 1.7 Schematic Diagram of the SEDS three component supercritical

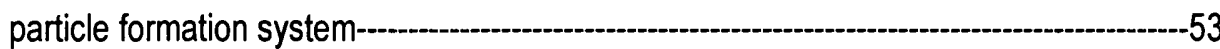

Figure 1.8 A typical phase diagram for a three component system of aqueous, organic and $\mathrm{CO}_{2}$ process streams---.--55

Figure 1.9 Antibody and derived fragments-.-58

Figure 2.1 Three component nozzle diagrams showing order of component addition-_-_-_--.-75

Figure 2.2 The rotating shear device--on

Figure 3.1 Results from temperature stability experiments using low concentrations of antibody fragment D1.3Fv-

Figure 3.2 Results from temperature stability experiments using medium concentrations of antibody fragment $\mathrm{D} 1.3 \mathrm{Fv}$ $-86$

Figure 3.3 Results from temperature stability experiments using high concentrations of antibody fragment D1.3Fv-

Figure 3.4 Graph showing the results obtained at $20^{\circ} \mathrm{C}$ and $60^{\circ} \mathrm{C}$ for all concentrations of antibody fragment$-88$

Figure 3.5 Results from 4D5Fab temperature stability experiment-_-

Figure 3.6 Results from solvent stability experiments--91

Figure 3.7 Results from solvent stability experiment with mannitol added to antibody solution$-92$

Figure $3.8 \quad$ Results from $8 \%$ and $96 \%$ solvent experiments using D1.3Fv

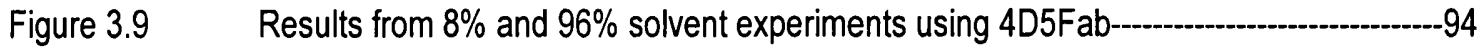

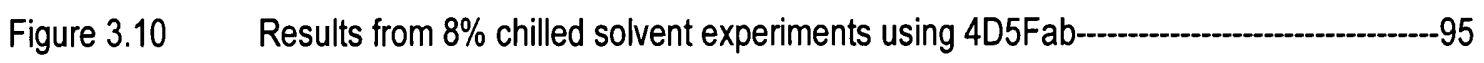

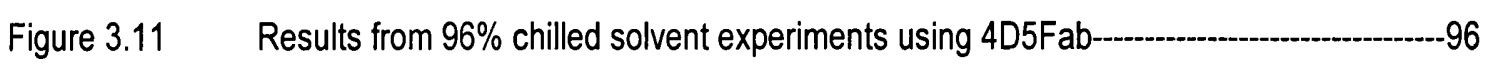

Figure 4.1 Part of phase diagram showing positioning of the two sets of drying conditions used for SEDS runs $-106$

Figure 4.2 Graph showing results of timed stability tests using CDP850-129 


\section{List of Tables}

Table 1.1 Some major excipient groups used for stabilising bioactivity 30

Table 1.2 Amino acids, carbohydrates and polyols most widely used as excipients and stabilisers$-30$

Table 1.3 Thermophysical Properties of Supercritical Fluids Compared to Gases and Liquids 41

Table 3.1

Comparison of lab-scale and SEDS 98

Table 3.2 Rate constants for temperature and solvent tests-99

Table 3.3 Results of shear experiments carried out on D1.3Fv and 4D5Fab- 101

Table $3.4 \quad$ Results of freeze-drying experiments-102

Table 4.1 Table of data from SEDS experiments using D1.3Fv-107

Table 4.2 Results of stability tests carried out using freeze-dried D1.3Fv-on

Table 4.3 Results of SEDS processing 4D5Fab, using IPA as the solvent and varying temperature---o-112

Table 4.4 Results of second set of SEDS processed 4D5Fab, using IPA as the solvent and varying temperature-

Table 4.5 Comparison of activity yields and specific activities recovered from 4D5Fab SEDS temperature experiments$-114$

Table 4.6 Results of SEDS runs carried out to investigate the effect of solvent on 4D5Fab

Table 4.7 Results obtained from second set of SEDS runs carried out to investigate the effect of solvent on 4D5Fab-

Table 4.8 Results of SEDS runs using different nozzle configurations--117

Table 4.9 Results of stability tests carried out using freeze-dried 4D5Fab-_-_-119

Table 4.10 Results of second set of stability tests carried out using freeze-dried 4D5Fab--------120

Table 4.11 Results of third set of stability tests carried out using freeze-dried 4D5Fab---a--------121

Table 4.12 Comparison of activity yields and specific activities recovered from 4D5Fab stability experiments--

Table 4.13 Results obtained from SEDS processing a whole antibody, CDP850-125

Table 4.14 Results obtained from second set of SEDS processing experiments using a whole antibody, CDP850-126

Table 4.15 Results of stability tests carried out using freeze-dried CDP850 at $0.5 \mathrm{mg} / \mathrm{ml}-\mathrm{a}_{------127}$ 
Investigation of Supercritical Fluid Technology to Produce Dry Particulate Formulations of Antibody Fragments List of Tables

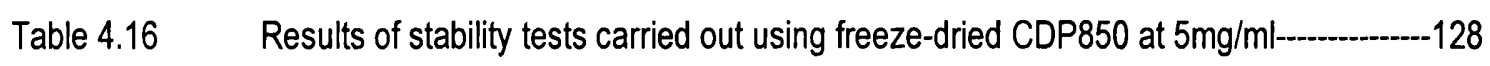
Table 4.17 Results of SEDS processing PEG-4D5Fab and CDP850 with PEG added to antibody solution- 


\section{CHAPTER ONE}

INTRODUCTION 


\section{Introduction}

\subsection{Purpose of Introduction}

Chapter One will give a broad introduction to the process area that the subject of this thesis, supercritical fluid particle production, fits into. The topics covered in this section of the thesis include drug delivery and the increasing interest that is being shown in this area. The sensitivity of proteins to damage and the most common methods of protein damage are covered. The process used in the work covered by this thesis, Solution Enhanced Dispersion by Supercritical Fluids (SEDS) is discussed in detail as is the use and production of antibodies and antibody fragments. The purpose of this chapter is to give a general overview of areas related to the research work conducted for this thesis.

\subsection{Drug Delivery and Particle Formation}

The tremendous growth in therapeutic products from biotechnology has led to the increased demand for improved methods of delivery of biopharmaceuticals. This has resulted in the development of numerous technologies and companies focused on drug delivery methods. Many new drugs are potent growth factors or monoclonal antibodies, both of which pose unique delivery challenges. It is critical to have a detailed understanding of the physiochemical characteristics of the protein, its pharmacology and intended clinical application prior to embarking on the development of a delivery system. Traditional drug development of proteins has relied on parenteral injections of liquid formulations as the fastest and often least expensive route to commercialisation. In the future, the success of drug development will depend upon innovative methods for protein delivery.

When selecting a protein delivery method for commercial development the main considerations include market competition, patient convenience and compliance, requirement for local or topical delivery and systemic toxicity or other safety issues. Several new protein delivery methods are being developed primarily to address market competition for approved protein therapeutics such as insulin, human growth hormone, interferons and erythropoetin. These systems seek to provide an advantage by improving patient convenience and/or regulatory compliance (Burgess, 1993).

Proteins, unlike small molecule drugs, are not easily administered by oral administration. However, there have been attempts to overcome the difficulties of parenteral protein administration through the development of non-invasive delivery methods. These methods may improve convenience and compliance for many proteins that are injected on a daily basis. The major barriers for protein delivery via 
these other routes include the permeability of proteins across cell barriers, proteolysis at the site of administration, immune reactions at the delivery site and limitations in surface area for absorption (Carpenter et al., 1997).

The lungs have been widely studied as a delivery route for proteins as they have a large surface area and allow for rapid absorption due to close contact between alveoli in the deep lung and the circulation. Another alternative is transdermal delivery (Cleland et al., 2001).

Micro and submicrometre particles and ultrafine powders are increasingly in demand as they have a broad application in pharmaceutical drug delivery especially in the fields of pulmonary delivery and needle-free powder injection. These delivery methods have advantages over conventional methods, as they are more amenable to patients. Such applications require bioactive particles of well-defined characteristics (Sarup et al., 2000). In the development of protein preparations for pulmonary delivery and controlled release systems, small particles $(<5 \mu \mathrm{m})$ with a narrow particle size distribution are desired. In respiratory delivery the particle size is critical to ensure that a sufficient amount of active substance reaches the lungs. For controlled release systems, smaller particles are preferable for the parenteral route of delivery.

The preparation of particulate raw materials for particulate delivery by inhalation generally necessitates secondary processing following preparation and harvesting of the active drug by conventional crystallisation and precipitation processes. This is because the demanding requirements for particle size and size distribution for particles targeted to reach deep lung regions (e.g. 1-5microns) are not obtained directly. Secondary processing, often by high energy comminution operations such as fluid energy or jet milling, can often provide products with the required particle size. However during this processing disadvantageous property changes can occur, such as surface charging and increases in crystallographic disorder. These phenomena constrain product manufacture and assembly, as well as raising concerns over the longevity of drug stability (Lucas et al., 1998).

Major advances in drug delivery and targeting in recent years have highlighted the limitations of conventional particle formation and pre-treatment processes in fine-tuning the characteristics required. Batch to batch variation of particle properties can occur and, together with increasing industrial and regulatory concern over retained solvent levels in drugs and excipients, there is a requirement for an alternative efficient particle formation process capable of providing consistent, uniform product with controlled particle properties, preferably with minimal levels of retained solvent (York et al., 1996 and 1998).

Conventional size-reduction processes are not always suitable for certain materials. When dealing with 
proteins the limitations are obvious. Spray drying can induce denaturation and a low product yield. Milling, which can result in activated surface particles and produce a broad size distribution and fluid energy grinding, which frequently results in electrostatically charged powders, are more efficient for hard and brittle materials than for soft substances like proteins (Moshashaée et al., 2000, Palakodaty et al., 2000).

One method of size reduction and particle formation capable of yielding very small particles and a narrow size distribution and devoid of certain drawbacks of conventional techniques, is one that utilises supercritical carbon dioxide. Supercritical fluid technology, and especially the solution enhanced dispersion by supercritical fluids (SEDS) process, has shown great promise in applications such as preparing particulate pharmaceuticals with defined physiochemical properties (Palakodaty et al., 2000).

\subsection{Introduction to SEDS Technology}

A novel particle formation method and apparatus involving supercritical fluid technologies has been developed. The key innovation in the supercritical enhanced dispersion by supercritical fluids (SEDS) process is the combined use of the special physio-chemical properties of supercritical fluids with a physiomechanical function as a dispersing medium and mixing function. In the SEDS process the supercritical fluid disperses and mixes a stream of drug solution while simultaneously extracting the organic solvent and rapidly forming dry particles. This is achieved by metering the solution and the supercritical fluid into a particle formation vessel held under controlled conditions of temperature and pressure, above the critical point of the supercritical fluid-solvent mixture. Dry, solvent free particles are recovered from the particleformation vessel. The SEDS process produces uniform size, regular-shaped and smooth crystalline surfaced particles. By altering the SEDS working conditions directed changes in particle properties are achieved (Hanna and York., 1993).

In many ways, supercritical fluid processing and controlled particle formation satisfies most of the demands for particle formation and regulatory requirements. As a single step, enclosed operation with mass balance, high yields of very consistent products can be achieved. Figure 1.1 gives a comparison of SEDS with conventional particle formation. The materials of construction of equipment components are pharmaceutical grade stainless steel. There are no moving parts and organic solvent requirements can often be reduced compared with crystallisation processes. Much of the equipment can be cleaned in place (York, 2000).

Supercritical fluids and the SEDS process are discussed fully in sections 1.7 and 1.8. Figures $1.2-1.4$ on the following pages show the experimental equipment used to process the antibody fragments and antibody studied for this thesis. 


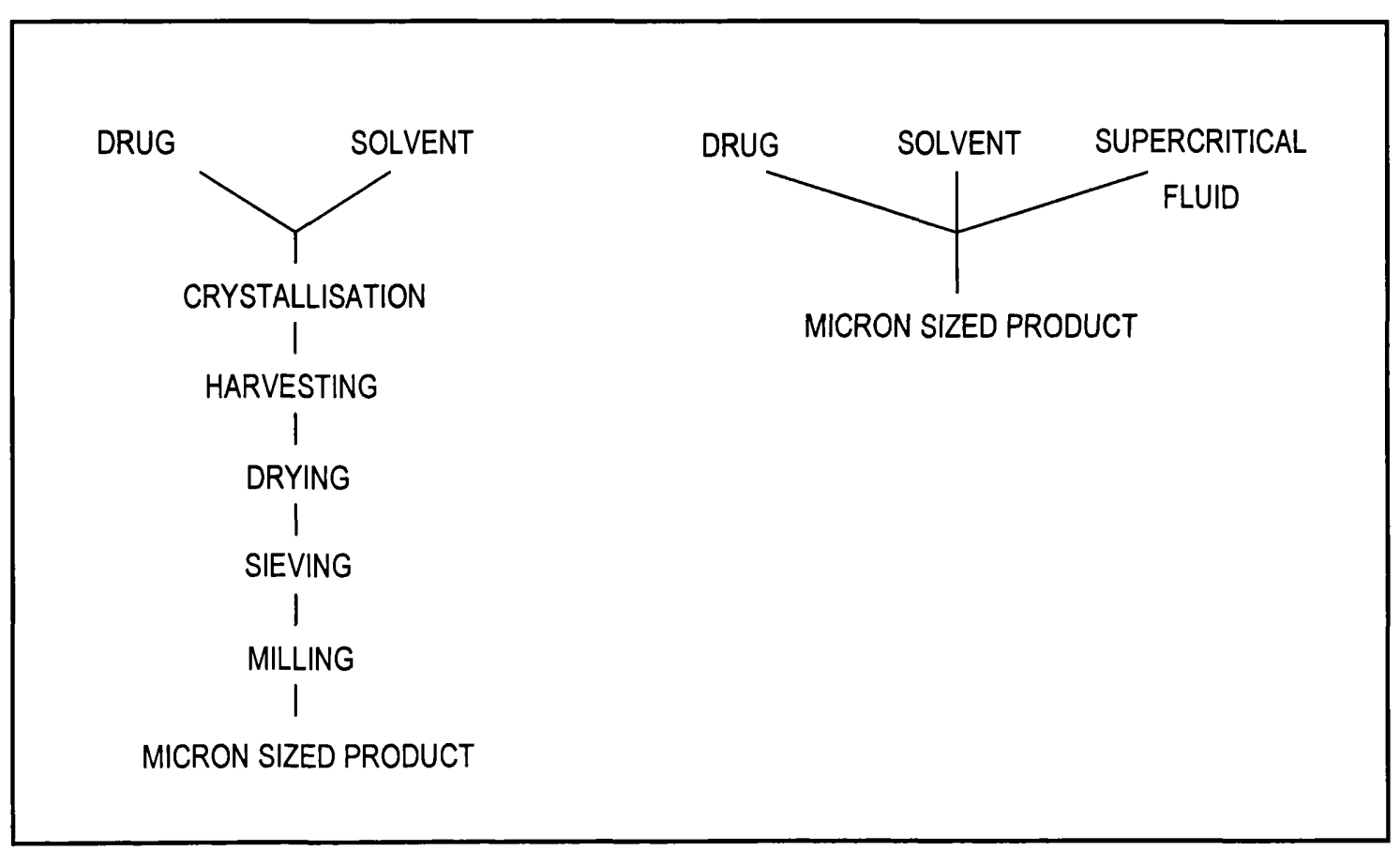

Figure 1.1 - Comparison of SEDS and Conventionai Particie Production

Diagramatic Representation of Processing Routes for Producing Micron Sized Drug Particles by

Conventional Crystallisation and Milling, and by SEDS process. (from: York et al., 1998) 


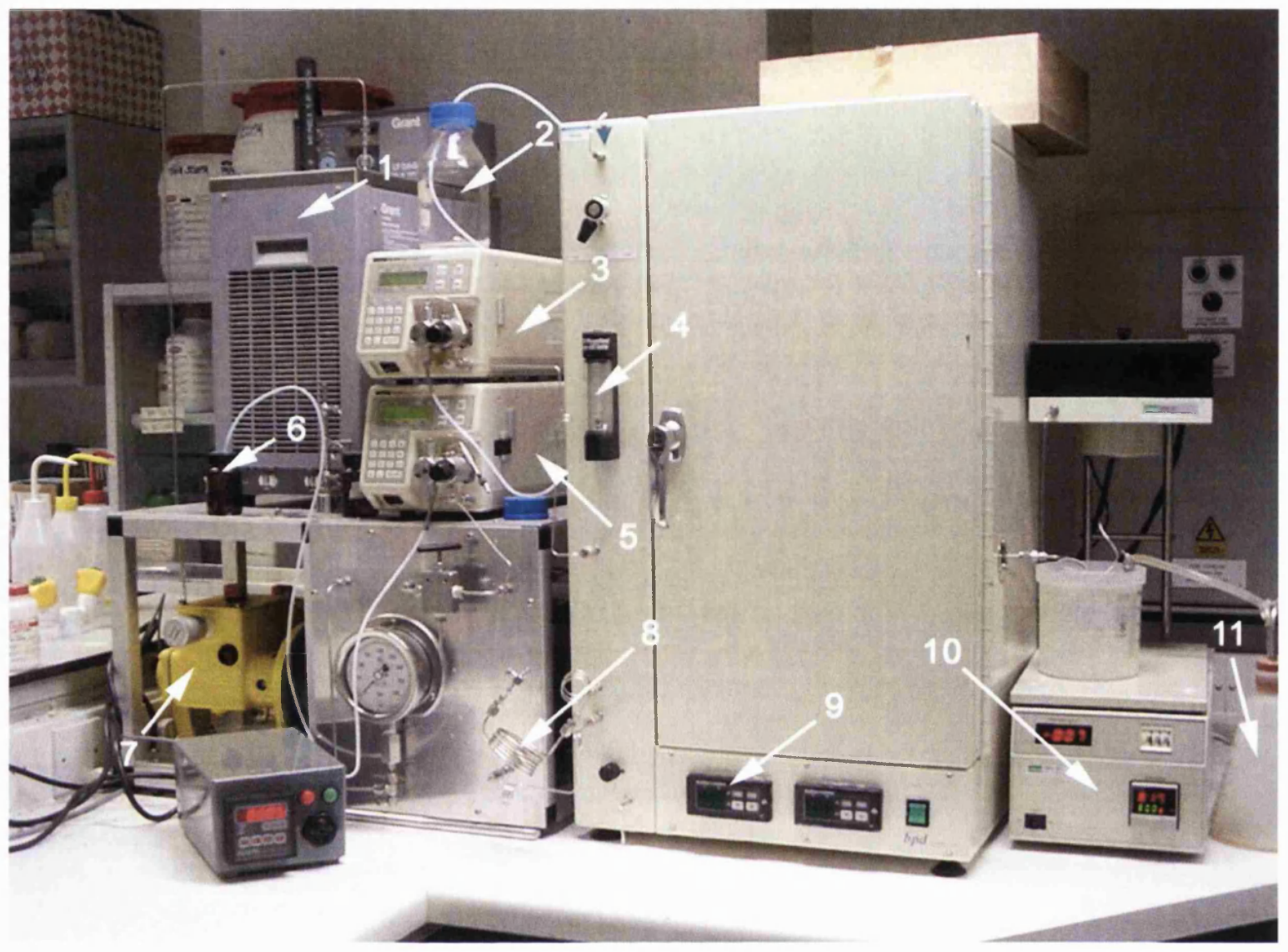

Figure 1.1 The SEDS Experimental set up

$1 \quad$ Cooling Bath

2 Solvent Reservoir

3 Solvent Pump

$4 \quad \mathrm{CO}_{2}$ Flow Meter

$5 \quad$ Antibody Solution Pump

$6 \quad$ Antibody Solution Reservoir
$7 \quad \mathrm{CO}_{2}$ Pump

8 Sample Loop

9 Temperature Gauge

10 Back Pressure Regulator

11 Solvent Trap 


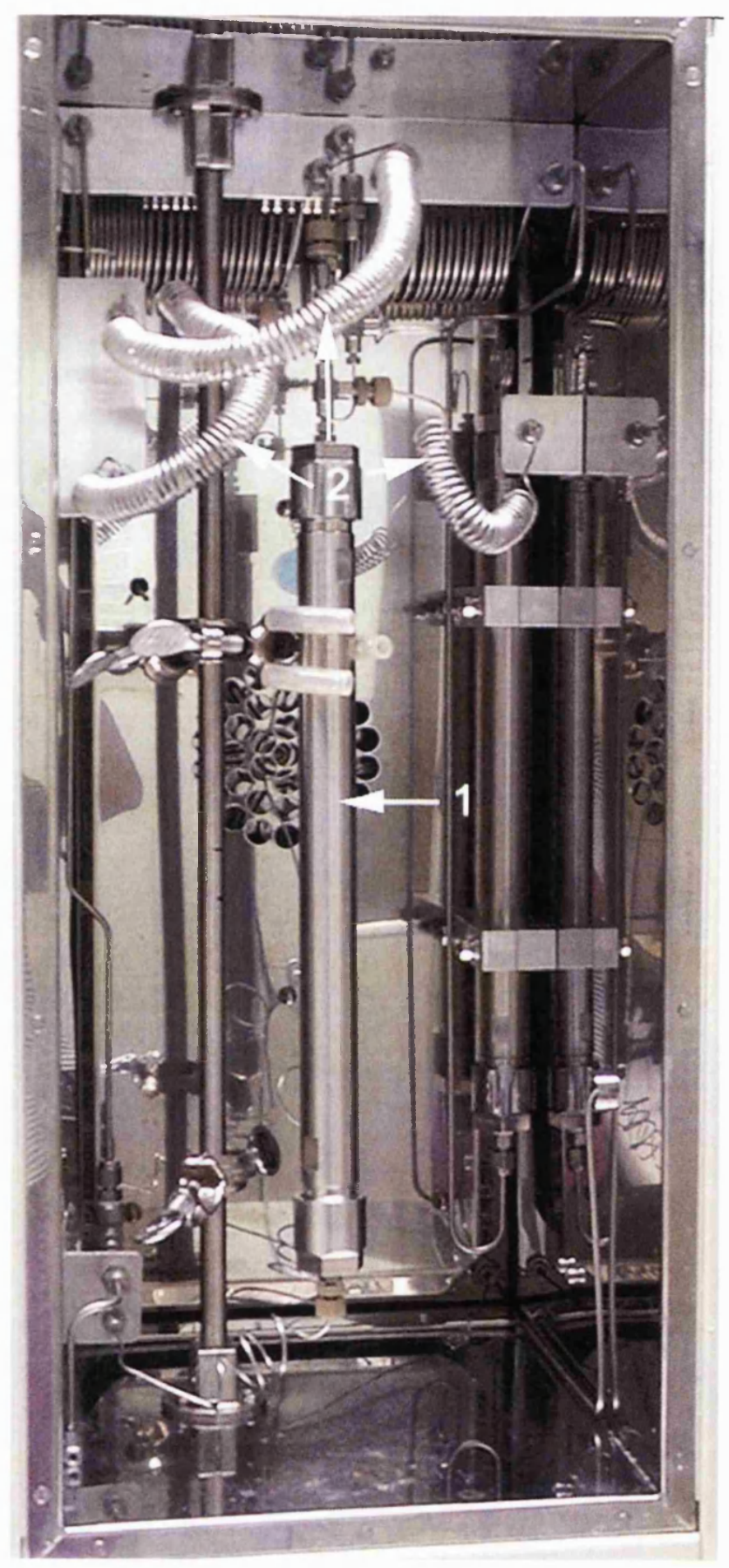

Figure 1.2 Inside the SEDS Oven

$1 \quad$ Drying Chamber

$2 \quad$ Antibody Solution, Solvent and $\mathrm{ScCO}_{2}$ Inlet lines 


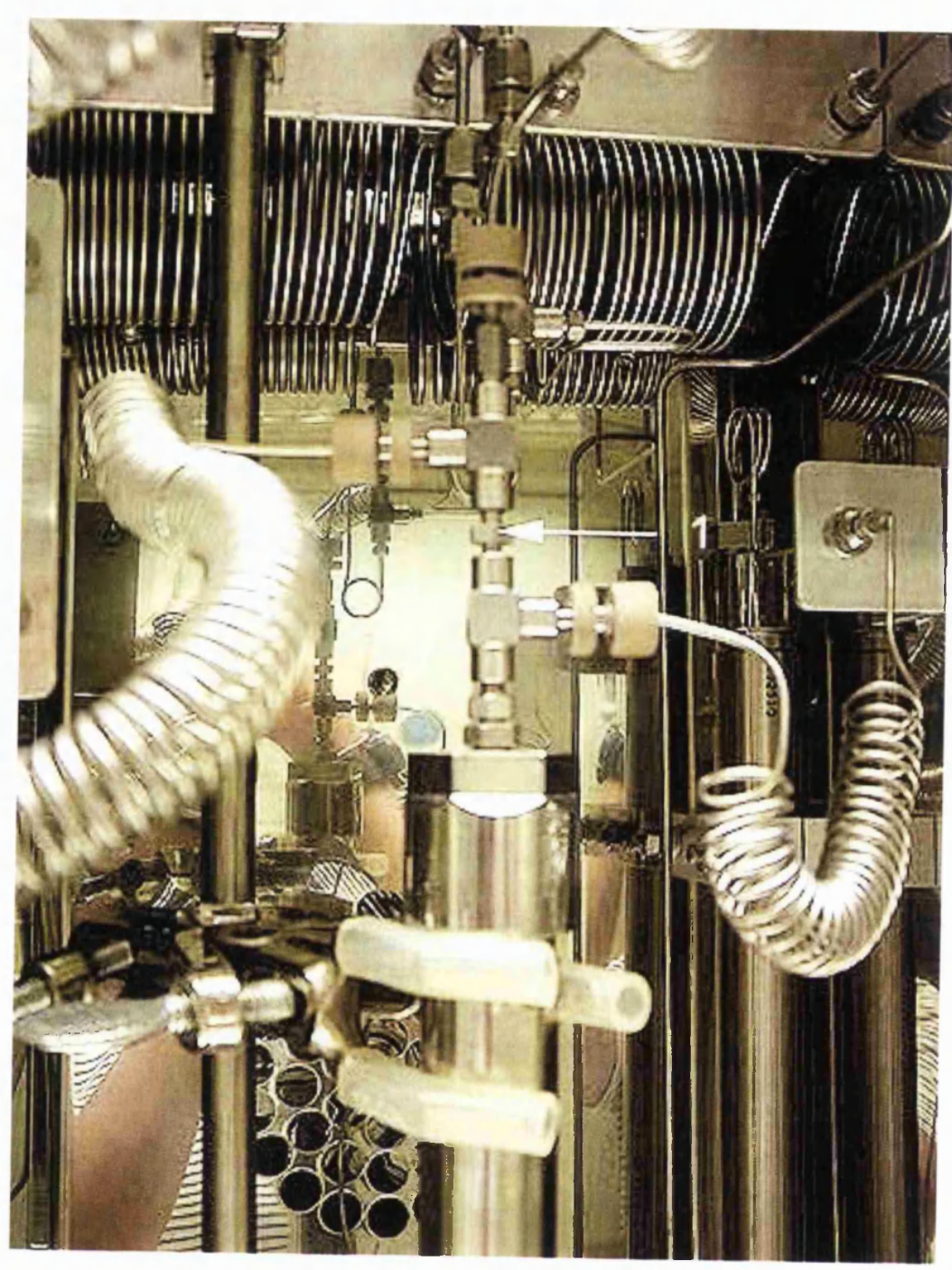

Figure 1.3 Nozzle Attachment to SEDS Drying Chamber

$1 \quad$ Nozzle Inlets 


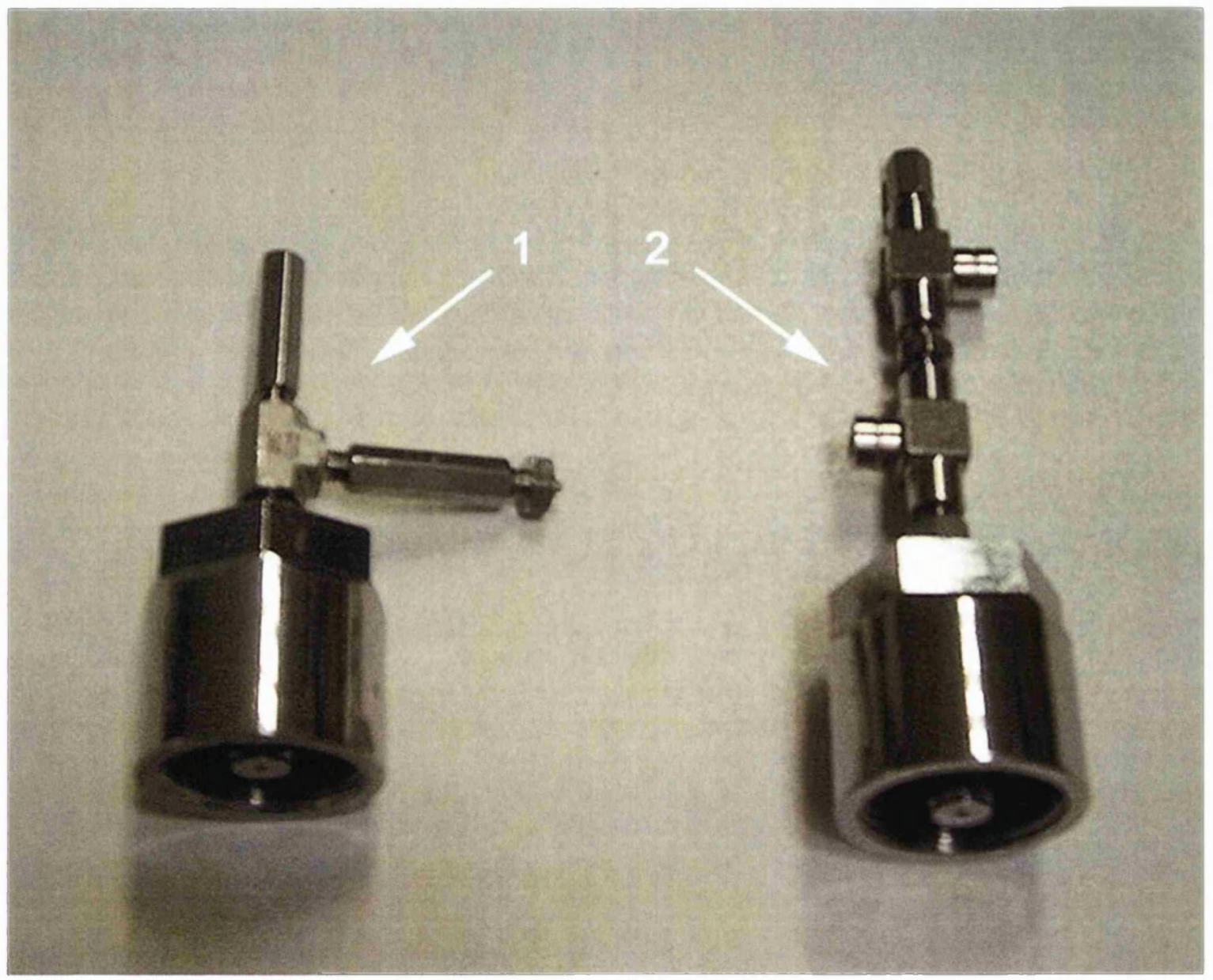

Figure 1.4 SEDS Nozzles 


\subsection{Effect of Operating Conditions on Biological Functionality}

One of the most challenging tasks in the development of protein pharmaceuticals is to deal with physical and chemical instabilities of proteins. Protein instability is one of the major reasons why protein pharmaceuticals are administered traditionally through injection rather than taken orally like most small chemical drugs. Protein pharmaceuticals, unlike small drug molecules, have a high molecular weight $(>5 \mathrm{kDa})$. Their large size, compositional variety, and amphipathic characteristics constitute specific behaviour such as folding, conformational stability and unfolding/denaturation (Wang, 1999).

Most biological molecules, (e.g. nucleic acids or proteins), are labile substances and sensitive to extreme $\mathrm{pH}$ values, high salt concentrations, extreme temperatures, presence of surfactant or metal ions and organic solvents (Banga, 1995). Very often they exhibit a unique three-dimensional structure which enables them to function as biocatalysts, structural elements or antibodies. The sensitivity of bioproducts to many operating conditions can be the cause of many problems during downstream processing. A major difference between the traditional chemical entities used as drugs and the new genetically engineered peptide and protein drugs lies in their stability. Peptides and proteins are highly susceptible to both chemical and physical instability when compared with traditional drugs. This presents unique difficulties in the purification, separation, formulation, storage and delivery of these compounds. Chemical instability results in the generation of a new chemical entity, by bond formation or cleavage. Physical instability involves changes in the secondary, tertiary, or quaternary structure of the molecule, which can be manifested as denaturation (structural rearrangement within the molecule), adsorption, aggregation, and precipitation. Therefore, denaturation rarely occurs in small peptides, which do not possess high levels of structural order. Both physical and chemical changes in peptides and proteins can result in a loss of biological activity (Banga, 1995, Burgess, 1993, Gölker, 1991, Krijgsman, 1992a, Wong et al., 1997). Macromolecules may also suffer damage as a result of their size and complexity. Macromolecules may be denatured from their native state into a non-functional one at a variety of interfaces.

Minimisation of inactivation can be achieved by reducing the exposure of the product stream to such influences, and undertaking downstream processing in as short a time as possible. The development of stable and effective protein and peptide products requires careful handling at every stage of protein processing and storage. To achieve a final product with high purity and potency, it is important to consider all possible sources of damage. 


\subsubsection{Temperature}

Temperature is one of the most important factors that influence and determine stability. Above a certain temperature, $T_{m}$, the free energy of denaturation becomes negative and the denatured state is favoured. As a result, biologicals lose their activity upon prolonged heating above their $T_{m}$ temperature.

The primary mechanism of thermo-inactivation is unfolding. In the literature, there is no consensus about the reversibility of this unfolding. Some authors (e.g. Gray, 1988) state that the later steps in the unfolding process are likely to be practically irreversible for kinetic reasons, arguing that in particular, the probability of correct refolding becomes considerably reduced. Other authors, however, believe that the conformational changes during thermal inactivation are fully reversible (Zale et al., 1986, Ahern et al., $1985)$ and that irreversible thermo-inactivation is due to irreversible, secondary processes such as covalent changes.

Most biologicals have maximum stability between $0^{\circ} \mathrm{C}$ and $4^{\circ} \mathrm{C}$. At temperatures lower than this freezing and thawing can occur leading to inactivation in some cases. Structural changes due to dehydration after freezing may play an important role, as well as other denaturation mechanisms (Banga, 1995). For example ice formation removes water from the protein environment leading to changes in $\mathrm{pH}$ and other chemical changes.

\section{$1.4 .2 \mathrm{pH}$}

The $\mathrm{pH}$ of a bioprocess can be critical to the stability and bioactivity of the biological being processed. The $\mathrm{pH}$ of supercritical $\mathrm{CO}_{2}$ is approximately 2.8 (Toews et al., 1995), this means that the processing environment in the equipment being used for this project will be acidic and potential damage due to this must be considered.

Unfolding, due to repulsion of like charges, and covalent changes are the main mechanisms of pH induced inactivation. Unfolding is influenced by ionic strength. It has been shown that the mechanism of irreversible thermoinactivation is greatly influenced by the $\mathrm{pH}$ (Zale et al., 1986, Ahern et al., 1985).

Some biologicals, such as lysozyme, are very stable towards low $\mathrm{pH}$, others, for example fumarase, are extremely sensitive and many show intermediate behaviour (Banga, 1995). At low pH and high temperatures hydrolysis of peptide bonds and deamidation can cause irreversible inactivation. Some proteins show similar behaviour at elevated $\mathrm{pH}$ to that at low $\mathrm{pH}$, some are more stable and others show 
faster inactivation. At high $\mathrm{pH}$ sulfhydryl groups and disulfide bonds are more reactive. At high temperature, disulfide interchange and $\beta$-elimination of cysteine residues can cause irreversible inactivation (Ahern et al., 1985, Weijers et al., 1992, Zale et al., 1986).

\subsubsection{Chemical Environment}

Chemical pathways of protein and peptide degradation include hydrolysis, deamidation, oxidation, disulphide exchange, $\beta$-elimination and racemization. These degradation pathways are often triggered by process conditions. The two most commonly observed pathways are those of oxidation and deamidation.

\subsubsection{Oxidation}

The side chains of a number of amino acids are highly susceptible to oxidation. Oxidation during protein processing and storage can be induced by contaminating oxidants, catalysed by the presence of transition metal ions and induced by light. Oxidative modification depends on the structural features of the proteins as well as the particular oxidation mechanisms inherent in various oxidative species. Temperature, $\mathrm{pH}$ and buffer composition may also be influence oxidation. Protein oxidation may result in loss of biological activity and other undesirable consequences (Shihong et al., 1995).

Oxidation is also one of the major degradation pathways in protein and peptide formulation and storage, both in solution and lyophilised formulations. Protein oxidation by hydrogen peroxide is especially relevant to pharmaceuticals since several commonly used excipients such as the polysorbate surfactants and polyethylene glycol often contain trace amounts of peroxides (Banga, 1995 and Shihong et al., 1995).

Whilst freezing or lyophilisation will generally reduce oxidation, it may sometimes increase oxidation. As freezing proceeds, the exclusion of protein from the ice matrix increases the available concentration of cysteine residues, which increases the possibility of oxidation. Also, the lowered temperature may increase the oxygen concentration in the solutions.

Although oxidation of a protein does not necessarily result in loss of biological activity, there is at least a partial loss of activity in most cases. Some proteins may still be biologically active after oxidation, but usually show altered pharmacokinetics and biological half-life, possibly due to their increased susceptibility to intracellular proteases. Oxidation may or may not affect protein immunogenicity, depending on whether conformational changes have taken place or not, it is likely that the effect of oxidation on immunogenicity 
is protein specific (Shihong et al., 1995).

Oxidation induced by the presence of oxidants in the system can effectively be inhibited by the appropriate addition of antioxidants or free radical scavengers.

\subsubsection{Deamidation by hydrolysis}

Deamidation refers to the hydrolysis of the side chain amide group of asparagine and/or glutamine, yielding aspartic and glutamic acid, respectively. These reactions are promoted especially at elevated temperatures and extremes of $\mathrm{pH}$. They represent the route by which insulin preparations usually degrade (Banga, 1995).

Deamidation may have significant effects on protein bioactivity, half-life, conformation and/or immunogenicity. The effects have to be evaluated on a case by case basis since deamidation does not always affect bioactivity. However, even if bioactivity is not affected, in the case of pharmaceuticals the deamidated protein may have a faster clearance from the body, e.g., an unfolded protein that has been deamidated may not be able to refold to its native state. Such damaged protein will then be effectively cleared by the body and will also be more susceptible to irreversible aggregation (Banga, 1995).

The rate of deamidation of a protein depends on its primary, secondary and tertiary structure, in addition to other factors such as temperature, $\mathrm{pH}$, buffer species, ionic strength and special molecular interactions. In general deamidation is catalysed by base, heat and ionic strength and inhibited by the addition of organic solvents. Since deamidation is a hydrolysis reaction, elimination of water by lyophilisation is expected to stop or decrease deamidation. However, it has been reported in the literature that the residual moisture present in the solid state will still allow deamidation to take place. Nonetheless, lyophilisation along with alteration of $\mathrm{pH}$ and addition of excipients remain conventional strategies for controlling the deamidation reaction (Banga, 1995).

\subsubsection{Shear Environment}

Shear stress is a force per unit area acting on and parallel to a surface. The term "shear" is often used in bioprocessing to broadly describe mechanical forces. Shear is present in almost all bioprocesses and high shear is associated with many of the operations associated with downstream processing. 
Shear can induce denaturation or aggregation of proteins though the exact mechanisms are not known and may involve complex processes. Early literature assumed that shear could directly disrupt or distort the molecules. However, more recent literature indicates that shear does not directly denature the molecules. Instead, shear accelerates the turnover of air-liquid interfaces, which causes denaturation and/or aggregation (Harrison et al., 1998). Increased hydrostatic pressure has been reported to cause structural changes in protein molecules due to compression. These damages may lead to dissociation, aggregation or gelation of proteins. Shear and surface stress can also occur in aerosol devices used for pulmonary dosing and in needle-less jet injector guns. Such stress can also induce aggregation, and the use of excipients may be required to stabilise the drug under these circumstances (Banga, 1995).

Detailed studies have been carried out on the effect of high shear levels on proteins. Early studies in the 1970 's suggested that shear fields damage globular proteins and that the damage increases in proportion to the length of time the protein is exposed to this force (Sadana, 1989). More detailed studies (Thomas et al., 1979) showed that at very high levels of shear, if there was no gas-liquid interface and low protein concentrations were avoided, then the protein suffered little or no damage. Another study used recombinant human growth hormone $(\mathrm{r} \mathrm{hH})$ and recombinant human deoxyribonuclease (rhDNase) as model proteins to investigate the effect of high shear on proteins (Maa et al., 1996). These proteins were subjected to high shear $\left(>10^{7}\right)$ and high shear rate $\left(>10^{5} \mathrm{~s}^{-1}\right)$ and it was found that neither of these had a significant effect on protein aggregation. However, a lower melting temperature and enthalpy were detected for rhGH after it had been subjected to high shear. This was presumed to have been due to some slight conformational changes. SDS-PAGE also indicated the presence of low molecular weight fragments suggesting that peptide bond breakage had occurred due to high shear. When exposed to high shear rhDNase was found to be relatively more stable than $\mathrm{rhGH}$, though no conformational changes or protein fragments were observed (Maa et al., 1996).

\subsubsection{Interfacial Environment}

Proteins undergo adsorption to solid-liquid and air-liquid interfaces. Such interfaces are readily generated during processing. For example, mixing of solutions will generate extensive air-water interfaces due to the resulting turbulence, while filtration of solutions will generate a solid-liquid interface. Even after the final product is marketed the container headspace still provides an air-liquid interface, while the container walls provide a solid-liquid interface. 


\subsubsection{Solid-Liquid Interfaces}

Although a folded protein is hydrophilic, it does have hydrophobic residues that lie in the interior of the molecule. At a hydrophobic interface, the polypeptide chain can unfold to allow the hydrophobic part of the molecule to interact with the surface, leading to adsorption. This adsorption can be followed by aggregation (Banga, 1995).

The primary sequence of the polypeptide chain determines the level of surface activity of each protein. Size, charge, structure, and other chemical properties of the protein will also influence surface activity, though these are all related to the primary sequence of the polypeptide chain. Size is considered important since larger proteins are believed to form multiple contact points upon adsorption to a surface. This suggests that a protein that is likely to unfold readily would be more surface active. In contrast, a disulphide cross-linked protein is less likely to unfold and will, therefore, be less surface active. The diversity in surface activity of peptides and proteins primarily depends on the nature of the side chains of constituent amino acids. In addition to the hydrophobicity of the protein, its polyelectrolyte behaviour is also an important determinant of its adsorption tendency. Depending on the $\mathrm{pH}$ or ionic strength of the media, charge interactions between protein and surface will differ considerably. Proteins adsorb the most to neutral or slightly charged surfaces near their isoelectric point. Due to the diversity in protein behaviour on adsorption, it can be expected that if a mixture of proteins is allowed to adsorb onto a surface, the adsorbed layer will be richer in some proteins than others. The adsorption process shows a saturation effect, with a plateau value close to that expected for a close-packed monolayer of protein $(\sim 0.1-0.5$ $\mu \mathrm{g} / \mathrm{cm}^{2}$ depending on protein diameter), (Banga, 1995).

Important determinants of protein adsorption on a solid-liquid interface will be the surface-to-volume ratio, the chemical nature of the solid, and the solution/ionic properties of the protein. The solution properties of the protein can be controlled by changing the $\mathrm{pH}$ or ionic strength or by addition of co-solvents.

An important characteristic of the adsorption process is its irreversibility, which may be due to multiple contact points between the protein and the surface. Whilst this irreversibility of adsorption poses some problems, it does have the advantage that any denaturation upon adsorption is limited to the fraction of the protein that is adsorbed.

Adsorption losses are very significant for dilute solutions but become less of a concern at concentrations higher than $\sim 0.2 \mathrm{mg} / \mathrm{mL} \sim 0.03 \mathrm{mM}$ as the percentage lost becomes negligible.

Protein adsorption has wide impacts on the processing and uses of proteins, for example biocompatibility 
of implants, bioadhesion and fouling of process equipment. An important example of the problem adsorption presents is the loss of insulin in vessels and delivery systems due to adhesion to surfaces. This is an obstacle to the development of insulin formulations and delivery systems. Insulin adsorption may be minimised by the addition of $0.1-1 \%$ of albumin.

\subsubsection{Air-Liquid Interfaces}

Air-liquid or gas-liquid interfaces are a feature of many bioprocessing operations, as many of these require aeration. Proteins diffuse to and subsequently adsorb on to the membrane formed at the gas-liquid interface (Harrison et al., 1998). The unfolding of the protein to its denatured state follows this process. Ultimately aggregation and precipitation occur. The capacity of proteins to unfold is dependent upon the conformational stability of the flexible segments of the protein molecule (Virkar et al., 1981). If the surface is a still one, that is there is no agitation of the mixture, then once a monolayer of protein has formed at the interface further access of protein to the interface is restricted. As a consequence a still surface does not entail major denaturation of the bulk of the protein in solution. The opposite is true of an agitated solution. For example, shaking allows a continuous creation of new interface, thus providing a massive surface area that can lead to large-scale denaturation and/or aggregation (Banga 1995). During mixing, the interfacial film is continually renewed with progressively more protein exposed to the gas phase resulting in further loss in activity. Therefore denaturation is likely to be greater at the air-liquid interface as compared to a solid-liquid interface, due to the mobility of the former.

Studies have shown that the stability of enzymes is adversely affected by air-liquid interfaces when in an agitated vessel (Virkar et al., 1981). It has also been shown that single-chain Fv fragments can have activity losses of up to $80 \%$ when exposed to shear in the presence of air-liquid interfaces (Harrison et al., 1998).

\subsubsection{Liquid-Liquid Interfaces}

In the presence of solvents the hydrophobic residues of proteins can become exposed thus the aqueous/organic extraction systems widely used in the chemical industry have been generally avoided in protein processing.

However a growing area of interest for either extraction or for a novel formulation procedure is the use of reverse micelles. Reverse micelles can provide a unique opportunity to put a protein in an organic solvent, 
while still maintaining an aqueous environment in the immediate vicinity of the molecule. Normally micelles form in water, whereby the inside of the micelle provides a lipophilic environment. However, if the surfactant is added to an organic solvent, the molecules can form a reverse micelle where the interior of the micelle would be hydrophilic. Such reverse micelles have been used to entrap enzymes in surfactant in organic solvents.

The inner core of reverse micelles contain an aqueous microphase that is able to dissolve polar substances such as enzymes. Phase transfer of an enzyme between a bulk aqueous phase and the aqueous microsphere of the reversed micelle is irreversible, and is manipulated using $\mathrm{pH}$, ionic strength and surfactant concentration.

\subsection{Brief Overview of Formulation}

Proteins are easily degraded in pharmaceutical processes such as purification, separation, freeze-drying, storage and dispensing. The addition of excipients, as well as protein engineering, have been used to stabilise protein and peptide molecules existing in adverse conditions. The effects of excipients on protein stability are primarily explained by the preferential hydration of protein molecules (Wong et al., 1997).

Products derived from fermentation or other biological processes must be rendered suitable for long shelf life or storage in a form suitable for final use. Purified biologicals will often degrade in a short time when stored in aqueous solution without additives.

One of the steps in the downstream processing of a product is the formulation of the material of interest into the final product format. This generally involves the addition of various excipients (substances other than the active ingredients) that stabilise the final product or enhance the characteristics of the final product in some way. The addition of stabilising excipients is not only important in producing a stable final product it can also be used to protect against some of the influences of processing operations detailed in section 1.2 .

The most sensitive element in the formulation is the protein, and primary concern in formulation design must be the choice of excipients that provide optimal stability. The final composition of product must be clearly defined prior to starting formulation efforts. Issues to be considered include route of administration, which is often parenteral, other agents to be co-administered to the patient, product volume, product concentration, and whether or not the product can be lyophilised in vials or whether alternative systems such as syringes must be employed. Also, if the final product is intended for multi-use, it will be necessary 
to include a preservative in the formulation, which may reduce protein stability (Carpenter et al., 1997)

The decision to market a product in liquid or powder form is often dictated by how stable the protein is in solution. This in turn must be determined experimentally as there is currently no way to predict the outcome for any particular protein. Some proteins may remain stable for months or even years in solution, particularly if stabilising excipients are added and the solution is refrigerated. Other proteins, particularly when purified, may retain biological activity for only a matter of hours or days when in aqueous solution.

The addition of stabilising agents is often essential to confer upon a product an acceptably long shelf life. During initial development considerable empirical study is undertaken by formulators to determine what excipients are most effective in enhancing the stability of the final product (Walsh, 1998).

Proteins and therapeutic drugs require formulation not only for stabilisation but also so that they can be administered in a suitable dosage form. Drugs are rarely, if ever, administered to patients in an unformulated state. The vast majority of available medicinal compounds which are potent at the milligram or microgram levels could not be presented in a form providing accurate and reproducible dosage unless mixed with a variety of excipients and converted by controlled technological processes into medicines.

There are two main aims to formulation:

1. A unit dose contains the intended quantity of drug. This is achieved by ensuring homogeneity during the manufacturing process and by a suitable choice of excipients, stabilisers and manufacturing conditions to ensure both drug and product stability over the validated shelf-life.

2. The drug is usually totally released but always in a controlled manner, in order to achieve the required onset, intensity and duration of clinical response. Most dosage forms can be designed to give a rapid response: if, however a long duration of response is required then it is easier to achieve sustained release using solid rather than liquid formulations (Smith, 1988).

Formulation of protein drugs is very different from the formulation of traditional drugs. Unlike traditional drugs proteins have primary, secondary, tertiary and quaternary structures and thus, degradation of proteins is not a simple one step reaction. Multiple inactivation pathways exist for the degradation of proteins. Furthermore, the products of these degradation reactions may not be easily detected by any one analytical technique. Also, accelerated stability studies for shelf-life determination may be more difficult to apply for protein drugs (Banga, 1995). 
The formulation of proteins is a very diverse field due to the complexity and individuality of the protein structures involved. However, although formulation and storage conditions need to be optimised on a case by case basis, instability occurs via several common processes. Knowledge of the structural properties of a protein facilitates a planned approach to designing the appropriate optimum formulation/storage conditions.

Listed in the tables below are a range of various substances that may be added to a purified protein biopharmaceutical product in order to stabilise and protect the product:

Table 1.1 - Some major excipient groups used for stabilising bioactivity

\begin{tabular}{ll}
\hline Serum Albumin & Surfactants \\
Alcohols and Polyols & Various Carbohydrates \\
Various Amino Acids & \\
\hline
\end{tabular}

from: (Walsh, 1998)

Table 1.2 - Amino acids, carbohydrates and polyols most widely used as excipienst/stabilisers

\begin{tabular}{lll}
\hline Amino Acids & Carbohydrates & Polyols \\
Glycine & Glucose & Glycerol \\
Alanine & Sucrose & Mannitol \\
Lysine & Trehalose & Sorbitol \\
Threonine & Maltose & Polyethylene glycol \\
\hline
\end{tabular}

from: (Walsh,1998)

\subsection{Requirements for Drying Proteins}

The economic advantage of a longer shelf life or storage stimulates continuous development in the search for new conditioning and stabilisation methods. Some methods available to solve the stabilisation problem include a number of different drying methods. Dry products are often easier to store, distribute and market.

Removal of residual water or organic solvents is often required to stabilise otherwise pure bioproducts for storage and handling. In general due to reduced mobility, removal of water from products greatly reduces 
the likelihood of chemical/biological-mediated inactivation of the biopharmaceutical (Blanch and Clark, 1996). The diversities of available drying methods and equipment are considerable. However, the heat sensitivity of most bioproducts necessitates that water be removed with a minimal increase in temperature (Blance et al., 1996).

As most biological products are heat sensitive, the major types of dryers used in biotechnology are spray and freeze dryers (Tijsterman, 1993).

\subsection{Drying of Materials - general overview}

Drying commonly describes the process of thermally removing moisture to yield a solid product. Many different types of dryers exist but there are some common themes to the specification and design of dryers. During the drying process complex heat and mass transfer events occur simultaneously within a solid phase. Both the mass and heat transfer events are unsteady-state, that is they change with time of operation. Furthermore the properties of the drying phase change with time and the drying phase is generally heterogeneous with respect to time and moisture content. These two operating properties of the solid phase determine the rate of the drying process and in the case of labile materials the rate of thermal degradation. In addition there are many other events which occur during the drying process, for example product expansion, explosion and collapse. The overall result is that the drying process is difficult to predict. Experimental work is usually required to examine the effect of drying conditions on the resultant product. The success of a drying process is strongly determined by the formulation of material making up the drying process stream.

\subsubsection{Drying of Foodstuffs}

The removal of water from solids is an integral part of food processing. Many processed food products undergo a drying stage during their preparation for human consumption.

The main objectives of dehydration are:

1. Extended Storage Life: A dry food product is less susceptible to spoilage caused by the growth of bacteria, moulds and insects. The activities of many micro-organisms and insects are inhibited in an environment in which the equilibrium relative humidity is below $70 \%$. Likewise, the risks of unfavourable oxidation and enzymatic reactions are reduced (Sokhansanj et al., 1987). 
2. Quality Enhancement: drying may enhance many favourable qualities and nutritional values of food or feed products. Palatability is improved, and likewise digestibility and metabolic conversions are increased. Drying also changes colour, flavour and the appearance of a food item.

3. Ease of Handling: Packaging, handling and transportation of a dried product is easier and cheaper because the weight and volume of the product are less than in its hydrated form. A dry product flows easier than a wet product, thus gravity forces can be utilised for loading and unloading and short distance hauling.

4. Further Processing: Food products are dried for improved milling, mixing or segregation. A dry product requires less energy than a wet product to be milled. A dry product mixes with other material more uniformly and is less sticky compared with a wet product (Sokhansanj et al., 1987).

\subsubsection{Drying of Pharmaceutical Products}

Pharmaceuticals represent a whole variety of different chemical or biological substances. They include acetylsalicyclic acid (ASA), produced in thousands of tons every year throughout the world, a substance relatively cheap and easy to dry. On the other hand, they include hormones, antibiotics, and other extremely valuable, often labile, and very difficult to dry products. The manufacture of pharmaceutical preparations that will usually reach the consumer in the form of tablets is carried out in the following three basic stages:

1. Synthesis of the intermediate products.

2. Final synthesis of the drug.

3. Manufacture of the tablets.

After the second stage, and often after the first, if the intermediate product is to be processed elsewhere, these products are dried. Drying is often accompanied by granulation, which is generally a necessary step before tableting.

Selection of a proper dryer for these products depends on the properties of materials, which include their physical form, particle size, moisture content and thermal sensitivity, as well as their heat and mass transfer characteristics as described by their drying kinetics. Since most pharmaceutical products are low tonnage and high value products, considerations of energy conservation or thermal efficiency are generally of secondary importance in the selection of the drying process (Pakowski, 1987). 


\subsubsection{Materials Processing for Particle Formation}

The demand for micro, submicrometre and ultra fine particles is increasing as these particles can be injected (subcutaneously or intramuscularly) or administered orally, provided that they are $<50 \mu \mathrm{m}$ in diameter, submicrometre particles can be injected directly into systemic circulation. Materials' processing is a major step in the pharmaceutical industry in terms of achieving the stringent properties of drug materials as laid out by in-house specifications and regulatory authorities. Therefore production of high purity, chemically stable submicron sized drug compounds in an eco-friendly, cost efficient process remains a challenge to the process industry (Palakodaty et al., 1997).

When developing protein delivery systems, one must minimise the denaturation of protein drugs during precipitation. Protein drugs are often applied as solid particles. In dry powder inhalation for instance, the most effective diameter for inhaled particles to reach the main absorption site - the alveoli - is about 2$3 \mu \mathrm{m}$. Spray-drying or jet milling has been frequently used in pharmaceutical productions to prepare fine protein particles with single micron-ordered sizes. With these methods, however, the denaturation of proteins by heat stress or various mechanical stresses can be critical problems (Morita et al., 2000).

The design of particles containing proteins must take into account the need to maintain higher order structural stability in addition to the conventional requirements of controlling interparticle interactions and the optimisation of production/handling properties, transportmechanical robustness and physical/chemical stability. Conventional techniques for the production of particles include: spray drying (products in the range of $5 \mu \mathrm{m}$, exposed to high temperatures); milling (10 - 50 $\mu \mathrm{m}$, broad size distribution); fluid-jet milling/communition (1 - $10 \mu \mathrm{m}$, broad size distribution, particles electrostatically charged); freeze-drying or lyophilisation (microparticles, broad size distribution) and precipitation from solutions using miscible organic antisolvents (particle size difficult to control, necessary to remove organic antisolvent), (Forbes et al, 1998 \& Jarzebski et al., 1995).

Many biological compounds are extremely unstable under conventional conditions and among the limitations associated with traditional particle formation processes are excessive solvent use and disposal, thermal and chemical degradation of products, trace residues, inter-batch particle size variability and batch to batch variation can occur. These, together with increasing industrial and regulatory concern over retained solvent levels in drugs and excipients mean that there is a requirement for an alternative efficient particle formation process that is capable of providing consistent, uniform products with controlled particle properties, preferably with minimum levels of retained solvents and in an environmentally responsible manner (Subramaniam et al., 1997). 
Formulation of biological macromolecules for pharmaceutical use is a crucial area for the development of biopharmaceutical products. The two mostly commonly used processes are considered below, these are freeze-drying and spray-drying. Freeze-drying is the most commonly used. Spray drying has also been explored for production of dry powders, although it does work for stable proteins, it is unlikely to be generally applicable.

\subsubsection{Freeze Drying}

Only a few proteins have sufficient stability to be marketed as solutions with a shelf life of a year or more; therefore, it becomes important to be able to dry the protein in order to prevent degradation. A dry product also weighs less, thus cutting down transportation costs. Since proteins are heat sensitive, such drying must be done without using elevated temperatures. The most common method to accomplish this is lyophilisation or freeze-drying. In addition to preventing degradation, freeze-drying also results in fast and complete dissolution during product reconstitution. Also, a freeze-drying process can be carried out aseptically to result in a sterile product. This allows the formation of injectable products, the dosage form most commonly used for peptide and protein drugs. As a result, almost one-half of all recombinant proteins on the market are lyophilised powders (Gölker, 1991).

Freeze-drying refers to the removal of solvent directly from a solution while in a frozen state. Removal of water directly from (frozen) biopharmaceutical products yields a powdered product, usually displaying a water content of the order of $3 \%$. Freeze-drying is the favoured method for drying many sensitive biological materials, for example, vaccines, pharmaceuticals, blood fractions, enzyme preparations, as well as labile and costly ingredients of diagnostics that are physically or chemically unstable in aqueous solution. It may be used in protein purification for concentration of proteins and to store the process intermediate in a relatively stable state. However, a major challenge in the development and manufacture of such products is the minimisation of damage to proteins due to stresses arising from the freeze-drying process itself (Sarciaux et al., 1999).

Freeze-drying, is the most gentle form of drying, but it is also the most complex and expensive. In freezedrying, drying is achieved by freezing the wet substance and subliming the ice directly to water vapour under very low pressure (often about $0.5 \mathrm{mbar}$ ). Freeze-drying is a process whereby water or other solvent is removed from a frozen solution by sublimation. The liquid formulation is placed in vials aseptically that are partially stoppered with slotted rubber closures that allow the escape of water vapour. The vials are then aseptically transferred to a freeze-drier, which is equipped with a chamber containing shelves, a vacuum pump, a condenser, and a refrigeration system. A lyophilisation process consists of three steps: 
(1) freezing, (2) primary drying and (3) secondary drying. To monitor the process, the product temperature, shelf temperature, and chamber pressure are continually recorded during the process. In the first step, the water and solutes are completely frozen. The microstructure formed during freezing must be retained during drying to get the desired physical attributes of a freeze-dried product. After freezing is accomplished, the chamber pressure is reduced and the temperature of the shelves is increased to provide energy for primary drying. Primary drying removes water under vacuum through sublimation. The driving force for sublimation is the difference in vapour pressure of water within the system. The process is limited by the rate of transfer of heat from the shelf to the sublimation front and the rate of transfer of water vapour from the product to the condenser. During primary drying, a receding boundary is observed in the vial when the thickness of dry solids increases as the sublimation interface and the thickness of frozen solution decrease. Once all the water is removed, the apparently 'dry' product still contains some bound water. The shelf temperature is further increased, and the chamber pressure is further decreased for this stage of lyophilisation. During this secondary drying, heat of sublimation is no longer required, and the applied heat, thus, causes an increase in the product temperature. This serves as an indicator that secondary drying has begun (Banga, 1995, (Blanch et al., 1996, Gölker, 1991, Willemer, 1999).

Many protein products are freeze-dried to provide adequate shelf-life stability. While a freeze-dried solid is generally much more stable than the corresponding aqueous solution, some proteins are inactivated during the freeze-drying process; the extent of inactivation is extremely sensitive to formulation. In addition, degradation and loss of activity may occur during storage, the extent of the stability problem being sensitive to both formulation variables and the level of residual water in the nominally dry solid (Pikal et al., 1991).

Freeze-drying is recognised by the regulatory authorities as being a safe and acceptable method of preserving many parenteral products. Freeze-drying requires careful process design and is quite time consuming. It also has high plant costs and energy consumption. Despite these shortcomings freezedrying is often chosen as the process method for high quality, labile pharmaceuticals (Tijsterman, 1993).

Freeze-dried biopharmaceutical products usually exhibit longer shelf lives than products sold in solution. Freeze-dried powders are mainly resolubilised before use; the novelty of the process being examined for this project is that one of the main intentions is to be able to produce powders that can be utilised in their dry state. 


\subsubsection{Impact of Freeze-Drying on Biological Functionality}

Although freeze-drying is a relatively gentle way of removing water from proteins in the solution this process can promote the inactivation of some protein types. To counteract this effect specific excipients (protectants) are usually added to the product in order to minimise such inactivation. Commonly used protectants include carbohydrates, such as glucose and sucrose; proteins, such as human serum albumin; and amino acids such as lysine or glutamic acid.

Another cause of damage during this process is the increased concentration of salts in the product. As ice crystals begin to form during freeze-drying so there is an effective concentration of all the solutes present in the remaining liquid phase, including the protein and all added excipients. This can result in the concentration of salts increasing to levels as high as $3 \mathrm{M}$. This concentration of salts can accelerate chemical reactions damaging to the protein product. In addition, such concentration effectively brings individual protein molecules into more intimate contact with each other, which can prompt protein-protein interactions and, hence aggregation.

As the temperature of the process drops still lower, some of the solutes present may also crystallise, thus being effectively removed from the solution. In some cases, individual buffer constituents can crystallise out of solution at different temperatures. This will dramatically alter the $\mathrm{pH}$ values of the remaining solution and, in this way, can lead to protein inactivation (Walsh, 1998).

Since lyophilisation can dry a protein solution without heat, it may seem that this is the perfect solution to all formulation problems relating to peptide and protein drugs. Unfortunately this is not the case. The lyophilisation process induces conformational instability in many proteins and the freeze-dried protein is also subject to degradation in the solid state. Two different types of stress can be encountered during lyophilisation. The mechanism of protein denaturation is different for these two situations. The first stress is due to the freezing itself, while the second stress is due to the drying process. A common denaturation reaction during lyophilisation is the aggregation of protein drugs. However, proteins that normally exist as an oligomer may dissociate during lyophilisation. For example, L-asparaginase normally exists as a tetramer in the active form. Upon lyophilisation, it dissociates into inactive monomer subunits. These monomers can reassociate into active tetramer if reconstituted at neutral $\mathrm{pH}$ and low ionic strength, however, if reconstituted at high $\mathrm{pH}$ and high ionic strength the monomers are not able to reassociate into a tetramer (Banga, 1995).

A typical lyophilised protein formulation may contain a bulking agent, buffer, tonicity modifier and other excipients, which may be classified as cryoprotectants and lyoprotectants. 


\subsubsection{Spray-Drying}

Spray drying has a wide range of applications within the chemical industry, food industry and the biochemical and pharmaceutical industries. Spray-dried powders are usually approximately spherical with a narrow size distribution and are usually hollow. The hollow nature imparts a low bulk density to the powders, but despite this, their spherical shape means that they are usually free flowing. By modifying the spray-drying process, it is possible to alter and control the following properties of spray-dried powders; appearance, particle size and size distribution, bulk density, particle density, porosity, moisture content, flowability, stability, dispersability, friability and retention of activity, aroma and flavour. The design of the nozzle and drying chamber will affect particle properties, and the desired powder characteristics should be borne in mind when a spray-dryer design is selected (Broadhead et al., 1992, Masters, 1991).

Spray drying is often regarded as a 'harsh' drying method, due to the high temperature of the drying gas, which could potentially be detrimental to sensitive biological materials. However, considering the drying process in more detail, it is evident that the spray droplets and the dried powder particles will maintain a temperature well below the inlet temperature of the drying gas throughout the process. As long as water evaporates from the droplets a cooling effect will be achieved, which prevents the temperature of the drying material rising above the wet bulb temperature of the drying air. Only in the last stages of drying, when the water activity of the drying material is low, can the temperature of the particles rise above this temperature, but will remain below the temperature of the air leaving the spray-dryer (typically $15-20{ }^{\circ} \mathrm{C}$ lower). In a typical spray-drying procedure for pharmaceutical materials, the inlet temperature is $180^{\circ} \mathrm{C}$ and the outlet temperature is $55-60^{\circ} \mathrm{C}$, indicating that the powder temperature is in the order of $40-45^{\circ} \mathrm{C}$ when leaving the spray-dryer. Furthermore, the drying time is in the order of milliseconds, and generally the total residence time in the spray-dryer is in the order of seconds (Masters, 1991 \& Millqvist-Fureby et al., 1999). From these arguments, extensive thermal damage to the protein seems less likely.

Spray drying is perhaps the most important example of a convective drying method for biological materials. The feed solution or slurry to be dried is atomised by a nozzle or rotating disc and then sprayed into a hot dry gas $\left(150^{\circ} \mathrm{C}-250^{\circ} \mathrm{C}\right)$. Evaporation proceeds rapidly enough that the temperature of the particle remains relatively low. Spray drying is a fast and efficient process that transforms a pumpable fluid feed into a dried product in a single operation. The fluid is atomised using a rotating wheel or a nozzle, and the spray of droplets comes immediately in contact with a flow of hot drying medium, usually air. The resulting rapid evaporation maintains a low droplet temperature so that high drying air temperatures can be applied without affecting the product i.e. the provision of latent heat prevents the particle products from reaching high temperatures until they are dry and relatively stable (Filkova et al., 1987, Tijsterman, 1993). Spray drying is commonly used in the pharmaceutical industry for various substances such as antibiotics, 
vitamins, vaccines, enzymes, plasma, plasma substitutes and excipients. It is also widely employed in the food and detergent industries. Unlike freeze-drying, the spray drying process can be used to control the size and shape of the dried product (Forbes et al., 1998). Spray drying has been used to produce stable dried liposomes that could be administered by inhalation. The preparation of the dry product will solve the stability problems. Once administered, the inhaled particles will rehydrate in contact with the moist surface of the airways. Using $10 \%$ lactose as a bulking agent, particles ranging from 1-20 $\mu \mathrm{m}$ were generated (Banga, 1995, Masters, 1991, Millqvist-Fureby et al., 1999).

\subsubsection{Impact of Spray-Drying on biological functionality}

Spray drying is a manufacturing process that yields powders that are small enough for aerosol delivery to the lower airways of the lung. This process consists of liquid atomisation into a fine mist followed by rapid hot air drying. Therefore, the stability of proteins prepared by spray drying may be influenced by denaturation at the gas-liquid interface, thermal stress and the stress of long term storage in the dried state. For instance, spray drying of a model protein, $\beta$-galactosidase resulted in soluble and insoluble protein aggregation following spray drying and storage of the powder. The application of spray drying to the production of protein pharmaceuticals has been reported with recombinant tissue-type plasminogen activator, human growth hormone and human deoxyribonuclease. In each case, soluble or insoluble protein aggregation was observed. While formulation additives such as carbohydrates may be employed to improve both the thermal and dehydration stability of proteins, such excipients must not interfere with the aerosol performance of a powder intended for pulmonary delivery (Andya et al., 1999, Forbes et al., 1998).

During the drying process the temperature of the droplets could reach values high enough to cause significant damage, especially to proteins/enzymes. However, it should be noted that the rate of protein/enzyme damage is a function of both temperature and water activity or moisture content of the particular product.

Spray drying is a well-established conventional drying process that has only recently been explored for its potential use as an alternative to the freeze-drying of protein drugs. Limited study is most likely due to concerns that proteins would not be able to withstand the heat during the spray drying process. A recent study looked at the feasibility of spray drying solution of recombinant human growth hormone $(\mathrm{hGH})$ and tissue-type plasminogen activator (t-PA). It was found that $h \mathrm{GH}$ underwent extensive aggregation during atomisation, but t-PA remained intact. Degradation of $\mathrm{hGH}$ during processing was due to surface denaturation at the air-liquid interface and this was overcome by re-formulating the solution by the addition 
of polysorbate-20, a surfactant (Banga, 1995).

This study suggested that spray drying might be a feasible alternative to lyophilisation but that some products may require modified formulations to be able to withstand the drying conditions. Another disadvantage of spray drying is that it is often inefficient with low product recovery and it produces a product that often has relatively high levels of associated water. Although high temperatures are used in spray drying, the key to avoiding degradation is that the contact time between droplets and the hot air in the spray drying chamber must be very short.

Successful formulation of a spray dried therapeutic protein requires a balance between improving the biochemical stability whilst not compromising the aerosol performance of the blended powder. In the case of a recombinant humanised anti-lgE monoclonal antibody (rhuMAbE25) the protein was susceptible to solid state aggregation, and improved stability was obtained by employing a strategy developed for freezedried proteins, namely, formulation with a carbohydrate (Andya et al., 1999, Constantino et al., 1998 \& Maa et al., 1998).

Bot et al., (2000), used spray drying to formulate immunoglobulins into hollow porous microspheres for delivery to the respiratory tract. They found that human $\lg G$ was readily released from these microspheres once added to an aqueous environment.

An alternative to spray drying is spray freeze-drying. Spray freeze-drying is the process of atomising a liquid to form droplets, freezing the droplets, and ice subliming at low temperatures and pressure. The atomisation step and the extremely rapid freezing of droplets impose stresses on proteins distinct from those provided by lyophilisation (Constantino et al., 2000). Maa et al., (1999) compared spray drying to spray freeze-drying for the production of protein inhalation powders. They demonstrated that spray freezedrying is a feasible technique for preparing protein aerosol powders. The spray freeze-dried powders showed much better aerosol performance than the spray dried powders, which was attributed to better aerodynamic properties as a result of the powder's large porous characteristics. However, protein formulation played an important role. Excipients that crystallised or tended to coalesce deteriorated the aerodynamic properties of the spray freeze-dried powder. Overall, spray freeze-drying is a more efficient process in terms of product recovery and product quality (Maa et al., 1999). 


\subsection{Use of Supercritical Fluids in Bioprocessing}

Supercritical fluids have a great potential for a wide range of processes. The well-known applications of supercritical fluids are situated in the field of extraction of plant materials, decaffeination of tea and coffee and hop extraction. There exist many publications dealing with the extraction of flavours, spices and essential oils from plant materials (Brennecke, 1996, Eckhert et al., 1996 and Hauthal, 2001). Beside the production of total extracts supercritical fluids can be used to separate and fractionate the extract into different products. This is achieved by adjusting the fluid solvent power by changing pressure and/or temperature. The separation of alcohol from different raw materials like cider, wine fermentation broth, alcohol-water mixtures and wine is an interesting alternative to distillation processes especially if heat sensitive substances are present (Venkat et al., 1995).

The use of $\mathrm{CO}_{2}$ has advantages over other gaseous or liquid solvents because it introduces no health hazards and processing is carried out at ambient temperatures. The sensitivity of many food and therapeutic compounds to heat, oxidation and mechanical shock on the one hand, and the growing drive to eliminate organic solvents from food and drug technologies on the other, render supercritical fluid technology an attractive alternative to the conventional methods used to date.

Supercritical $\mathrm{CO}_{2}$ (or other supercritical fluids) is an environmentally benign alternative to conventional organic solvents. Supercritical fluids offer possibilities to reduce the size of reactor volumes to a great extent, and to accelerate chemical processes. The rapid expansion of supercritical solution (RESS) process allows the production of powders with a narrow distribution curve of the (therefore well-defined) particle sizes (Hauthal, 2001).

Hannay and Hogarth published the first paper in 1879 detailing particle formation using supercritical fluids. They described the formation of 'snow' by expansion of a binary solution and detailed the properties of supercritical fluids. However it was not until 1940 that Pilat and Godlewicx proposed their use in modern industry.

Supercritical fluid technology has advanced in recent years with ever increasing applications covering a wide variety of processes encompassing the chemical, biochemical, food and pharmaceutical industries. The growing interest in supercritical fluid technology results from the attractive possibilities offered by this technology: processing at moderate, usually ambient temperatures, use of non-toxic, non-flammable, environmentally acceptable solvents (for the most part carbon dioxide) and easy change of solvent power (not possible with conventional organics). The physio-chemical properties of supercritical fluids are flexible with temperature and pressure and could thus be selected to suit many given applications (Palakodaty et 
al., 1997).

In the last few years there has been a rapid increase in using supercritical fluids for particle generation. In most cases it is the aim to produce particles with micron and submicron size especially with a narrow size distribution, which cannot be obtained by milling. The main interest in these products comes from the pharmaceutical industry which needs these fine particles and the narrow size distribution for bioavailability via inhalation sprays so that particles are not too small which cause inhalation into the lungs or on the other had too large which causes particles to be exhausted (Marr et al., 2000).

Supercritical fluids are materials above their critical temperature $\left(T_{c}\right)$ and critical pressure $\left(P_{c}\right)$. Above the critical point, molecular thermal energy exceeds the attractive forces between molecules, and a gas-like state exists; consequently, the properties of supercritical fluids bridge the gap between the properties of liquids and gases. The densities of supercritical fluids are comparable to those of liquids, while the viscosities and diffusion coefficients of supercritical fluids are comparable to those of gases. There is at least an order of magnitude difference between the viscosities of supercritical fluids and liquids (Table 1.3), and thus the diffusion coefficients of supercritical fluids are an order of magnitude higher that those of liquids. Low viscosities increase mass transfer rates; thus elevating rates for diffusionally controlled reactions. The liquid like densities of supercritical fluids results in higher solubilising power than those observed for gases. Furthermore supercritical fluids show almost zero surface tension. Unlike the behaviour of gases and liquids, the physical properties of a supercritical fluid can be adjusted over a wide range by a relatively small change in pressure or temperature (Kamat et al., 1995).

Table 1.3 - Thermophysical Properties of Supercritical Fluids Compared to Gases and Liquids

\begin{tabular}{llll}
\hline Property & Liquids & Gases & Supercritical Fluids \\
Density $(\mathrm{g} / \mathrm{ml})$ & $\approx 1$ & $\approx 0.001$ & $0.05-1.0$ \\
Viscosity $(\mathrm{cp})$ & $\approx 1$ & $\approx 0.01$ & $0.05-0.15$ \\
\hline
\end{tabular}

from: (Kamat et al., 1995)

The most commonly used supercritical fluid is supercritical carbon dioxide. This supercritical fluid is already widely used in several large-scale industrial processes. Carbon dioxide is non-toxic, nonflammable, relatively inexpensive ( $\$ 0.02$ and $\$ 0.03$ per $\mathrm{kg}$.), recyclable and 'generally regarded as safe'. Therefore for pharmaceutical applications carbon dioxide is an ideal processing medium. Because of its relatively mild critical temperature $\left(31.1^{\circ} \mathrm{C}\right)$, it is possible to exploit the advantages of near-critical 
operation at temperatures lower than $35^{\circ} \mathrm{C}$. Even though the critical pressure $(73.3 \mathrm{bar})$ of carbon dioxide is relatively high, such operating pressures and operating equipment are fairly routine in large-scale separation processes involving supercritical carbon dioxide such as the decaffeination of coffee beans and extraction of hops.

\subsubsection{Phase Diagram for Carbon Dioxide}

Figure 1.6 shows a schematic projection of the phase diagram of carbon dioxide on the pressuretemperature plane. The three lines divide the diagram into three regions: solid, liquid and gas. Along the lines the two phases are in equilibrium and the three states coexist at the triple point. The discontinuous transition from liquid to gas ends at the critical point $\left(T_{c}, P_{c}\right)$. Beyond this point, a low-density gas can be compressed into a dense fluid continuously. Strictly speaking, a fluid whose temperature and pressure are simultaneously higher than at the critical point is supercritical. In practice the term is reserved for the description of fluids in the relative vicinity of the critical point. In this region, the thermophysical properties exhibit very high rates of changes with respect to temperature and pressure.

In the vicinity of the critical point vapour and liquid coexist. The term supercritical is normally reserved for fluids within the approximate temperature and pressure range $1.01<T / T_{c}<1.1,1.01<P / P_{c}<1.1$.At these conditions the fluid exists as a single phase having some of the advantageous properties of both a liquid and a gas. At the critical point, the fluid's compressibility diverges. As a consequence the entire supercritical region is characterised by very large compressibilities. At the same time fluid densities can be very close to liquid-like. The distinguishing feature of supercritical fluid is the fact that, though almost liquid-like in density, it possesses a very high compressibility. This allows the use of pressure as a very sensitive means of manipulating and controlling the solvent's characteristics (in particular, its solvent power), spanning the continuum range from gas-like to liquid-like.

Looking at the phase diagram for $\mathrm{CO}_{2}$ (Figure 1.6) it can be seen that at room temp and 1 bar pressure $\mathrm{CO}_{2}$ exists as a gas. However by changing the temperature and/or pressure the $\mathrm{CO}_{2}$ can be made to enter a different phase, for example by compressing the gas it will eventually liquefy and if the temperature is reduced solid $\mathrm{CO}_{2}$ or dry ice is formed. 


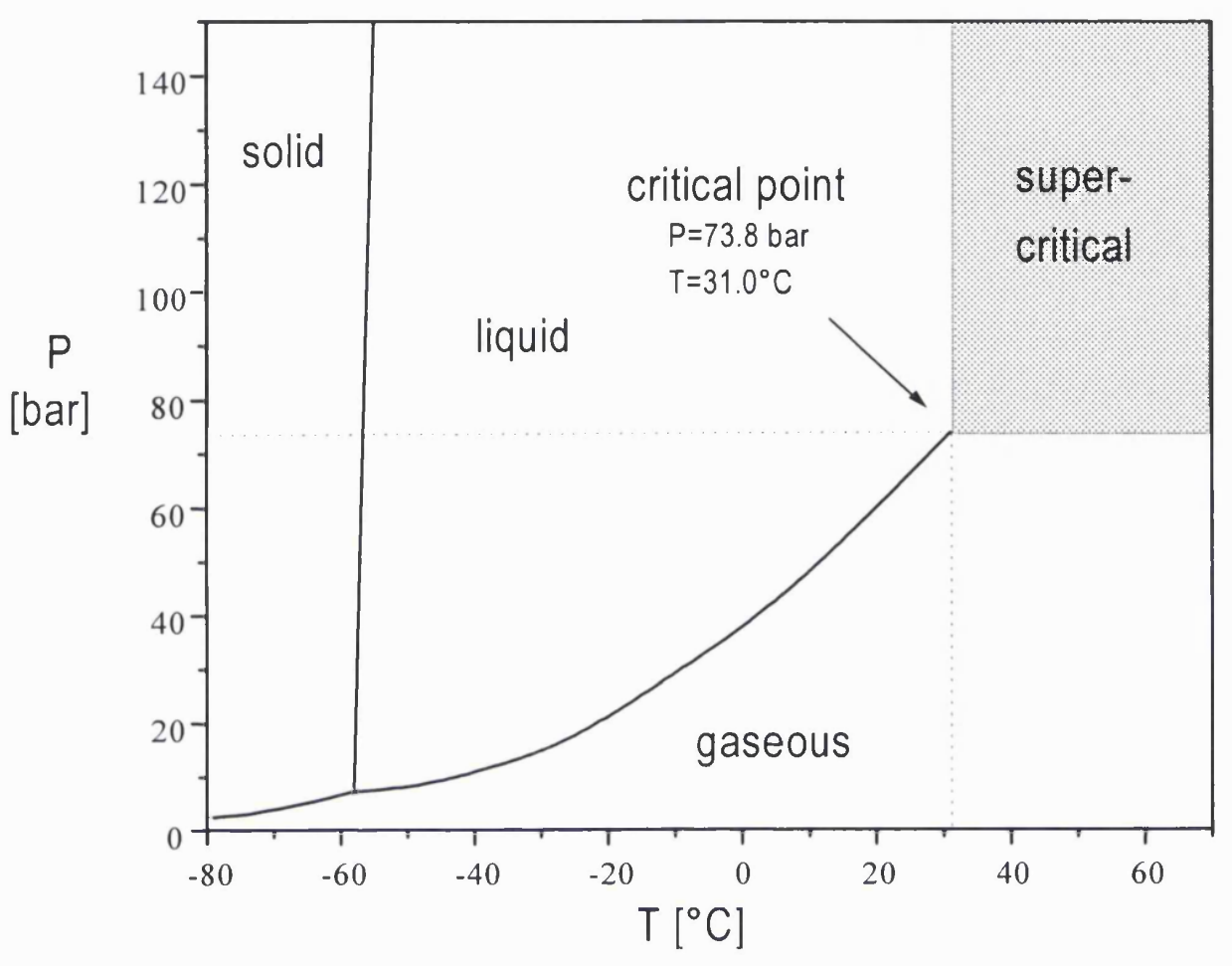

Figure 1.6 - Phase Diagram of Carbon Dioxide 


\subsubsection{Use for Supercritical Fluids}

\subsubsection{Chromatography, Extraction and Environmental Applications}

The extractive properties of supercritical fluids have been exploited for many years on an industrial scale however their use in preparative chromatography is more recent and limited. Analytical scale supercritical fluid chromatography (SCF) employs much of the apparatus used in HPLC. Supercritical fluids have flow properties that are similar to gases under high pressure and hence they can flow fairly easily at high velocities through relatively narrow tubing. The pressure drop across a packed chromatographic column is considerably less for a supercritical fluid than for a liquid. It is advantageous to have a low-pressure drop across a SFC column because the solvating power of the fluid, and consequently its eluting strength, is proportional to the applied pressure. To obtain reproducible chromatography the elution strength should remain constant along the length of the column. If the pressure differential is large the solutes may precipitate from solution as the pressure, and hence density of the fluid falls (Bevan et al., 1994).

The main field in which SFC has been applied is that of natural products. Supercritical fluids have been used for many complex separations. Preparative SFC has been used to fractionate lemon peel and to isolate tocopherols from wheat-germ oil. Supercritical fluids have been used to extract and then chromatograph eicosapentanoic acid and docosahexaenoic acid esters from esterified fish oil by employing programmed extraction-elution with supercritical $\mathrm{CO}_{2}$.

SFC has the potential to replace normal-phase preparative HPLC because when coupled with supercritical fluid extraction, the extraction, pre-concentration and chromatographic fractionation can be carried out in a single run. The use of supercritical $\mathrm{CO}_{2}$ allows easy separation of solutes at low temperatures in an oxygen free environment that is essential for the separation of labile compounds. In addition a nonflammable, non-polluting and inexpensive mobile phase is helpful in terms of safety and economy.

It has been found that analytical SFC is about five times faster than HPLC in achieving the same separation efficiency, and chromatographic peaks are very sharp. Re-equilibration of the column following changes in mobile-phase composition is also more rapid than for HPLC. 
Despite the advantages SFC seems to offer over HPLC the technique has not been widely adopted or developed more intensively and comprehensively. This may be due more to the success of HPLC in being able to do things adequately, rather than any serious limitations of SFC. Commercial HPLC instrumentation is widely available and highly developed whereas SFC instrumentation is in its relative infancy (Bevan et al., 1994).

Supercritical fluid extraction is a form of liquid extraction where the usual liquid solvent phase has been replaced with a supercritical fluid (Bevan et al., 1994). Although the ability of supercritical fluids (SCFs) to dissolve non-volatile solids has been known for more than a century, interest in their commercial exploitation has occurred only in the past twenty years. The capability of some SCFs to replace toxic industrial solvents, the ability to make new materials at mild conditions and the possibility of tuning solvent characteristics for highly specific reactions or separations are the main considerations that underlie the current industrial and scientific interest in SCFs (Eckert et al., 1996).

Large scale supercritical extraction is well established, examples being the decaffeination of coffee and tea with supercritical $\mathrm{CO}_{2}$ and the ROSE process for separating the components of the heavy fraction of petroleum using supercritical pentane. A plethora of smaller scale applications exist, such as the extraction of drugs from plant materials, and the processing of heat-sensitive pharmaceutical compounds, which benefits from both the mild operating temperatures and the recovery of a dry product requiring no further solvent separation.

The main commercial successes of SCFs have been in the food processing industry. Large supercritical $\mathrm{CO}_{2}$ tea and coffee decaffeination plants are in operation in both Europe and the United States. The other large food processing application of supercritical $\mathrm{CO}_{2}$ is the extraction of hops, spices and flavours. New discoveries in the extraction of natural products with supercritical $\mathrm{CO}_{2}$ include pharmaceutical compounds, various health supplements, flavours and fragrances. For example, at the Georgia Institute of Technology, taxol, a promising anti-cancer agent has been extracted, using supercritical $\mathrm{CO}_{2}$, from the bark of Taxus brevifolia, a variety of yew tree. The extraction of taxol with supercritical $\mathrm{CO}_{2}$ has been found to be more selective than conventional liquid ethanol extraction (Jarzebski et al., 1995 and Brennecke, 1996). It has also been used to extract gamma-linolenic acid, which is used as a health aid, from evening primrose oil seeds.

There are over 80 varieties of seeds, roots, leaves, flowers, fruits and barks that have been successfully extracted with either liquid or supercritical $\mathrm{CO}_{2}$. Supercritical $\mathrm{CO}_{2}$ extracts of celery, ginger, paprika, rosemary, sage and vanilla are currently available commercially (Brennecke, 1996). 
In general, the use of SCF solvents offers several advantages for heterogeneous reaction processes (Eckert et al., 1996):

1. Environmentally benign solvents such as cheap, non-toxic, non-flammable $\mathrm{CO}_{2}$, which can be used pure or with small amounts of modifiers.

2. Ease of solvent removal.

3. Reduction of mass transfer limitations.

4. Milder reaction conditions. Use of solvents with moderate critical temperature, such as $\mathrm{CO}_{2}\left(31^{\circ} \mathrm{C}\right)$, combined with extreme sensitivity of reaction rates to pressure allows fast rates to be obtained at mild conditions.

5. Higher yield and selectivity. Temperature, pressure and cosolvents can be used to tailor rates and selectivites in chemical reactions.

In addition to the environmentally driven replacement of organic solvents, SCFs have many direct environmental applications in soil, water and waste remediation. Soils and sludges contaminated with organics have been treated with supercritical $\mathrm{CO}_{2}$. This solvent has been used to regenerate granular activated carbon, which is used to purify wastewaters, ground waters and leachates. Another significant environmental application is the wet oxidation of organic contaminants in supercritical water, an alternative to incineration. At supercritical conditions, water is readily miscible with both oxygen and organics. Organic contaminants are oxidised completely ( $>99.99 \%)$ in a few seconds to form small product molecules such as $\mathrm{H}_{2} \mathrm{O}$ and $\mathrm{CO}_{2}$. This technology is being considered for the destruction of chemical weapons and stockpiled explosives, as well as the clean-up of industrial waste steams, municipal waste and used water from naval vessels (Brennecke, 1996).

Although there are many attractive characteristics of SCFs they should not be seen as a panacea to all the problems associated with conventional separation methods. If a separation can be carried out by traditional methods, such as liquid extraction or adsorption it is generally less expensive than by SCF processing. Typically SCFs are less dense than liquids, this means that although their solvent power is appreciable it is smaller than that of a corresponding liquid. Furthermore, the cost associated with the compression and containment of the fluid may limit the economic feasibility of the SCF extraction process. Thus, the most promising applications of SCFs are those in which their unusual properties are exploited towards making products with characteristics and specifications that cannot be obtained by other means. 
SCFs can be feasible alternatives to conventional solvent systems when they are associated with the production of high-value-added products (e.g. pharmaceuticals), in applications where environmental concerns are of primary importance (organic solvent free polymers), or when the possibility of coupling processing steps exists (Eckert et al., 1996, Brennecke, 1996 and Bevan et al., 1994).

\subsubsection{Use for Drying/Materials Processing}

Winters et al., (1997) used supercritical antisolvent precipitation (GAS and SAS) to process microparticulate protein powders of alkaline phosphatase, ribonuclease, insulin, lysozyme and trypsin from DMSO. Insulin, lysozyme, ribonuclease, and trypsin precipitates recovered substantial amounts of biological activity upon redissolving in aqueous media. Alkaline phosphatase, however, was irreversibly denatured (Winters et al., 1999). The structural perturbations induced during the SAS precipitation process were found to be protein specific (Winters et al., 1996).

Materials' processing is also a promising area of application of supercritical technology. The use of SCFs for materials' processing is one of the new, efficient and novel approaches to achieve high purity micronsized particles with well-defined morphological structures in a single step. Particle production using supercritical fluids could potentially mean the elimination of the need for harvesting and drying stages and also the reduction of residual solvents.

Supercritical carbon dioxide has been exploited both as a solvent and as a non-solvent or antisolvent in pharmaceutical applications. The ability to rapidly vary the solvent strength, and thereby the rate of supersaturation and nucleation of dissolved compounds, is a unique aspect of supercritical technology for particle formation.

Three or four main processes have been developed that use supercritical fluids for materials processing: the rapid expansion of supercritical fluid solutions (RESS) process, the gas anti-solvent (GAS) process, the precipitation with a compressed anti-solvent (PCA) process and the solution enhanced dispersion by supercritical fluids (SEDS). The first three processes are described briefly in this section, the fourth, SEDS, is described in more detail in section 1.8 .

\subsubsection{Rapld Expansion of Supercritical Fluid Solutlons (RESS)}

The principle of the rapid expansion of supercritical solution process (RESS) is that the substance that has 
to be powdered is first dissolved in a supercritical fluid. This mixture is then expanded into an atmospheric pressure or even vacuum spray chamber with the help of a nozzle. This sudden depressurisation loses solvent power of the compressed fluid immediately causing the dissolved matter to precipitate in fine dispersed form. Depending on nozzle design, temperature of the mixture before and in the nozzle, and pressure in the spray chamber different forms of solids can be obtained ranging from fine powders to crystalline needles and even thin films. Vital to this process is that substances can be dissolved in supercritical fluids and that solubility is satisfactory. The disadvantages of RESS are the high pressure range for obtaining good solubilities, the high fluid flow rate, the difficult separation of gas from solid particles because of the very small particle size and the discontinuous operating of the process (Marr et al., 2000).

The RESS process involves the dissolving of the solute of interest in the supercritical fluid at high pressures and then expanding the solution through a nozzle or capillary. Very high supersaturation ratios can be achieved, resulting in the nucleation (and subsequent growth) of very fine particles. There have been numerous successful applications of this technology to achieve size reduction and produce interesting morphologies. By changing the nozzle dimensions and the pre-expansion temperature it is possible to control particle size and shape.

Several groups have reported on the use of RESS to obtain micro and ultrafine particles of compounds of pharmaceutical interest (Jarzebski et al., 1995). P.G. Debenedetti and co-workers at Princeton University have demonstrated the potential of this technique for microencapsulation. They were able to produce composite drug-polymer microspheres, of poly-L-lactic acid and lovastatin) using a $\mathrm{CO}_{2}$ RESS process (Debenedetti et al., 1993).

\subsubsection{Gas Anti-Solvent (GAS)}

If the RESS process cannot be used because of no or too low solubility in the compressed gas of material which has to be powdered, the Gas Anti-Solvent process (GAS) is an alternative. The GAS process is a batch precipitation technique that utilises near critical or supercritical fluid antisolvents to precipitate solutes from solution. The addition of an antisolvent expands the solution, leading to a decrease in its ability to hold protein in solution. At a critical antisolvent concentration or solution expansion, homogeneous nucleation and growth of protein occurs. The advantages of the GAS process over conventional protein precipitation techniques is that powders may be produced at ambient temperatures, in a low shear environment, with a low level of oxygen exposure (Marr et al., 2000, Thiering et al., 2000a). 
The GAS processes exists in two modes - the first known simply as the gas anti-solvent process (GAS) involves the gradual addition of anti-solvent to the organic solution containing the solute until precipitation occurs. The second mode known as the Aerosol Extraction System (ASES) involves introducing the organic solution of the solute through a capillary nozzle into a flowing dense gas stream. Gas anti-solvent processes have been utilised for the generation of micro-sized particles of insulin, lysozyme, tyrosine, peroxidase and myoglobin. The difficulty of applying these techniques to the processing of proteins is that they involve exposure of the protein to organic solvents, the latter being potential denaturants and very poor solvents for most macromolecules (Bustami et al., 2000).

Bustami et al., (2000) successfully generated micro-sized particles of lysozyme, albumin and insulin with satisfactory inhalation performance using the modified ASES technique. They found that biochemical integrity of the processed proteins was a function of the operating conditions and the nature of the individual protein.

Thiering et al., (2000a) used the GAS process to produce protein powders with narrow size ranges, of lysozyme, insulin and myoglobulin powders. In a second paper Thiering et al., (2000b) showed that dense gas techniques were suitable for the production of protein micorspheres for application in specialised pharmaceutical preparations. Lysozyme and insulin were precipitated from DMSO as monodisperse microspheres with average diameters of $0.1 \mu \mathrm{m}$ and $1.5 \mu \mathrm{m}$, respectively. These precipitates were nonagglomerated and free of residual solvents.

This process relies on the high solubility of supercritical fluids in liquids at relatively low pressures. The dissolution of the supercritical fluid causes the liquids solvent strength to decrease, resulting in the selective precipitation of solutes. The solid(s) of interest is dissolved in a liquid and a supercritical fluid with a poor ability to dissolve solids but a fair power of dissolving the liquid is added, creating a pronounced volume expansion and hence supersaturation. This leads to precipitation. In this method a supercritical fluid forces other solutes out of solution (Jarzebski et al., 1995). Since the supercritical fluid is really a solute in this process, it is used like a small amount of organic solvent added to an aqueous solution to 'salt out' the ionisable compounds, a relatively small amount is needed (Brennecke, 1996).

This method has been used to precipitate a wide variety of products including food products, proteins and explosives. It is considered a suitable method for producing fine particles, particularly fine powders of proteins and polypeptides (Jarzebski et al., 1995). 


\subsubsection{Precipitation with a Compressed Anti-Solvent (PCA)}

The PCA process involves spraying a liquid solution containing the desired compound into a supercritical fluid. The liquid from the droplets then dissolves in the supercritical fluid, inducing precipitation of the compound of interest. This process relies on rapid mass transfer of the fluid into the droplet and of the liquid into the fluid phase. It is essentially spray drying into a supercritical fluid, and has been used effectively to produce numerous different microstructures including microspheres, microporous fibres and hollow microporous fibres.

\subsubsection{Particles from gas saturated solution process}

A new process was developed by Weidner et al., as cited in Marr et al., (2000) to form fine particles from gas saturated solutions (PGSS). The substance to be powdered is melted in an autoclave and a pressurised gas is dissolved in this melt. This solution is expanded over a nozzle into a spray tower. As well as cooling of the mixture by the Joule-Thompson effect volume increase of the released gas causes precipitation of the substance. The particles are recovered from the exhaust gas by a cyclone and a filter, so that fractionation according to particle size takes place. The advantages of this PGSS process are the low gas demand and low operating pressure. Limitations arise because only substances that can be melted can be processed although by solving the compressed gas in the substance melting temperature decreases. Further research is being done with this process for coating powders where additives are either mixed directly in the melted product or added in the spraying nozzle (Marr et al., 2000).

\subsection{Solution Enhanced Dispersion (SEDS)}

A novel technique involving supercritical fluid technology which provides control over particle characteristics such as morphology, size and shape and provides direct production of fine particles has been developed over the last four years at Bradford University.

Termed as Solution Enhanced Dispersion by Supercritical Fluids or SEDS for short the process involves the rapid dispersion, mixing and extraction of the drug solution solvent by the supercritical fluid. The equipment exists in two formats, the two component and three component systems, the three component system is schematically illustrated in Figure 1.7 .

The supercritical formation system, illustrated in Figure 1.7, provides control over the physical 
Investigation of Supercritical Fluid Technology to Produce Dry Particulate Formulations of Antibody Fragments Chapter One - Introduction

characteristics (e.g. size, shape and morphology) of particulate products. Such control is attributed to a high degree of manipulation of the working conditions of this system. The $\mathrm{CO}_{2}$ is cooled through a cooling head to achieve liquefaction to enable it to be pumped. It is then pumped at 200 bar by a high pressure reciprocating pump. The liquid $\mathrm{CO}_{2}$ passes through a length of tubing in the air oven, which is maintained at a temperature above $31.1^{\circ} \mathrm{C}$, this tubing acts as a heat exchanger and changes the state of the $\mathrm{CO}_{2}$ from liquid to supercritical. In the two component system the supercritical $\mathrm{CO}_{2}$ is pumped into one of the concentric tubes of the coaxial nozzle whilst the solvent containing the solute of interest is pumped through the other tube. The nozzle is designed to ensure the simultaneous introduction of the supercritical fluid and the vehicle containing the material of interest into the particle formation vessel and to achieve enhanced dispersion of the vehicle. Under these conditions the supercritical fluid will extract the vehicle from the mixture leading to rapid particle formation of the material of interest. Particles formed are retained in the vessel by a special retention device placed at the bottom of the particle formation vessel. The resultant supercritical fluid solution (that is the supercritical fluid and the vehicle) emerging from the back pressure regulator is allowed to expand in a pressure vessel. This pressure drop, due to volume expansion, will cause the supercritical fluid to separate as a gas from the liquid vehicle, and both the gas and the vehicle are recycled.

Particle formation or crystallisation of a compound using supercritical fluids relies on the compound having high solubility in an organic solvent but being insoluble in the supercritical fluid. The insolubility of proteins in most organic solvents, requires an alternative approach, the protein is precipitated from aqueous solution by an organic solvent and the resultant organic/aqueous mixture is removed by dissolution in the supercritical fluid. This means that the protein is in a more favourable aqueous environment until transient time of passage into compressed $\mathrm{CO}_{2}$ to leave dry particles. This system uses a specially designed three channelled co-axial nozzle in which the supercritical $\mathrm{CO}_{2}$ disperses and mixes streams of an aqueous protein solution and an organic solvent into the particle formation vessel. The solvent precipitates the protein from the aqueous solution feed and the solvent/aqueous mixture is rapidly extracted by the supercritical $\mathrm{CO}_{2}$ leaving dried protein particles.

In SEDS, the supercritical fluid, is introduced in a way which not only dissolves and extracts the solvent but also controls the dispersion of the liquid solution containing the material of interest and hence the final droplet size. Changes in working conditions (pressure, temperature, and flow-rates) allow control of the size, shape and morphology of the particles. At high $\mathrm{CO}_{2}$ and low solution flow-rates the droplets will be finer, in contrast to lower $\mathrm{CO}_{2}$ and higher solution flow-rates where the resulting droplets will be coarser. When the carrier liquid is extracted from a droplet the solute will precipitate as a particle. Therefore, at constant solution concentration, the final particle size is dependent on the initial droplet size. If control over droplets size is achieved, highly desirable manipulation of particle characteristics become possible. 
Work carried out at Bradford Particle Design and Bradford University using the SEDS kit to dry lysozyme has shown that the SEDS kit is capable of producing dried protein particles whilst retaining the enzyme's catalytic activity. The process produces particle with a relatively narrow size distribution and these are typically of spherical geometry. Reduced $\mathrm{CO}_{2}$ flow rates (relative to aqueous and organic flows) enables particle formation from an organic rich phase, this enables more consistent drying. The SEDS process is unable to remove the final $10 \%$ of tightly bound water from the protein, a value normally associated with water required for maintenance of protein catalytic activity.

A study by Moshashaée et al., (2000) showed that the SEDS process can be utilised to precipitate $\mu \mathrm{m}$ sized lysozyme particles, with minimal amount of residual DMSO and with a defined range of conditions, tertiary structure and full biological activity can be retained. By means of an experimental design procedure, the process has been optimised with data indicating that the most critical parameter affecting the biological activity of lysozyme precipitates is the operating pressure; at a lower pressure precipitates retain reduced biological activity compared with higher pressures. Pressure also influenced particle morphology with well formed primary particles of $1-5 \mu \mathrm{m}$ formed at lower pressure (80bar) while higher pressures (150Bar) gave rise to partially bridged particles and agglomerates (Moshashaée et al., 2000).

Nicotinic acid prepared by laboratory and pilot scale SEDS equipment showed that similar product was obtained at both scales of preparation in terms of size and size distribution, particle morphology and topography. In addition a high level of consistency and reproducibility of the process for particle sizes of products at both scales was indicated. Salbuterol sulphate was also successfully dried using SEDS. This study demonstrated that the direct production in a single stage process of micron sized particles suitable for respiratory drug delivery by SEDS (York et al., 1998).

Tservistas et al., (2001) investigated the processing of nucleic acids with SEDS. Dry formulations of plasmid DNA with mannitol as the main excipient were obtained from aqueous solution. The $\mathrm{pH}$ drop in the aqueous phase due to carboxylic acid formation was identified as the crucial factor for the recovery of intact supercoiled plasmid DNA. When a high-buffer capacity was used in the aqueous feed, a high degree of the original supercoiled proportion of the plasmid could be recovered (Tservistas et al., 2001). The SEDS formulation of plasmid DNA powders is of interest for the delivery of DNA, for example by inhalation or even transdermally. 


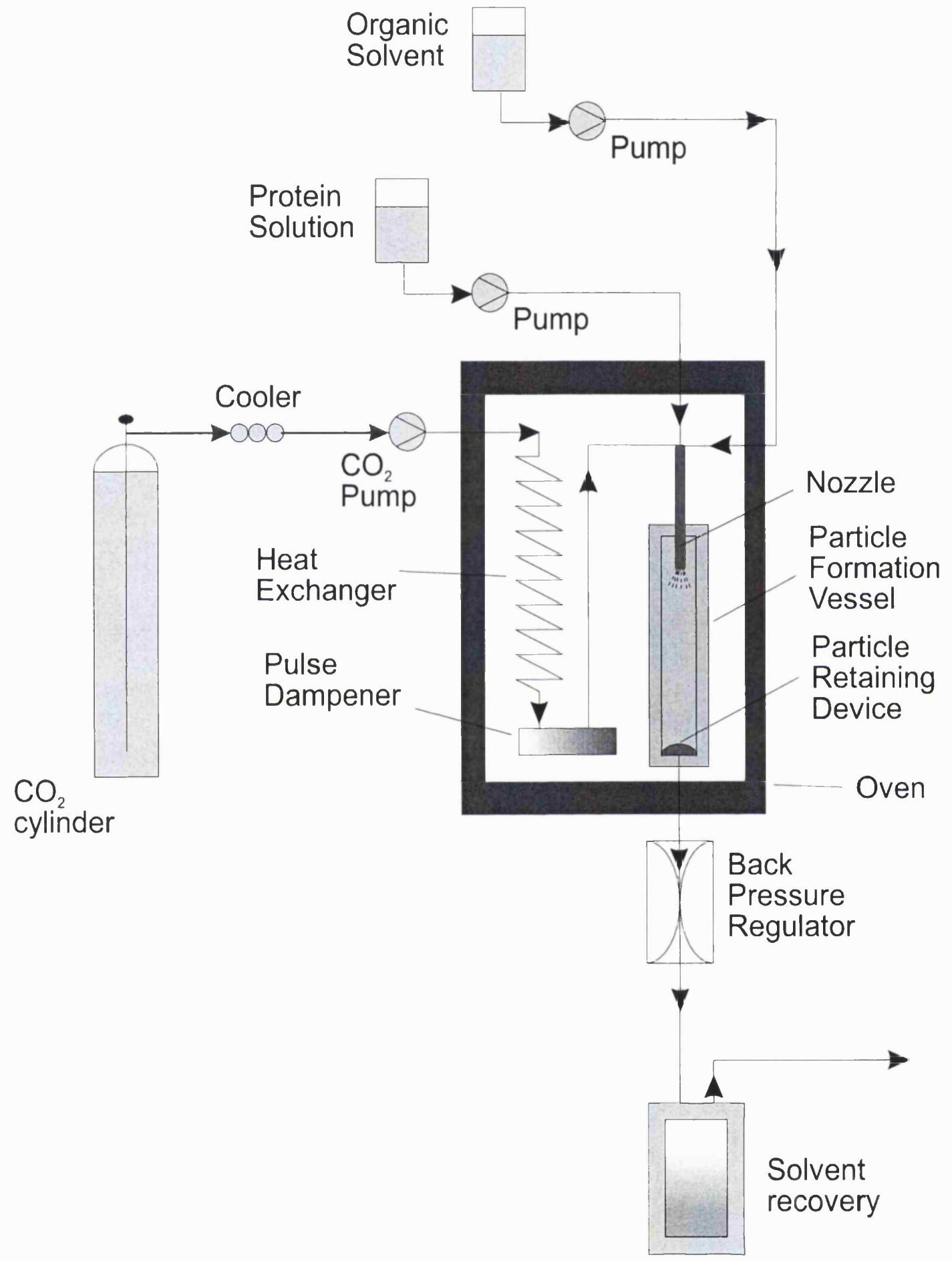

Figure 1.7 - Schematic diagram of the SEDS three component supercritical particle formation system. 


\subsection{Three component supercritical phase behaviour}

A system that contains three components is known as a ternary system. Whereas a binary system has three variables (temperature, pressure and mole fraction) a ternary system has four because two independent mole fractions are needed to describe the system. Usually ternary phase equilibria are plotted in so-called Gibbs-triangles, where composition is plotted at constant pressure and temperature (Kordikowski, 1999). Figure 1.8 shows a typical phase diagram for a three component system of the aqueous, organic and $\mathrm{CO}_{2}$ process streams employed in SEDS.

The corners of a Gibbs-triangle represent the pure components (aqueous, organic, $\mathrm{CO}_{2}$ ). The edges represent the three binary systems (water/ $\mathrm{CO}_{2}, \mathrm{CO}_{2} /$ organic, water/organic), so any ternary mixture lies inside the borders of the triangle. It can be seen that the region of immiscibility (the area bounded by and below the binodial curve) is large and more than half of all possible concentrations lie inside it. Above the critical point of the organic and $\mathrm{CO}_{2}$ there is complete miscibility of $\mathrm{CO}_{2} /$ organic and organic/water mixtures. The 'bottom' of the triangle represents the binary system $\mathrm{CO}_{2} / \mathrm{H}_{2} \mathrm{O}$ and it can be seen that only a small amount of either component is miscible with the other, this necessitates the use of an organic antisolvent.

The aim of the SEDS process is to form dry solute particles in a single equilibrium phase, while removing the water and organic anti-solvent from the particle formation vessel. Aqueous, organic and supercritical fluid feeds are introduced into the particle formation vessel through the nozzle at flow-rates aimed to achieve a single equilibrium phase within the particle formation vessel. The process path occurring in SEDS is from a two-phase flow (aqueous/organic and supercritical fluid/organic phases) to the desired single equilibrium phase. This process path follows the tie lines (the shortest path). The phase transition and subsequent particle formation comprises concurrent phenomena initiated by a two-way mass transfer between the supercritical fluid/organic and organic/water phases.

These phenomena are precipitation of the solute from the aqueous feed by the organic anti-solvent and extraction of water into the supercritical $\mathrm{CO}_{2}$ facilitated by the organic solvent modifier.

Unlike a binary system the tielines for a ternary system are not parallel. This non-paralleity of the tielines provides the SEDS process with some unique possibilities. By manipulating only the flow ratios of the three fluid components, and without changing temperature or pressure the properties of the SEDS product can be influenced. Figure 1.8 shows two different experimental systems, corresponding to points $A$ and $B$ on the phase diagram. $L(A)$ and $L(B)$ show the composition of the liquid immediately after the nozzle 
outlet, particle formation occurs from this liquid phase with points $A$ and $B$ representing the finally resulting supercritical mixture. The difference in composition of $A$ and $B$ is small but their corresponding liquid phases points, $L(A)$ and $L(B)$, differ significantly. $L(A)$ being an organic rich phase and $L(B)$ being an aqueous rich one. Thus for two experimental systems the drying proceeds from significantly different liquid phases. The make up of the feeds to the nozzle represents an important operating variable defining the chemical environment of particle formation (Sloan et al., 1999). The role of phase behaviour on derived particle size and morphology has been demonstrated during the SEDS processing of aqueous solutions of small water soluble molecules (Palakodaty et al., 1998).

Palakodaty et al., (1998) found that the underlying mechanism controlling the SEDS process or any process involving supercritical fluids, organic solvents and aqueous solutions, is defined by the phase behaviour of the resulting ternary system. a-lactose monohydrate was recrystallised as micron sized particles with two alternative morphologies when working at different non-equilibrium solubility regions of the aqueous and $\mathrm{CO}_{2}+$ cosolvent phases. When crystallisation was initiated in a water rich liquid phase, lactose exhibited a higher water content compared to those samples crystallised in the co-solvent-carbon dioxide rich phase. Such flexibility in altering the physio-chemical properties of the crystallised material is attractive and exemplifies the fact that the SEDS technique is an efficient and reliable means of comminuting water soluble compounds in a simple and environmentally benign process (Palakodaty et al., 1998).

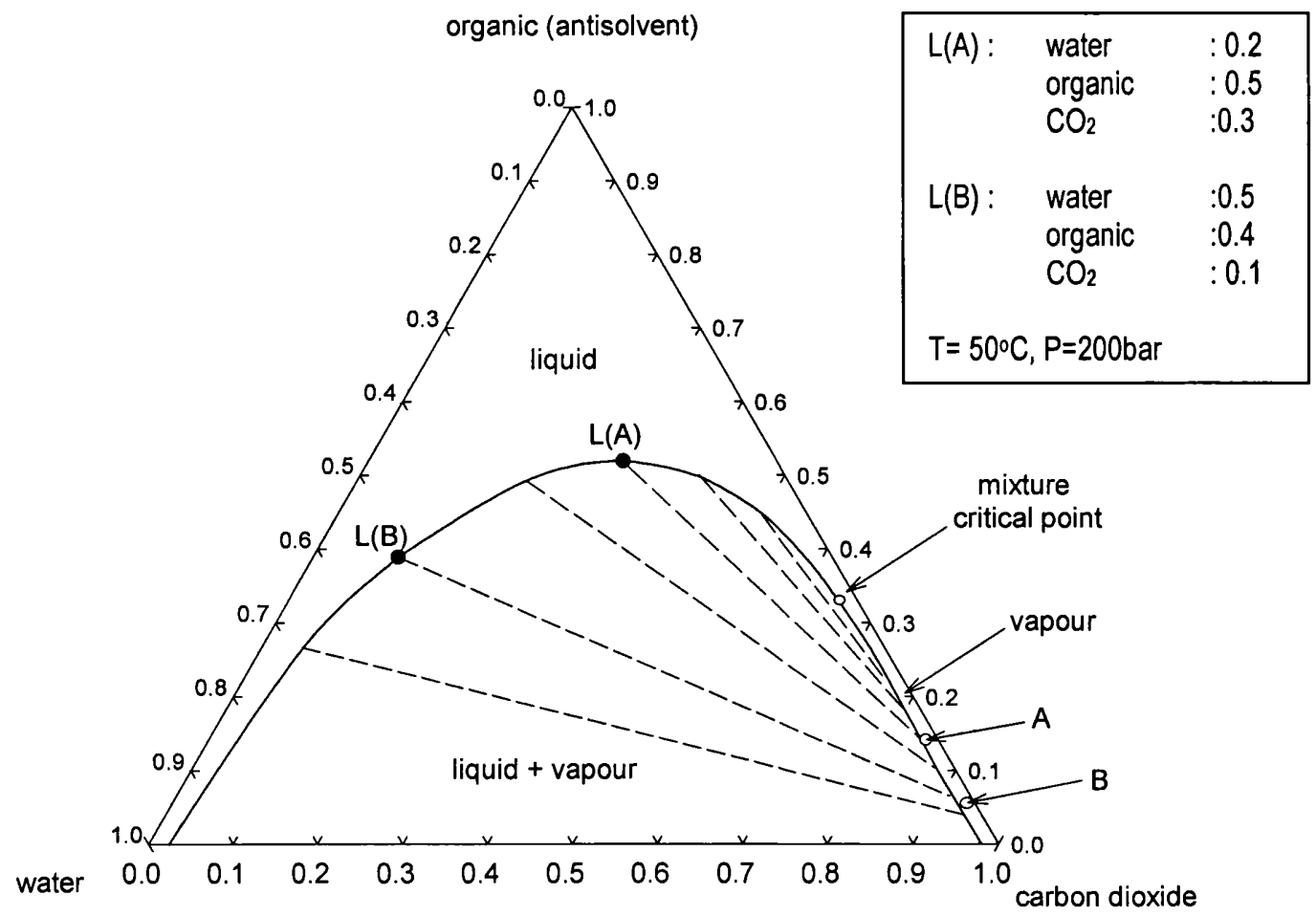

Figure 1.8 A typical phase diagram for a three component system of the aqueous, organic and $\mathrm{CO}_{2}$ process streams employed in SEDS (see text for explanation). 


\subsection{Antibodies}

Antibodies are the most important elements of what is known as the humoral immune system, which comprises soluble proteins that help defend against foreign entities such as microorganisms and transformed (malignant) cells. Antibodies belong to a group of serum proteins known as $\mathrm{Y}$-globulins. Most $y$-globulins are immunoglobulins; an antibody, in turn, is an immunoglobulin that binds specifically to a particular structural component (epitope) of an antigen. Immunoglobulins are glycoproteins containing 4 $18 \%$ carbohydrate by weight. Antibodies are highly specific targeting agents. Therefore they are invaluable for in vitro and in vivo diagnostic applications. With the advent of monoclonal antibody technology, the utilisation of antibodies has increased dramatically in almost every field of biological sciences (Engle et al., 1993, Khaw, 1999, Klegerman, 1993).

Antibodies have the ability to bind selectively and specifically to their target antigens, a property that may be exploited for many applications. Therapeutic uses concerned with tumour imaging and therapy appear to be the major target applications for antibody fragments. In addition to their clinical applications, antibodies may become invaluable in industrial processes as refined immunopurification tools (Brown, 1993 \& Solomon et at 1984), and as catalytic antibodies (Pollack et al., 1986 \& Tramontano et al., 1986).

Recombinant antibodies and their fragments now represent over $30 \%$ of all biological proteins undergoing clinical trials for diagnosis and therapy. The focus on antibodies as the ideal cancer-targeting reagents recently culminated in approval by the FDA for the first engineered therapeutic antibodies. Innovative selection methods have enabled the isolation of high-affinity cancer-targeting and antiviral antibodies, the latter capable of redirecting viruses for gene therapy applications. In other strategies for cancer diagnosis and therapy, recombinant antibody fragments have been fused to radioisotopes, drugs, toxins, enzymes and biosensor surfaces (Hudson, 1999).

Immunoglobulins are of potential value for prophylaxis or treatment of certain diseases. Specific or hyperimmune antibodies raised in various species against microbes or microbial antigens are used for the purpose of passive immunisation. Antibodies directed against cancer specific antigens might be used to target toxins to tumour cells. More recent engineering approaches have extended the utility of immunoglobulins as carriers for bioactive compounds. For example, fusion constructs between immunoglobulin fragments and cytokines, ligands for cellular receptors or antigens, have been used to optimise the bioactivity of such compounds. Mucosal delivery of immunoglobulins (either native or engineered) may provide improved efficacy compared to systemic delivery via needle, both for the purpose of active and passive immunisation. For example it is known that only mucosal vaccination can result in secreted IgA responses that are associated with an optimal immunity at the port of entry. Finally, 
the potential exists that chronic or repeated administration of immunoglobulins to the systemic circulation can be achieved by non-invasive administration via the respiratory tract (Bot et al., 2000).

The experimental work detailed in this thesis looks at the SEDS processing of three antibody fragments (one Fv fragment and two Fab fragments) and a full antibody.

\subsubsection{Structure and Function of Antibodies}

An immunoglobulin subunit consists of a short polypeptide chain, the light chain (approximately 25,000 molecular weight), and a longer polypeptide chain, the heavy chain (approximately 50,000 molecular weight), covalently linked together by a single cystine disulphide bond. The immunoglobulin monomer consists of two sub units linked by two disulphide bonds. Each chain consists of a series of globular domains, like a string of beads, each containing a single intrachain disulphide bond. The heavy chain usually consists of four domains and the light chain has two (Klegerman, 1993).

Antibody molecules are multi-chain proteins. The antibody ( $\lg G)$ is a $Y$-shaped molecule, in which the domains forming the tips of the arms bind to the antigen and those forming the stem are responsible for triggering effector functions that eliminate the antigen (Figure 1.9). The antibody molecule consists of a $Y$ shaped tetramer of polypeptides composed of two heavy and two light chains. The amino terminal end provides variability $(V)$ in both the heavy $(H)$ and light $(L)$ chains. These variable regions are known as $V_{H}$ and $V_{L}$ respectively, and together they form the antigen-binding site. The remainder of the whole antibody consists of constant domains, known as $\mathrm{C}_{\mathrm{L}} \mathrm{C}_{\mathrm{H} 1}, \mathrm{C}_{\mathrm{H} 2}$, and $\mathrm{C}_{\mathrm{H} 3}$. Glycosylation usually occurs in the constant domains of heavy chains and is not involved in antigen binding. This is important when considering the expression of recombinant antigen binding fragments in organisms such as Escherichia coli (E.Coli) which cannot perform post-translational modifications such as glycosylation of antibodies.

The whole antibody molecule may be cleaved at the hinge region resulting in three approximately equal sized fragments. Two Fab fragments (fragments that retain the ability to bind antigen) and an Fc fragment (that part of the antibody which triggers the immune response). This cleavage is obtained via digestion with the proteolytic enzyme papain. Fv fragments (the region concerned with antigen binding) are obtained by digestion with pepsin. Recombinant proteins of the two domains $V_{H}$ and $V_{L}$ may be joined by a polypeptide linker to form single chain Fv (scFV) fragments. Recombinant DNA technology has facilitated the engineering of this into E.coli plasmid vectors enabling expression as a single protein (Bird et al., 1988). The inclusion of the polypeptide linker in scFv fragments ensures expression of both domains in an equal ratio, and increase the stability of the fragment (Bhat et al., 1990, Glockschuber et al., 1990). 
The domain structure of the molecule makes it particularly accessible to protein engineering, as functional domains carrying antigen-binding activities ( $F v, F a b$ fragments) or effector functions ( $F c$ fragments) can be used separately as fragments or swapped between antibodies (Winter \& Milstein 1991). Binding sites can also be transplanted from one antibody to another. These structural features have spawned a range of 'designer' antibodies, from complete antibodies, capable of destroying pathogens or tumour cells through their natural effector mechanisms, to antigen-binding fragments that can be used to target attached toxins, or for diagnosis through bound radioiostropes (Winter \& Milstein 1991).

The Fab and Fv molecules are monovalent antibody fragments and represent a single antigen-binding arm of the parent immunoglobulin. The Fv module comprises aligned $V_{H}$ and $V_{L}$ domains and is the smallest fragment that retains the full monovalent binding affinity of the intact parent antibody. Antibody fragments clear rapidly from the blood due to their small size have relatively high off-rates due to the single binding site. On the other hand, whole immunoglobulins appear to be too large for effective tumour penetration and their slow clearance can result in high retention in liver and other organs (Hudson, 1999).

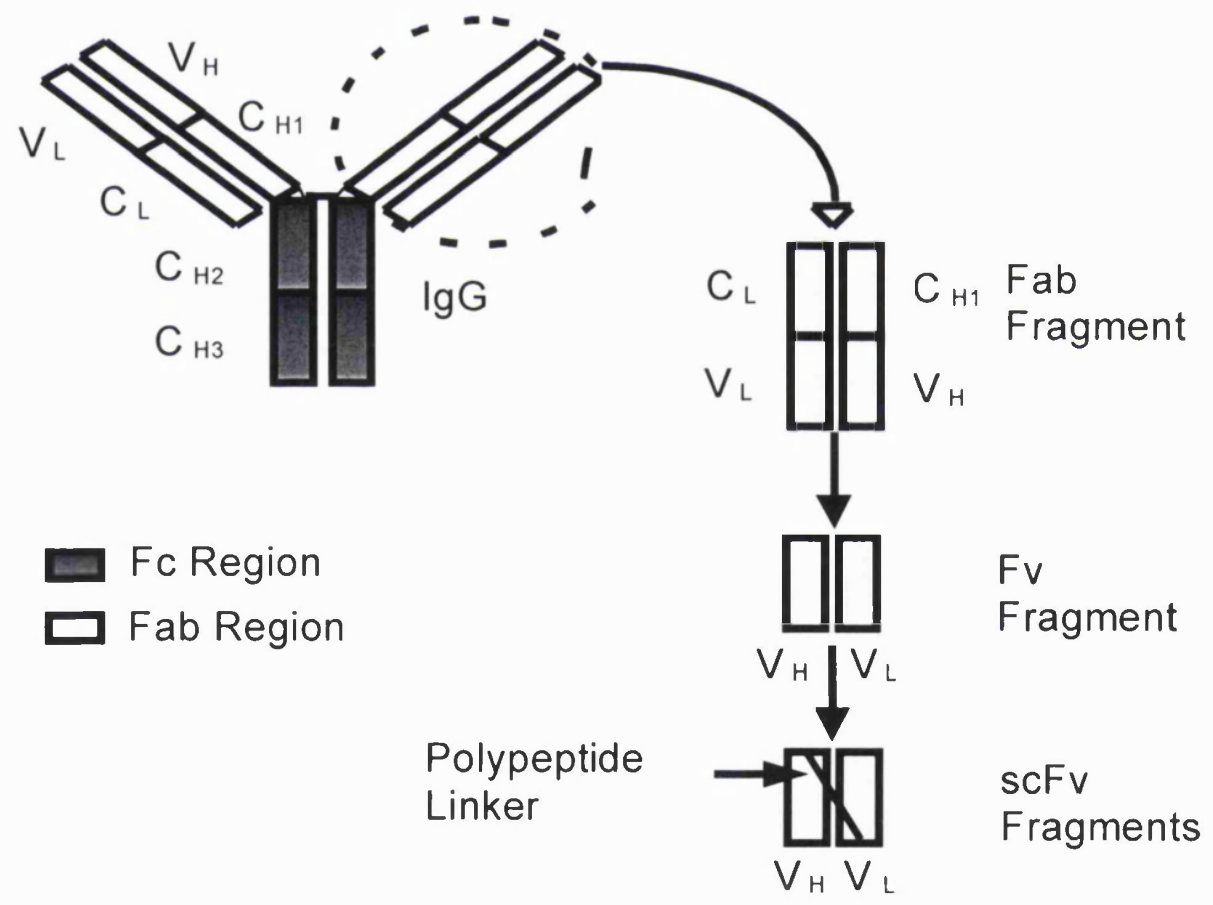

Figure 1.9 - Antibody and derived fragments. 


\subsubsection{Antibody Production}

The development of hybridoma technology by Kohler and Milstein (1975) paved the way for commercial production of monoclonal antibodies in vitro. Bacterial expression, in for example E.coli, where genetic manipulations and fermentation have been highly investigated, provides a more realistic alternative for large scale production of antibody fragments and engineered antibodies (Stranberg et al., 1991).

It was in 1975 the Köhler and Milstein first developed hybridoma technology - cell lines secreting a single species of antibody or monoclonal antibody (Mab) with specificity to an antigen. This was achieved by fusion of mouse myeloma and mouse spleen cells resulting in a stable cell line secreting monoclonal antibodies.

Hybridoma technology proved to be general, and a wide range of Mabs have been made which bind to protein, carbohydrate, nucleic acids and hapten antigens, and which even have catalytic activities, leading to many practical applications for Mabs in research and human health care (Winter \& Milstein 1991).

The initial approach to antibody production involved implantation of hybridomas into mice (Chandler, 1987). Although the concentration of monoclonal antibodies can be high (typically $50 \mathrm{mg} / \mathrm{mouse}$ ) there are a number of drawbacks. For significant scale-up a large number of mice are required and increased manual effort, contamination by mouse viruses cannot be ruled out, complex fluids containing mouse immunoglobulins are a challenge for purification, and batch to batch reproducibility is not achievable.

Controlled in vitro methods are, for the above reasons favoured for commercial production. Production of Mabs in a suspension culture in an airlift reactor have been reported (Birch et al., 1985), with titres of up to $500 \mathrm{mg} / \mathrm{L}$ in a $1000 \mathrm{~L}$ vessel. Hybridomas cultured in hollow fibres or microcapsules have been shown to increase productivity and produce more concentrated solutions of Mabs. In both of these cases hybridoma cells and secreted Mabs are separated from culture medium by a membrane.

Commercial production of whole monoclonal antibodies from hybridoma culture is now well established, however few reports of recombinant antibody fragment expression such as Fv and Fab fragments from cultures of animal cell origin are reported. The main reason is that these fragments do not require glycoslylation or other post translational modifications for antigen binding activity and therefore are candidates for expression and production from recombinant microorganisms.

E.coli is a genetically versatile organism in which recombinant DNA technology is well established. Genetic manipulation techniques have allowed for introduction of plasmid DNA encoding antibody genes 
under the control of strong promoters to allow for generation of antibody fragments to high titres at specific locations within the cell. The possibilities of 'designer' antibodies such as bifunctional molecules may also be realised (Ward, 1992). Expression of recombinant antibodies in E.coli is well documented (Skerra et al., 1993), as is the expression of numerous other recombinant proteins. E.coli is an attractive host organism for large-scale production due to the well-developed understanding of its fermentation and its fast growth rate. Scale-up of processes involving E.coli has also been widely investigated. To date the expression of $\mathrm{Fab}, \mathrm{Fv}, \mathrm{scFv}$, single domains and various engineered antibody based molecules have been demonstrated in E.coli.

\subsubsection{Applications of Antibodies and Antibody Fragments}

Complete antibodies are large molecules but much smaller fragments can be prepared that retain antigenbinding activity. Small fragments equipped with radioisotopes could be used for imaging or therapy and are in some ways particularly attractive for use in vivo as they penetrate tissue boundaries more effectively. Fragments are also cleared faster from the serum and tissues and although this may compromise their use as targeting agents, it can aid the clearance of toxic drugs, such as digoxin, from the circulation. Small fragments also have advantages in fundamental research, for high-resolution $X$-ray crystallographic studies of antigen-binding sites. The size of antibodies and flexibility of the hinge connecting Fab arms and Fc domain has prompted crystallographers to turn to Fab fragments and now Fv fragments. These fragments are expected to be used extensively as they are readily expressed in an active form from genes introduced into mammalian and bacterial cells. But antibody fragments may require further engineering to eliminate undesirable properties (Winter \& Milstein, 1991).

For example $F v$ fragments are noncovalently associated heterodimers of $V_{H}$ and $V_{L}$ domains which may dissociate. Some Fv fragments are less prone to dissociation than others, stable Fv fragments can be engineered either by linking the domains with a hydrophobic and flexible peptide to create single-chain Fv fragments (scFv), or by introducing disulphide bonds between the domains (Winter \& Milstein, 1991).

Engineering of antibody proteins for specific use in medical applications has been reviewed extensively (Chester \& Hawkins 1995). The small size of Fv and scFV fragments is a characteristic that makes these particular proteins attractive for the basis of medical products. Whole monoclonal antibodies, due to their large size, are slow to reach the tissues to which they are targeted and subsequently have slow clearance times from blood and tissues. Fv and scFv fragments have been shown to overcome these problems (Colcher et al., 1990) and can easily be attached to radiolabels or toxins to enable imaging and treatment of tumours (Bird \& Walker 1991). Prodrugs can be coupled to monoclonal antibodies so that active drugs 
can form in situ at the target site (Huennekens, 1994). Fv and scFv fragments offer attractive possibilities for this technology. Whole monoclonal antibodies may also attach non-specifically to other tissues via the heavy chain constant regions and if developed in non-human cell lines may elicit an immune response. This is also true of the smaller antibody fragments. However this maybe easily overcome in Fab fragments by fusing murine variable regions with human constant domains and in Fv fragments by grafting complementarity determining regions (CDRs) from murine antibodies onto a human framework thus humanising the antibody and enabling use in therapy (Verhoyen \& Reichmann 1988).

Antibody fragments have also been fused with a wide range of molecules limited only by the imagination including enzymes for prodrug therapy, toxins for cancer targeting, viruses for gene therapy, cationic tails for DNA delivery, liposomes for improved drug therapy and biosensors for real-time detection of target molecules. Clinical diagnostic applications of antibody fragments include the full range of in vitro immunoassays (30\% of the diagnostic industry world-wide, worth approximately $\$ 10$ billion per annum) through to in vivo tumour and clot imaging reagents (Hudson, 1999).

Intact immunoglobulins are routinely used in the diagnostic industry as trapping agents in immunoassays. For over-the-counter applications in dipstick technologies, a limitation on sensitivity is often the concentration of antibody that can be immobilised upon a small area. Much higher concentrations of antigens can be captured with Fv fragments since they have only 16 per cent of the mass of an intact antibody. Fv molecules also have the ability to penetrate cells, tissues and tumours (Harris, 1991).

Potential industrial applications of smaller antigen binding proteins such as Fv and scFv are in protein purification. Here the smaller size of the fragments allows immobilisation to a greater capacity on porous supports (Berry et al., 1991), increasing the column capacity for the target antigen and also increasing the lifetime of the immunoaffinity column (Berry \& Pierce, 1993). The addition of histidine tails to aid purification of antibody fragments has also been engineered (Skerra et al., 1991). The use of antibody fragments as the mediators of signals could be greatly expanded by the direct incorporation of catalytic activity within the antigen-binding site of the antibody itself. Such catalytic monoclonal antibodies or 'abzymes' have already been developed where antibodies are created which act as catalysts by binding the substrate in its intermediate state thus lowering the activation energy for the reaction. A third application is as the specific ligand for immobilisation onto biosensors.

Antibody fragments could also be used to inhibit microbial growth or their secreted products, in cosmetics and toiletries, or as additives during food processing to protect sensitive motifs or mask unwanted flavours. There is a lack of techniques available to remove low concentrations of contaminants from drinking, recreational and industrial process waters. Since antibodies commonly have high binding affinities they 
Investigation of Supercritical Fluid Technology to Produce Dry Particulate Formulations of Antibody Fragments Chapter One - Introduction

can chelate materials present at concentrations as low as $1 \mathrm{ng} / \mathrm{l}$. The ability of antibody fragments to remove bacteria from food related environments and also to remove polychlorinated biphenyls from dilute solutions is being studied

Antibody fragments with custom built specificity and affinity may soon become a legitimate class of specialised chemicals, with a wide industrial and medical applications (Harris, 1991).

\subsection{Project Objectives}

This project was designed to explore the applicability of a new supercritical fluid technology for the formulation of macromolecules and in particular antibody fragments. It is based on the work carried out at Bradford Particle Design and Bradford University where they have worked predominantly on small molecules.

The overall objective of the project is to carry out fundamental underpinning work on SEDS to enable its application in the preparative production of biopharmaceuticals. Preliminary studies carried out at Bradford on R-TEM $\beta$-lactamase and polyclonal IgG indicated the potential of SEDS to provide a viable alternative in many instances for spray-drying or freeze-drying.

A large part of this process study used controlled experimentation, together with biochemical engineering to characterise of the sequence of process events occurring during the SEDS process. This was used to identify critical aspects that lead to loss of biological activity. Using the results of these experiments means by which damaging aspects could be minimised or eliminated were sought.

A number of areas have been considered during the study. The nozzle configurations, use of different solvents, temperature, $\mathrm{pH}$, shear and protein choice have all been systematically examined. The key consideration has been the effect of these factors on antibody activity.

The main objectives were to establish conditions that produced dry particulate protein powders with recovery of high specific activity.

Engineering pharmaceutical particles by supercritical fluid SEDS processing, and the scaleability of the process has many advantages. Studies will continue to probe the underlying mechanisms and extend the theoretical understanding of the process. Practical applications in fine chemical processing and drug delivery will also be explored as part of the overall work of Bradford Particle Design and its associated projects. As ever increasing demand is made of particles by chemists, formulators and regulators, for 
Investigation of Supercritical Fluid Technology to Produce Dry Particulate Formulations of Antibody Fragments Chapter One - Introduction

example in terms of chemistry of composition, size and shape, as well as purity and low residual solvent, the supercritical approach is likely to provide wide ranging opportunities to meet such needs. With proven ability to process delicate biological materials into stable and active particulates, the SEDS process also provides a much needed simplified alternative to both spray and freeze-drying operations (York, 2000). 


\section{CHAPTER TWO}

\section{MATERIALS AND METHODS}




\section{Materials and Methods}

\subsection{Materials}

All reagents used were of analytical grade. Phosphate buffered saline sachets (PBS), phosphate buffered saline with Tween-20 sachets (PBS/T), sodium chloride, glacial acetic acid, hen egg lysozyme (HEL) (code L-6876), turkey egg lysozyme (TEL) (code L-6255), ethanolamine, hydrochloric acid (HCl), diethylamine, glycine, sodium glycinate, tetramethlybenzidine (TMB), tris-aminomethane, polyethylene glycol - average molecular weight 600 (PEG600), methanol, ethanol, isopropanol and D-mannitol (ACS reagent) were obtained from Sigma Chemical Company (Poole, Dorset, UK). Sodium azide, sodium acetate, Tween-20, casein, citric acid, dimethyl sulphoxide (DMSO), sodium hydrogen carbonate $\left(\mathrm{NaHCO}_{3}\right)$ and ethylenediaminetetra-acetic acid (EDTA) were obtained from BDH (Poole, Dorset, UK). Bovine serum albumin (BSA) standard and Coomassie ${ }^{\circledR}$ Plus Protein Assay Reagent were supplied by Pierce (Pierce Chemical Company, Illinois, USA). Tri-sodium citrate was supplied by Fisons Scientific Equipment (Loughborough, Leics, UK). 1-ethyl-3-(3-dimethylaminopropyl)carbodimide (EDC), Nhydroxysuccinimide (NHS) were obtained from Labsystems Affinity Sensors (Cambridge, UK). Anti-human kappa light chain clone GD12 peroxidase, catalogue number MP135, was supplied by The Binding Site (Birmingham, UK). Murine anti-Human $\operatorname{lgG}_{4}$-HRP and normal mouse serum (NMS) were obtained from Serotec (Kidlington, Oxon, UK).

Bell filters, Sartobran 300 capsules, were supplied by Sartorius Limited (Epsom, Surrey, UK). NUNC 96 well microtitre plates, Immunoplate I F96, Maxisorp, catalogue no. 4-39454A, were obtained from Life Technologies Ltd (Paisley, Scotland, UK). Slide-A-Lyzer Dialysis Cassettes were supplied by Pierce (Pierce Chemical Company, Illinois, USA). IAsys carboxymethy dextran cuvettes were obtained from Labsystems Affinity Sensors (Cambridge, UK).

HP6045, anti human Fd, CDP850, 4D5 PEG-Fab, antibody $34.2(1.29 \mathrm{mg} / \mathrm{ml})$ and lectin-EGF $(1.07 \mathrm{mg} / \mathrm{ml})$ fragment were all supplied by Celltech (Slough, UK).

Recombinant D1.3Fv anti-lysozyme was produced by batch fermentation of E.Coli strain BMH 71-18. Clarified supernatant from these fermentations was prepared in collaboration with Robert Brown, UCL.

4D5Fab was produced by batch fermentation of E. Coli strain W3110.

All solutions were made using ultra high purity water. PBS/T/S buffer was made by adding $29.25 \mathrm{~g} / \mathrm{L} \mathrm{NaCl}$ to PBS/T buffer. Sodium acetate buffer was adjusted to $\mathrm{pH} 5.5$ with glacial acetic acid. $1 \mathrm{M}$ ethanolamine 
Investigation of Supercritical Fluid Technology to Produce Dry Particulate Formulations of Proteins

Chapter Two - Materials and Methods

was adjusted to $\mathrm{pH} 8.5$ with concentrated $\mathrm{HCl}$. $\mathrm{HEL}$ and TEL $(30 \mathrm{mg} / \mathrm{ml})$ were prepared in $10 \mathrm{mM}$ acetate buffer. Purified D1.3Fv was diluted with sodium acetate for the production of a calibration curve.

\subsection{Purification of D1.3Fv}

\subsubsection{Affinity Chromatography}

The clarified supernatant supplied was stored at $4{ }^{\circ} \mathrm{C}$ with $0.01 \%$ sodium azide added in order to prevent microbial contamination, prior to affinity chromatography.

Affinity purification of the D1.3Fv was performed using a $20 \mathrm{ml} \mathrm{NHS-activated} \mathrm{HiTrap} \mathrm{affinity} \mathrm{column}$ (Pharmacia LKB Biotech Ltd., St Albans, UK) to which hen egg lysozyme was attached, using the supplied protocol. The column was incorporated into a chromatography rig consisting of a P1 peristaltic pump, fitted with $3.1 \mathrm{~mm}$ (internal diameter) tubing, a UV-1 Optical unit (280nm wavelength), Frac-100 fraction collector and Rec-1 chart recorder (all Pharmacia LKB).

Prior to loading, the column was washed through with 5 column volumes of elution buffer $(50 \mathrm{mM}$ diethylamine, $\mathrm{pH} 12$ ) to remove any non-covalently coupled lysozyme followed by 5 column volumes of PBS buffer. $1.5 \mathrm{~L}$ of supernatant was loaded onto the column at a rate of $10 \mathrm{ml} / \mathrm{min}$ before breakthrough was detected on the biosensor. After the broth had been passed through the column it was washed with 5 column volumes of PBS prior to elution. Three column volumes of pre-elution buffer, $(50 \mathrm{mM}$ diethylamine, $\mathrm{pH} 10$ ), were passed through the column to remove any non-specifically bound material. Elution was then initiated and the fraction collector brought online. $2.5 \mathrm{ml}$ fractions were collected; these were buffered to neutral $\mathrm{pH}$ using $2 \mathrm{M}$ Tris $(\mathrm{pH} 7)$. Three column volumes of elution buffer were followed by five column volumes of PBS buffer. The column was stored at $4^{\circ} \mathrm{C}$ in PBS with $0.02 \%$ sodium azide in order to prevent microbial contamination.

The collected $2.5 \mathrm{ml}$ fractions were analysed for D1.3Fv concentration, using the optical biosensor, and those with the highest concentrations were combined.

\subsubsection{Sample Dialysis}


After fraction combination the antibody solution was dialysed from PBS buffer into $10 \mathrm{mM}$ sodium acetate buffer (a minimal salts buffer) containing $0.01 \%$ sodium azide in order to prevent microbial contamination. The dialysis was performed using Pierce Slide-A-Lyzer Cassettes. The cassette was filled with the antibody solution and floated in a container of $10 \mathrm{mM}$ sodium acetate buffer with $0.01 \%$ sodium azide to prevent microbial contamination. The dialysis took place overnight at $4{ }^{\circ} \mathrm{C}$. After dialysis the antibody solution was removed from the dialysis cassette and stored at $4{ }^{\circ} \mathrm{C}$

\subsection{Purification of 4D5Fab}

\subsubsection{Periplasmic Extraction}

Cell paste was re-suspended in periplasmic extraction buffer to OD80. Approximately $145 \mathrm{~g}$ of cell paste in $1 \mathrm{~L}$ of periplasmic extraction buffer will give OD80.

The extraction was carried out overnight in a $7 \mathrm{~L}$ reactor at $60^{\circ} \mathrm{C}$. The resultant material was centrifuged for 1.5 hours at $8000 \mathrm{rpm}$. The supernatant was then filtered using Satorious bell filters.

Periplasmic extraction buffer: $\quad 100 \mathrm{mM}$ Tris amino-methane

$10 \mathrm{mM}$ EDTA

$\mathrm{pH}$ to 7.4 with $\mathrm{HCl}$

\subsubsection{Fluid Protein Liquid Chromatography (FPLC)}

Purification of 4D5Fab was performed using protein A (Pharmacia) media to allow application of crude samples without extensive clarification.

Cell supernatant from cells expressing 4D5Fab was made $1 \mathrm{M}$ with respect to glycine and adjusted to pH7.5 with sodium glycinate. The sample was then applied to a protein $A$ column equilibrated in $1 \mathrm{M}$ glycine/glycinate, $\mathrm{pH} 8.0$ at an operating flow-rate of $1 \mathrm{~m} / \mathrm{min}$. The column was washed with 5 column volumes of equilibration buffer. The Fab was then eluted with a 10 column volume linear gradient from $1 \mathrm{M}$ glycine $\mathrm{pH} 8.0$ to $0.1 \mathrm{M}$ citrate $\mathrm{pH} 3.3 \mathrm{ml}$ fractions were collected and the OD280 of these measured. The fractions containing the highest amounts of Fab were pooled and the $\mathrm{pH}$ adjusted to 6.0 with $2 \mathrm{M}$ tris- $\mathrm{HCl}$, pH8.5. 


\subsubsection{Sample Dialysis}

After fraction combination the antibody solution was dialysed into $100 \mathrm{mM}$ sodium acetate buffer (a minimal salts buffer) containing $0.02 \%$ sodium azide in order to prevent microbial contamination. The dialysis was performed as described in section 2.2.2. After dialysis the Fab solution was sterile filtered through a $0.2 \mu \mathrm{m}$ filter and stored at $4^{\circ} \mathrm{C}$.

\subsection{Analytical Techniques}

\subsubsection{Optical Biosensor}

Samples from all experiments and purifications using D1.3FV were analysed for antibody activity using an optical biosensor.

The IAsys ${ }^{T M}$ optical biosensor (Labsystems Affinity Sensors, Cambridge, UK) was operated according to the 'user documentation' and controlled by a dedicated software package operating under Microsoft $\circledast$ Windows ${ }^{\mathrm{TM}}$ using a personal computer. The instrument employed a stirred cuvette for sample delivery to the immobilised ligand, which was used with a $200 \mu$ l working volume. Stored interaction profiles were analysed using the manufacturers' software package FASTfit for exponential curve fitting and Origin ${ }^{\mathrm{TM}}$ (MicroCal Software Inc, Northampton, MA 01060, USA) for linear curve fitting analysis.

\subsubsection{Making Biosensor Cuvettes}

The carboxymethyl dextran of the IAsys cuvette sample cell was first activated using NHS/EDC. The ligand to be immobilised (HEL) was then added at a concentration of $50 \mu \mathrm{g} / \mathrm{ml}$ and $\mathrm{pH} 5$. Coupling occurs in most instances through primary amino groups in the biomolecules; for example lysines in a protein. Other nucleophilic groups such as phenolic groups in tyrosines and imidazole groups of histidine may be involved to a limited extent. Carboxyl groups on the dextran which have been activated with NHS/EDC but which are not coupled to the biomolecule are deactivated with ethanolamine.

\section{IMMOBILISATION PROTOCOL:}

$0.2 \mathrm{grams}$ of NHS was dissolved in $15 \mathrm{ml}$ of deionised water and aliquoted into $250 \mu \mathrm{l}$ volumes. $1.15 \mathrm{grams}$ of EDC was also dissolved in $15 \mathrm{ml}$ of deionised water and aliquoted into $250 \mu$ l volumes. These were stored at $-18^{\circ} \mathrm{C}$ prior to use. 
An un-activated sample cell was incubated in the biosensor to thermally equilibrate by pipetting $200 \mu l$ of PBS/T buffer into the cuvette and leaving for 10 minutes. A baseline for PBS/T buffer was then obtained for 7 minutes. One vial each of NHS and EDC were thawed. Immediately prior to use, the contents of the vials were thoroughly mixed. This constitutes the activation mixture. The carboxyl groups on the dextran were activated with the activation mixture for 7 minutes.

After 7 minutes any unreacted activation mixture was removed and the sample cell was washed with PBS/T buffer for 2 minutes. The ligand solution $(50 \mu \mathrm{g} / \mathrm{ml} \mathrm{HEL}$ in $10 \mathrm{mM}$ acetate buffer, pH5) was added and left in the sample cell for 10 minutes. After this time non-coupled ligand was removed and the sample cell was washed with PBS/T buffer for 2 minutes.

$200 \mu \mathrm{l}$ of $1 \mathrm{M}$ ethanolamine, pH8.5 was added for 2 minutes. The sample cell was then washed with PBS/T for 5 minutes followed by a wash with $50 \mathrm{mM} \mathrm{HCl}$ and three washes with PBS/T. The third wash was used to provide the final baseline that allowed calculation of the amount of immobilised ligand. The activated chip was stored at $4^{\circ} \mathrm{C}$ with $180 \mu$ l of PBS/T/S in the sample cell.

\section{SAMPLE MEASUREMENT:}

The activated cuvette was incubated in the biosensor to thermally equilibrate for 10-15 minutes. The cuvette was then washed twice with $\mathrm{HCl}$ and three times with PBS/T/S. After the third wash with PBS/T/S $180 \mu \mathrm{l}$ of PBS/T/S was left in the cuvette and the baseline was allowed to settle for 30 seconds. $20 \mu \mathrm{l}$ of sample was added to the cuvette well. After 20 seconds the sample and PBS/T/S were ejected from the cuvette and the washing procedure repeated before the next sample was measured. Amount of active protein present was measured by analysing the data generated by the biosensor using the manufacturers' software package FASTfit.

\subsubsection{D5Fab and 4D5 PEG-Fab ELISA}

A sandwich ELISA was used to measure 4D5Fab and 4D5 PEG-Fab. Plates were coated with an antibody (HP6045) that recognised the $\mathrm{CH}_{1}$ heavy chain of the fragment. Then a second antibody conjugated to an enzyme (horseradish peroxidase) was added. This antibody (GD12 peroxidase) recognised the kappa light chain of the antibody. A substrate solution was then added that reacted with horseradish peroxidase to develop colour. The intensity of the colour developed related to the amount of antibody present.

96 well NUNC plates were coated with HP6045 (anti human Fd) diluted to $2 \mu \mathrm{g} / \mathrm{ml}$ in PBS. $100 \mu \mathrm{l}$ of HP6045 coating solution was loaded into each well. The plates were then covered and left overnight at $4^{\circ} \mathrm{C}$. 
Prior to use for analysis the plates were washed four times in PBS/T and dried. $200 \mu$ l of sample or standard was loaded into each well in the top row of the plate. Samples were diluted to approximately $1 \mu \mathrm{g} / \mathrm{ml}$ in sample conjugate buffer. $100 \mu \mathrm{l}$ of sample conjugate buffer was added to all the other wells of the plate. Using a multi-pipette $100 \mu$ l was removed from the wells of the top row. This was then added to and thoroughly mixed with the sample conjugate buffer in the wells of the second row. This technique was repeated through all the rows in the plate. This meant that included on each plate was a 1 in 2 dilution series of purified 4D5Fab standard $(1 \mu \mathrm{g} / \mathrm{ml})$ and also the samples. Each well contained $100 \mu \mathrm{l}$ of sample or standard. The plates were then covered and incubated for 1 hour at room temperature on plate rocker.

The plates were then washed four times in PBS/T and dried. $100 \mu$ of GD12 peroxidase was added to each well at a dilution of 1:2000 in sample conjugate buffer. The plates were covered and incubated for 1 hour at room temperature on a plate rocker.

After the plates had been washed four times in PBS/T, $100 \mu \mathrm{l}$ of TMB substrate solution was added per well. After 4-6 minutes the absorbance at $630 \mathrm{~nm}$ was read. A standard curve for $4 \mathrm{D} 5 \mathrm{Fab}$ was plotted $\left(A_{630}\right.$ $V s \log _{10}$ concentration) and the concentrations of the unknown samples read from this.

Sample Conjugate Buffer:

Substrate Solution:
0.1M Tris amino-methane

0.1M Sodium Chloride

$0.02 \% \mathrm{v} / \mathrm{v}$ Tween- 20

$0.2 \%$ w/v Casein

$\mathrm{pH}$ to 7.0 with $\mathrm{HCL}$, filter and store at $4^{\circ} \mathrm{C}$

$10 \mathrm{ml} 0.1 \mathrm{M}$ sodium acetate/citrate buffer, $\mathrm{pH} 6$

$100 \mu \mathrm{I} \mathrm{H}_{2} \mathrm{O}_{2}$ solution

$100 \mu \mathrm{ITMB}$

The substrate solution was prepared immediately prior to use from stock solutions. Excess of substrate solution was discarded.

\section{STOCK SOLUTIONS:}

(i) Tetramethylbenzidine (TMB) made up as a $10 \mathrm{mg} / \mathrm{ml}$ solution in dimethylsulphoxide (DMSO). Stored at room temperature in the dark.

(ii) $\quad 0.1 \mathrm{M}$ sodium acetate buffer, $\mathrm{pH}$ to 6.0 with citric acid. Stored at room temperature.

(iii) Hydrogen peroxide solution, 1 in 50 dilution of $30 \% \mathrm{H}_{2} \mathrm{O}_{2}$. Stored at room temperature. 


\subsubsection{CDP850 ELISA}

ELISA for the measurement of CDP850 phamacokinetics. The plate is coated with a non-competing murine anti-E-Selectin(34.27), which is used to capture E-Selectin (in the form of a lectin-EGF construct). CDP850 binds to this and is revealed with an anti-human $\lg \mathrm{G}_{4}$ - HRP followed by TMB substrate.

96 well NUNC plates were coated with murine anti-E-Selectin(34.27), diluted to $2.5 \mu \mathrm{g} / \mathrm{ml}$ in $0.1 \mathrm{M}$ $\mathrm{NaHCO}_{3}, \mathrm{pH} 8.4 .100 \mu \mathrm{l}$ of coating solution was loaded into each well. The plates were then covered and left overnight at $4^{\circ} \mathrm{C}$.

After the plates had been washed three times in PBS, $100 \mu$ l of Lectin-EGF diluted to $200 \mathrm{ng} / \mathrm{ml}$ in PBS was added to each well. The plates were then covered and incubated again overnight at $4^{\circ} \mathrm{C}$. The plates were washed three times with PBS and the wells were then blocked by adding $200 \mu$ of $1 \%$ BSA/PBS $/ 0.005 \%$ TWEEN to each well. The plates were incubated for 30 minutes at $37^{\circ} \mathrm{C}$ and then washed three times with PBS.

Standards and samples were diluted to $250 \mathrm{ng} / \mathrm{ml}$ in $1 \%$ BSA/PBS/2\%NMS/0.005\%TWEEN. $200 \mu \mathrm{l}$ of sample or standard was added to the top row of wells. To all the other wells $100 \mu$ l of $1 \%$ BSA/PBS/2\%NMS/0.005\%TWEEN was added. 1 in 2 dilutions were then carried out down the plate as described in section 2.4.2. The plates were covered and incubated for 1 hour at room temperature on a plate rocker.

After 1 hour the plates were washed three times with PBS. Murine anti-Human $\lg G_{4}$-HRP was diluted 1 in 2000 with $1 \%$ BSA/PBS/ $2 \%$ NMS and $100 \mu$ l of this added to each well. The plates were covered and incubated for 30 minutes at room temperature on a plate rocker.

The plates were then washed four times with PBS and $100 \mu$ l of TMB substrate solution added per well. The absorbance was then read at $630 \mathrm{~nm}$. TMB substrate solution was made up as per section 2.4.2.

\subsubsection{Total Protein Measurements}

The total protein present in all samples was measured using the Pierce Coomassie ${ }^{\circledR}$ Plus Protein Assay Reagent following the protocol supplied by the manufacturer (Pierce Chemical Company, Illinois, USA). When Coomassie ${ }^{\circledast}$ binds protein in an acidic medium, an immediate absorbance shift occurs from $465 \mathrm{~nm}$ 


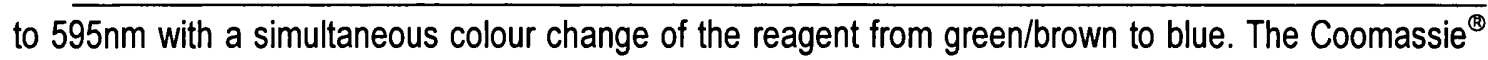
protein reaction scheme is:

Protein + Coomassie ${ }^{\circledR}$ Protein Plus Reagent $\longrightarrow$ Protein-Dye Complex (blue colour, measured at $595 \mathrm{~nm}$ )

\section{ASSAY PROTOCOL}

BSA $(2 \mathrm{mg} / \mathrm{ml})$ was used as the protein standard. The diluent used for the standards and samples varied according to which antibody fragment or antibody was being measured $-10 \mathrm{mM}$ sodium acetate was used for D1.3Fv, $100 \mathrm{mM}$ sodium acetate for $4 \mathrm{D} 5 \mathrm{Fab}, 50 \mathrm{mM}$ sodium acetate $/ 100 \mathrm{mM}$ sodium chloride for CDP850 and 50mM sodium acetate/125mM sodium chloride was used for PEG-4D5Fab.

Protein standards were prepared by diluting BSA stock solution in the same diluent as the samples being measured. BSA standards between $2000 \mu \mathrm{g} / \mathrm{ml}$ and $25 \mu \mathrm{g} / \mathrm{ml}$ were used.

The Coomassie ${ }^{\circledR}$ Protein Plus Reagent was allowed to come to room temperature. Prior to use the solution was mixed by gently inverting the bottle several times.

Microwell plates were used rather than test tubes, as this method requires the use of smaller amounts of sample and also allowed several samples to be assayed at the same time. $10 \mu \mathrm{l}$ of each standard or unknown sample was pipetted into the plate wells. A minimum of three replicates of each standard or sample was used. If possible a larger number of replicates was used. $10 \mu$ l of diluent was used for 'blank' wells.

$300 \mu \mathrm{l}$ of Coomassie ${ }^{\circledR}$ Protein Plus Reagent was added to each well and the plate mixed on a plate shaker for 30 seconds. The absorbance at $595 \mathrm{~nm}$ was then measured on a plate reader. The average $595 \mathrm{~nm}$ reading for the blanks was subtracted from the $595 \mathrm{~nm}$ reading for each standard or unknown sample.

A standard curve was prepared by plotting the average blank corrected $595 \mathrm{~nm}$ readings for each BSA standard versus its concentration in $\mu \mathrm{g} / \mathrm{ml}$. This standard curve was used to determine the protein concentration of each unknown sample.

\subsection{Experimental Procedures}

\subsubsection{Temperature Stability Experiments}


Eppendorfs containing $200 \mu \mathrm{l}$ of D1.3Fv were placed in water baths set at $40{ }^{\circ} \mathrm{C}, 50^{\circ} \mathrm{C}$ and $60^{\circ} \mathrm{C}$. Three eppendorfs were placed in each water bath. Three were also kept at room temperature. $20 \mu \mathrm{l}$ samples were taken from each eppendorf at $0,30,60,120$ and 240 minutes. These samples were measured for bioactivity on the optical biosensor.

This experiment was repeated using different concentrations of D1.3FV.

The temperature stability experiments using 4D5Fab were carried out in collaboration with Leigh Bowering, UCL.

\subsubsection{Solvent Stability Experiments}

\subsubsection{Initial Solvent Experiments}

These solvent experiments were carried out using the D1.3Fv fragment only. Samples were made up containing D1.3Fv plus different amounts of methanol so that there were samples containing $0 \%, 25 \%$, $50 \%$ and $75 \%$ solvent. A second set of samples was made in the same way but with the addition of mannitol at $0.1 \mathrm{~g} / \mathrm{ml}$.

$200 \mu \mathrm{l}$ of each sample was pipetted into eppendorfs. Three eppendorfs of each sample were placed into a water bath set at $40^{\circ} \mathrm{C} .20 \mu \mathrm{l}$ samples were taken from each eppendorf at $0,30,60,120$ and 240 minutes. These samples were measured for bioactivity on the optical biosensor.

\subsubsection{Modified Solvent Experiments}

After further consideration of the SEDS process the solvent stability experiments were modified. Figure 2.1 illustrates the three feed streams involved in SEDS and how they mix together in the nozzle. Depending on how the feed streams are added to the nozzle and taking into consideration the flow-rates used, the concentration of solvent present could be $8 \%$ or $96 \%$. Thus it was decided to examine the effect of these two different concentrations of solvent. Both D1.3Fv and 4D5Fab were used for this experiment.

Solvent assays were carried out using two concentrations of solvent. Both assays followed the same procedure, the only variant being the concentration of solvent used. Three different solvents were used isopropanol, methanol and ethanol.

Stock solution of antibody was used and $0.1 \mathrm{~g} / \mathrm{ml}$ of mannitol added to this. $500 \mu l$ samples were made up 
in eppendorfs containing antibody solution plus $8 \%$ or $96 \%$ solvent. Three replicates were made of each sample for each solvent. The eppendorfs were kept at room temperature $\left(25^{\circ} \mathrm{C}\right)$ and $10 \mu$ samples taken at time intervals of $0.5,10,30,60$ and 120 minutes. The samples were quenched in $100 \mathrm{mM}$ sodium acetate buffer.

A control was run using the stock solution of antibody. $10 \mu \mathrm{l}$ samples were taken at the same time intervals as the other samples. These were quenched in the same amount of buffer as the other samples. Solvent was added to the same concentration as that in the actual samples after they have been quenched.

These samples were all assayed for antibody activity using either the optical biosensor or ELISA. Total protein measurements were also made.

\subsubsection{Chilled Solvent Experiments}

The above procedure was followed but the solvents were chilled to $0^{\circ} \mathrm{C}$ before use. Samples were also kept in ice buckets throughout the experiment. 

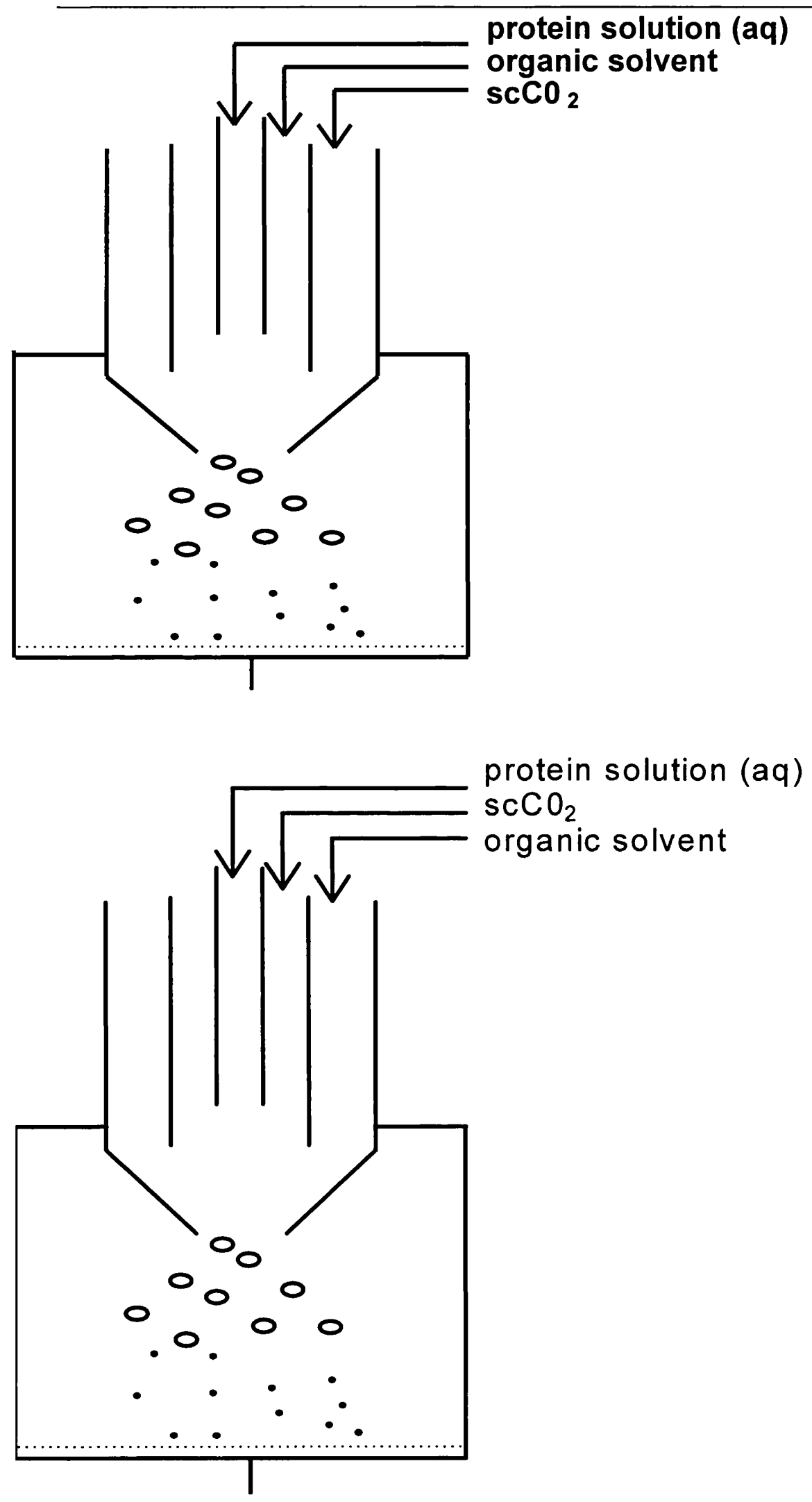

Figure 2.1 - Three component nozzle diagrams showing order of component addition.

The top diagram shows the configuration that has initial 96\% solvent/antibody mix. The bottom one shows the configuration that has initial $8 \%$ solvent/antibody mix. Note - drawings not to scale. 


\subsubsection{Shear Experiments}

The shear device shown in Figure 2.2 was used for all shear experiments. Stock antibody fragment solution was diluted with the appropriate buffer and $0.1 \mathrm{~g} / \mathrm{ml}$ of mannitol was added.

\subsubsection{Shear without air/liquid interface}

The shear device was filled with approximately $10 \mathrm{ml}$ of antibody fragment/mannitol solution. The device was filled so that there were no air bubbles present. Shear was applied to the sample for 20 seconds. The sheared solution was collected and stored at $4^{\circ} \mathrm{C}$ prior to analysis. Samples of un-sheared material were also stored at $4^{\circ} \mathrm{C}$ prior to analysis.

\subsubsection{Shear with air/liquid interface.}

The shear device was filled with $7 \mathrm{ml}$ of antibody fragment/mannitol solution. The meniscus of the fluid in the device was approximately $1 \mathrm{~mm}$ above the disk (see Figure 2.2). Shear was applied for 20 seconds. The sheared solution was collected and stored at $4{ }^{\circ} \mathrm{C}$ prior to analysis. Samples of un-sheared material were also stored at $4^{\circ} \mathrm{C}$ prior to analysis.

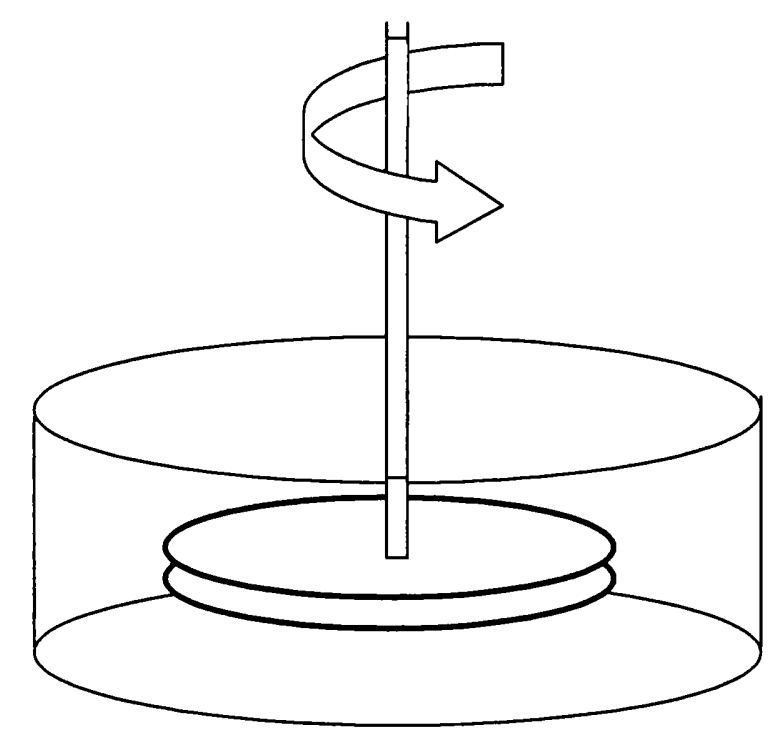

Figure 2.2 - The rotating shear device.

The circular disk spins when a current is applied to it. This disk is used to apply shear forces to the liquid present in the chamber. 


\subsubsection{Freeze Drying}

Mannitol as added at $0.1 \mathrm{~g} / \mathrm{ml}$ to a solution of antibody fragment or antibody. Eppendorf tubes were weighed and their weight noted. To each of the eppendorfs $1 \mathrm{ml}$ of antibody fragment/mannitol solution was added. These were then re-weighed and the new weight noted. The condenser for the freeze drier was turned on 45 minutes prior to use. The eppendorfs containing antibody solution were placed into the freeze drier and the rotor and pump switched on. The solution was dried for 4 hours. When the eppendorfs were removed from the drier they were weighed again and the final weight recorded.

\subsection{5 pH Experiment}

Supercritical carbon dioxide has been found to have a pH of $2.80-2.95$ (Toews, 1995). Mannitol was added to antibody fragment solution at $0.1 \mathrm{~g} / \mathrm{ml}$. The buffer for the antibody fragments is $\mathrm{pH} 5.5$.

Sodium acetate buffer was made up to the following molarities and $\mathrm{pH}$ :

1. $10 \mathrm{mM}$ sodium acetate, $\mathrm{pH} 2.5$

2. $10 \mathrm{mM}$ sodium acetate, $\mathrm{pH} 7.0$

3. $100 \mathrm{mM}$ sodium acetate, $\mathrm{pH} 7.0$

$200 \mu \mathrm{l}$ of the antibody solution was added to $800 \mu \mathrm{l}$ of $10 \mathrm{mM}$ Sodium acetate buffer, $\mathrm{pH} 2.5$. The resultant $\mathrm{pH}$ of this solution was pH2.8. At time intervals of 10 seconds, 30 seconds, 10 minutes and 30 minutes, $100 \mu \mathrm{l}$ samples of this solution were taken and added to $100 \mu \mathrm{l}$ of $100 \mathrm{mM}$ Sodium acetate buffer, $\mathrm{pH} 7$. The resultant $\mathrm{pH}$ of this solution was $\mathrm{pH} 7$.

A control was run by taking $200 \mu$ l of the antibody solution and adding it to $800 \mu \mathrm{l}$ of $10 \mathrm{mM}$ sodium acetate buffer, $\mathrm{pH} 7.100 \mu$ l samples were taken from this solution at 10 seconds, 30 seconds, 10 minutes and 30 minutes and added to $100 \mu \mathrm{l}$ of $100 \mathrm{mM}$ sodium acetate buffer, $\mathrm{pH} 7$.

\subsubsection{Stability Tests}

Freeze-dried antibody fragment/mannitol or antibody/mannitol powder was either packed into a $1.5 \mathrm{ml}$ vessel or packed between two filter papers in a $50 \mathrm{ml}$ vessel. The vessel containing the freeze-dried 
powder was then connected up to the SEDS kit. For the first stability test just $\mathrm{scCO}_{2}$ was passed through the vessel. This powder was removed, the vessel cleaned and more freeze-dried powder added, $\mathrm{scCO}_{2}$ and IPA were then passed through the vessel. For the final stability test $\mathrm{scCO}_{2}$, IPA and $\mathrm{H}_{2} \mathrm{O}$ were passed through the vessel. The flow-rates used were the same as those used for the SEDS runs. All stability tests were carried out at $200 \mathrm{bar}$ and $40^{\circ} \mathrm{C}$.

Prior to analytical measurements the freeze-dried powder was reconstituted, to the concentration of the starting solution, using the appropriate buffer.

\subsubsection{Timed Stability Runs}

These were carried out in the same manner as the stability tests described in 2.5.6. However these tests were carried out for different lengths of time ranging between 5 - 90 minutes.

\subsubsection{SEDS Experiment}

The SEDS kit (Bradford Particle Design, Bradford, UK) was operated by following the standard operating procedure supplied with the equipment.

The SEDS process is essentially a method used to produce particulate materials using supercritical fluid technology. A stream of supercritical carbon dioxide is injected into the particle-formation vessel along with an aqueous solution of the process material (antibody fragment or whole antibody), and an organic solvent through a specially designed nozzle under stable, controlled temperature and pressure.

The supercritical fluid disperses, mixes and rapidly extracts the solvent and water, leading to the formation of particles, which are subsequently retained in the vessel. By changing the working parameters (which include pressure, temperature, solution concentration and flow-rates), it is possible to control the size, shape and morphology of the products.

A schematic diagram of the SEDS process is given in Chapter 1, Figure 1.7.

\section{OPERATING THE SEDS KIT}

The cooler is used to ensure that $\mathrm{CO}_{2}$ present in the $\mathrm{CO}_{2}$ pump is in a liquid state and may be pumped 
effectively. The cooler temperature was allowed to reach $-10^{\circ} \mathrm{C}$ before SEDS runs were performed. Before each run the $\mathrm{CO}_{2}$ cylinder was checked for gas levels to ensure that enough gas was available to complete the run.

If a different solvent was being used from the previous SEDS run the SEDS system was pre-flushed before use. The system was flushed with the solvent to be used for the intended run. A union was used to connect the solvent line inside the oven to the back pressure regulator (bpr) line and the bpr set to the intended run pressure. The solvent pump was started and allowed to flow for one minute before turning on the bpr and flushing for at least five minutes. When the flushing was complete then bpr was turned off and the solvent line disconnected from the bpr line. The gas line was then connected to the bpr line and the cylinder valve turned on for a few seconds to flush out the bpr. The same procedure was followed for flushing out the solution line.

Two particle retention filters were inserted into one end of the vessel and the vessel held vertically on a clean even surface with the filter end at the bottom. The filters were compressed with an aluminium rod. The chosen nozzle tip was fitted to the nozzle. The end cap and nozzle were connected onto the vessel and hand tightened. The vessel was then placed in the vessel holding device and the end cap tightened using a spanner. The vessel was then turned over and the nozzle tightened. Care was taken not to overtighten either connection.

Antibody fragment or antibody solution was diluted, if necessary, to the required concentration and $0.1 \mathrm{~g} / \mathrm{ml}$ of mannitol added. A bottle containing purified water was connected to the solution pump. The solution line was primed prior to the run. The sample loop was disconnected from the sample line entering the oven. The sample line was then flushed with air until it was dry. The sample was then injected into this portion of the line using a syringe with a screw fitting. Water was then pumped along the solution line up to the end of the sample loop. The sample loop was then reconnected to the sample line and water pumped until the first drop of sample appeared at the end of the sample line. A bottle containing the desired solvent was connected to the solvent pump and the pump and line primed until the first drop of solvent appeared at the end of the solvent line.

The assembled vessel was clamped into the oven and the thermocouple clamped such that the tip touched the vessel as close to the nozzle tip area as possible. The solution, $\mathrm{CO}_{2}$, solvent and bpr lines were connected to the vessel via slip-free connectors. The oven was turned on and set to the desired temperature. The system was allowed to equilibrate for approximately 15 minutes.

The rheodyne valve on the front of the SEDS oven was set to 'run' and the bpr temperature set to $80^{\circ} \mathrm{C}$ 
and the bpr pressure set to the required pressure. The gas cylinder was turned on and the pressure allowed to equilibrate throughout the system. Once equilibrated the system was checked for leaks using a dilute detergent solution.

If no leaks were found the $\mathrm{CO}_{2}$ pump was set to the desired percentage displacement and the $\mathrm{CO}_{2}$ pump switched on. Once the desired pressure was reached the $\mathrm{CO}_{2}$ variable displacement control was adjusted, if necessary, to obtain the required $\mathrm{CO}_{2}$ outlet flow on the ball flow meter attached to the front of the oven.

The system was left to equilibrate for at least 15 minutes prior to starting a run. The bpr was adjusted via the needle valve on top of the bpr if the pressure reading was erratic or excessively noisy.

Once the system had equilibrated for temperature and pressure the solvent pump was set to the desired flow-rate and switched on. After 5 minutes the solution pumped was switched on.

During the SEDS run the following parameters were observed and recorded - solution pumping time, oven temperature, probe temperature, bpr pressure, solution, solvent and $\mathrm{CO}_{2}$ pump head pressures, ball flow meter reading and $\mathrm{CO}_{2} \%$ displacement setting.

The SEDS run was observed closely for the first 15 minutes, any pressure build-up at the pump or bpr was noted and checked carefully. If there were no apparent problems the system was checked every 15 minutes for the duration of the run.

When sufficient volume of solution had been processed the solution pump was stopped. The solution purge valve was carefully opened for a few seconds to remove any solution from between the pump head and the nozzle. The solvent pump was stopped 5 minutes later. The solvent line was purged in the same way as the solution line.

The $\mathrm{CO}_{2}$ pump was left to flush through the particle formation vessel. This process dries the product in the vessel; the drying time allowed for most of the experiments was approximately 20 minutes. After this time the $\mathrm{CO}_{2}$ pump was switched off and the cylinder valve closed. The oven heater was turned off and the oven door opened. The pressure in the system was slowly released manually using the bpr.

When fully de-pressurised the solution, solvent, $\mathrm{CO}_{2}$ and bpr lines were carefully disconnected from the vessel. The vessel was then placed in the vessel holding device and the nozzle and end fitting loosened. The material collected in the vessel was removed by pushing the particle collection filters from the filter 
end using an aluminium rod. The material was collected on paper and then transferred to a labelled and pre-weighed vial. This was then re-weighed to determine the amount of material collected.

After each run the SEDS kit was thoroughly cleaned using the manufacturers supplied protocol.

Samples were taken of the starting solution and the dried material. Prior to analytical measurements the dried material was reconstituted using the appropriate buffer.

\subsubsection{Different Temperature SEDS}

SEDS runs were carried out at different temperatures. Altering the oven set temperature controls the temperature of the SEDS run. The temperature of the drying vessel is monitored by a probe attached to the outside of the vessel. All the temperature runs were carried out using IPA as the solvent.

\subsubsection{Different Solvents SEDS}

SEDS runs were carried out using four different solvents. In between each run the solvent line was washed thoroughly to remove any traces of the previous solvent. All the solvent runs were carried out at $40^{\circ} \mathrm{C}$.

\subsubsection{Different Nozzle Configuration SEDS}

SEDS runs were carried out using an alternative nozzle order (see Figure 2.1). All of these SEDS were carried out at $40^{\circ} \mathrm{C}$, using IPA as the solvent. 


\section{CHAPTER THREE}

\section{PRELIMINARY STABILITY STUDIES}




\section{Preliminary Stability Studies on D1.3Fv and 4D5Fab}

\subsection{Introduction}

Any material being processed using SEDS will be subjected to a minimum temperature of $35^{\circ} \mathrm{C}$ and to potentially much higher temperatures. Protein processing using SEDS also uses organic solvents as an integral part of the process. To try and predict how the antibody fragments would behave in such an environment some preliminary bench top experiments were carried out to investigate the effect of different temperatures and solvents on solutions of the antibody fragments in buffer.

In this chapter all data (unless otherwise stated) is presented in ratio form $\left(P / P_{0}\right)$, where $P$ is the concentration $(\mu \mathrm{g} / \mathrm{ml})$ of the antibody fragment at a given time and $P_{0}$ is the concentration of antibody fragment at the beginning of the experiment. Hence the data has been normalised for clarity and ease of comparison between different experiments. Where appropriate the data is presented in both linear and log form. This is to establish the appropriate rate order for the data. Linear plots may relate to a zero order rate and $\log _{10} /$ linear plots may indicate first order rates. All lines fitted on the plots are appropriate to the model for each data set; otherwise no data fitting is presented (unless indicated).

\subsection{Temperature Studies}

SEDS experiments are performed at temperatures between $35^{\circ} \mathrm{C}$ and $50^{\circ} \mathrm{C}$. Therefore it was necessary to test the stability of $\mathrm{D} 1.3 \mathrm{Fv}$ at these temperatures. The results of these experiments are presented in Figures 3.1 - 3.5. Linear and log/linear plots of normalised data are shown.

The temperature experiments were carried out using three different concentrations of D1.3Fv (referred to in the text as low, medium and high concentrations). These experiments were used to determine not only the effect of temperature on the antibody fragment but also to examine whether or not antibody concentration has an effect on the stability of the antibody fragment.

The low concentration temperature experiment showed that the antibody lost activity at all the temperatures looked at. The higher the temperature the greater the loss of activity seen. The medium and high concentration experiments showed that for temperatures between $20^{\circ} \mathrm{C}$ and $50^{\circ} \mathrm{C}$ the antibody was stable. At $60{ }^{\circ} \mathrm{C}$ there was a loss in activity seen over time for both the medium and high concentration experiments. There was a greater loss in activity seen for the medium concentration experiment. 
The 4D5Fab temperature experiments (Figure 3.5) were conducted in collaboration with Leigh Bowering, UCL and were carried out over a slightly different temperature range and for a longer time period. The concentration of Fab used was $120 \mu \mathrm{g} / \mathrm{ml}$, lower than both the medium and high concentration D1.3Fv temperature experiments. These experiments show that $4 D 5 F a b$ is more stable at lower concentrations and higher temperatures than the D1.3Fv antibody fragment. 4D5Fab is stable up to $70^{\circ} \mathrm{C}$. At $80^{\circ} \mathrm{C}$ the antibody fragment becomes unstable and starts to loose activity. The sudden increase in rate of loss from $70^{\circ} \mathrm{C}$ to $80^{\circ} \mathrm{C}$ could be due to the melting point of the antibody fragment being reached.

\subsection{Solvent Experiments}

During SEDS experiments the antibody fragments are exposed to potentially high concentrations of solvent. A series of solvent experiments were carried out to assess the stability of the antibody fragments when exposed to different concentrations of solvent over time.

Two different sets of solvent experiments were carried out. The initial solvent experiments looked at the effect different concentrations of methanol have on the D1.3Fv antibody fragment. These experiments were carried out with and without mannitol being added to the antibody solution. The results of these experiments are presented in Figures 3.6 and 3.7.

It was found from these experiments that in the presence of methanol concentrations of $25 \%, 50 \%$ and $75 \%$, D1.3Fv antibody fragment lost bioactivity over the time it was exposed to the solvent. The higher the concentration of methanol present the greater the loss of bioactivity. The presence of mannitol as an excipient does not appear to have any protecting or destabilising effect.

There is also some loss seen in the sample that did not contain any methanol $(0 \% \mathrm{MeOH}$ data). These solvent experiments were carried out at $40^{\circ} \mathrm{C}$ with D1.3Fv at a concentration of $50 \mu \mathrm{g} / \mathrm{ml}$. The lower concentration temperature stability experiments (D1.3Fv concentration $65 \mu \mathrm{g} / \mathrm{ml}$ ) indicate that the loss seen in the $0 \%$ methanol sample is a loss due to temperature effect. This result also suggests that the loss of bioactivity seen in the other samples $(25 \%, 50 \%$ and $75 \%$ methanol) cannot be wholly attributed to solvent effect and is due to the combined effect of temperature and solvent. 


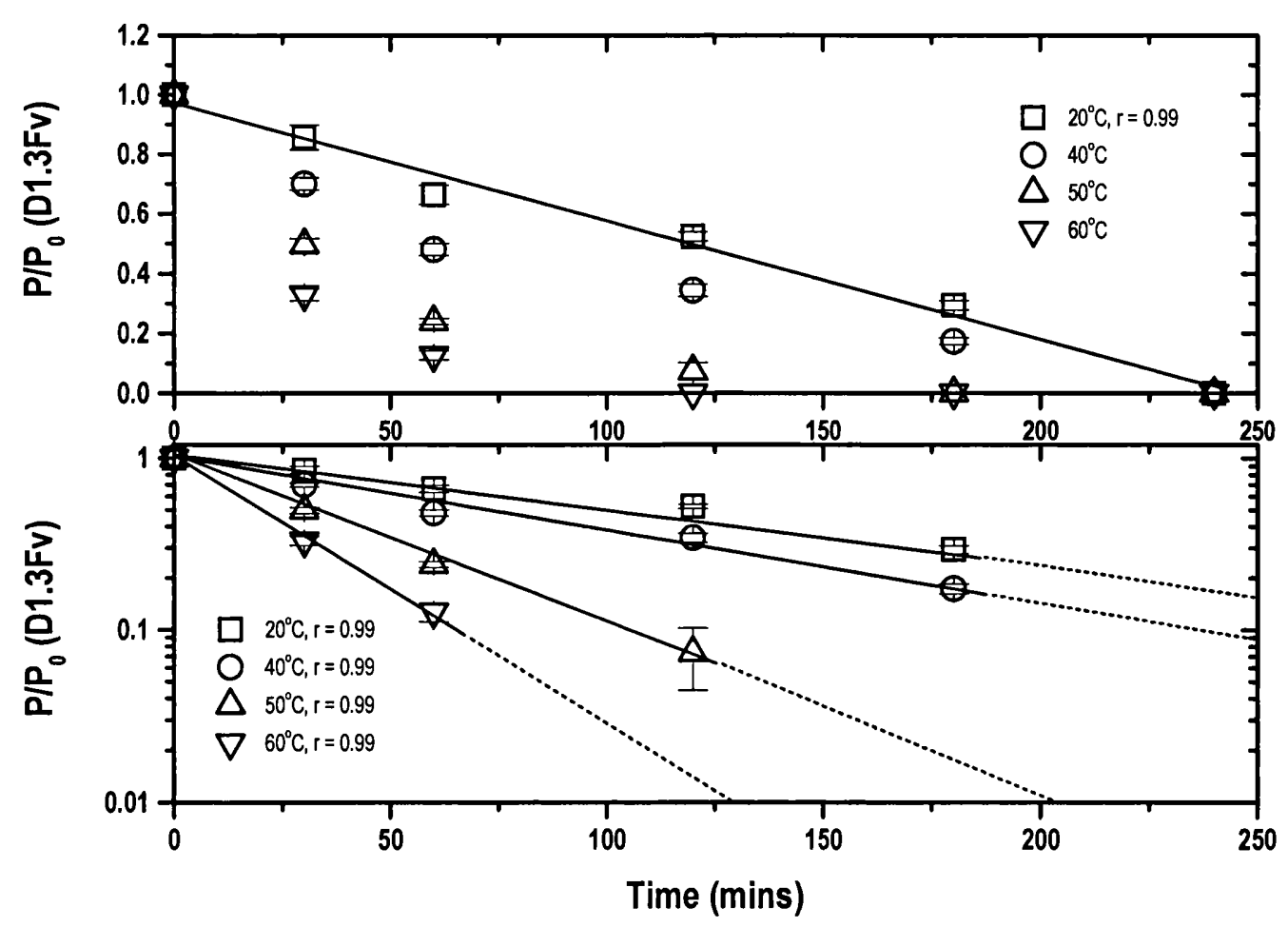

Figure 3.1: Results from temperature stability experiments using low concentrations of antibody fragment D1.3Fv.

The starting concentration of D1.3Fv in this experiment was $65 \mu \mathrm{g} / \mathrm{ml}$. The data obtained from this experiment has been normalised to give $P / P_{0}$, where $P$ is the concentration $(\mu \mathrm{g} / \mathrm{m} /)$ of the antibody fragment $D 1.3 F v$ at a given time and $P_{0}$ is the concentration of D1.3Fv at the beginning of the experiment. The above graph shows the plot of $P / P_{0}$ and also $\log _{10}\left(P / P_{0}\right)$ against time for all the temperatures at which the stability of the antibody was tested. The data points shown are mean value ( $n=3)$, error bars show the standard deviation. The lines show the best linear fit for each set of data.

The dotted lines show the extrapolated linear fits for the data. There appears to be inconsistency between the two plots. The linear plot indicates that for the $20^{\circ} \mathrm{C}$ and $40^{\circ} \mathrm{C}$ data at 240 minutes the measured activity of D1.3Fv has dropped to zero. However, if this is true then the linear extrapolation of the log plot for these two temperatures to 240 minutes should give a value of $P / P_{0}$ at 0.01 . It can be seen from the extrapolated lines for these data sets that this is not the case. The lowest reading for the biosensor is $1 \mu \mathrm{g} / \mathrm{ml}$, giving a value of $P / P_{0}=0.0166$. For the data in question there are no outliers and the standard deviations and standard errors for the data are small so the only explanations are a deviation from the expected model or a significant offset in the biosensor measurement of $8 \mu \mathrm{g} / \mathrm{ml}$ - this is unlikely. 


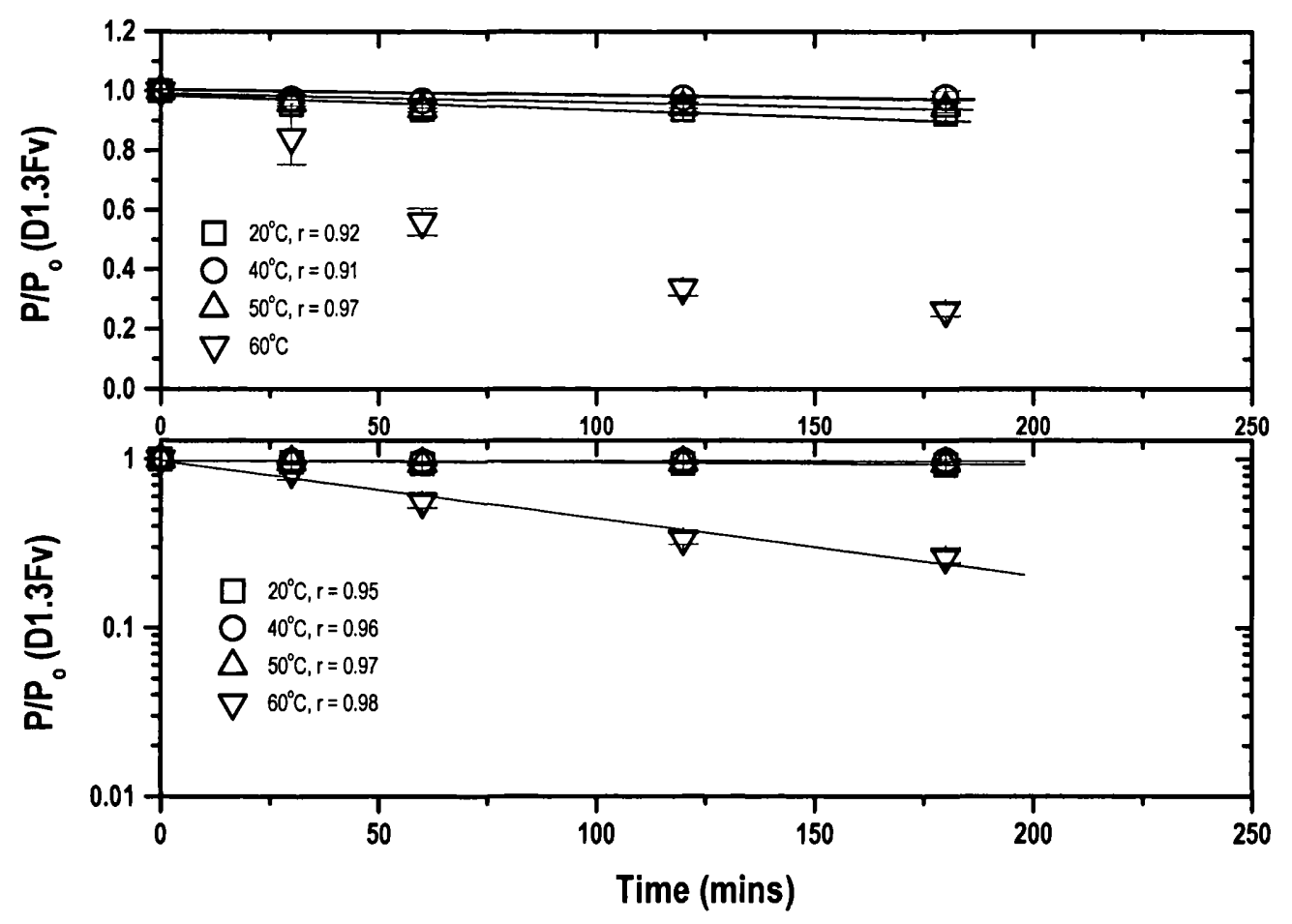

Figure 3.2: Results from temperature stability experiments using a medium concentration of antibody fragment $D 1.3 F v$.

The starting concentration of D1.3Fv in this experiment was $300 \mu \mathrm{g} / \mathrm{ml}$. The time-scale over which this experiment was carried out was shorter than the previous experiment (180 minutes opposed to 240 minutes). Linear and $\log _{10}$ linear plots of the normalised experimental data are shown. The data points shown are mean value $(n=3)$, error bars show the standard deviation. These results suggest that at this concentration for temperatures $20^{\circ} \mathrm{C}, 40^{\circ} \mathrm{C}$ and $50^{\circ} \mathrm{C}$ the reaction could be either a zero order $(d P / d t=k)$ or first order reaction $(d P / d t=k P)$. The results for $60^{\circ} \mathrm{C}$ suggest that this is a first order reaction. 


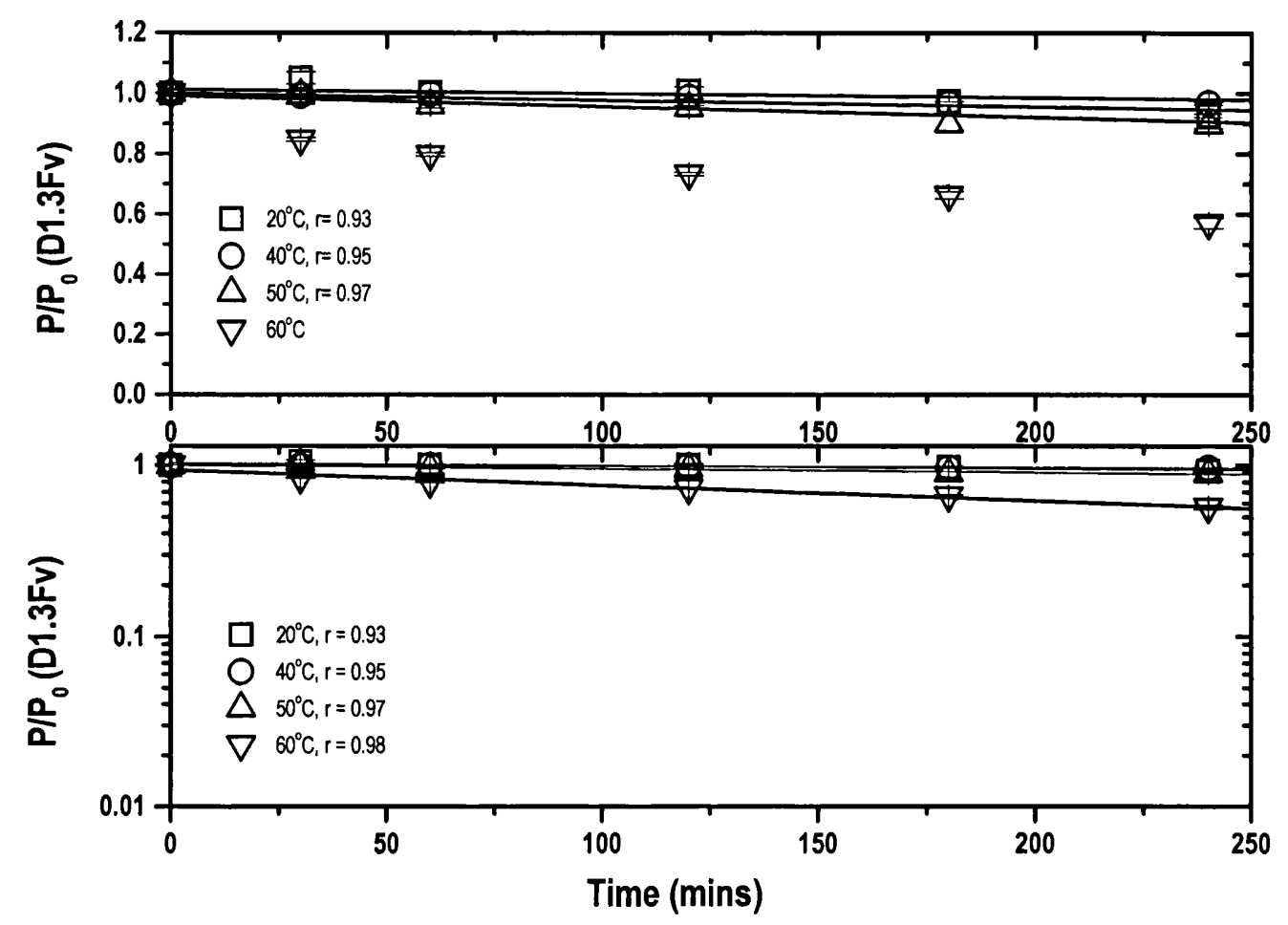

Figure 3.3: Results from temperature stability experiments using a high concentration of antibody fragment.

The starting concentration of D1.3Fv in this experiment was $650 \mu \mathrm{g} / \mathrm{ml}, 10$ times the concentration of the first experiment and slightly over twice the concentration of the second experiment. The data obtained from this experiment has been normalised to give $P / P_{0}$, where $P$ is the concentration $(\mu \mathrm{g} / \mathrm{ml})$ of the antibody fragment $D 1.3 F v$ at a given time and $P_{0}$ is the concentration of $D 1.3 F v$ at the beginning of the experiment. The data points shown are mean value $(n=3)$, error bars show the standard deviation. The results from this experiment are similar to those obtained from the medium concentration experiment (previous figure). The antibody fragment is stable up to $50^{\circ} \mathrm{C}$. At $60^{\circ} \mathrm{C}$ it becomes unstable and starts to lose activity over time when exposed to this temperature. These results suggest that at this concentration for temperatures $20^{\circ} \mathrm{C}, 40^{\circ} \mathrm{C}$ and $50^{\circ} \mathrm{C}$ the reaction could be either a zero order ( $d P / d t=k$ ) or first order reaction $(d P / d t=k P)$. The results for $60^{\circ} \mathrm{C}$ suggest that this is a first order reaction. 


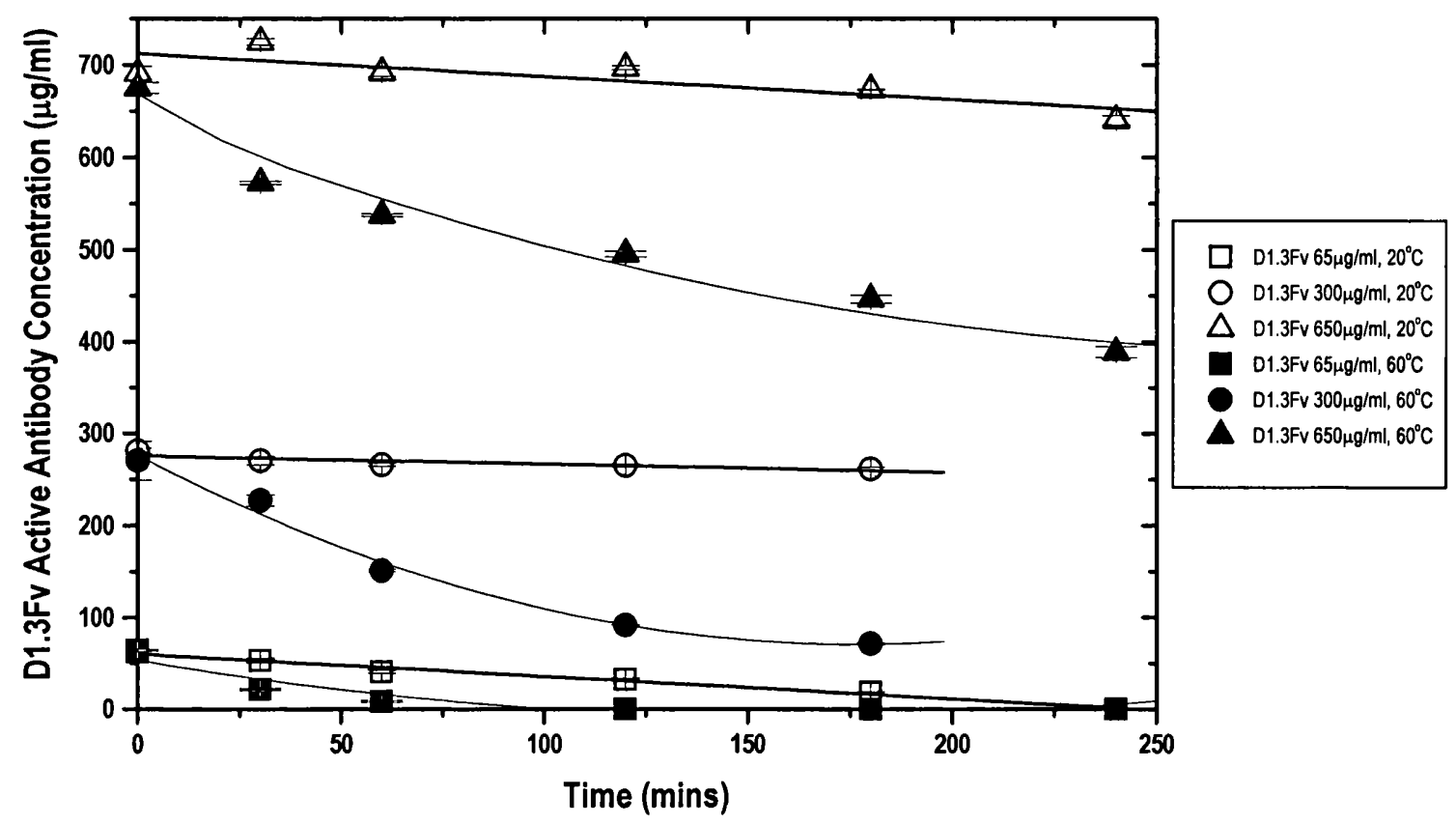

Figure 3.4: Graph showing the results obtained at $20{ }^{\circ} \mathrm{C}$ and $60^{\circ} \mathrm{C}$ for all concentrations of antibody fragment.

The above linear plot shows the data obtained at $20^{\circ} \mathrm{C}$ and $60^{\circ} \mathrm{C}$ for all three of the temperature experiments carried out using D1.3Fv antibody fragment. This graph shows the non-normalised data. The data points shown are mean value $(n=3)$, error bars show the standard deviation. This graph helps to illustrate that for all concentrations of antibody investigated it is likely that at low temperatures the reaction seen is probably zero order and at higher temperature the rate order is first order. 


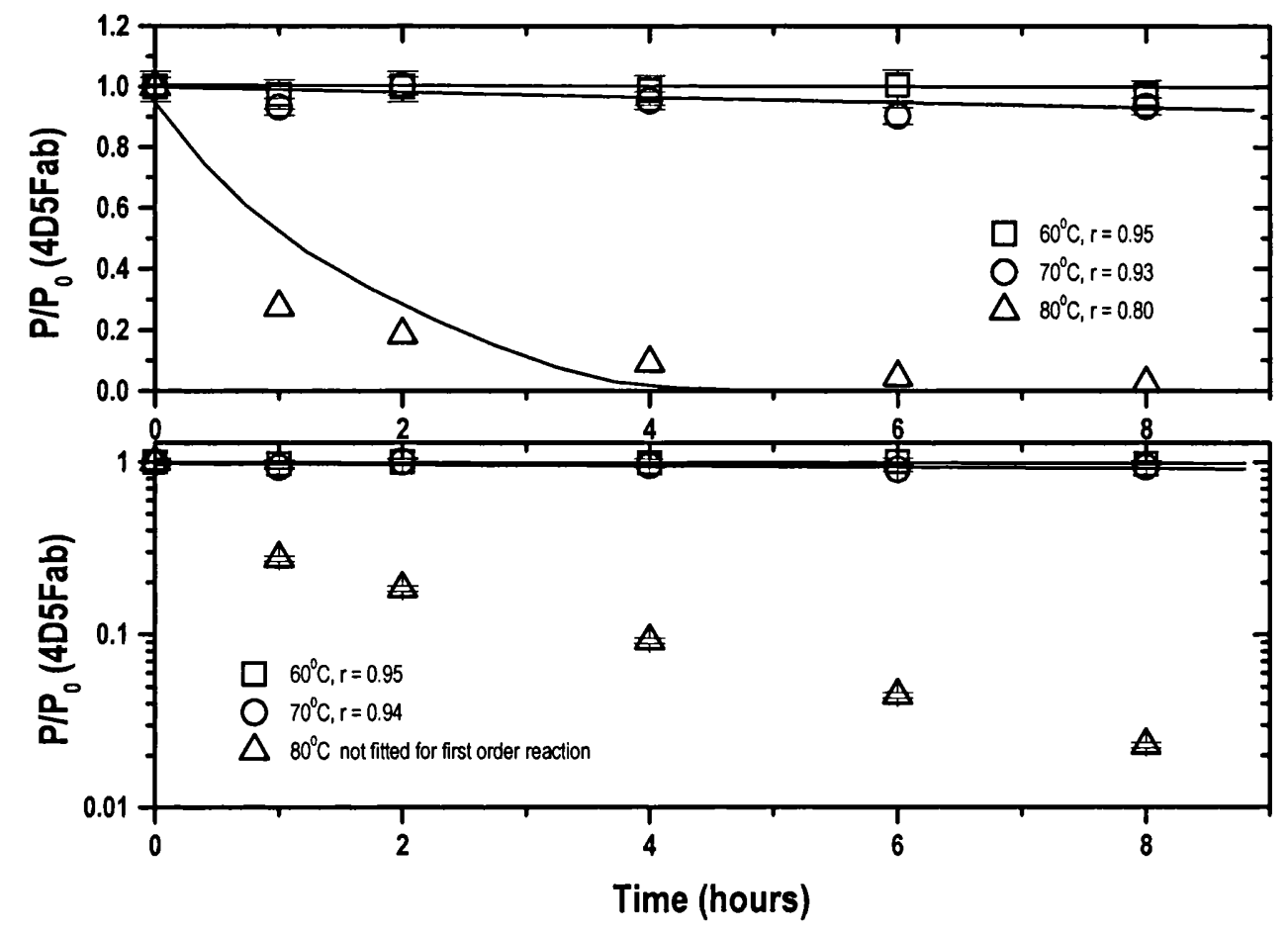

Figure 3.5: Results from 4D5Fab Temperature Stability Experiment.

This experiment was carried out over a different temperature range $-60-80^{\circ} \mathrm{C}$ and over a longer time period (8 hours, instead of 3-4 hours). The starting concentration of $4 D 5 F a b$ was $120 \mu \mathrm{g} / \mathrm{ml}$. The data obtained from this experiment has been normalised to give $P / P_{0}$, where $P$ is the concentration $(\mu \mathrm{g} / \mathrm{ml})$ of the antibody fragment 4D5Fab at a given time and $P_{0}$ is the concentration of 4D5Fab at the beginning of the experiment. The data points shown are mean value $(n=3)$, error bars show the standard deviation. The 4D5Fab antibody fragment was found to be stable at higher temperatures than the D1.3Fv fragment. These results suggest that at this concentration for temperatures $60^{\circ} \mathrm{C}$ and $70^{\circ} \mathrm{C}$ the reaction could be either a zero order $(d P / d t=k)$ or first order reaction $(d P / d t=k P)$. The $80^{\circ} \mathrm{C}$ data does not fit to a first order reaction (see Appendix 2 where it has been attempted to fit this data to a second order equation $(\mathrm{dP} / \mathrm{dt}=$ $\left.k P^{2}\right)$. This experiment was carried out in collaboration with Leigh Bowering, UCL. 
Investigation of Supercritical Fluid Technology to Produce Dry Particulate Formulations of Antibody Fragments Chapter Three - Preliminary Stability Studies

Modified solvent stability experiments were designed after the SEDS process had been studied in more detail. These experiments attempted to mimic the solvent conditions within the SEDS vessel and nozzle. The solvent concentration in the nozzle was calculated using the flow-rates in the nozzle:

- Antibody Solution line:flow-rate $-0.06 \mathrm{ml} / \mathrm{min}$ (top inlet)

- Solvent Line flow-rate $-1.5 \mathrm{~m} / \mathrm{min}$ (middle inlet)

- $\mathrm{scCO}_{2}$ line flow-rate $-18 \mathrm{ml} / \mathrm{min}$ (bottom inlet)

With the initial nozzle configuration (see top diagram in Figure 2.1) the antibody solution and solvent lines mix first. When these two components meet the mixture is $96 \%$ solvent $4 \%$ antibody solution. When all three components mix or if the solvent is added through the bottom inlet (see bottom diagram in Figure 2.1) then the mixture is $8 \%$ solvent. The effect of $8 \%$ and $96 \%$ solvent on both D1.3Fv and 4D5Fab fragments was looked at. These results are presented in Figures 3.8 and 3.9.

The presence of $8 \%$ solvent appears to have no detrimental effect on D1.3Fv. In contrast $96 \%$ solvent has a highly damaging effect. After exposure to $96 \%$ solvent for 10 minutes no further samples could be taken as the antibody solution had become gel-like in texture.

$8 \%$ solvent had a slightly more damaging effect on $4 \mathrm{D} 5 \mathrm{Fab}$. The damage seems to happen during the first 30 minutes of exposure to the solvent. After this time there is no decrease in bioactivity despite continued exposure to the solvent. $96 \%$ solvent causes instantaneous total loss in bioactivity of 4D5Fab. It would appear to be a different type of damage to that seen for D1.3Fv. As the samples of 4D5Fab remained in liquid form and did not develop the gel-like texture seen in the D1.3Fv samples.

It is known that irreversible denaturation of proteins by solvents in some cases can be prevented by working at sufficiently low temperatures (Foster, 1994, Rothstein, 1994). To investigate this as a possible solution to the solvent damage problem, the $8 \%$ and $96 \%$ solvent experiments were repeated using solvent chilled to $0^{\circ} \mathrm{C}$. During the experiment all the samples were maintained at $0^{\circ} \mathrm{C}$. Only the effect on $4 \mathrm{D} 5 \mathrm{Fab}$ was looked at due to shortage of D1.3Fv. The results of these experiments are presented in Figures 3.10 and 3.11 .

In the presence of $8 \%$ chilled solvent the overall damaging effect of the solvent does not appear to have been lessened by the lower temperature. However with the $96 \%$ solvent samples chilling of the solvent has a very positive effect. The instantaneous complete loss of activity seen previously was improved to a $40 \%$ loss and the total loss overtime was about $60 \%$. 


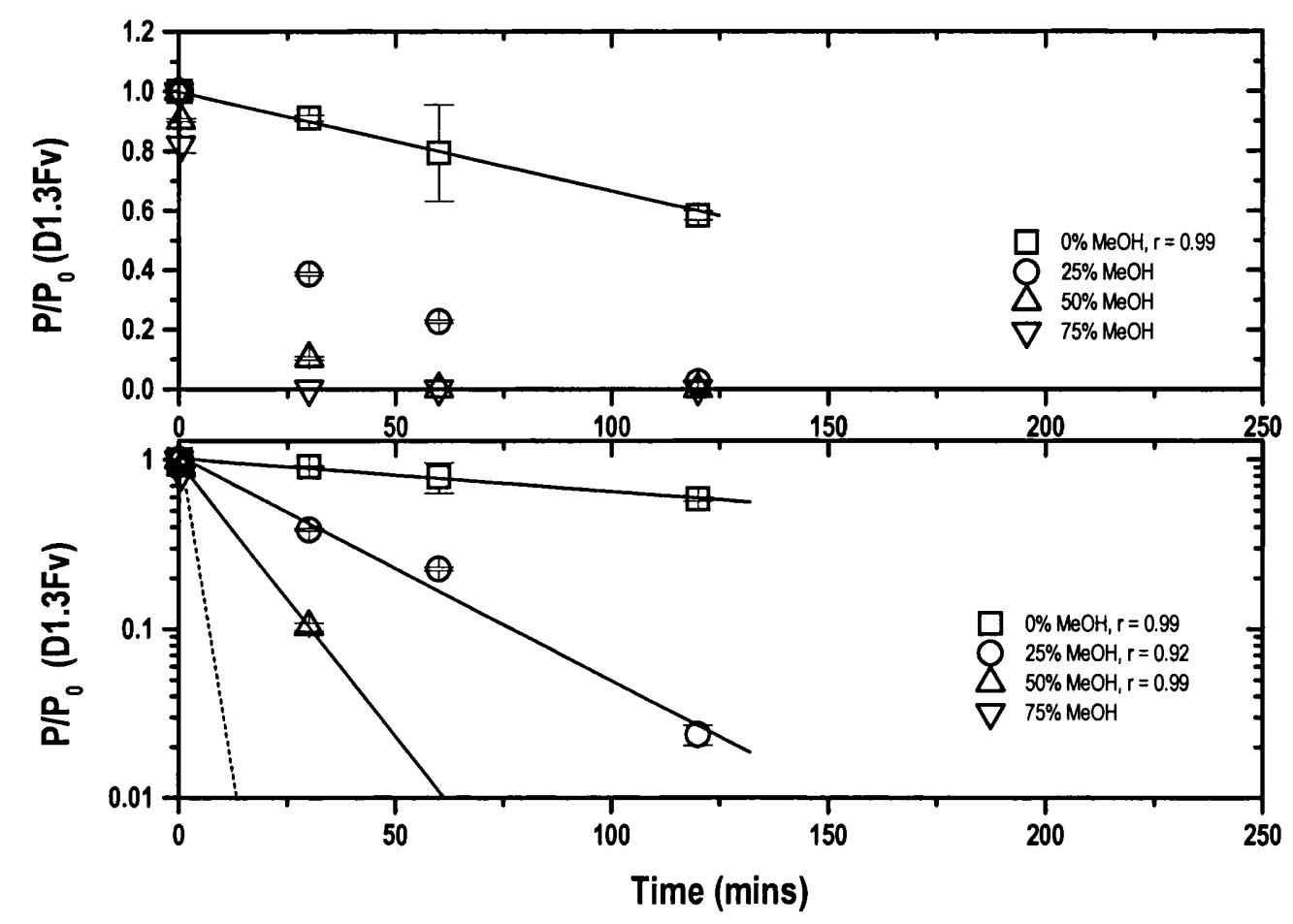

Figure 3.6: Results from Solvent Stability Experiments

$D 1.3 \mathrm{Fv}$ was exposed to different concentrations of methanol $(\mathrm{MeOH})$ at $40^{\circ} \mathrm{C}$, antibody concentration $50 \mu \mathrm{g} / \mathrm{ml}$. The data obtained from this experiment has been normalised to give $P / P_{0}$, where $P$ is the concentration $(\mu \mathrm{g} / \mathrm{ml})$ of the antibody fragment $D 1.3 F v$ at a given time and $P_{0}$ is the concentration of $D 1.3 F v$ at the beginning of the experiment. The data points shown are mean value $(n=3)$, error bars show the standard deviation. The point at $t=0$ minutes is the mean of measurements taken just before the addition of solvent. The point at $t=0.5$ minutes is the first measurement taken after solvent has been added to the antibody solution and mixed thoroughly for 30 seconds. The measurements taken at $t=0$ minutes and $t=0.5$ minutes enable a fix to be given on the initial rate of activity loss. The dotted line shows the expected fit of the data, as there are only two data points the data cannot be fitted accurately.

These are the results of a modified solvent experiment. An initial solvent experiment was carried out but it was found that there was inadequate mixing at the beginning of the experiment. For this experiment the solvent and antibody mixture was thoroughly mixed for 30 seconds before the first measurement was taken. 


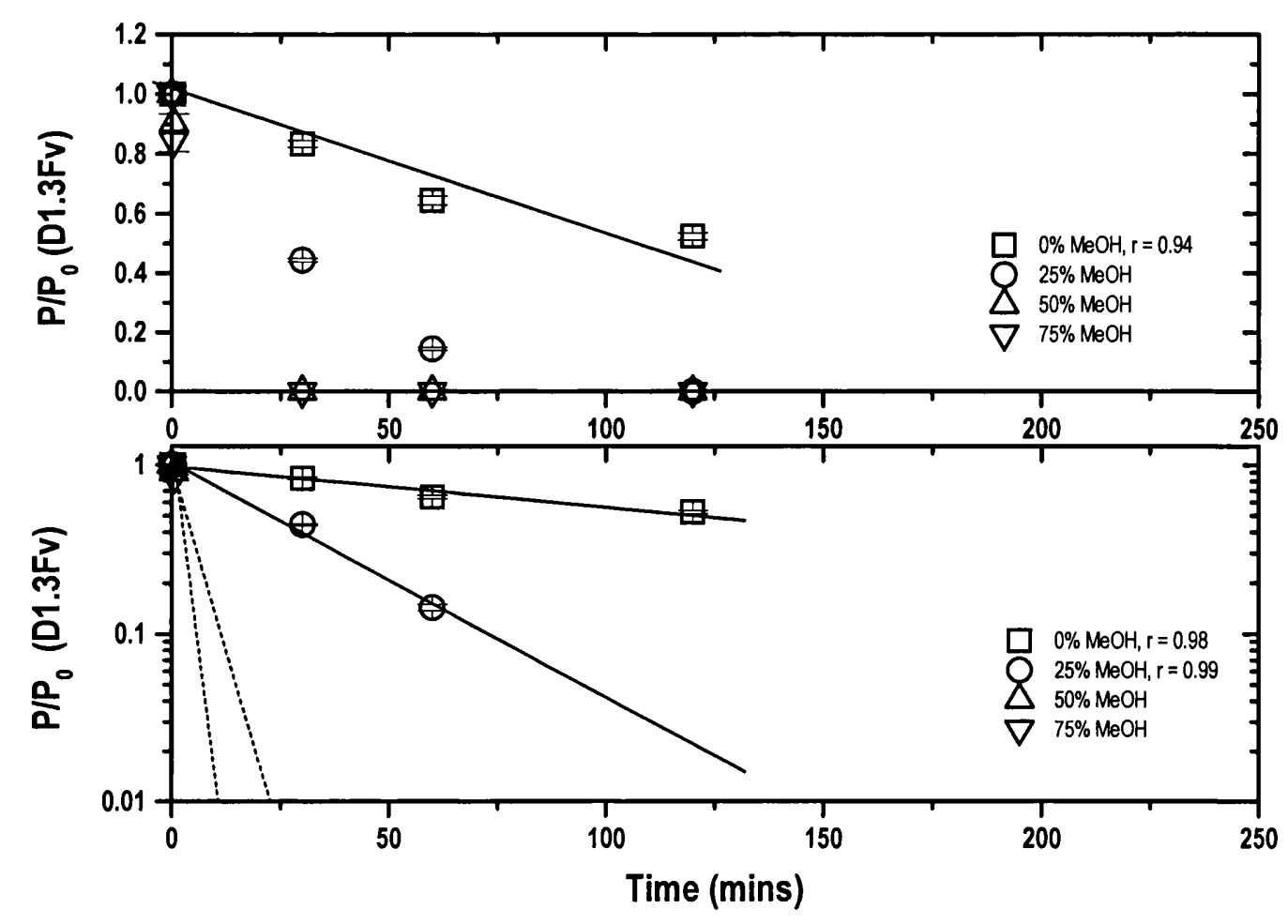

Figure 3.7: Results from solvent stability experiment with mannitol added to antibody solution.

A solution of D1.3Fv plus mannitol $(0.1 \mathrm{~g} / \mathrm{ml})$ was exposed to different levels of methanol at $40^{\circ} \mathrm{C}$. The data obtained from this experiment has been normalised to give $P / P_{0}$. Linear and $\log _{10} /$ linear plots of the normalised experimental data are shown. The data points shown are mean value $(n=3)$, error bars show the standard deviation. The results from this experiment are very similar to those presented in Figure 3.6 suggesting that the addition of mannitol has no effect on the stability of the antibody in the presence of solvent. The measurements taken at $t=0$ minutes and $t=0.5$ minutes enable a fix to be given on the initial rate of activity loss. The dotted lines shows the expected fit of the data from these two initial measurements, as there are only two data points the data cannot be fitted accurately. 


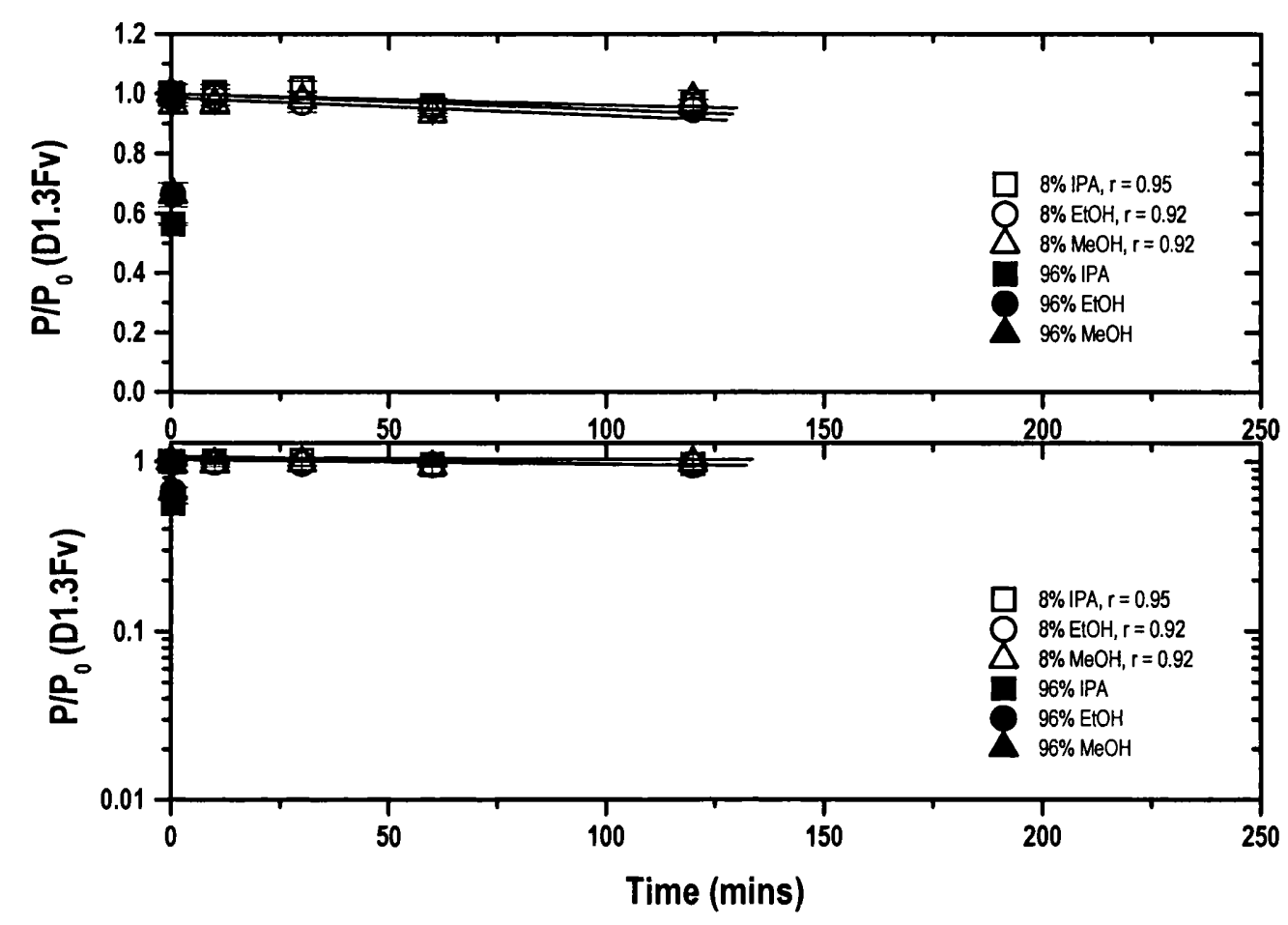

Figure 3.8: Results from $8 \%$ and $96 \%$ solvent experiments using D1.3Fv.

D1.3Fv antibody fragment $(50 \mu \mathrm{g} / \mathrm{ml})$ was exposed to $8 \%$ and $96 \%$ solvent at room temperature $\left(20^{\circ} \mathrm{C}\right)$. Three different solvents were used - Isopropanol (IPA), Ethanol (EtOH) and Methanol (MeOH). Measurements were taken over time. However for the $96 \%$ solvent samples only two measurements were taken. These were at $t=0$ minutes and $t=0.5$ minutes. This was because once $t=10$ minutes had been reached all the $96 \%$ solvent samples had become a solid gel. The data obtained from this experiment has been normalised to give $P / P_{0}$, where $P$ is the concentration $(\mu \mathrm{g} / \mathrm{ml})$ of the antibody fragment $D 1.3 F v$ at a given time and $P_{0}$ is the concentration of D1.3Fv at the beginning of the experiment. The data points shown are mean value $(n=3)$, error bars show the standard deviation. 


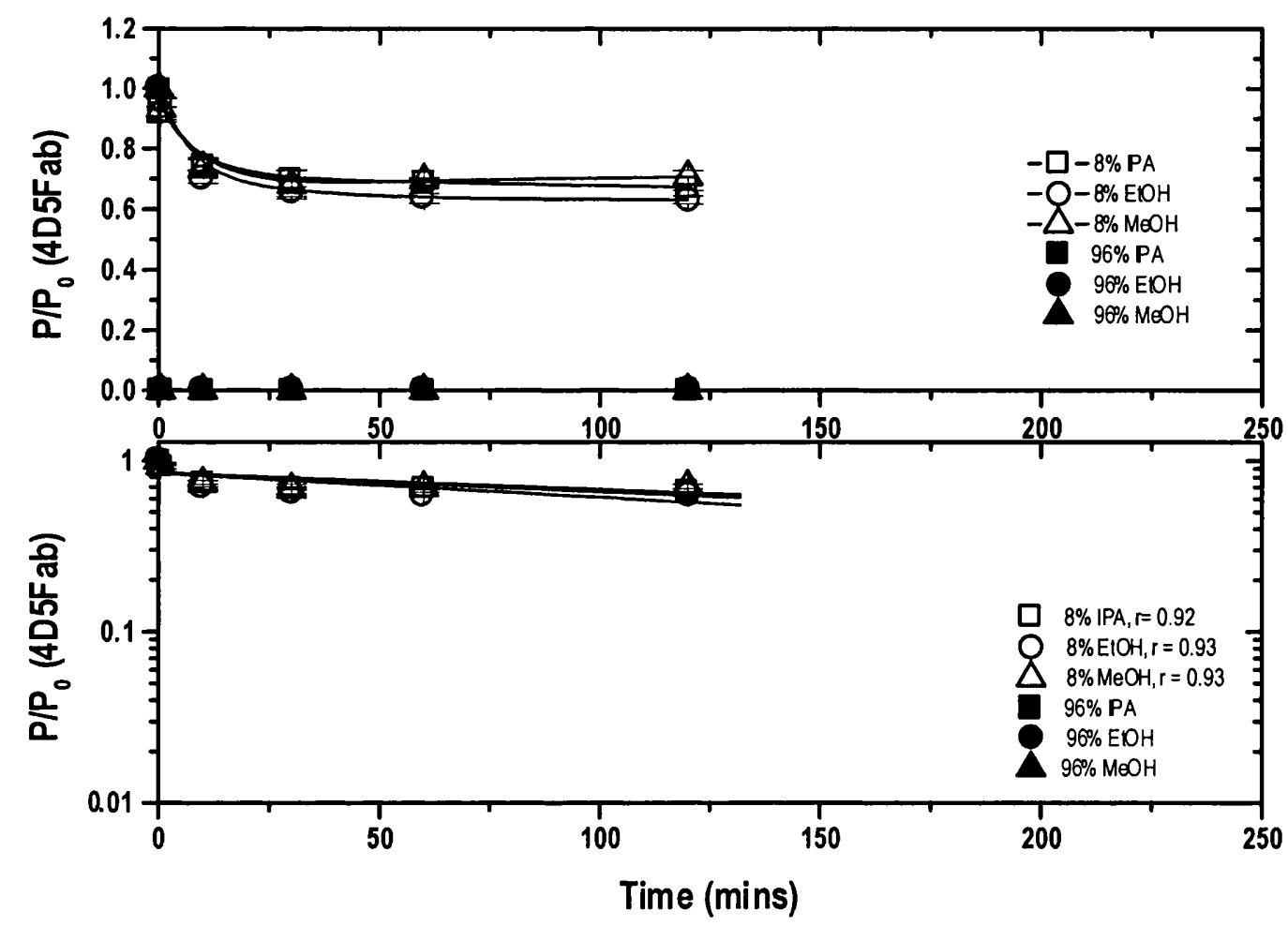

Figure 3.9: Results from $8 \%$ and $96 \%$ solvent experiments using 4D5Fab.

4D5Fab antibody fragment was exposed to $8 \%$ and $96 \%$ solvent at room temperature $\left(20{ }^{\circ} \mathrm{C}\right)$. Three different solvents were used - Isopropanol (IPA), Ethanol (EtOH) and Methanol (MeOH). Measurements were taken over time. The above graph shows the linear and $\log _{10}$ linear plots of $P / P_{0}$ against time for all three solvents and both concentrations. The data points shown are mean value $(n=3)$, error bars show the standard deviation. The lines fitted to the linear data are B-Spline fits. The lines fitted to the log/linear data are linear fits. 


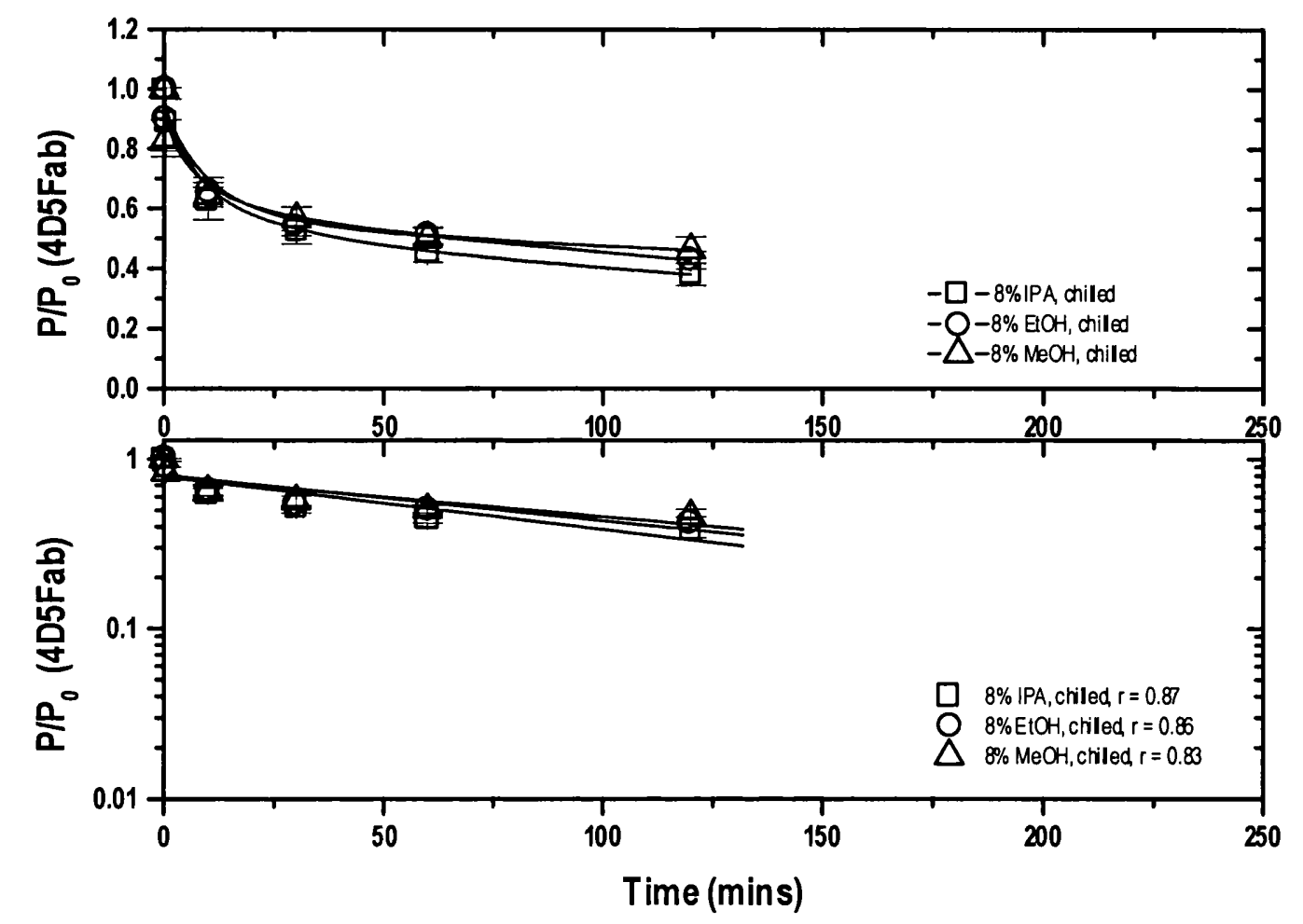

Figure 3.10: Results from 8\% chilled solvent experiments using 4D5Fab.

4D5Fab antibody fragment was exposed to $8 \%$ chilled solvent. Three different solvents were used Isopropanol (IPA), Ethanol (EtOH) and Methanol (MeOH). The solvent was chilled to $0^{\circ} \mathrm{C}$ prior to the experiment and then samples were kept in ice buckets for the duration of the experiment. Measurements were taken over time. The data obtained from this experiment has been normalised to give $P / P_{0}$, where $P$ is the concentration $(\mu \mathrm{g} / \mathrm{ml})$ of the antibody fragment $4 D 5 F a b$ at a given time and $P_{0}$ is the concentration of $4 D 5 F a b$ at the beginning of the experiment. The above graph shows the plot of $P / P_{0}$ and $\log _{10}\left(P / P_{0}\right)$ against time for all three solvents and both concentrations. The data points shown are mean value $(n=3)$, error bars show the standard deviation. The lines fitted to the linear data are B-Spline fits. The lines fitted

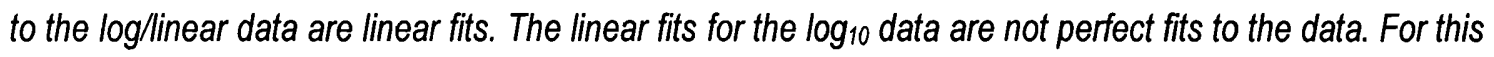
data it is thought that there are two reactions happening. An initial reaction which may be second order (from $t=0$ minutes to $t=30$ minutes) followed by a linear reaction (possibly first order reaction). 


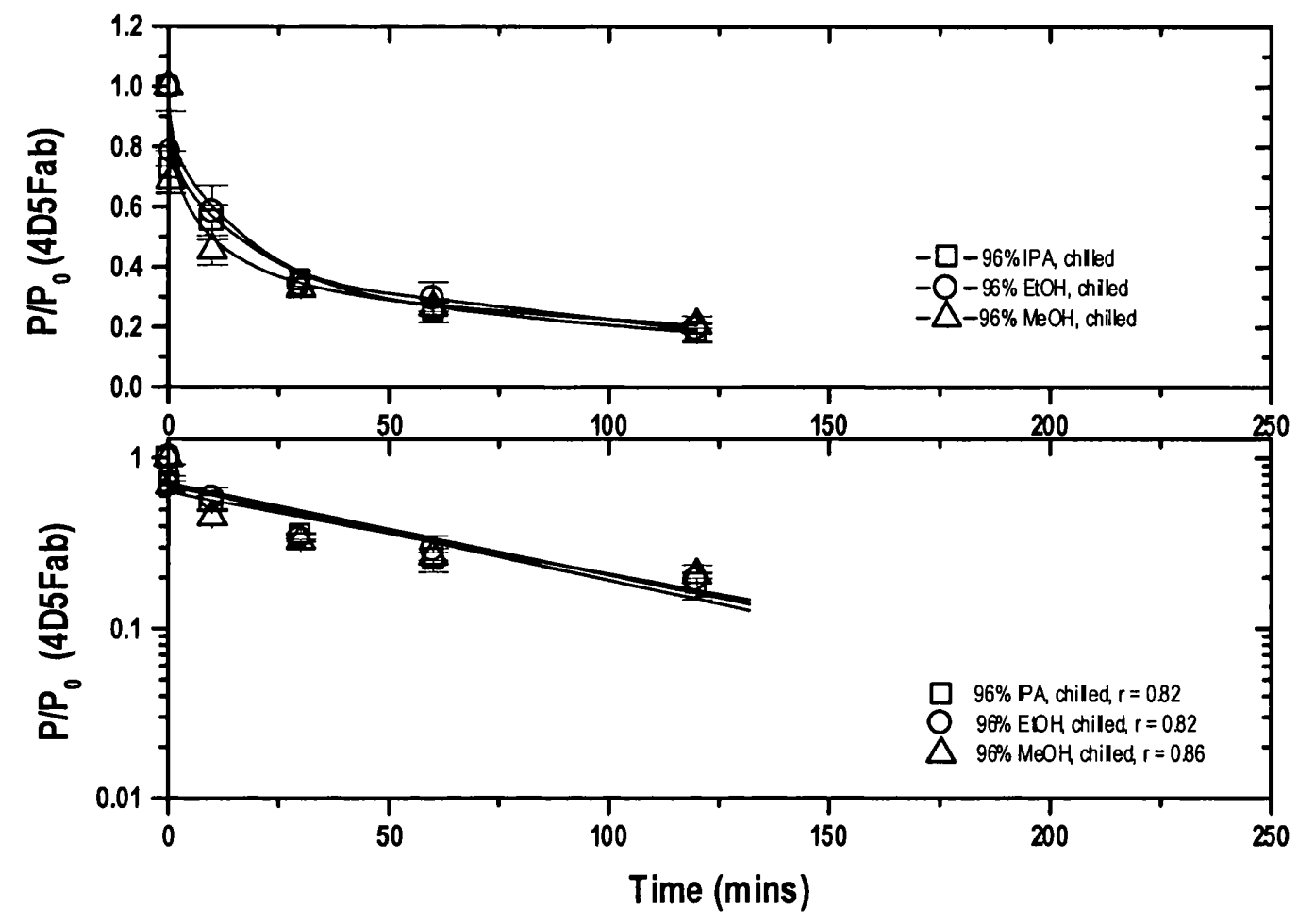

Figure 3.11: Results from 96\% chilled solvent experiments using 4D5Fab.

4D5Fab antibody fragment was exposed to $96 \%$ chilled solvent. Three different solvents were used Isopropanol (IPA), Ethanol (EtOH) and Methanol (MeOH). The solvent was chilled to $0^{\circ} \mathrm{C}$ prior to the experiment and then samples were kept in ice buckets for the duration of the experiment. Measurements were taken over time. The above graph shows the plot of $P / P_{0}$ and $\log _{10} P / P_{0}$ against time for all three solvents and both concentrations. The data points shown are mean values ( $n=6$, outliers removed) and the error bars represent +/- standard deviations of these measurements. The lines fitted to the linear data are B-Spline fits. The lines fitted to the log/linear data are linear fits. As with the previous data it is thought that there are two reactions happening. An initial reaction which may be second order (from $t=0$ minutes to $t=30$ minutes) followed by a linear reaction (possibly first order reaction). 


\subsection{The Effects of Temperature and Solvent}

The graphs plotted from the experimental data obtained for the temperature and solvent experiments allowed calculation of the rate constants for the reactions. For some of the data a linear fit could be made to both the linear plot of the data and the $\log _{10} /$ inear plot. This data could either be a zero order reaction or a first order reaction. There is insufficient data to subscribe a particular reaction order to this data. The rate constants for the reactions are given in Table 3.1. These rate constants give an indication of how damaging the experimental conditions are to the antibody fragment. These will also give an idea of how damaging the SEDS process could be to the antibody fragments.

In Table 3.1 the level of antibody activity loss seen during each experiment the damage is indicated by a plus or minus signs. A minus sign indicates no damage. A plus sign indicates loss of activity; multiple plus signs indicate greater losses in activity with 3 plus signs indicating complete loss of activity.

During SEDS the antibody fragment will experience the combined effect of both temperature and solvent effects. The conditions of SEDS are most likely to be temperatures of $40^{\circ} \mathrm{C}$ or higher and greater than $8 \%$ solvent. The final column of Table 3.1 tries to predict the effect on the antibody of temperatures greater than $40^{\circ} \mathrm{C}$ and solvent levels of above $8 \%$. To do this it has been assumed that the effects of temperature and solvent would be additive. If this is the case then whenever there is a combination of temperatures greater than $40^{\circ} \mathrm{C}$ and solvent levels of above $8 \%$ then the antibody fragments will always suffer either high levels of damage or complete loss of activity.

The experiments detailed in this chapter looked at the effects of temperature and solvent over a timescale of minutes whereas in the SEDS process the time-scale involved is a fraction of a second. However, these experiments were designed to look at $100 \%$ recovery of activity. As the residence time in the SEDS drying chamber is very long and the state of the material in the chamber is not known, these experiments could be used as indicators of the damage that may occur to the antibody fragments during the SEDS process.

The principle for these preliminary experiments is that, if no damage is seen during lab-scale experiments then it is unlikely that damage will occur in the SEDS equipment. Though damage due to length of exposure during the lab experiments must be offset against the greater surface area of the particles in SEDS. In the lab-scale experiments the time-scale is high but the surface area is low. In SEDS the time scale of the solutions passing through the nozzle is low but the surface area is high. Table 3.2 compares these two scenarios. 


\begin{tabular}{|c|c|c|c|c|c|c|}
\hline D1.3Fv Expt & Conditions & $\begin{array}{l}\text { Zero Order } \\
k^{\star} 2.303\left(\mathrm{~min}^{-1}\right)\end{array}$ & & $\begin{array}{l}\text { First Order } \\
k^{\star} 2.303\left(\min ^{-1}\right)\end{array}$ & & $\begin{array}{l}\text { Predicted Damage if } \\
T>40, \text { Solvent }>8 \%\end{array}$ \\
\hline Temp - $20^{\circ} \mathrm{C}$ & $\begin{array}{l}65 \mu \mathrm{g} / \mathrm{ml}, \\
\text { No Solvent }\end{array}$ & 0.009 & + & 0.0065 & + & \\
\hline Temp $-40^{\circ} \mathrm{C}$ & $\begin{array}{l}65 \mu \mathrm{g} / \mathrm{ml}, \\
\text { No Solvent }\end{array}$ & 0.0087 & + & 0.0092 & + & ++ \\
\hline Temp $-50^{\circ} \mathrm{C}$ & $\begin{array}{l}65 \mu \mathrm{g} / \mathrm{ml}, \\
\text { No Solvent }\end{array}$ & & & 0.022 & ++ & +++ \\
\hline Temp $-60^{\circ} \mathrm{C}$ & $\begin{array}{l}65 \mu \mathrm{g} / \mathrm{ml}, \\
\text { No Solvent }\end{array}$ & & & 0.034 & ++ & $++t$ \\
\hline Temp $-20^{\circ} \mathrm{C}$ & $\begin{array}{l}300 \mu \mathrm{g} / \mathrm{ml}, \\
\text { No Solvent }\end{array}$ & $0.000(8)$ & $\cdot$ & $0.000(4)$ & $\cdot$ & \\
\hline Temp $-40^{\circ} \mathrm{C}$ & $\begin{array}{l}300 \mu \mathrm{g} / \mathrm{ml}, \\
\text { No Solvent }\end{array}$ & $0.000(1)$ & $\cdot$ & $0.000(1)$ & $\cdot$ & ++ \\
\hline Temp $-50^{\circ} \mathrm{C}$ & $\begin{array}{l}300 \mu \mathrm{g} / \mathrm{ml}, \\
\text { No Solvent }\end{array}$ & $0.000(5)$ & $\cdot$ & $0.000(3)$ & $\cdot$ & ++ \\
\hline Temp $-60^{\circ} \mathrm{C}$ & $\begin{array}{l}300 \mu \mathrm{g} / \mathrm{ml} \\
\text { No Solvent }\end{array}$ & & & 0.008 & + & $++t$ \\
\hline Temp - $20^{\circ} \mathrm{C}$ & $\begin{array}{l}650 \mu \mathrm{g} / \mathrm{ml} \\
\text { No Solvent }\end{array}$ & $0.000(8)$ & $\cdot$ & $0.000(4)$ & $\cdot$ & \\
\hline Temp $-40^{\circ} \mathrm{C}$ & $\begin{array}{l}650 \mu \mathrm{g} / \mathrm{ml} \\
\text { No Solvent }\end{array}$ & $0.000(3)$ & $\cdot$ & $0.000(2)$ & $\cdot$ & ++ \\
\hline Temp - $50^{\circ} \mathrm{C}$ & $\begin{array}{l}650 \mu \mathrm{g} / \mathrm{ml} \\
\text { No Solvent }\end{array}$ & $0.000(9)$ & - & $0.000(5)$ & $\cdot$ & ++ \\
\hline Temp $-60^{\circ} \mathrm{C}$ & $\begin{array}{l}650 \mu \mathrm{g} / \mathrm{ml} \\
\text { No Solvent } \\
\end{array}$ & & & 0.002 & + & $++t$ \\
\hline Solvent-0\% & $\begin{array}{l}50 \mu \mathrm{g} / \mathrm{ml} \\
40^{\circ} \mathrm{C}, \mathrm{MeOH}\end{array}$ & 0.008 & + & 0.004 & + & \\
\hline Solvent - $25 \%$ & $\begin{array}{l}50 \mu \mathrm{g} / \mathrm{ml} \\
40^{\circ} \mathrm{C}, \mathrm{MeOH}\end{array}$ & & & 0.03 & ++ & ++ \\
\hline Solvent - $50 \%$ & $\begin{array}{l}50 \mu \mathrm{g} / \mathrm{ml} \\
40^{\circ} \mathrm{C}, \mathrm{MeOH}\end{array}$ & & & 0.075 & ++ & ++ \\
\hline Solvent - $75 \%$ & $\begin{array}{l}50 \mu \mathrm{g} / \mathrm{ml} \\
40^{\circ} \mathrm{C}, \mathrm{MeOH}\end{array}$ & & & 0.397 & +++ & +++ \\
\hline $\begin{array}{l}\text { Solvent - 0\% } \\
+ \text { mannitol }\end{array}$ & $\begin{array}{l}50 \mu \mathrm{g} / \mathrm{ml} \\
40^{\circ} \mathrm{C}, \mathrm{MeOH}\end{array}$ & 0.0095 & + & 0.005 & + & \\
\hline $\begin{array}{l}\text { Solvent - } 25 \% \\
+ \text { mannitol }\end{array}$ & $\begin{array}{l}50 \mu \mathrm{g} / \mathrm{ml} \\
40^{\circ} \mathrm{C}, \mathrm{MeOH}\end{array}$ & & & 0.03 & ++ & ++ \\
\hline $\begin{array}{l}\text { Solvent - } 50 \% \\
+ \text { mannitol }\end{array}$ & $\begin{array}{l}50 \mu \mathrm{g} / \mathrm{ml} \\
40^{\circ} \mathrm{C}, \mathrm{MeOH}\end{array}$ & & & 0.2 & +++ & +++ \\
\hline $\begin{array}{l}\text { Solvent - } 75 \% \\
+ \text { mannitol }\end{array}$ & $\begin{array}{l}50 \mu \mathrm{g} / \mathrm{ml} \\
40^{\circ} \mathrm{C}, \mathrm{MeOH}\end{array}$ & & & 0.341 & $++t$ & $++t$ \\
\hline $\begin{array}{l}\text { Solvent - } 8 \% \\
\text { IPA }\end{array}$ & $\begin{array}{l}50 \mu \mathrm{g} / \mathrm{ml} \\
20^{\circ} \mathrm{C}\end{array}$ & $0.000(9)$ & $\cdot$ & $0.000(4)$ & $\cdot$ & \\
\hline $\begin{array}{l}\text { Solvent - } 8 \% \\
\mathrm{MeOH}\end{array}$ & $\begin{array}{l}50 \mu \mathrm{g} / \mathrm{ml} \\
20^{\circ} \mathrm{C}\end{array}$ & $0.000(9)$ & $\cdot$ & $0.000(4)$ & $\cdot$ & \\
\hline $\begin{array}{l}\text { Solvent - 8\% } \\
\text { EtOH }\end{array}$ & $\begin{array}{l}50 \mu \mathrm{g} / \mathrm{ml} \\
20^{\circ} \mathrm{C}\end{array}$ & $0.000(1)$ & $\cdot$ & $0.000(1)$ & $\cdot$ & \\
\hline $\begin{array}{l}\text { Solvent - } 96 \% \\
\text { IPA }\end{array}$ & $\begin{array}{l}50 \mu \mathrm{g} / \mathrm{ml} \\
20^{\circ} \mathrm{C}\end{array}$ & $>1$ & +++ & $>1$ & +++ & +++ \\
\hline
\end{tabular}




\begin{tabular}{|c|c|c|c|c|c|c|}
\hline $\begin{array}{l}\text { Solvent }-96 \% \\
\mathrm{MeOH}\end{array}$ & $\begin{array}{l}50 \mu \mathrm{g} / \mathrm{ml}, \\
20^{\circ} \mathrm{C}\end{array}$ & $>1$ & +++ & $>1$ & +++ & +++ \\
\hline $\begin{array}{l}\text { Solvent - } 96 \% \\
\text { EtOH }\end{array}$ & $\begin{array}{l}50 \mu \mathrm{g} / \mathrm{ml}, \\
20^{\circ} \mathrm{C}\end{array}$ & $>1$ & $++t$ & $>1$ & +++ & $++t$ \\
\hline 4D5Fab Expt & Conditions & $\begin{array}{l}\text { Zero Order } \\
k^{\star 2} 2.303\left(\mathrm{~min}^{-1}\right)\end{array}$ & & $\begin{array}{l}\text { First Order } \\
k^{\star} 2.303\left(\mathrm{~min}^{-1}\right)\end{array}$ & & \\
\hline Temp - $60^{\circ} \mathrm{C}$ & $\begin{array}{l}120 \mu \mathrm{g} / \mathrm{ml}, \\
\text { No Solvent }\end{array}$ & 0.0026 & + & 0.001 & + & ++ \\
\hline Temp $-70^{\circ} \mathrm{C}$ & $\begin{array}{l}120 \mu \mathrm{g} / \mathrm{ml} \\
\text { No Solvent }\end{array}$ & 0.018 & ++ & 0.008 & + & ++ \\
\hline Temp $-80^{\circ} \mathrm{C}$ & $\begin{array}{l}120 \mu \mathrm{g} / \mathrm{ml}, \\
\text { No Solvent }\end{array}$ & & & 0.425 & +++ & $++t$ \\
\hline $\begin{array}{l}\text { Solvent - 8\% } \\
\text { IPA }\end{array}$ & $\begin{array}{l}50 \mu \mathrm{g} / \mathrm{ml}, \\
20^{\circ} \mathrm{C}\end{array}$ & & & 0.003 & + & \\
\hline $\begin{array}{l}\text { Solvent - } 8 \% \\
\mathrm{MeOH}\end{array}$ & $\begin{array}{l}50 \mu \mathrm{g} / \mathrm{ml}, \\
20^{\circ} \mathrm{C}\end{array}$ & & & 0.003 & + & \\
\hline $\begin{array}{l}\text { Solvent - } 8 \% \\
\text { EtOH }\end{array}$ & $\begin{array}{l}50 \mu \mathrm{g} / \mathrm{ml}, \\
20^{\circ} \mathrm{C}\end{array}$ & & & 0.002 & + & \\
\hline $\begin{array}{l}\text { Solvent-96\% } \\
\text { IPA }\end{array}$ & $\begin{array}{l}50 \mu \mathrm{g} / \mathrm{ml}, \\
20^{\circ} \mathrm{C}\end{array}$ & $>1$ & +++ & $>1$ & +++ & +++ \\
\hline $\begin{array}{l}\text { Solvent - } 96 \% \\
\mathrm{MeOH}\end{array}$ & $\begin{array}{l}50 \mu \mathrm{g} / \mathrm{ml} \\
20^{\circ} \mathrm{C}\end{array}$ & $>1$ & +++ & $>1$ & +++ & $++t$ \\
\hline $\begin{array}{l}\text { Solvent }-96 \% \\
\text { EtOH }\end{array}$ & $\begin{array}{l}50 \mu \mathrm{g} / \mathrm{ml}, \\
20^{\circ} \mathrm{C}\end{array}$ & $>1$ & +++ & $>1$ & $++t$ & $++t$ \\
\hline $\begin{array}{l}\text { Solvent - } 8 \% \\
\text { IPA }\end{array}$ & $\begin{array}{l}50 \mu \mathrm{g} / \mathrm{ml}, \\
0 \circ \mathrm{C}\end{array}$ & & & 0.007 & + & \\
\hline $\begin{array}{l}\text { Solvent - } 8 \% \\
\mathrm{MeOH}\end{array}$ & $\begin{array}{l}50 \mu \mathrm{g} / \mathrm{ml} \\
0^{\circ} \mathrm{C}\end{array}$ & & & 0.006 & + & \\
\hline $\begin{array}{l}\text { Solvent - } 8 \% \\
\text { EtOH }\end{array}$ & $\begin{array}{l}50 \mu \mathrm{g} / \mathrm{ml}, \\
0^{\circ} \mathrm{C}\end{array}$ & & & 0.005 & + & \\
\hline $\begin{array}{l}\text { Solvent - } 96 \% \\
\text { IPA }\end{array}$ & $\begin{array}{l}50 \mu \mathrm{g} / \mathrm{ml}, \\
0{ }^{\circ} \mathrm{C}\end{array}$ & & & 0.013 & ++ & \\
\hline $\begin{array}{l}\text { Solvent - } 96 \% \\
\text { MeOH }\end{array}$ & $\begin{array}{l}50 \mu \mathrm{g} / \mathrm{ml} \\
0{ }^{\circ} \mathrm{C}\end{array}$ & & & 0.012 & $+t$ & \\
\hline $\begin{array}{l}\text { Solvent - } 96 \% \\
\text { EtOH }\end{array}$ & $\begin{array}{l}50 \mu \mathrm{g} / \mathrm{ml} \\
0 \circ \mathrm{C}\end{array}$ & & & 0.011 & $+t$ & \\
\hline
\end{tabular}

Table 3.1: Rate Constants for Temperature and Solvent Stability Tests.

The reactions are identified as zero order, first order or both. The plus and minus signs are used as an indication of the level of antibody activity loss seen for each experiment. A minus sign indicates no damage. A plus sign indicates loss of activity; multiple plus signs indicate greater losses in activity with 3 plus signs indicating complete loss of activity. The shaded cells indicate no applicable value.

\begin{tabular}{|l|l|l|l|}
\hline & Lab Scale Experiments & SEDS Equipment & Estimated Ratios \\
\hline Time & HIGH & LOW & $10^{2}-10^{3}: 1$ \\
\hline Surface Area & LOW & HIGH & $1: 10^{3} \cdot 10^{4}$ \\
\hline Time x Surface Area & $? ?$ & $? ?$ & $1: 1-10^{2}$ \\
\hline
\end{tabular}

Table 3.2: Comparison of lab-scale experiments and SEDS experiments with estimates of ratios. 


\subsection{Freeze Drying, Shear and pH Experiments}

\subsubsection{Introduction}

As well as the effect of temperature and solvent other potentially detrimental aspects of the SEDS process were considered. The effects of shear and $\mathrm{pH}$ were looked at, as both of these are possible causes of damage during SEDS. Dried powders of the antibody fragments were produced using freeze drying to test whether or not the antibody fragments were robust enough to withstand drying via a conventional method.

\subsubsection{Shear Experiments}

When first contemplating the design of the SEDS equipment it would seem logical that as the feed streams are being sprayed out of the nozzle they would be subjected to a high shear rate. Samson Yim, UCL, used computational fluid dynamics to model the shear rate in the nozzle region. The rate of shear in the nozzle was calculated to be of a magnitude of $10^{4} \mathrm{~s}^{-1}$. A shear device was used to test whether or not this level of shear would damage the antibody fragments. These experiments looked at the effect of two types of shear - shear without an air/liquid interface and shear with an air/liquid interface. The shear applied to the antibody solution was in the order of $10^{5} \mathrm{~s}^{-1}$. The results of these experiments are presented in Table 3.2.

It can be seen that for the D1.3Fv antibody fragment when there is no air/liquid interface shear causes very little damage to the antibody fragment. However, when shear is applied with an air/liquid interface the antibody fragment loses all of its bioactivity.

It was found that the 4D5Fab fragment was slightly more susceptible to damage from shear without an air/liquid interface than the D1.3Fv fragment. However the Fab fragment was more robust in the presence of shear with an air/liquid interface. 


\begin{tabular}{|l|l|l|}
\hline Sample & $\begin{array}{l}\text { Antibody Concentration } \\
(\mu \mathrm{g} / \mathrm{ml})\end{array}$ & \% loss bioactivity \\
\hline D1.3Fv No Shear (Control) & $650 \quad(+/-10, \mathrm{n}=3)$ & 3 \\
\hline $\begin{array}{l}\text { D1.3Fv Shear without } \\
\text { Air/Liquid Interface }\end{array}$ & $635 \quad(+/-12, \mathrm{n}=3)$ & 99 \\
\hline $\begin{array}{l}\text { D1.3Fv Shear with Air/Liquid } \\
\text { Interface }\end{array}$ & $6.0 \quad(+/-1, \mathrm{n}=3)$ & \\
\hline 4D5Fab No Shear (Control) & $574 \quad(+/-15, n=8)$ & 19 \\
\hline $\begin{array}{l}\text { 4D5Fab Shear without } \\
\text { Air/Liquid Interface }\end{array}$ & $466 \quad(+/-10, \mathrm{n}=8)$ & 34 \\
\hline $\begin{array}{l}\text { 4D5Fab Shear with Air/Liquid } \\
\text { Interface }\end{array}$ & $378 \quad(+/-11, \mathrm{n}=8)$ & \\
\hline
\end{tabular}

Table 3.3: Results of shear experiments carried out on D1.3Fv and 4D5Fab.

D1.3Fv results are the mean values of triplicate measurements using an Optical Biosensor. 4D5Fab results are the mean values of 8 measurements made using an ELISA. The experiments were carried out at room temperature $\left(20^{\circ} \mathrm{C}\right)$ using a specially designed shear device. Shear was applied to the samples for 20 seconds.

\subsection{3 pH Experiments}

Supercritical Carbon Dioxide has a pH value of approximately 2.7. To test whether the acidic environment of the $\mathrm{scCO}_{2}$ has a detrimental effect on the antibody fragments solutions of the fragments were subjected to $\mathrm{pH} 2.7$ for 30 minutes. It was found that there was no loss in activity due to an acidic $\mathrm{pH}$ environment.

\subsubsection{Freeze Drying}

To test whether or not the antibody fragments were able to withstand drying via a conventional method, solutions of the antibodies were freeze dried. Solutions of D1.3Fv, 4D5Fab and CDP850 (a whole antibody) had mannitol $(0.1 \mathrm{~g} / \mathrm{ml})$ added to them. These solutions were then freeze-dried. The results are shown in Table 3.4. 


\begin{tabular}{|c|c|c|}
\hline Sample & $\begin{array}{l}\text { Antibody Concentration } \\
(\mu \mathrm{g} / \mathrm{ml})\end{array}$ & $\%$ loss bioactivity \\
\hline $\begin{array}{llll}\begin{array}{l}\text { D1.3Fv } \\
\text { (Control) }\end{array} & \text { Fo Freeze } & \text { Drying } \\
\end{array}$ & $635 \quad(+/-12, n=3)$ & \\
\hline D1.3Fv Freeze Dried & $542 \quad(+/-15, n=3)$ & 15 \\
\hline $\begin{array}{l}\text { 4D5Fab No Freeze Drying } \\
\text { (Control) }\end{array}$ & $556 \quad(+/-10, n=9)$ & \\
\hline 4D5Fab Freeze Dried & $553 \quad(+/-12, n=8)$ & 0 \\
\hline $\begin{array}{ll}\text { CDP850 (full antibody) No } \\
\text { Freeze Drying (Control) }\end{array}$ & $(+/-15, n=8)$ & \\
\hline CDP850 Freeze Dried & $460 \quad(+/-12, n=8)$ & 6 \\
\hline $\begin{array}{l}\text { CDP850 (full antibody) No } \\
\text { Freeze Drying (Control) }\end{array}$ & $6 \mathrm{mg} / \mathrm{ml} \quad(+/-0.9, \mathrm{n}=8)$ & \\
\hline CDP850 Freeze Dried & $5.4 \mathrm{mg} / \mathrm{ml}(+/-0.8, \mathrm{n}=8)$ & 10 \\
\hline
\end{tabular}

Table 3.4: Results of freeze drying experiments.

The above table shows the results of freeze drying experiments carried out on solutions of D1.3Fv and 4D5Fab antibody fragments and a whole antibody CDP850. D1.3Fv results are the mean values of triplicate measurements using an Optical Biosensor. 4D5Fab and CDP850 results are the mean values of 8 measurements made using ELISAS.

The results show that for D1.3Fv there is some loss of activity after drying and rehydration (15\%). For 4D5Fab there is no loss in activity. The results of this experiment indicate that both antibody fragments are robust enough to survive conventional drying and rehydration. The whole antibody CDP850 which was freeze dried at two concentrations $(490 \mu \mathrm{g} / \mathrm{ml}$ and $6 \mathrm{mg} / \mathrm{ml})$ suffered $5-10 \%$ loss of activity upon rehydration after freeze drying. These results provided a measure against which, the effect of the conditions inside the SEDS vessel on the activity of dried antibody fragments (Chapter Four - SEDS Stability Tests) can be assessed. 


\section{CHAPTER FOUR}

\section{RESULTS OF SEDS EXPERIMENTS}




\section{Results of SEDS Experiments}

\subsection{Introduction}

SEDS experiments were carried out using two antibody fragments D1.3Fv and 4D5Fab and whole antibody CDP850. Different process parameters were varied to examine the effect of these on the SEDS processed product. Runs were performed using different concentrations of the whole antibody to look at concentration effect.

The results of these experiments are presented in Tables 4.1 - 4.17 and in Figure 4.2. The tables detail the amount of protein present before and after SEDS and the amount of active antibody present before and after SEDS. Specific activities are also given. These are a measure of the amount of active protein present (active antibody fragment or antibody) in relation to the total amount of protein. For example the specific activity before SEDS was calculated by (active antibody in)/(protein in). Specific activity yield was calculated by dividing specific activity out by specific activity in. Activity yield was calculated by dividing active protein out by active protein in. The specific activity values are the most relevant results for the study of inactivation within the SEDS process. This is because they discount for any loss of protein that occurs during processing, for example in the exit solvent stream. However they do assume that there is no selective loss of a particular protein or group of proteins. In general it is these results that will be subject to detailed consideration and discussion.

As the antibody fragments were available in limited supply and each SEDS run took a substantial amount of time, each SEDS run was very important. Thus assays were done with many repeats to ensure that a limited number of SEDS runs could still be used to give a confident prediction of experimental trends.

Initial SEDS runs were carried out using a higher set of flow-rates: $\mathrm{ScCO}_{2}-18 \mathrm{ml} / \mathrm{min}$, solvent $-1.5 \mathrm{ml} / \mathrm{min}$, antibody solution $-0.06 \mathrm{~m} / / \mathrm{min}$. Due to problems experienced with the $\mathrm{CO}_{2}$ pump the flow-rates were reduced to: $\mathrm{scCO}_{2}-10 \mathrm{ml} / \mathrm{min}$, solvent $-0.9 \mathrm{ml} / \mathrm{min}$, antibody solution $-0.03 \mathrm{~m} / / \mathrm{min}$ to decrease the load on this pump. These flow-rates were chosen so that the drying conditions were very similar (i.e. the points for both sets of flow-rates lie very close to each other on the phase diagram), see Figure 4.1. This allows for direct comparisons of the SEDS runs even though different flow-rates have been used. The $\mathrm{CO}_{2}$ pump was eventually replaced with a diaphragm pump that was found to be more reliable.

The results of stability tests are also detailed in this chapter. These tests involved placing freeze-dried formulations of the antibody fragment or whole antibody in the SEDS vessel and subjecting it to $\mathrm{ScCO}_{2}$, $\mathrm{scCO}_{2}$ and solvent and then $\mathrm{scCO}_{2}$, solvent and water. These tests were used to try and establish 
whether or not damage occurred to the dried product in the SEDS vessel. Timed stability tests were carried out using the whole antibody to test the effect of exposure time on the freeze-dried formulation.

The results are presented in the following order D1.3Fv results, 4D5Fab results, CDP850 results and finally PEG-4D5 Fab and CDP805 plus PEG 600 results.

\subsection{D1.3FV SEDS Experiments}

The preliminary temperature stability studies detailed in Chapter Three indicated that at a concentration of $500 \mu \mathrm{g} / \mathrm{ml} \mathrm{D1} 1.3 \mathrm{Fv}$ would be stable at temperatures up to $60^{\circ} \mathrm{C}$. To reach supercritical conditions $\mathrm{CO}_{2}$ must be held at a temperature of at least $31{ }^{\circ} \mathrm{C}$. Thus a temperature of $40^{\circ} \mathrm{C}$ was chosen as an initial temperature for SEDS processing as this allowed both higher and lower temperatures to be investigated later on.

The influence of solvent choice on SEDS processed D1.3Fv was investigated. The processing temperature was $40^{\circ} \mathrm{C}$ and the three solvents looked at were Methanol(MeOH), Ethanol(EtOH) and Isopropanol(IPA). These results are presented in Table 4.1. The SEDS run that used Methanol as the solvent gave a very low specific activity of $2 \%$. The SEDS runs carried out with EtOH and IPA both gave the same specific activity of $32 \%$. The results of these experiments were used to select the solvent used for looking at the effect of temperature on SEDS processed D1.3Fv. IPA was chosen as the solvent for the SEDS runs used to investigate the effect of temperature.

SEDS runs were carried out at $35^{\circ} \mathrm{C}$ and $50^{\circ} \mathrm{C}$ using IPA as the solvent. These results are also presented in Table 4.1. When the standard errors are taken into consideration the recovered specific activities for the three temperatures studied (all using IPA as the solvent) all lead to similar recovered specific activities, between $22-32 \%$. However the SEDS run carried out at $40^{\circ} \mathrm{C}$ gave the highest specific activity recovery. This is perhaps an unusual result as it may have been expected that the lower temperature would prove to be the least damaging towards the antibody fragment. This maybe due to the $\mathrm{CO}_{2}$ not being supercritical due to any temperature drops across the system thus extraction of the antibody fragment may not be occurring. However one would expect this to lead to a highly reduced yield rather than reduced activity. Another suggestion for this result could be that at lower temperatures less removal of water may have been achieved and therefore the protein powder is wetter and less stable. 


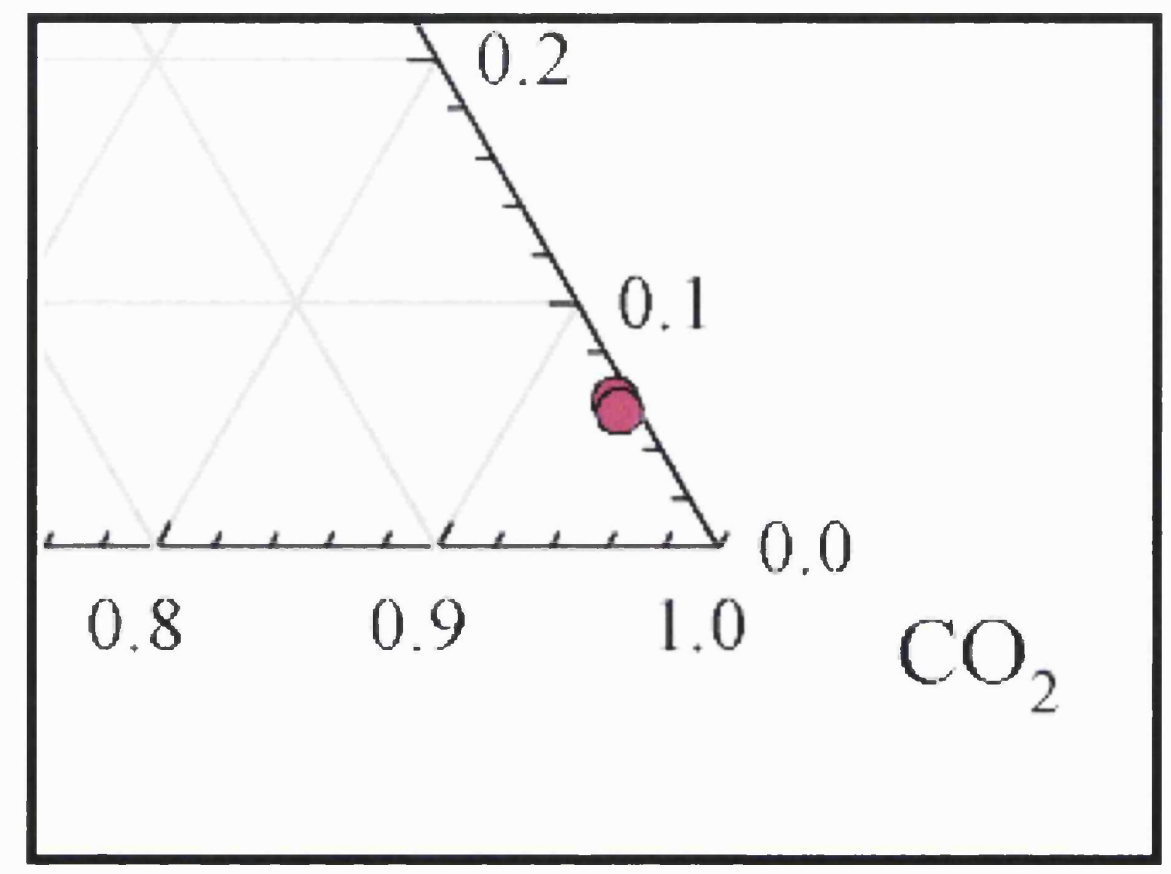

Figure 4.1 Part of a phase diagram showing the positioning of the two sets of drying conditions

The above figure shows the two sets of drying conditions used for the SEDS runs. The two pink dots indicate the two different conditions used. It can be seen from this diagram that the two conditions are very similar. 


\begin{tabular}{|c|c|c|c|c|c|c|c|c|}
\hline SEDS Expt & $\begin{array}{l}\text { Total Protein } \\
\ln (\mathrm{mg})\end{array}$ & $\begin{array}{l}\text { Total D1.3Fv } \\
\ln (\mathrm{mg})\end{array}$ & $\begin{array}{l}\text { Total Protein } \\
\text { Out (mg) }\end{array}$ & $\begin{array}{l}\text { Total D1.3Fv } \\
\text { Out (mg) }\end{array}$ & $\begin{array}{l}\text { Specific } \\
\text { Activity In } \\
\text { (mg/mg) }\end{array}$ & $\begin{array}{l}\text { Specific } \\
\text { Activity Out } \\
\text { (mg/mg) }\end{array}$ & $\begin{array}{l}\text { Activity } \\
\text { Yield \% }\end{array}$ & $\begin{array}{l}\text { \% Specific } \\
\text { Activity } \\
\text { Recovered }\end{array}$ \\
\hline $\begin{array}{l}\text { Solvent } \cdot \mathrm{MeOH} \\
\text { Temp }-40^{\circ} \mathrm{C} \\
\text { scCO }-18 \mathrm{~m} / \mathrm{min} \\
\text { solvent }-1.5 \mathrm{ml} / \mathrm{min} \\
\text { D1.3Fv soln }-0.06 \mathrm{~m} / / \mathrm{min}\end{array}$ & $\begin{array}{c}4.9 \\
+/-0.02 \\
n=4\end{array}$ & $\begin{array}{c}4.01 \\
+/-0.02 \\
n=3\end{array}$ & $\begin{array}{c}4.1 \quad+/-0.01 \\
n=4\end{array}$ & $\begin{array}{c}0.08 \\
+/-0.01 \\
n=3\end{array}$ & $\begin{array}{l}0.82+/-0.04 \\
\end{array}$ & 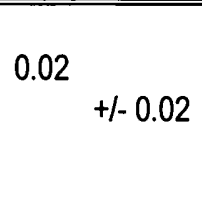 & $2+\mid-0.1$ & $2+1-0.2$ \\
\hline $\begin{array}{l}\text { Solvent }- \text { EtOH } \\
\text { Temp }-40^{\circ} \mathrm{C} \\
\mathrm{scCO}_{2}-10 \mathrm{~m} / \mathrm{min} \\
\text { solvent }-0.9 \mathrm{~m} / \mathrm{min} \\
\text { D1.3Fv soln }-0.03 \mathrm{~m} / / \mathrm{min}\end{array}$ & $\begin{array}{c}1.2 \quad+/-0.02 \\
n=4\end{array}$ & $\begin{array}{c}0.95 \\
+/-0.02 \\
n=3\end{array}$ & $\begin{array}{c}1.0 \\
+/-0.01 \\
n=4\end{array}$ & $\begin{array}{r}0.25 \\
+1-0.006 \\
n=3\end{array}$ & 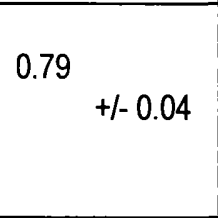 & $\begin{array}{l}0.62+1-0.02 \\
\end{array}$ & $\begin{array}{l}26 \\
+\mid-1\end{array}$ & ${ }^{32}+1-4$ \\
\hline $\begin{array}{l}\text { Solvent - IPA } \\
\text { Temp - 40 } \\
\text { scCO }-10 \mathrm{~m} / \mathrm{min} \\
\text { solvent }-0.9 \mathrm{~m} / / \mathrm{min} \\
\text { D1.3Fv soln }-0.03 \mathrm{~m} / \mathrm{min}\end{array}$ & $\begin{array}{c}1.6 \\
+/-0.02 \\
n=4\end{array}$ & $\begin{array}{c}1.44 \\
+/-0.02 \\
n=3\end{array}$ & $\begin{array}{c}1.4 \quad c 0.01 \\
n=4\end{array}$ & $\begin{array}{c}0.41 \\
+1-0.006 \\
n=3\end{array}$ & ${ }^{0.92}+1-0.04$ & 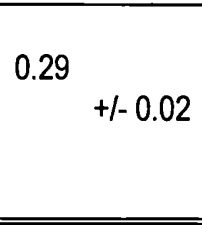 & $\begin{array}{l}28 \\
+1.1 .4\end{array}$ & $\begin{array}{l}32 \\
+1-4\end{array}$ \\
\hline $\begin{array}{l}\text { Temp - } 35^{\circ} \mathrm{C} \\
\text { Solvent - IPA } \\
\text { scCO }-10 \mathrm{~m} / \mathrm{min} \\
\text { solvent }-0.9 \mathrm{~m} / \mathrm{min} \\
\text { D1.3Fv soll }-0.03 \mathrm{~m} / \mathrm{min}\end{array}$ & $\begin{array}{c}1.6 \\
+/-0.02 \\
n=4\end{array}$ & $\begin{array}{c}1.56 \\
+/-0.03 \\
n=3\end{array}$ & $\begin{array}{c}1.5 \\
+/-0.01 \\
n=4\end{array}$ & $\begin{array}{c}0.31 \\
+/-0.01 \\
n=3\end{array}$ & $\begin{array}{l}0.96 \\
+1-0.05\end{array}$ & $\begin{array}{l}0.21+1-0.02 \\
\end{array}$ & $\begin{array}{l}20 \\
+\mid-1.4\end{array}$ & $22+1-3$ \\
\hline $\begin{array}{l}\text { Temp - } 50^{\circ} \mathrm{C} \\
\text { Solvent - IPA } \\
\text { scCO }-10 \mathrm{~m} / \mathrm{min} \\
\text { solvent }-0.9 \mathrm{~m} / \mathrm{min} \\
\text { D1.3Fv soln }-0.03 \mathrm{ml} / \mathrm{min}\end{array}$ & $\begin{array}{c}1.2 \\
+/-0.03 \\
n=4\end{array}$ & $\begin{array}{c}1.06 \\
+/-0.02 \\
n=3\end{array}$ & $\begin{array}{c}1.1+/-0.01 \\
n=4\end{array}$ & $\begin{array}{l}0.24 \\
\quad+/-0.01 \\
n=3\end{array}$ & $\begin{array}{l}0.88+-0.05 \\
\end{array}$ & $\begin{array}{l}0.22+1-0.02 \\
\end{array}$ & ${ }^{23}+1-1.4$ & $\begin{array}{l}25 \\
+1-4\end{array}$ \\
\hline
\end{tabular}

Table 4.1 - Table of data from SEDS experiments using D1.3Fv (please refer to Appendix 1, page 168)

The table above presents the data obtained from a series of SEDS experiments performed using the D1.3Fv antibody fragment. The first three rows show the results of SEDS processing using temperature as the constant condition $\left(40^{\circ} \mathrm{C}\right)$ and varying the solvent. The last two rows give the results of SEDS runs carried out at different temperatures but using a constant solvent (isopropanol). The table shows the results of Coomassie Blue protein assays, which established the total amount of protein present before and after the SEDS runs. The amount of active D1.3Fv before and after SEDS is shown, these values were obtained using an optical biosensor. Activity yields have been calculated 


\begin{tabular}{|c|c|c|c|c|c|c|c|c|}
\hline $\begin{array}{l}\text { Freeze-Dried } \\
\text { D1.3Fv Plus }\end{array}$ & $\begin{array}{l}\text { Total Protein } \\
\ln (\mathrm{mg})\end{array}$ & $\begin{array}{l}\text { Total D1.3Fv } \\
\ln (\mathrm{mg})\end{array}$ & $\begin{array}{l}\text { Total Protein } \\
\text { Out (mg) }\end{array}$ & $\begin{array}{l}\text { Total D1.3Fv } \\
\text { Out (mg) }\end{array}$ & $\begin{array}{l}\text { Specific } \\
\text { Activity In } \\
\text { (mg/mg) }\end{array}$ & $\begin{array}{l}\text { Specific } \\
\text { Activity Out } \\
\text { (mg/mg) }\end{array}$ & $\begin{array}{l}\text { Activity Yield } \\
\%\end{array}$ & $\begin{array}{l}\text { \% Specific } \\
\text { Activity } \\
\text { Recovered }\end{array}$ \\
\hline $\begin{array}{l}\mathrm{scCO}_{2} \\
\mathrm{scCO}_{2}-10 \mathrm{~m} / / \mathrm{min} \\
\mathrm{Temp}-40^{\circ} \mathrm{C}\end{array}$ & $\begin{array}{c}0.87 \\
\quad+/-0.02 \\
n=4\end{array}$ & $\begin{array}{c}0.73 \\
+/-0.006 \\
n=3\end{array}$ & $\begin{array}{c}0.70 \\
+/-0.01 \\
n=4\end{array}$ & $\begin{array}{r}0.63 \\
+/-0.02 \\
n=3\end{array}$ & $+1-0.03$ & $+1-0.03$ & $\begin{array}{ll}86 & \\
& +1-0.86\end{array}$ & $\begin{array}{l}107 \\
\quad+1-9.6\end{array}$ \\
\hline $\begin{array}{l}\mathrm{scCO}_{2}+\mathrm{IPA} \\
\mathrm{scCO}_{2}-10 \mathrm{ml} / \mathrm{min} \\
\text { solvent }-0.9 \mathrm{ml} / \mathrm{min} \\
\text { Temp - } 40^{\circ} \mathrm{C}\end{array}$ & $\begin{array}{c}0.85 \\
+/-0.01 \\
n=4\end{array}$ & $\begin{array}{c}0.72 \begin{array}{c} \\
+/-0.006 \\
n=3\end{array}\end{array}$ & $\begin{array}{c}0.67 \\
+/-0.02 \\
n=4\end{array}$ & $\begin{array}{r}0.53 \\
+/-0.01 \\
n=3\end{array}$ & 0.85 & $+1-0.03$ & $\begin{array}{l}74 \\
\end{array}+1-2.2$ & $\begin{array}{l}93 \\
+\mid-9.3\end{array}$ \\
\hline $\begin{array}{l}\mathrm{scCO}_{2}+\mathrm{IPA}+\mathrm{H}_{2} \mathrm{O} \\
\text { scCO }-10 \mathrm{ml} / \mathrm{min} \\
\text { solvent }-0.9 \mathrm{~m} / \mathrm{min} \\
\mathrm{H}_{2} \mathrm{O}-0.03 \mathrm{ml} / \mathrm{min} \\
\mathrm{Temp}-40^{\circ} \mathrm{C}\end{array}$ & $\begin{array}{c}0.84 \\
+/-0.02 \\
n=4\end{array}$ & 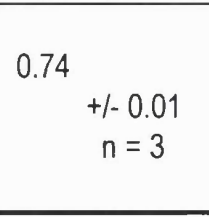 & $\begin{array}{c}0.64 \\
+/-0.01 \\
n=4\end{array}$ & $\begin{array}{c}0.34 \\
+/-0.02 \\
n=3\end{array}$ & $\begin{array}{lll}0.88 & +/-0.03\end{array}$ & 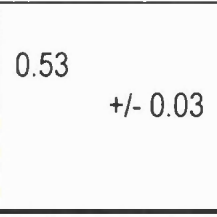 & $\begin{array}{ll}46 & \\
& +1.2 .3\end{array}$ & ${ }^{60}+1.6 .6$ \\
\hline
\end{tabular}

Table 4.2 - Results of stability tests carried out using freeze-dried D1.3Fv

The above table shows the results of stability tests carried out using freeze dried D1.3Fv. Freeze dried powders of D1.3Fv were loaded into the SEDS vessel and subjected to each of the conditions described above. All experiments were carried out at $40^{\circ} \mathrm{C}$. See Table 4.1 for explanation of presentation of results. 
Recovered activity yields are always lower than the recovered specific activity yields because there is some actual loss of product; that is, not everything is captured. The specific activity values only take into account losses in product incurred during SEDS processing due to denaturation and other mechanisms of loss of activity.

The protein recovery seen for all the SEDS runs detailed in Table 4.1 ranges from $84-92 \%$. This loss can be accounted for in a number of ways. Some product may be lost during a SEDS run by being swept out of the SEDS vessel and into the solvent trap with the solvent and $\mathrm{scCO}_{2}$ that is being constantly removed from the drying vessel during each run. Further losses will be seen when the product is collected from the vessel. No matter how carefully the dried product is removed from the vessel some will be lost via spillage, attachment to the vessel walls or attachment to the filter papers that block the end of the drying vessel. In the cases where the antibody concentration was low this loss will have a greater impact on the protein recovery than in the cases where the antibody concentration was higher (see results obtained for the whole antibody CDP850, Table 4.14).

The next set of experiments carried out using D1.3Fv were designed to examine the stability of the dried product as it sits in the vessel during a SEDS run. This was looked at as the duration of a SEDS run can be quite long (up to several hours) which means that the powder that is formed at the beginning of a SEDS run can be sitting in the vessel for a substantial amount of time. During this time it will be subjected to conditions of high solvent, acidic $\mathrm{pH}$ and raised temperature. Freeze-dried formulations of D1.3Fv plus mannitol were placed in the vessel and the effect of the three different components involved in a SEDS runs examined. These runs were carried out at a temperature of $40^{\circ} \mathrm{C}$ using IPA as the solvent. These conditions were chosen as the previous SEDS runs indicated that out of all of the conditions looked at these were the most ideal for processing D1.3Fv. The results from these experiments showed that the freeze-dried powder did lose activity when it was exposed to the various components. When subjected to just $\mathrm{scCO}_{2}$ there is no damage caused to the dried antibody fragment. The same is true when the powder is exposed to $\mathrm{scCO}_{2}$ plus solvent, though there maybe some very slight loss in activity seen with these two components. However, the most striking result is seen when the freeze-dried antibody comes into contact with the $\mathrm{scCO}_{2} /$ solvent/water mix. In this case there was a $40 \%$ loss in specific activity, indicating that the presence of water has some damaging effect on the dried powder. This result also points to the fact that damage during a SEDS run could be caused in two stages, one perhaps occurring during the actual drying process, the other as the dried product sits in the vessel. Larger protein losses were seen during this set of experiments. This is due to a number of factors, during the loading of the dried powder into the vessel some product was lost and again during collection of the powder after the experiments further powder was lost. As only small amounts of powder were being packed into this vessel, these losses although small had significant impact on the protein yield. This is the most likely explanation of loss 
rather than the protein being dissolved during the experiment and being lost in the exit stream from the vessel.

It was not possible to investigate the effect of $\mathrm{scCO}_{2}$ and water as $\mathrm{scCO}_{2}$ and water are not miscible. Therefore the water would dissolve or wet the powder and the $\mathrm{scCO}_{2}$ would not be able to extract this water without the presence of a solvent. For similar reasons the effect of solvent and water could not be investigated as any dried powder packed into the vessel would be dissolved or become wet as the liquid streams passed through the vessel.

\subsection{D5Fab SEDS Experiments}

Tables 4.3 and 4.4 show the results of SEDS experiments that looked at the effect of temperature on SEDS processed 4D5Fab. The solvent in all of these experiments was IPA, this solvent was chosen as the SEDS runs detailed in the previous section had shown this to be the solvent that led to highest activity yield for D1.3Fv. Table 4.3 also shows the results of a SEDS run carried out without the addition of mannitol to the antibody solution. This was an inadvertent omission but it is a useful result in that it illustrates that mannitol as an excipient does not offer any stabilising or destabilising effects to the antibody fragment during a SEDS run.

Two sets of SEDS runs looking at temperature effect were carried out to test the reproducibility of the results. Table 4.5 compares the Specific Activities and Activity Yields obtained from the two sets of runs. It can be seen from this table that both sets of runs produced similar results. In both sets of experiments the runs performed at $40^{\circ} \mathrm{C}$ gave the highest recovered specific activity $(53 \%$ and $65 \%)$ whilst the $50^{\circ} \mathrm{C}$ runs gave the lowest activity yield (8\%, $11 \%$ and $11 \%)$. The $35^{\circ} \mathrm{C}$ SEDS runs yielded specific activity recoveries of $29 \%$ and $32 \%$. Interestingly the trend seen with the 4D5Fab SEDS runs mirrors that seen with the D1.3Fv temperature SEDS runs (Table 4.1); that a processing temperature of $40^{\circ} \mathrm{C}$ produces higher recovered specific activities than $35^{\circ} \mathrm{C}$. For both antibody fragments $50^{\circ} \mathrm{C}$ produced the lowest recovered specific activity values.

The results presented in Table 4.4 show higher protein losses ( $40 \%, 33 \%$ and $48 \%)$, than any of the other previous SEDS runs. This could be due to the fact that these SEDS runs were run for a shorter length of time (between 30 and 45 minutes shorter) than the previous SEDS runs and therefore less antibody solution was pumped into the system. Therefore any losses of material would have a greater influence on the protein recovery. 
Using a processing temperature of $40^{\circ} \mathrm{C}$ SEDS runs were carried out to examine the influence of solvent on SEDS processing of 4D5Fab. SEDS runs were carried out using methanol, ethanol and isopropanol. Again to test reproducibility two sets of experiments were carried out. The results of these are presented in Tables 4.6 and 4.7. The two sets of data show similar results. As with the D1.3Fv antibody fragment the SEDS runs using IPA as the solvent produce the highest specific activity recoveries ( $65 \%$ and $54 \%$ ). Methanol seems to cause the most damage during a SEDS runs with a low specific activity recovery being seen for these runs $(10 \%$ and $11 \%)$.

Table 4.8 shows the results of SEDS runs carried out using a different nozzle configuration. These runs were used to look at the effect of introducing the feed streams differently. Figure 2.1 shows a schematic diagram of the co-axial nozzle used for the SEDS process. In all the previous SEDS runs the antibody solution and solvent were mixed first before being mixed with the $\mathrm{scCO}_{2}$. The runs that were used to look at the influence of feed stream order mixed the antibody solution and $\mathrm{scCO}_{2}$ first. All of these runs were performed at $40^{\circ} \mathrm{C}$ and used IPA as the solvent. It is hard to draw any firm conclusion about the effect of nozzle configuration on the specific activities recovered. The run carried out with the standard nozzle tip of $200 \mu \mathrm{m}$ resulted in a specific activity of $72 \%$ which is slightly higher than the specific activities recovered from any of the other $40^{\circ} \mathrm{C} / \mathrm{IPA}$ SEDS. However, the run carried out using the new nozzle order plus the larger nozzle tip $(820 \mu \mathrm{m})$ produced a specific activity of $59 \%$ which is similar to the results seen for previous SEDS runs using $40^{\circ} \mathrm{C} / \mathrm{IPA}$ processing conditions. The use of a larger nozzle tip would not have been expected to cause additional damage to the antibody fragment, if it were expected to have any effect at all it would have been to reduce the damage seen. Also included in Table 4.8 are results of SEDS runs carried out using the original nozzle configuration but using the two different sets of flow-rates used for the SEDS experiments. These two runs were performed to illustrate that the two sets of flowrates chosen produce similar results (59\% and $62 \%$ specific activity recovery). 


\begin{tabular}{|c|c|c|c|c|c|c|c|c|}
\hline SEDS Expt & $\begin{array}{l}\text { Total Protein } \\
\text { In }(\mathrm{mg})\end{array}$ & $\begin{array}{l}\text { Total Fab In } \\
(\mathrm{mg})\end{array}$ & $\begin{array}{l}\text { Total Protein } \\
\text { Out (mg) }\end{array}$ & $\begin{array}{l}\text { Total Fab } \\
\text { Out (mg) }\end{array}$ & $\begin{array}{l}\text { Specific } \\
\text { Activity In } \\
\text { (mg/mg) }\end{array}$ & $\begin{array}{l}\text { Specific } \\
\text { Activity Out } \\
\text { (mg/mg) }\end{array}$ & $\begin{array}{l}\text { Activity } \\
\text { Yield \% }\end{array}$ & $\begin{array}{l}\text { \% Specific } \\
\text { Activity } \\
\text { Recovered }\end{array}$ \\
\hline $\begin{array}{l}\text { Temp - } 35^{\circ} \mathrm{C} \\
\text { Solvent - IPA } \\
\mathrm{scCO}_{2}-18 \mathrm{~m} / \mathrm{min} \\
\text { solvent }-1.5 \mathrm{~m} / \mathrm{min} \\
\text { 4D5Fab soln }-0.06 \mathrm{~m} / \mathrm{min}\end{array}$ & $\begin{array}{c}2.6 \\
+/-0.03 \\
n=3\end{array}$ & $\begin{array}{c}2.5 \\
+/-0.01 \\
n=8\end{array}$ & $\begin{array}{c}2.0 \\
+/-0.01 \\
n=4\end{array}$ & $\begin{array}{c}0.55 \\
+/-0.007 \\
n=8\end{array}$ & $\begin{array}{ll}0.96 & \\
& +/-0.04\end{array}$ & $\begin{array}{l}0.31+1-0.02 \\
\end{array}$ & 22 & ${ }^{29}+1.4$ \\
\hline $\begin{array}{l}\text { Temp - } 40^{\circ} \mathrm{C} \\
\text { Solvent - IPA } \\
\text { scCO }-18 \mathrm{~m} / / \mathrm{min} \\
\text { solvent }-1.5 \mathrm{~m} / \mathrm{min} \\
\text { 4D5Fab soln }-0.06 \mathrm{~m} / \mathrm{min}\end{array}$ & $\begin{array}{c}2.2 \\
+/-0.03 \\
n=3\end{array}$ & $\begin{array}{c}2.0 \\
+/-0.007 \\
n=8\end{array}$ & $\begin{array}{c}1.8 \\
+/-0.01 \\
n=4\end{array}$ & $\begin{array}{c}0.87 \\
+/-0.01 \\
n=8\end{array}$ & 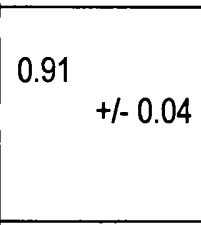 & 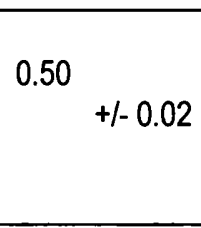 & $\begin{array}{l}44 \\
+1-2\end{array}$ & $\begin{array}{l}53 \\
+1.5\end{array}$ \\
\hline $\begin{array}{l}\text { Temp - } 50^{\circ} \mathrm{C} \\
\text { Solvent - IPA } \\
\text { scCO }-18 \mathrm{~m} / \mathrm{min} \\
\text { solvent }-1.5 \mathrm{~m} / / \mathrm{min} \\
\text { 4D5Fab soln }-0.06 \mathrm{~m} / \mathrm{min}\end{array}$ & $\begin{array}{c}3.0 \\
\quad+/-0.03 \\
n=3\end{array}$ & $\begin{array}{c}2.9 \\
+1-0.008 \\
n=6\end{array}$ & $\begin{array}{c}2.1 \\
\quad+/-0.01 \\
n=4\end{array}$ & $\begin{array}{l}0.15 \\
+1-0.003 \\
n=6\end{array}$ & $\begin{array}{l}0.95 \\
+/-0.04\end{array}$ & $\begin{array}{ll}0.07 & \\
& +/-0.02\end{array}$ & $\begin{array}{l}5 \\
+1.0 .2\end{array}$ & ${ }^{8}+1-0.9$ \\
\hline $\begin{array}{l}\text { Temp - } 50^{\circ} \mathrm{C} \text { (no } \\
\quad \text { mannitol) } \\
\text { Solvent - IPA } \\
\text { scCO }_{2}-18 \mathrm{ml} / \mathrm{min} \\
\text { solvent }-1.5 \mathrm{ml} / \mathrm{min} \\
\text { 4D5Fab soln }-0.06 \mathrm{ml} / \mathrm{min}\end{array}$ & $\begin{array}{ccc}3.0 & & \\
& +1-0.03 \\
& n=3\end{array}$ & $\begin{array}{c}2.7 \\
+1-0.008 \\
n=6\end{array}$ & $\begin{array}{c}2.2 \quad+/-0.01 \\
n=4\end{array}$ & $\begin{array}{r}0.22 \\
+1-0.004 \\
n=6\end{array}$ & $0.91+1-0.04$ & $\begin{array}{l}0.10+/-0.02 \\
\quad 02\end{array}$ & $8+1-0.3$ & ${ }^{11}+\mid-1.2$ \\
\hline
\end{tabular}

\section{Table 4.3 - Results of SEDS processing 4D5Fab, using IPA as the solvent and varying temperature}

This table details the results obtained from the SEDS processing of $4 D 5 F a b$ using IPA as the solvent and looking at the effect of temperature. Mannitol was inadvertently omitted from one of the runs $\left(50^{\circ} \mathrm{C}\right)$. The result of this run illustrates that the presence of mannitol does not appear to have any stabilizing or destabilizing effect. See Table 4.1 for explanation of presentation of results. 


\begin{tabular}{|c|c|c|c|c|c|c|c|c|}
\hline SEDS Expt & $\begin{array}{l}\text { Total } \\
\text { Protein In } \\
\text { (mg) } \\
\end{array}$ & $\begin{array}{l}\text { Total Fab In } \\
(\mathrm{mg})\end{array}$ & $\begin{array}{l}\text { Total Protein } \\
\text { Out }(\mathrm{mg})\end{array}$ & $\begin{array}{l}\text { Total Fab } \\
\text { Out (mg) }\end{array}$ & \begin{tabular}{|l|} 
Specific \\
Activity In \\
(mg/mg) \\
\end{tabular} & $\begin{array}{l}\text { Specific } \\
\text { Activity Out } \\
\text { (mg/mg) }\end{array}$ & $\begin{array}{l}\text { Activity } \\
\text { Yield \% }\end{array}$ & $\begin{array}{l}\text { \% Specific } \\
\text { Activity } \\
\text { Recovered }\end{array}$ \\
\hline $\begin{array}{l}\text { Temp - } 35^{\circ} \mathrm{C} \\
\text { Solvent }-\mathrm{IPA} \\
\mathrm{scCO}_{2}-18 \mathrm{~m} \mathrm{~m} / \mathrm{min} \\
\text { solvent }-1.5 \mathrm{~m} / \mathrm{min} \\
\text { 4D5Fab soln }-0.06 \mathrm{~m} / \mathrm{min}\end{array}$ & $\begin{array}{c}2.0 \\
+1-0.03 \\
n=3\end{array}$ & $\begin{array}{r}1.8 \\
+/-0.01 \\
n=18\end{array}$ & $\begin{array}{c}1.2 \\
+/-0.05 \\
n=4\end{array}$ & $\begin{array}{l}0.35 \\
+1-0.005 \\
n=15\end{array}$ & ${ }^{0.91}+1-0.04$ & $\begin{array}{l}0.29 \\
+/-0.01\end{array}$ & $19+1$ & $32+1-4$ \\
\hline $\begin{array}{l}\text { Temp - } 40^{\circ} \mathrm{C} \\
\text { Solvent - IPA } \\
\text { scCO }_{2}-18 \mathrm{~m} / / \mathrm{min} \\
\text { solvent }-1.5 \mathrm{~m} / / \mathrm{min} \\
\text { 4D5Fab soln }-0.06 \mathrm{~m} / \mathrm{min}\end{array}$ & $\begin{array}{c}2.1 \\
+/-0.02 \\
n=3\end{array}$ & $\begin{array}{r}1.8 \\
+/-0.01 \\
n=18\end{array}$ & $\begin{array}{cc}1.4 & \\
& +/-0.03 \\
& n=4\end{array}$ & $\begin{array}{l}0.78 \\
+/-0.003 \\
n=12\end{array}$ & ${ }^{0.86}+/-0.03$ & $\begin{array}{l}0.56 \\
+/-0.03\end{array}$ & $\begin{array}{ll}43 & \\
& +1-1\end{array}$ & $\begin{array}{ll}65 & \\
& +/ .5\end{array}$ \\
\hline $\begin{array}{l}\text { Temp - } 50^{\circ} \mathrm{C} \\
\text { Solvent - IPA } \\
\mathrm{scCO}_{2}-18 \mathrm{~m} / \mathrm{min} \\
\text { solvent - } 1.5 \mathrm{~m} / \mathrm{min} \\
4 \mathrm{D} 5 \mathrm{Fab} \text { soln }-0.06 \mathrm{~m} / \mathrm{min}\end{array}$ & $\begin{array}{c}1.7 \\
+1-0.03 \\
n=3\end{array}$ & $\begin{array}{r}1.4 \\
+/-0.01 \\
n=18\end{array}$ & $\begin{array}{cc}0.9 & \\
& +/-0.03 \\
& n=4\end{array}$ & $\begin{array}{l}0.08 \\
\quad+1-0.003 \\
n=12\end{array}$ & ${ }^{0.81}+1-0.04$ & ${ }^{0.09}+/-0.03$ & $\begin{array}{ll}6 & \\
& +1-0.4\end{array}$ & $11+\mid-2$ \\
\hline
\end{tabular}

Table 4.4 - Results of second set of SEDS processed 4D5Fab, using IPA as the solvent and varying temperature

The table above shows the results of a repeat set of the runs looking at the effect of temperature on SEDS processed 4D5Fab. All these experiments used IPA as the solvent. These results show the same trend as that seen in the first set of temperature experiments (Table 4.3). See Table 4.1 for explanation of presentation of results. 


\begin{tabular}{|c|c|c|c|c|}
\hline & Run 1 & & Run 2 & \\
\hline & Activity Yield \% & $\begin{array}{l}\text { \% Specific Activity } \\
\text { Recovered }\end{array}$ & Activity Yield \% & $\begin{array}{l}\text { \% Specific Activity } \\
\text { Recovered }\end{array}$ \\
\hline $\begin{array}{l}\text { Temp - } 35^{\circ} \mathrm{C} \\
\text { Solvent - IPA } \\
\text { scCO }_{2}-18 \mathrm{ml} / \mathrm{min} \\
\text { solvent }-1.5 \mathrm{ml} / \mathrm{min} \\
\text { 4D5Fab sol }-0.06 \mathrm{~m} / / \mathrm{min}\end{array}$ & $22+/-1$ & $29+1-4$ & $19+/-1$ & $32+/-4$ \\
\hline $\begin{array}{l}\text { Temp - } 40^{\circ} \mathrm{C} \\
\text { Solvent - IPA } \\
\text { scCO }_{2}-18 \mathrm{~m} / / \mathrm{min} \\
\text { solvent }-1.5 \mathrm{~m} / \mathrm{min} \\
\text { 4D5Fab soln }-0.06 \mathrm{ml} / \mathrm{min}\end{array}$ & $44+/-1$ & $53+1-5$ & $43+1-1$ & $65+/-5$ \\
\hline $\begin{array}{l}\text { Temp - } 50^{\circ} \mathrm{C} \\
\text { Solvent - IPA } \\
\text { scCO }_{2}-18 \mathrm{~m} / / \mathrm{min} \\
\text { solvent }-1.5 \mathrm{~m} / / \mathrm{min} \\
\text { 4D5Fab soln }-0.06 \mathrm{ml} / \mathrm{min}\end{array}$ & $5+1-0.2$ & $8+/-0.9$ & $6+1-0.4$ & $11+/-2$ \\
\hline $\begin{array}{l}\text { Temp - } 50^{\circ} \mathrm{C} \text { (no mannitol) } \\
\text { Solvent - IPA } \\
\text { scCO }_{2}-18 \mathrm{~m} / \mathrm{min} \\
\text { solvent }-1.5 \mathrm{~m} / \mathrm{min} \\
\text { 4D5Fab sol }-0.06 \mathrm{~m} / \mathrm{min}\end{array}$ & $8+/-0.3$ & $11+/-1$ & & \\
\hline
\end{tabular}

Table 4.5- Comparison of activity yields and specific activities recovered from 4D5Fab SEDS temperature experiments

This table shows a comparison of the activity yields and specific activities recovered from the two sets of temperature experiments. It can be seen that they both produce similar results and the same overall trend. A processing temperature of $40^{\circ} \mathrm{C}$ gives the highest activity yield. See Table 4.1 for explanation of presentation of results. 


\begin{tabular}{|c|c|c|c|c|c|c|c|c|}
\hline SEDS Expt & $\begin{array}{l}\text { Total Protein } \\
\ln (\mathrm{mg})\end{array}$ & $\begin{array}{l}\text { Total Fab ln } \\
\text { (mg) }\end{array}$ & $\begin{array}{l}\text { Total Protein } \\
\text { Out (mg) }\end{array}$ & $\begin{array}{l}\text { Total Fab } \\
\text { Out (mg) }\end{array}$ & $\begin{array}{l}\text { Specific } \\
\text { Activity In } \\
\text { (mg/mg) }\end{array}$ & $\begin{array}{l}\text { Specific } \\
\text { Activity Out } \\
\text { (mg/mg) }\end{array}$ & $\begin{array}{l}\text { Activity } \\
\text { Yield \% }\end{array}$ & $\begin{array}{l}\text { \% Specific } \\
\text { Activity } \\
\text { Recovered }\end{array}$ \\
\hline $\begin{array}{l}\text { Solvent }-\mathrm{MeOH} \\
\text { Temp }-40^{\circ} \mathrm{C} \\
\mathrm{scCO}_{2}-18 \mathrm{~m} / \mathrm{min} \\
\text { solvent }-1.5 \mathrm{~m} / \mathrm{min} \\
4 \mathrm{D} 5 \mathrm{Fab} \text { soln }-0.06 \mathrm{~m} / \mathrm{min}\end{array}$ & $\begin{array}{c}2.3 \\
+1-0.03 \\
n=3\end{array}$ & $\begin{array}{c}1.9 \\
+/-0.01 \\
n=8\end{array}$ & $\begin{array}{c}1.9 \\
+/-0.02 \\
n=3\end{array}$ & $\begin{array}{c}0.16 \\
+/-0.007 \\
n=8\end{array}$ & $\begin{array}{l}0.82 \\
+1-0.04\end{array}$ & $\begin{array}{l}0.08+1-0.03 \\
0\end{array}$ & ${ }^{8}+/-1$ & ${ }^{10}+1-2$ \\
\hline $\begin{array}{l}\text { Solvent - EtOH } \\
\text { Temp }-40^{\circ} \mathrm{C} \\
\text { scCO }_{2}-18 \mathrm{~m} / \mathrm{min} \\
\text { solvent }-1.5 \mathrm{~m} / \mathrm{min} \\
4 \mathrm{D} 5 \mathrm{Fab} \text { sol }-0.06 \mathrm{~m} / \mathrm{min}\end{array}$ & $\begin{array}{c}2.2 \\
+/-0.03 \\
n=3\end{array}$ & $\begin{array}{c}2.0 \\
+/-0.007 \\
n=8\end{array}$ & $\begin{array}{c}1.85 \\
+/-0.01 \\
n=3\end{array}$ & $\begin{array}{c}0.3 \\
+/-0.001 \\
n=8\end{array}$ & $\begin{array}{r}0.91 \\
+/-0.04\end{array}$ & $\begin{array}{l}0.16 \\
+/-0.01\end{array}$ & $\begin{array}{l}15 \\
+/-1\end{array}$ & $\begin{array}{l}18 \\
+/-2\end{array}$ \\
\hline $\begin{array}{l}\text { Solvent - Acetone } \\
\text { Temp }-40^{\circ} \mathrm{C} \\
\text { scCO }_{2}-18 \mathrm{~m} / / \mathrm{min} \\
\text { solvent }-1.5 \mathrm{~m} / / \mathrm{min} \\
4 \mathrm{D} 5 \mathrm{Fab} \text { sol }-0.06 \mathrm{~m} / \mathrm{min}\end{array}$ & $\begin{array}{c}2.3 \\
+/-0.03 \\
n=3\end{array}$ & $\begin{array}{c}1.9 \begin{array}{c} \\
+/-0.008 \\
n\end{array}=6\end{array}$ & $\begin{array}{c}1.8 \\
+/-0.02 \\
n=3\end{array}$ & $\begin{array}{l}0.15 \\
\quad+/-0.002 \\
n=6\end{array}$ & $\stackrel{0.82}{+1-0.04}$ & $\stackrel{0.08}{+1-0.02}$ & ${ }^{8}+1-0.2$ & ${ }^{10}+\mid-1$ \\
\hline $\begin{array}{l}\text { Solvent - IPA } \\
\text { Temp }-40^{\circ} \mathrm{C} \\
\text { scCO }_{2}-18 \mathrm{~m} / / \mathrm{min} \\
\text { solvent }-1.5 \mathrm{~m} / \mathrm{min} \\
4 \mathrm{D} 5 \mathrm{Fab} \text { sol }-0.06 \mathrm{~m} / \mathrm{min}\end{array}$ & $\begin{array}{c}2.1 \\
\quad+/-0.03 \\
n=3\end{array}$ & $\begin{array}{c}2.0 \\
\quad+1-0.008 \\
n=6\end{array}$ & $\begin{array}{c}1.9 \\
+/-0.02 \\
n=3\end{array}$ & $\begin{array}{r}1.2 \\
+/-0.001 \\
n=6\end{array}$ & $\begin{array}{l}0.95 \\
+/-0.04\end{array}$ & $\begin{array}{l}0.63 \\
+1-0.03\end{array}$ & $\begin{array}{l}60 \\
+1-1.4\end{array}$ & $\begin{array}{l}66 \\
\quad+1-2\end{array}$ \\
\hline
\end{tabular}

Table 4.6 - Results of SEDS runs carried out to investigate the effect of solvent on 4D5Fab

This table shows the results obtained from the SEDS runs carried out to look at the effect of solvent on SEDS processing of 4D5Fab. From the temperature experiments $40^{\circ} \mathrm{C}$ seemed to be the ideal SEDS processing temperature for 4D5Fab so this temperature was used and the solvent varied. See Table 4.1 for explanation of presentation of results. 


\begin{tabular}{|c|c|c|c|c|c|c|c|c|}
\hline SEDS Expt & $\begin{array}{l}\text { Total Protein } \\
\ln (\mathrm{mg})\end{array}$ & $\begin{array}{l}\text { Total Fab In } \\
\text { (mg) }\end{array}$ & $\begin{array}{l}\text { Total Protein } \\
\text { Out (mg) }\end{array}$ & $\begin{array}{l}\text { Total Fab } \\
\text { Out (mg) }\end{array}$ & $\begin{array}{l}\text { Specific } \\
\text { Activity In } \\
\text { (mg/mg) }\end{array}$ & $\begin{array}{l}\text { Specific } \\
\text { Activity Out } \\
\text { (mg/mg) }\end{array}$ & $\begin{array}{l}\text { Activity } \\
\text { Yield \% }\end{array}$ & $\begin{array}{l}\text { \% Specific } \\
\text { Activity } \\
\text { Recovered }\end{array}$ \\
\hline $\begin{array}{l}\text { Solvent - MeOH } \\
\text { Temp - 40 } 40 \\
\text { scCO }_{2}-18 \mathrm{~m} / / \mathrm{min} \\
\text { solvent - } 1.5 \mathrm{ml} / \mathrm{min} \\
4 \mathrm{D} 5 \mathrm{Fab} \text { soln }-0.06 \mathrm{~m} / / \mathrm{min}\end{array}$ & $\begin{array}{c}2.0 \\
\quad+l-0.02 \\
n=3\end{array}$ & $\begin{array}{c}1.7 \\
+/-0.009 \\
n=10\end{array}$ & $\begin{array}{c}1.7 \\
\quad+/-0.02 \\
n=3\end{array}$ & $\begin{array}{c}0.16 \\
+/-0.02 \\
n=8\end{array}$ & $\begin{array}{l}0.85 \\
+/-0.03\end{array}$ & ${ }^{0.09}+1-0.04$ & ${ }^{9}+1-0.8$ & ${ }^{11}+1-2$ \\
\hline $\begin{array}{l}\text { Solvent - EtOH } \\
\text { Temp - 40 } \\
\text { scCO }-18 \mathrm{~m} / / \mathrm{min} \\
\text { solvent }-1.5 \mathrm{~m} / / \mathrm{min} \\
\text { 4D5Fab soln }-0.06 \mathrm{~m} / / \mathrm{min}\end{array}$ & $\begin{array}{cc}2.1 & \\
& +/-0.02 \\
& n=3\end{array}$ & $\begin{array}{c}1.8 \\
+1-0.007 \\
n=8\end{array}$ & $\begin{array}{c}1.9 \\
+/-0.02 \\
n=3\end{array}$ & $\begin{array}{cc}0.4 & \\
& +/-0.01 \\
& n=8\end{array}$ & $\stackrel{0.86}{+1-0.03}$ & ${ }^{0.22}+1-0.03$ & ${ }^{22}+1-1$ & $\begin{array}{l}25 \\
+1-3\end{array}$ \\
\hline $\begin{array}{l}\text { Solvent - Acetone } \\
\text { Temp }-40^{\circ} \mathrm{C} \\
\mathrm{scCO}_{2}-18 \mathrm{~m} / \mathrm{min} \\
\text { solvent }-1.5 \mathrm{~m} / \mathrm{min} \\
4 \mathrm{D} 5 \mathrm{Fab} \text { sol }-0.06 \mathrm{ml} / \mathrm{min}\end{array}$ & $\begin{array}{c}2.1 \\
\quad+/-0.01 \\
n=3\end{array}$ & $\begin{array}{cc}1.7 & \\
& +/-0.01 \\
& n=8\end{array}$ & $\begin{array}{c}1.9 \\
+/-0.02 \\
n=3\end{array}$ & $\begin{array}{l}0.2 \\
+/-0.02 \\
n=8\end{array}$ & $\begin{array}{l}0.81 \\
+/-0.02\end{array}$ & ${ }^{0.11}+1-0.04$ & ${ }^{12}+\mid-1$ & $\stackrel{13}{+1-2}$ \\
\hline $\begin{array}{l}\text { Solvent - IPA } \\
\text { Temp - 40 } \\
\text { scCO }-18 \mathrm{~m} / \mathrm{min} \\
\text { solvent }-1.5 \mathrm{~m} / / \mathrm{min} \\
\text { 4D5Fab sol }-0.06 \mathrm{~m} / / \mathrm{min}\end{array}$ & $\begin{array}{c}2.0 \\
\quad+1-0.02 \\
n=3\end{array}$ & 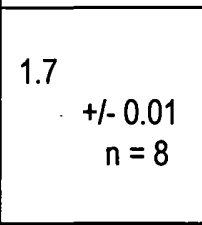 & $\begin{array}{c}1.8 \\
+/-0.02 \\
n=3\end{array}$ & $\begin{array}{r}0.98 \\
+1-0.003 \\
n=8\end{array}$ & $\stackrel{0.85}{+1-0.03}$ & ${ }^{0.54}+1-0.02$ & ${ }^{58}+1-2$ & $\begin{array}{l}64 \\
+1-6\end{array}$ \\
\hline
\end{tabular}

Table 4.7 - Results obtained from second set of SEDS runs carried out to investigate the effect of solvent on 4D5Fab

This table shows the results obtained from the second set of SEDS runs carried out to look at the effect of solvent on SEDS processing of 4D5Fab. From the temperature experiments

$40^{\circ} \mathrm{C}$ seemed to be the ideal SEDS processing temperature for $4 D 5 F a b$ so this temperature was used and the solvent varied. See Table 4.1 for explanation of presentation of results. 


\begin{tabular}{|c|c|c|c|c|c|c|c|c|}
\hline SEDS EXPT & $\begin{array}{l}\text { Total Protein } \\
\ln (\mathrm{mg})\end{array}$ & $\begin{array}{l}\text { Total Fab In } \\
\text { (mg) }\end{array}$ & $\begin{array}{l}\text { Total Protein } \\
\text { Out (mg) }\end{array}$ & $\begin{array}{l}\text { Total Fab Out } \\
\text { (mg) }\end{array}$ & $\begin{array}{l}\text { Specific } \\
\text { Activity In } \\
\text { (mg/mg) }\end{array}$ & $\begin{array}{l}\text { Specific } \\
\text { Activity Out } \\
\text { (mg/mg) }\end{array}$ & $\begin{array}{l}\text { Activity Yield } \\
\%\end{array}$ & $\begin{array}{l}\% \text { Specific } \\
\text { Activity } \\
\text { Recovered }\end{array}$ \\
\hline $\begin{array}{l}\text { Temp - } 40^{\circ} \mathrm{C} \\
\text { Solvent - IPA } \\
\text { New nozzle configuration } \\
\text { normal nozzle tip - 200 } \mathrm{\mu m} \\
\text { scCO }-18 \mathrm{~m} / \mathrm{min} \\
\text { solvent }-1.5 \mathrm{~m} / / \mathrm{min} \\
\text { 4D5Fab sol }-0.06 \mathrm{~m} / / \mathrm{min}\end{array}$ & $\begin{array}{c}2.4 \\
\quad+-0.02 \\
n=3\end{array}$ & $\begin{array}{r}1.6 \\
H-0.01 \\
n=18\end{array}$ & $\begin{array}{c}2.1 \\
\quad+-0.03 \\
n=4\end{array}$ & $\begin{array}{l}1.0 \\
\quad H-0.01 \\
n=15\end{array}$ & $\begin{array}{l}0.66 \\
H-0.03\end{array}$ & ${ }^{0.48}+-0.04$ & ${ }^{63}+1-4$ & ${ }^{72}+1-9$ \\
\hline $\begin{array}{l}\text { Temp - } 40^{\circ} \mathrm{C} \\
\text { Solvent - IPA } \\
\text { New nozzle configuration } \\
\text { larger nozzle tip - 820 } \mu \mathrm{m} \\
\text { scCO }-18 \mathrm{~m} / \mathrm{min} \\
\text { solvent }-1.5 \mathrm{~m} / \mathrm{min} \\
4 \mathrm{D} 5 \mathrm{Fab} \text { sol }-0.06 \mathrm{~m} / \mathrm{min} \\
\end{array}$ & $\begin{array}{c}2.4 \\
\quad+-0.02 \\
n=3\end{array}$ & $\begin{array}{r}1.5 \\
H-0.01 \\
n=18\end{array}$ & $\begin{array}{c}2.3 \\
\quad+0.02 \\
n=4\end{array}$ & $\begin{array}{r}0.84 \\
\quad H-0.005 \\
\quad n=15\end{array}$ & $\begin{array}{l}0.62 \\
+1-0.03\end{array}$ & ${ }^{0.37}+-0.03$ & ${ }^{56}+1-4$ & $\begin{array}{l}59 \\
+1-10\end{array}$ \\
\hline 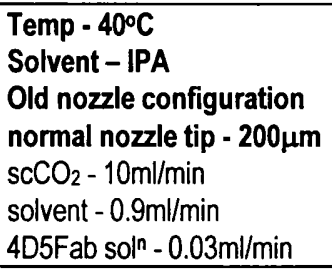 & $\begin{array}{c}2.2 \\
\quad+/-0.03 \\
n=3\end{array}$ & $\begin{array}{c}2.0 \\
H-0.007 \\
n=8\end{array}$ & $\begin{array}{c}2.0 \\
\quad+0.01 \\
n=4\end{array}$ & $\begin{array}{r}1.1 \\
+-0.01 \\
n=8\end{array}$ & $\stackrel{0.92}{+1-0.04}$ & ${ }^{0.54}+1-0.02$ & ${ }^{55}+1-3$ & ${ }^{59}+\mid-7$ \\
\hline 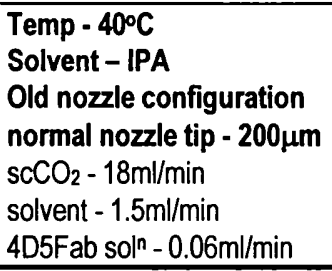 & $\begin{array}{c}2.4 \\
\quad+-0.03 \\
n=3\end{array}$ & $\begin{array}{r}1.8 \\
+-0.01 \\
n=18\end{array}$ & $\begin{array}{c}2.0 \\
\quad+0.03 \\
n=4\end{array}$ & $\begin{array}{r}0.95 \\
\quad H-0.003 \\
n=12\end{array}$ & $\begin{array}{l}0.75 \\
+1-0.03\end{array}$ & $\begin{array}{l}0.47 \\
+1-0.03\end{array}$ & ${ }^{53}+1-3$ & $62+1-10$ \\
\hline
\end{tabular}

\section{Table 4.8 - Results of SEDS runs using different nozzle configurations}

The above table details the results obtained from the SEDS experiments using a different nozzle configuration. In these runs the $4 D 5 F a b$ solution mixed with the $\mathrm{scCO}_{2}$ first then with the solvent. IPA was used as the solvent and $40^{\circ} \mathrm{C}$ as the processing temperature. Three of the runs detailed above used the standard size nozzle tip (200 $\left.\mu \mathrm{m}\right)$ and one used a larger nozzle tip $(820 \mu \mathrm{m})$. Also from this table we can compare SEDS runs carried out at different flow-rates. See Table 4.1 for explanation of presentation of results. 
Three sets of runs were carried out to look at the stability of freeze-dried formulations of 4D5Fab in the SEDS vessel. The data from these runs is shown in Tables $4.9-4.11$. A comparison of the Specific Activities and Activity Yields is given in Table 4.12. These runs were designed, as with the D1.3Fv stability runs, to try and establish the effect of the processing conditions on the powder of it sitting in the SEDS vessel once dried. They were also designed to test the reproducibility of these experiments.

A third set of runs was carried out as the results from the second set of runs differed quite substantially from the first set of runs. The results from the third set of runs concurred with those obtained from the first set. The difference in the second set could be due to experimental error, some difficulties were being experienced with the $\mathrm{CO}_{2}$ pump and this may explain the discrepancies.

The results from runs 1 and 3 (Tables 4.9 and 4.11) show that when subjected to either just $\mathrm{scCO}_{2}$ or $\mathrm{scCO}_{2}$ plus solvent then the antibody fragment powder remained undamaged and there was no loss of activity seen. The results from run 2 (Table 4.10 ) differ from the other two runs as there was some loss of antibody activity seen after exposure to $\mathrm{scCO}_{2}, 17 \%$ loss and $\mathrm{scCO}_{2} /$ solvent, $23 \%$ loss. When the third component, water, was added to the mix then loss of activity was seen in all runs. With runs 1 and 3 less damage was seen, $38 \%$ and $23 \%$ respectively than with the second run where a $47 \%$ loss was seen.

The results of these stability experiments concur with the results of the same experiments carried out using the D1.3Fv antibody fragment and again implicate water as the major damaging component of the dried powder as it sits in the SEDS vessel. 


\begin{tabular}{|c|c|c|c|c|c|c|c|c|}
\hline $\begin{array}{l}\text { Freeze Dried Fab } \\
\text { Plus }\end{array}$ & $\begin{array}{l}\text { Total Protein } \\
\ln (\mathrm{mg})\end{array}$ & $\begin{array}{l}\text { Total Fab In } \\
\text { (mg) }\end{array}$ & $\begin{array}{l}\text { Total Protein } \\
\text { Out (mg) }\end{array}$ & $\begin{array}{l}\text { Total Fab Out } \\
\text { (mg) }\end{array}$ & \begin{tabular}{|l|} 
Specific \\
Activity In \\
(mg/mg)
\end{tabular} & $\begin{array}{l}\text { Specific } \\
\text { Activity Out } \\
\text { (mg/mg) }\end{array}$ & $\begin{array}{l}\text { Activity Yield } \\
\%\end{array}$ & $\begin{array}{l}\text { \% Specific } \\
\text { Activity } \\
\text { Recovered }\end{array}$ \\
\hline $\begin{array}{l}\mathrm{scCO}_{2} \\
\mathrm{scCO}_{2}-10 \mathrm{ml} / \mathrm{min} \\
\mathrm{Temp}-40{ }^{\circ} \mathrm{C}\end{array}$ & $\begin{array}{c}2.9 \\
\quad+1-0.02 \\
n=3\end{array}$ & $\begin{array}{c}2.6 \\
+1-0.003 \\
n=9\end{array}$ & $\begin{array}{c}2.8 \\
+1-0.015 \\
n=4\end{array}$ & $\begin{array}{r}2.6 \\
+1-0.02 \\
n=9\end{array}$ & $\begin{array}{l}0.91 \\
+1-0.02\end{array}$ & $\stackrel{0.92}{+1-0.02}$ & $\begin{array}{l}98 \\
+1-0.5\end{array}$ & $\begin{array}{l}102 \\
+\mid-13\end{array}$ \\
\hline $\begin{array}{l}\mathrm{scCO}_{2}+\mathrm{IPA} \\
\text { scCO }-10 \mathrm{ml} / \mathrm{min} \\
\text { solvent }-0.9 \mathrm{ml} / \mathrm{min} \\
\text { Temp - } 40^{\circ} \mathrm{C}\end{array}$ & $\begin{array}{c}2.9 \\
+/-0.02 \\
n=3\end{array}$ & 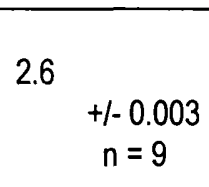 & $\begin{array}{c}2.5 \\
\quad+/-0.03 \\
n=4\end{array}$ & $\begin{array}{r}2.2 \\
+1-0.03 \\
n=8\end{array}$ & $\begin{array}{l}0.93 \\
+1-0.02\end{array}$ & ${ }^{0.87}+1-0.04$ & $84+1.8$ & ${ }^{94}+\mid-18$ \\
\hline $\begin{array}{l}\mathrm{scCO}_{2}+\mathrm{IPA}+\mathrm{H}_{2} \mathrm{O} \\
\text { scCO }-10 \mathrm{~m} / \mathrm{min} \\
\text { solvent }-0.9 \mathrm{~m} / \mathrm{min} \\
\mathrm{H}_{2} \mathrm{O}-0.03 \mathrm{~m} / / \mathrm{min} \\
\text { Temp - } 40^{\circ} \mathrm{C}\end{array}$ & $\begin{array}{c}2.8 \\
+/-0.02 \\
n=3\end{array}$ & 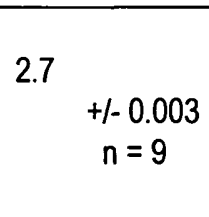 & $\begin{array}{cc}2.7 & \\
& +/-0.01 \\
& n=4\end{array}$ & $\begin{array}{c}1.6 \\
+/-0.005 \\
n=15\end{array}$ & $\stackrel{0.95}{+1-0.02}$ & $\stackrel{0.59}{+1-0.02}$ & $\begin{array}{l}60 \\
+\mid-1.8\end{array}$ & $\begin{array}{l}62 \\
+1-6\end{array}$ \\
\hline
\end{tabular}

\section{Table 4.9 - Results of stability tests carried out using freeze-dried 4D5Fab}

The above table shows the results of stability tests carried out using freeze-dried 4D5Fab. Freeze-dried powders of 4D5Fab were loaded into the SEDS vessel and subjected to each of the conditions described above. All experiments were carried out at $40^{\circ} \mathrm{C}$. See Table 4.1 for explanation of presentation of results. 


\begin{tabular}{|c|c|c|c|c|c|c|c|c|}
\hline $\begin{array}{l}\text { Freeze Dried Fab } \\
\text { Plus }\end{array}$ & $\begin{array}{l}\text { Total Protein } \\
\text { In (mg) }\end{array}$ & $\begin{array}{l}\text { Total Fab In } \\
\text { (mg) }\end{array}$ & $\begin{array}{l}\text { Total Protein } \\
\text { Out (mg) }\end{array}$ & $\begin{array}{l}\text { Total Fab Out } \\
\text { (mg) }\end{array}$ & $\begin{array}{l}\text { Specific } \\
\text { Activity In } \\
\text { (mg/mg) }\end{array}$ & $\begin{array}{l}\text { Specific } \\
\text { Activity Out } \\
\text { (mg/mg) }\end{array}$ & $\begin{array}{l}\text { Actlvity Yield } \\
\%\end{array}$ & $\begin{array}{l}\text { \% Specific } \\
\text { Activity } \\
\text { Recovered }\end{array}$ \\
\hline $\begin{array}{l}\mathrm{scCO}_{2} \\
\mathrm{scCO}-10 \mathrm{~m} / / \mathrm{min} \\
\mathrm{Temp}-40^{\circ} \mathrm{C}\end{array}$ & $\begin{array}{c}1.0 \\
+/-0.01 \\
n=4\end{array}$ & $\begin{array}{c}0.86 \\
+1-0.006 \\
n=9\end{array}$ & $\begin{array}{c}0.9 \\
\quad+1-0.02 \\
n=4\end{array}$ & $\begin{array}{c}0.64 \\
\quad+1-0.003 \\
n=9\end{array}$ & $\begin{array}{l}0.86 \\
+/-0.02\end{array}$ & $\begin{array}{l}0.71+/-0.003 \\
\end{array}$ & ${ }^{75}+1-2$ & ${ }^{83}+1-8$ \\
\hline $\begin{array}{l}\mathrm{scCO}_{2}+\mathrm{IPA} \\
\mathrm{scCO}_{2}-10 \mathrm{ml} / \mathrm{min} \\
\text { solvent }-0.9 \mathrm{~m} 1 / \mathrm{min} \\
\text { Temp - } 40^{\circ} \mathrm{C}\end{array}$ & $\begin{array}{c}1.3 \\
+/-0.005 \\
n=4\end{array}$ & $\begin{array}{c}0.95 \\
+/-0.006 \\
n=9\end{array}$ & $\begin{array}{c}1.0 \\
+/-0.02 \\
n=4\end{array}$ & $\begin{array}{r}0.56 \\
+/-0.02 \\
n=9\end{array}$ & $\begin{array}{l}0.73 \\
+/-0.01\end{array}$ & $\begin{array}{l}0.56 \\
+/-0.04\end{array}$ & $\begin{array}{l}59 \\
+1-5\end{array}$ & $\begin{array}{l}77+1-10 \\
+\end{array}$ \\
\hline $\begin{array}{l}\mathrm{scCO}_{2}+\mathrm{IPA}+\mathrm{H}_{2} \mathrm{O} \\
\text { scCO }-10 \mathrm{~m} / / \mathrm{min} \\
\text { solvent }-0.9 \mathrm{~m} / \mathrm{min} \\
\mathrm{H}_{2} \mathrm{O}-0.03 \mathrm{ml} / \mathrm{min} \\
\text { Temp }-40^{\circ} \mathrm{C}\end{array}$ & $\begin{array}{c}1.2 \\
+/-0.005 \\
n=4\end{array}$ & 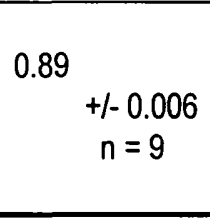 & $\begin{array}{c}1.1 \\
+/-0.01 \\
n=4\end{array}$ & $\begin{array}{c}0.43 \\
\quad+1-0.003 \\
n=9\end{array}$ & $\begin{array}{r}0.74 \\
+/-0.01\end{array}$ & $\begin{array}{l}0.39 \\
+/-0.01\end{array}$ & $\begin{array}{l}48 \\
+1-2\end{array}$ & $53+1-3$ \\
\hline
\end{tabular}

\section{Table 4.10 - Results of second set of stability tests carried out using freeze-dried 4D5Fab}

The above table shows the results of the second set of stability tests carried out using freeze-dried 4D5Fab. Freeze-dried powders of 4D5Fab were loaded into the SEDS vessel and subjected to each of the conditions described above. All experiments were carried out at $40^{\circ} \mathrm{C}$. See Table 4.1 for explanation of presentation of results. 


\begin{tabular}{|c|c|c|c|c|c|c|c|c|}
\hline $\begin{array}{l}\text { Freeze Dried Fab } \\
\text { Plus }\end{array}$ & $\begin{array}{l}\text { Total Protein } \\
\ln (\mathrm{mg})\end{array}$ & $\begin{array}{l}\text { Total Fab In } \\
\text { (mg) }\end{array}$ & $\begin{array}{l}\text { Total Protein } \\
\text { Out (mg) }\end{array}$ & $\begin{array}{l}\text { Total Fab Out } \\
\text { (mg) }\end{array}$ & $\begin{array}{l}\text { Specific } \\
\text { Activity ln } \\
\text { (mg/mg) }\end{array}$ & $\begin{array}{l}\text { Specific } \\
\text { Activity Out } \\
\text { (mg/mg) }\end{array}$ & $\begin{array}{l}\text { Activity Yield } \\
\%\end{array}$ & $\begin{array}{l}\text { \% Specific } \\
\text { Activity } \\
\text { Recovered }\end{array}$ \\
\hline $\begin{array}{l}\mathrm{scCO}_{2} \\
\mathrm{scCO}-10 \mathrm{~m} / / \mathrm{min} \\
\mathrm{Temp}-40^{\circ} \mathrm{C}\end{array}$ & 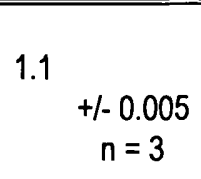 & $\begin{array}{c}0.85 \\
+/-0.03 \\
n=7\end{array}$ & $\begin{array}{c}1.0 \\
+/-0.02 \\
n=3\end{array}$ & $\begin{array}{r}0.8 \\
+1-0.03 \\
n=7\end{array}$ & ${ }^{0.77}+/-0.04$ & $\begin{array}{l}0.80 \\
+/-0.05\end{array}$ & $94+15$ & $\begin{array}{l}104 \\
+\mid-21\end{array}$ \\
\hline $\begin{array}{l}\mathrm{SCCO}_{2}+\mathrm{IPA} \\
\text { scCO} \\
\text { solvent }-10.9 \mathrm{~m} / \mathrm{min} / \mathrm{min} \\
\text { Temp - } 40^{\circ} \mathrm{C}\end{array}$ & 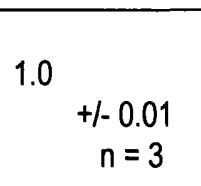 & $\begin{array}{c}0.85 \\
+1-0.03 \\
n=7\end{array}$ & $\begin{array}{c}0.9 \\
+1-0.005 \\
n=3\end{array}$ & $\begin{array}{r}0.7 \\
+1-0.02 \\
n=7\end{array}$ & $\begin{array}{l}0.81 \\
+/-0.04\end{array}$ & $\begin{array}{l}0.79+/-0.03 \\
\end{array}$ & $\begin{array}{l}79+13 \\
+13\end{array}$ & $\begin{array}{l}97 \\
+\mid-16\end{array}$ \\
\hline $\begin{array}{l}\mathrm{ScCO}_{2}+\mathrm{IPA}+\mathrm{H}_{2} \mathrm{O} \\
\text { scCO }-10 \mathrm{~m} / / \mathrm{min} \\
\text { solvent }-0.9 \mathrm{~m} / / \mathrm{min} \\
\mathrm{H}_{2} \mathrm{O}-0.03 \mathrm{~m} / / \mathrm{min} \\
\mathrm{Temp}-40^{\circ} \mathrm{C}\end{array}$ & $\begin{array}{c}1.1 \quad+-0.01 \\
n=3\end{array}$ & $\begin{array}{c}0.85 \\
+1-0.03 \\
n=7\end{array}$ & $\begin{array}{c}1.0 \\
+/-0.01 \\
n=3\end{array}$ & $\begin{array}{c}0.6 \\
+1-0.02 \\
n=6\end{array}$ & $\begin{array}{l}0.77+/-0.04 \\
\end{array}$ & $\begin{array}{l}0.59+1-0.03 \\
\end{array}$ & $\begin{array}{l}67+1-9 \\
+9\end{array}$ & $\begin{array}{l}77+14 \\
+14\end{array}$ \\
\hline
\end{tabular}

\section{Table 4.11 - Results of third set of stability tests carried out using freeze-dried 4D5Fab}

The above table shows the results of the third set of stability tests carried out using freeze-dried 4D5Fab. Freeze-dried powders of 4D5Fab were loaded into the SEDS vessel and subjected to each of the conditions described above. All experiments were camied out at $40{ }^{\circ} \mathrm{C}$. See Table 4.1 for explanation of presentation of results. 


\begin{tabular}{|l|l|l|l|l|l|l|}
\hline & Run 1 & & Run 2 & Run 3 & \\
\hline \hline & Activity Yield \% & $\begin{array}{l}\text { \% Specific Activity } \\
\text { Recovered }\end{array}$ & Activity Yield \% & $\begin{array}{l}\text { \% Specific Activity } \\
\text { Recovered }\end{array}$ & Activity Yield \% & $\begin{array}{l}\% \text { Specific } \\
\text { Activity } \\
\text { Recovered }\end{array}$ \\
\hline $\begin{array}{l}\mathrm{scCO} 2 \\
\mathrm{Temp}-40^{\circ} \mathrm{C}\end{array}$ & $98+/-0.5$ & $102+/-13$ & $75+/-2$ & $83+/-8$ & $94+/-15$ & $104+/-21$ \\
\hline $\begin{array}{l}\mathrm{scCO}+\mathrm{IPA} \\
\mathrm{Temp}-40^{\circ} \mathrm{C}\end{array}$ & $84+/-8$ & $94+/-18$ & $59+/-5$ & $77+/-10$ & $79+/-13$ & $97+/-16$ \\
\hline $\begin{array}{l}\mathrm{scCO}+\mathrm{IPA}+\mathrm{H}_{2} \mathrm{O} \\
\mathrm{Temp}-40^{\circ} \mathrm{C}\end{array}$ & $60+/-1.8$ & $62+/-6$ & $48+/-1.4$ & $53+/-3$ & $67+/-9$ & $77+/-14$ \\
\hline
\end{tabular}

Table 4.12 - Comparison of activity yields and specific activities recovered from 4D5Fab stability experiments

This table shows a comparison of the activity yields and specific activities recovered from the three sets of stability experiments. The data obtained for runs 1 and 3 are quite similar. However run 2 shows lower yields for all three conditions. This may be due to some experimental variation. 


\subsection{CDP850 SEDS Experiments}

As this antibody was available at much higher concentrations than the two antibody fragments this antibody was used to test the effect of antibody concentration on SEDS processing. Three different concentrations of CDP850 were used: $0.5 \mathrm{mg} / \mathrm{ml}, 5 \mathrm{mg} / \mathrm{ml}$ and $10 \mathrm{mg} / \mathrm{ml}$. The results shown in Table 4.13 indicate that concentration does not have a great deal of influence on the activity yields obtained after SEDS processing. The specific activities recovered were virtually the same for all three concentrations, $65 \%, 58 \%$ and $66 \%$. The repeat set of these SEDS runs yielded similar results, though the highest concentration run $(10 \mathrm{mg} / \mathrm{ml})$ gave a slightly higher recovered specific activity $(72 \%)$ this difference can be attributed to experimental differences and if the $+/$ - values are taken into account then the results of the two sets of runs agree with each other. This data again verifies the reproducibility of SEDS runs.

Higher levels of protein recovery, between 92 - $98 \%$, were seen with the higher concentration runs. This result fits in with the theory that with the experiments carried out using low concentrations of protein a small loss can have a great influence of recovery levels, whereas the same level of loss with a higher concentration of product will have less of a relative or proportional effect.

Stability runs were also carried out using CDP850. The first two sets of stability runs (Tables 4.15 and 4.16) were designed to look at the effect of concentration. One set was carried out using an antibody concentration of $0.5 \mathrm{mg} / \mathrm{ml}$ and the other $5 \mathrm{mg} / \mathrm{ml}$. A slightly different pattern emerged from these experiments compared to that seen for the two antibody fragments. In the case of the whole antibody some loss of specific activity was seen when the dried antibody was exposed to $\mathrm{scCO}_{2}$ alone. This loss was greater with the lower concentration of antibody, $21 \%$ compared to $10 \%$ for the higher concentration. Loss of specific activity was also seen after exposure to $\mathrm{scCO}_{2}$ and solvent. This time similar levels of loss were seen for both concentrations of antibody: $18 \%$ for $0.5 \mathrm{mg} / \mathrm{ml}$ antibody and $23 \%$ for $5 \mathrm{mg} / \mathrm{ml}$ antibody. As would be expected from the results of previous experiments the greatest levels of loss were seen when the powders were exposed to all three components. The losses seen then were: $39 \%$ for the lower concentration powder and $35 \%$ for the higher concentration one.

Once again for the stability experiments, higher levels of protein recovery were seen than for the SEDS experiments. This was not only due, in the one case to a higher concentration of protein being present but also due to an experimental modification. For these stability tests (and timed stability test detailed below) a special $1.5 \mathrm{ml}$ vessel was used which allowed for more accurate packing and unpacking of the powdered material, thus reducing losses of material.

Figure 4.1 shows graphically the results obtained from timed stability tests carried out using the whole antibody. These were designed to examine whether or not the length of time the dried product spends in 
the SEDS vessel has a bearing on the amount of activity lost. It can be seen from this graph that for all three conditions there is an initial loss over the first fifteen minutes of exposure, followed by no further loss. As with the previous stability tests carried out with the whole antibody damage occurs to varying degrees dependent of the component or combination of components that the antibody is being exposed too.

Although some level of damage is seen with $\mathrm{scCO}_{2}$ and $\mathrm{scCO}_{2} /$ solvent, the greatest level of damage was seen on addition of water. These results again suggest that the presence of water plays quite a significant role in the damage seen during a SEDS run.

\subsection{SEDS runs using PEG}

PEGylated antibodies and antibody fragments are thought to be more stable than normal antibodies and fragments (Peters et al, 1999). Also the addition of PEG to protein solution is often used as a stabiliser (Wong et al, 1997, Mahadevan et al, 1992, Bhat et al, 1992).

SEDS runs were carried out using the PEGylated form of the 4D5Fab fragment and also CDP850 with PEG 600 added to the antibody solution. The results of these are presented in Table 4.17. The specific activities recovered from the runs that used the PEG-4D5Fab yield similar values to those obtained with the non-PEGylated Fab: $59 \%$ and $54 \%$, suggesting that pegylation does not give the antibody any additional stability against the damage incurred during SEDS processing.

The SEDS runs carried out with the whole antibody with PEG600 added to the feed solution gave recovered specific activity values similar though perhaps slightly lower than those obtained from comparable SEDS runs carried out without the addition of PEG600. The runs using CDP850 at a concentration of $10 \mathrm{mg} / \mathrm{ml}$ with PEG600 present resulted in recovered specific activities of $66 \%$ and $69 \%$. SEDS runs without PEG present and CDP850 at $10 \mathrm{mg} / \mathrm{ml}$ yielded recovered specific activities of $76 \%$ and $66 \%$.

It would have been expected that the four runs detailed in Table 4.17 would have resulted in higher recovered specific activities due to the presence of PEG. However from these initial SEDS runs the addition of PEG or use of PEGylated antibody does not appear to improve the recovered specific activities obtained. 


\begin{tabular}{|c|c|c|c|c|c|c|c|c|}
\hline SEDS Expt & $\begin{array}{l}\text { Total Protein } \\
\ln (\mathrm{mg})\end{array}$ & $\begin{array}{l}\text { Total } \\
\text { CDP850 In } \\
\text { (mg) }\end{array}$ & $\begin{array}{l}\text { Total Protein } \\
\text { Out }(\mathrm{mg})\end{array}$ & $\begin{array}{l}\text { Total } \\
\text { CDP850 Out } \\
\text { (mg) }\end{array}$ & $\begin{array}{l}\text { Specific } \\
\text { Activity In } \\
\text { (mg/mg) }\end{array}$ & $\begin{array}{l}\text { Specific } \\
\text { Activity Out } \\
\text { (mg/mg) }\end{array}$ & $\begin{array}{l}\text { Activity } \\
\text { Yield \% }\end{array}$ & $\begin{array}{l}\% \text { Specific } \\
\text { Activity } \\
\text { Recovered }\end{array}$ \\
\hline $\begin{array}{l}\text { CDP850 Conc }=0.5 \mathrm{mg} / \mathrm{ml} \\
\text { Temp }-40^{\circ} \mathrm{C} \\
\text { Solvent }- \text { IPA } \\
\text { scCO }-10 \mathrm{~m} / / \mathrm{min} \\
\text { solvent }-0.9 \mathrm{~m} / \mathrm{min} \\
\text { CDP850 soln }-0.03 \mathrm{~m} / \mathrm{min}\end{array}$ & $\begin{array}{c}0.94 \\
+/-0.02 \\
n=4\end{array}$ & $\begin{array}{r}0.89 \\
+/-0.01 \\
n=16\end{array}$ & $\begin{array}{c}0.84 \\
+/-0.01 \\
n=4\end{array}$ & $\begin{array}{l}0.52 \\
+1-0.005 \\
n=14\end{array}$ & $\stackrel{0.94}{+/-0.03}$ & $\stackrel{0.62}{+1-0.02}$ & $\begin{array}{l}58 \\
+1-3\end{array}$ & $\begin{array}{l}65 \\
+/ 1.9\end{array}$ \\
\hline $\begin{array}{l}\text { CDP850 Conc }=5 \mathrm{mg} / \mathrm{ml} \\
\text { Temp }-40^{\circ} \mathrm{C} \\
\text { Solvent }-\mathrm{IPA} \\
\text { scCO }-10 \mathrm{~m} / / \mathrm{min} \\
\text { solvent }-0.9 \mathrm{~m} / \mathrm{min} \\
\text { CDP850 soln }-0.03 \mathrm{~m} / \mathrm{min}\end{array}$ & $\begin{array}{c}13.40 \\
+/-0.02 \\
n=4\end{array}$ & $\begin{array}{r}13.29 \\
+/-0.11 \\
n=12\end{array}$ & $\begin{array}{l}13.20 \\
+/-0.01 \\
n=4\end{array}$ & $\begin{array}{c}7.60 \\
+1-0.007 \\
n=8\end{array}$ & $\begin{array}{l}0.99 \\
+1-0.04\end{array}$ & ${ }^{0.58}+1-0.02$ & ${ }^{57}+1-3$ & $\begin{array}{l}58 \\
+1-8\end{array}$ \\
\hline $\begin{array}{l}\text { CDP850 Conc }=10 \mathrm{mg} / \mathrm{ml} \\
\text { Temp }-40^{\circ} \mathrm{C} \\
\text { Solvent }-\mathrm{IPA} \\
\text { scCO }-10 \mathrm{ml} / \mathrm{min} \\
\text { solvent }-0.9 \mathrm{~m} 1 / \mathrm{min} \\
\text { CDP850 soln }-0.03 \mathrm{ml} / \mathrm{min}\end{array}$ & $\begin{array}{c}22.80 \\
+1-0.01 \\
n=4\end{array}$ & $\begin{array}{r}20.55 \\
+/-0.01 \\
n=16\end{array}$ & $\begin{array}{c}21.42 \\
+1-0.005 \\
n=4\end{array}$ & $\begin{array}{l}12.78 \\
+1-0.006 \\
n=11\end{array}$ & $\begin{array}{l}0.90 \\
+1-0.02\end{array}$ & $\begin{array}{l}0.60 \\
+1-0.01\end{array}$ & $\begin{array}{l}62 \\
+1-5\end{array}$ & $\begin{array}{l}66 \\
+1.7\end{array}$ \\
\hline
\end{tabular}

Table 4.13 - Results obtained from SEDS processing a whole antibody, CDP850

This table details the results obtained from the SEDS processing of the whole antibody CDP850. As the results from the SEDS processing of $4 D 5 F a b$ indicated that IPA and 400 $\mathrm{C}$ were the process conditions that gave the highest yield of active antibody, these were chosen as the processing conditions for the initial runs using CDP850. CDP850 was available at higher concentrations than the antibody fragments so this was used to test the effect of concentration on SEDS processing. See Table 4.1 for explanation of presentation of results. 


\begin{tabular}{|c|c|c|c|c|c|c|c|c|}
\hline SEDS Expt & $\begin{array}{l}\text { Total Protein } \\
\ln (\mathrm{mg})\end{array}$ & $\begin{array}{l}\text { Total } \\
\text { CDP850 ln } \\
\text { (mg) }\end{array}$ & $\begin{array}{l}\text { Total Protein } \\
\text { Out }(\mathrm{mg})\end{array}$ & $\begin{array}{l}\text { Total } \\
\text { CDP850 Out } \\
\text { (mg) }\end{array}$ & $\begin{array}{l}\text { Specific } \\
\text { Activity ln } \\
\text { (mg/mg) }\end{array}$ & $\begin{array}{l}\text { Specific } \\
\text { Activity Out } \\
\text { (mg/mg) }\end{array}$ & $\begin{array}{l}\text { Activity } \\
\text { Yield \% }\end{array}$ & $\begin{array}{l}\% \text { Specific } \\
\text { Activity } \\
\text { Recovered }\end{array}$ \\
\hline $\begin{array}{l}\text { CDP850 Conc }=0.5 \mathrm{mg} / \mathrm{ml} \\
\text { Temp }-40^{\circ} \mathrm{C} \\
\text { Solvent }- \text { IPA } \\
\text { scCO }-10 \mathrm{ml} / \mathrm{min} \\
\text { solvent }-0.9 \mathrm{~m} 1 / \mathrm{min} \\
\text { CDP850 soln }-0.03 \mathrm{~m} / / \mathrm{min}\end{array}$ & $\begin{array}{c}1.10 \\
+/-0.02 \\
n=4\end{array}$ & $\begin{array}{c}0.97 \\
+/-0.009 \\
n=10\end{array}$ & $\begin{array}{c}0.91 \\
+/-0.02 \\
n=4\end{array}$ & $\begin{array}{c}0.52 \\
+1-0.007 \\
n=8\end{array}$ & $\begin{array}{l}0.88 \\
+/-0.03\end{array}$ & ${ }^{0.57}+1-0.03$ & $\begin{array}{l}54 \\
+1-3\end{array}$ & $\begin{array}{l}64 \\
+1-10\end{array}$ \\
\hline $\begin{array}{l}\text { CDP850 Conc }=5 \mathrm{mg} / \mathrm{ml} \\
\text { Temp }-40^{\circ} \mathrm{C} \\
\text { Solvent }-\mathrm{IPA} \\
\text { scCO }-10 \mathrm{~m} / \mathrm{min} \\
\text { solvent }-0.9 \mathrm{~m} 1 / \mathrm{min} \\
\text { CDP850 soln }-0.03 \mathrm{ml} / \mathrm{min}\end{array}$ & $\begin{array}{c}14.15 \\
\quad+/-0.02 \\
n=4\end{array}$ & $\begin{array}{c}13.98 \\
+1-0.006 \\
n=9\end{array}$ & $\begin{array}{l}13.81 \\
+/-0.01 \\
n=4\end{array}$ & $\begin{array}{r}7.90 \\
+/-0.03 \\
n=12\end{array}$ & $\begin{array}{l}0.99 \\
+/-0.03\end{array}$ & ${ }^{0.57}+/-0.02$ & ${ }^{56}+1-3$ & $\begin{array}{l}58 \\
+\mid-7\end{array}$ \\
\hline $\begin{array}{l}\text { CDP850 Conc }=10 \mathrm{mg} / \mathrm{ml} \\
\text { Temp }-40^{\circ} \mathrm{C} \\
\text { Solvent }- \text { IPA } \\
\text { scCO }-10 \mathrm{~m} / / \mathrm{min} \\
\text { solvent }-0.9 \mathrm{ml} / \mathrm{min} \\
\text { CDP850 soln }-0.03 \mathrm{ml} / \mathrm{min}\end{array}$ & $\begin{array}{c}20.50 \\
\quad+/-0.02 \\
n=4\end{array}$ & $\begin{array}{r}19.40 \\
+/-0.01 \\
n=10\end{array}$ & $\begin{array}{c}18.90 \\
\quad+/-0.02 \\
n=4\end{array}$ & $\begin{array}{r}13.60 \\
+/-0.01 \\
n=10\end{array}$ & $\begin{array}{l}0.95 \\
+1-0.03\end{array}$ & $\stackrel{0.72}{+/-0.03}$ & $\begin{array}{l}70 \\
+1-5\end{array}$ & $\begin{array}{l}76 \\
+/-11\end{array}$ \\
\hline
\end{tabular}

Table 4.14 - Results obtained from second set of SEDS processing experiments using a whole antibody, CDP850

This table details the results obtained from the second set of SEDS processing of the whole antibody CDP850. As the results from the SEDS processing for 4D5Fab indicated that IPA and $40^{\circ} \mathrm{C}$ were the process conditions that gave the highest yield of active antibody these were chosen as the processing conditions for the initial runs using CDP850. CDP850 was available at higher concentrations than the antibody fragments so this was used to test the effect of concentration on SEDS processing. See Table 4.1 for explanation of presentation of results. 


\begin{tabular}{|c|c|c|c|c|c|c|c|c|}
\hline $\begin{array}{l}\text { Freeze Dried } \\
\text { CDP850 } 0.5 \mathrm{mg} / \mathrm{ml} \\
\text { Plus }\end{array}$ & $\begin{array}{l}\text { Total Protein } \\
\text { In (mg) }\end{array}$ & $\begin{array}{l}\text { Total CDP850 } \\
\ln (\mathrm{mg})\end{array}$ & $\begin{array}{l}\text { Total Protein } \\
\text { Out (mg) }\end{array}$ & $\begin{array}{l}\text { Total CDP850 } \\
\text { Out }(\mathrm{mg})\end{array}$ & $\begin{array}{l}\text { Specific } \\
\text { Activity In } \\
\text { (mg/mg) }\end{array}$ & $\begin{array}{l}\text { Specific } \\
\text { Activity Out } \\
\text { (mg/mg) }\end{array}$ & $\begin{array}{l}\text { Activity Yield } \\
\%\end{array}$ & $\begin{array}{l}\text { \% Specific } \\
\text { Activity } \\
\text { Recovered }\end{array}$ \\
\hline $\begin{array}{l}\mathrm{scCO}_{2} \\
\mathrm{scCO}-10 \mathrm{~m} / / \mathrm{min} \\
\mathrm{Temp}-40^{\circ} \mathrm{C}\end{array}$ & $\begin{array}{c}0.99 \\
+/-0.005 \\
n=4\end{array}$ & $\begin{array}{r}0.92 \\
+/-0.02 \\
n=16\end{array}$ & $\begin{array}{c}0.94 \\
+/-0.03 \\
n=4\end{array}$ & $\begin{array}{r}0.69 \\
+/-0.002 \\
n=16\end{array}$ & $\begin{array}{l}0.93+/-0.02 \\
\end{array}$ & $\begin{array}{l}0.73+/-0.03\end{array}$ & ${ }^{75}+1-6$ & $\begin{array}{l}79 \\
+1-12\end{array}$ \\
\hline $\begin{array}{l}\mathrm{scCO}+\mathrm{IPA} \\
\mathrm{scCO}_{2}-10 \mathrm{ml} / \mathrm{min} \\
\text { solvent }-0.9 \mathrm{ml} / \mathrm{min} \\
\text { Temp - } 40^{\circ} \mathrm{C}\end{array}$ & $\begin{array}{c}0.99 \\
+/-0.005 \\
n=4\end{array}$ & $\begin{array}{r}0.92 \\
+/-0.02 \\
n=16\end{array}$ & $\begin{array}{c}0.84 \\
+/-0.02 \\
n=4\end{array}$ & $\begin{array}{r}0.64 \\
+1-0.006 \\
n=10\end{array}$ & $\begin{array}{l}0.93 \\
+/-0.02\end{array}$ & $\begin{array}{l}0.76+1-0.03\end{array}$ & $\begin{array}{l}70 \\
+1-6\end{array}$ & ${ }^{82}+1-12$ \\
\hline $\begin{array}{l}\mathrm{scCO}_{2}+\mathrm{IPA}+\mathrm{H}_{2} \mathrm{O} \\
\text { scCO }-10 \mathrm{ml} / \mathrm{min} \\
\text { solvent }-0.9 \mathrm{~m} / \mathrm{min} \\
\mathrm{H}_{2} \mathrm{O}-0.03 \mathrm{ml} / \mathrm{min} \\
\mathrm{Temp}-40^{\circ} \mathrm{C}\end{array}$ & $\begin{array}{c}0.99 \\
+/-0.005 \\
n=4\end{array}$ & $\begin{array}{r}0.92 \\
+/-0.02 \\
n=16\end{array}$ & $\begin{array}{c}0.92 \\
+/-0.02 \\
n=4\end{array}$ & $\begin{array}{c}0.52 \\
+/-0.01 \\
n=8\end{array}$ & $\begin{array}{l}0.93 \\
+/-0.02\end{array}$ & $\begin{array}{l}0.57+/-0.03 \\
\end{array}$ & $\begin{array}{l}57+1-6 \\
+\end{array}$ & ${ }^{61}+\mid-10$ \\
\hline
\end{tabular}

Table 4.15 - Results of stability tests carried out using freeze-dried CDP850 at $0.5 \mathrm{mg} / \mathrm{ml}$

The above table shows the results of stability tests carried out using freeze dried CDP850. CDP850 was used to examine whether or not concentration has an effect on the results obtained from the stability experiments. This experiment was carried out with CDP850 at a concentration of $0.5 \mathrm{mg} / \mathrm{ml}$. Freeze-dried powders of $4 D 5 F$ ab were loaded into the SEDS vessel and subjected to each of the conditions described above. All experiments were carried out at $40^{\circ} \mathrm{C}$. See Table 4.1 for explanation of presentation of results. 


\begin{tabular}{|c|c|c|c|c|c|c|c|c|}
\hline $\begin{array}{l}\text { Freeze Dried } \\
\text { CDP850 } 5 \mathrm{mg} / \mathrm{ml} \\
\text { Plus }\end{array}$ & $\begin{array}{l}\text { Total Protein } \\
\ln (\mathrm{mg})\end{array}$ & $\begin{array}{l}\text { Total CDP850 } \\
\ln (\mathrm{mg})\end{array}$ & $\begin{array}{l}\text { Total Protein } \\
\text { Out (mg) }\end{array}$ & $\begin{array}{l}\text { Total CDP850 } \\
\text { Out }(\mathrm{mg})\end{array}$ & $\begin{array}{l}\text { Specific } \\
\text { Activity In } \\
\text { (mg/mg) }\end{array}$ & $\begin{array}{l}\text { Specific } \\
\text { Activity Out } \\
\text { (mg/mg) }\end{array}$ & $\begin{array}{l}\text { Activity Yield } \\
\%\end{array}$ & $\begin{array}{l}\text { \% Specific } \\
\text { Activity } \\
\text { Recovered }\end{array}$ \\
\hline $\begin{array}{l}\mathrm{scCO}_{2} \\
\mathrm{scCO}_{2}-10 \mathrm{~m} / / \mathrm{min} \\
\mathrm{Temp}-40^{\circ} \mathrm{C}\end{array}$ & $\begin{array}{c}10.08 \\
+/-0.03 \\
n=4\end{array}$ & $\begin{array}{c}9.98 \\
+/-0.02 \\
n=8\end{array}$ & $\begin{array}{c}9.96 \\
+/-0.03 \\
n=4\end{array}$ & $\begin{array}{r}8.86 \\
+/-0.01 \\
n=8\end{array}$ & $\begin{array}{l}0.99+/-0.05 \\
\quad\end{array}$ & $\begin{array}{l}0.89 \\
+/-0.04\end{array}$ & $\begin{array}{l}88 \\
+1-6\end{array}$ & $\begin{array}{l}90 \\
+\mid-16\end{array}$ \\
\hline $\begin{array}{l}\mathrm{scCO}_{2}+\mathrm{IPA} \\
\text { scCO }-10 \mathrm{ml} / \mathrm{min} \\
\text { solvent }-0.9 \mathrm{~m} / / \mathrm{min} \\
\text { Temp - } 40^{\circ} \mathrm{C}\end{array}$ & $\begin{array}{c}11.08 \\
+l-0.02 \\
n=4\end{array}$ & $\begin{array}{c}10.58 \\
+/-0.02 \\
n=8\end{array}$ & $\begin{array}{c}10.89 \\
+/-0.01 \\
n=4\end{array}$ & $\begin{array}{r}8.04 \\
+1-0.006 \\
n=10\end{array}$ & $\begin{array}{l}0.96 \\
+1-0.04\end{array}$ & ${ }^{0.74}+/-0.02$ & $\begin{array}{l}76+1.4 \\
+\end{array}$ & $\begin{array}{l}77 \\
+/ 1 \\
\end{array}$ \\
\hline $\begin{array}{l}\mathrm{scCO}+\mathrm{IPA}+\mathrm{H}_{2} \mathrm{O} \\
\mathrm{scCO}-10 \mathrm{~m} / \mathrm{min} \\
\text { solvent }-0.9 \mathrm{~m} / \mathrm{min} \\
\mathrm{H}_{2} \mathrm{O}-0.03 \mathrm{~m} / \mathrm{min} \\
\text { Temp }-400^{\circ} \mathrm{C}\end{array}$ & $\begin{array}{c}10.08 \\
+/-0.02 \\
n=4\end{array}$ & $\begin{array}{c}10.00 \\
+l-0.02 \\
n=8\end{array}$ & $\begin{array}{c}9.98 \\
+/-0.02 \\
n=4\end{array}$ & $\begin{array}{c}6.80 \\
+1-0.01 \\
n=8\end{array}$ & $\begin{array}{l}0.91 \\
+/-0.04\end{array}$ & $\begin{array}{l}0.68 \\
+/-0.03\end{array}$ & $\begin{array}{l}68 \\
+1.5\end{array}$ & ${ }^{65}+1-11$ \\
\hline
\end{tabular}

\section{Table 4.16- Results of stability tests carried out using freeze-dried CDP850 at $5 \mathrm{mg} / \mathrm{ml}$}

The above table shows the results of stability tests carried out using freeze-dried CDP850. CDP850 was used to examine whether or not concentration has an effect on the results obtained from the stability experiments. This experiment was carried out with CDP850 at a concentration of $5 \mathrm{mg} / \mathrm{ml}$. Freeze-dried powders of 4D5Fab were loaded into the SEDS vessel and subjected to each of the conditions described above. All experiments were carried out at $40^{\circ} \mathrm{C}$. See Table 4.1 for explanation of presentation of results. 


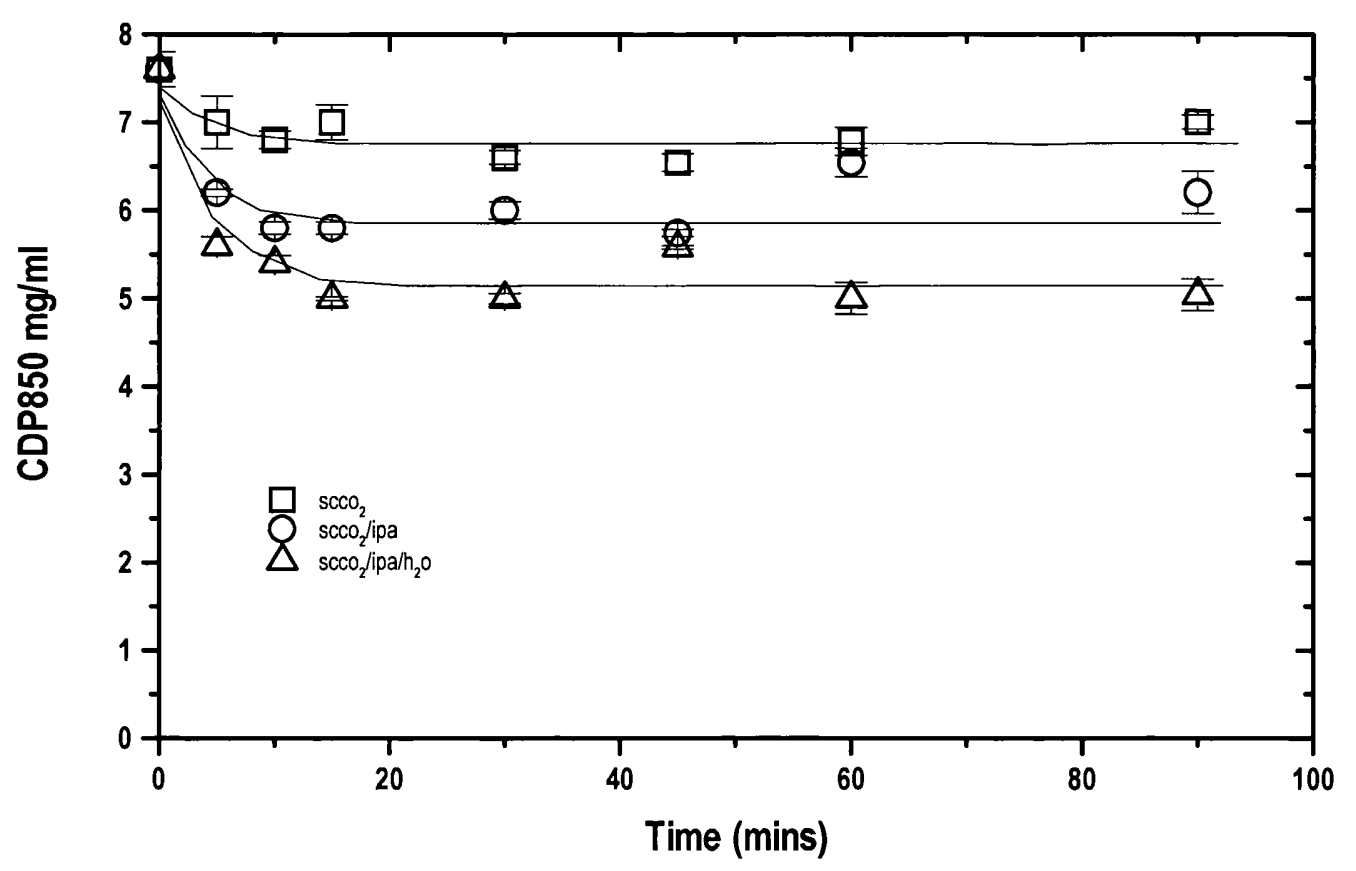

Figure 4.1 - Timed Stability Tests

Timed Stability Tests were carried out using the whole antibody CDP850. These were used to investigate whether the length of time the freeze-dried powder was subjected to the different conditions in the SEDS vessel had an effect on the loss of activity seen. The above graph shows the results of these tests. The points shown are mean values (where $n=9-12$ ) and the error bars show +/-standard deviation. 


\begin{tabular}{|c|c|c|c|c|c|c|c|c|}
\hline SEDS Expt & $\begin{array}{l}\text { Total Protein } \\
\ln (\mathrm{mg})\end{array}$ & $\begin{array}{l}\text { Total } \\
\text { Antibodyln } \\
\text { (mg) }\end{array}$ & $\begin{array}{l}\text { Total Protein } \\
\text { Out (mg) }\end{array}$ & $\begin{array}{l}\text { Total } \\
\text { Antibody Out } \\
\text { (mg) }\end{array}$ & $\begin{array}{l}\text { Specific } \\
\text { Activity ln } \\
\text { (mg/mg) }\end{array}$ & $\begin{array}{l}\text { Specific } \\
\text { Activity Out } \\
\text { (mg/mg) }\end{array}$ & $\begin{array}{l}\text { Activity } \\
\text { Yield \% }\end{array}$ & $\begin{array}{l}\text { \% Specific } \\
\text { Activity } \\
\text { Recovered }\end{array}$ \\
\hline $\begin{array}{l}\text { Peg-4D5Fab } \\
\text { scCO }_{2}-10 \mathrm{ml} / \mathrm{min} \\
\text { solvent }-0.9 \mathrm{ml} / \mathrm{min} \\
\text { PEG-4D5 Fab soln }-0.03 \mathrm{ml} / \mathrm{min}\end{array}$ & $\begin{array}{c}7.51 \\
+/-0.01 \\
n=4\end{array}$ & $\begin{array}{c}7.02 \\
+/-0.01 \\
n=8\end{array}$ & $\begin{array}{c}7.12 \\
+/-0.01 \\
n=4\end{array}$ & $\begin{array}{c}3.90 \\
+/-0.01 \\
n=8\end{array}$ & $\begin{array}{l}0.94+1-0.02 \\
\end{array}$ & $\begin{array}{l}0.55+1-0.02 \\
\end{array}$ & $\begin{array}{l}55 \\
+1-3\end{array}$ & $5^{59}+1-7$ \\
\hline $\begin{array}{l}\text { Peg-4D5Fab } \\
\text { scCO }-10 \mathrm{ml} / \mathrm{min} \\
\text { solvent - } 0.9 \mathrm{ml} / \mathrm{min} \\
\text { PEG-4D5 Fab soln }-0.03 \mathrm{~m} / \mathrm{min}\end{array}$ & $\begin{array}{r}6.10 \\
+/-0.01 \\
n=4\end{array}$ & $\begin{array}{c}5.76 \\
+/-0.01 \\
n=6\end{array}$ & $\begin{array}{c}5.71 \\
+/-0.01 \\
n=4\end{array}$ & $\begin{array}{c}1.72 \\
+1-0.004 \\
n=6\end{array}$ & 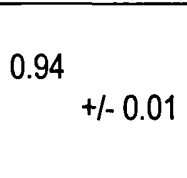 & 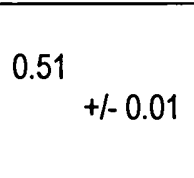 & $\begin{array}{l}51 \\
+/-2\end{array}$ & 54 \\
\hline $\begin{array}{l}\text { CDP850 }(10 \mathrm{mg} / \mathrm{ml})+\text { Peg }+ \text { Mannitol } \\
\text { scCO }-10 \mathrm{ml} / \mathrm{min} \\
\text { solvent }-0.9 \mathrm{ml} / \mathrm{min} \\
\text { CDP850 soln }-0.03 \mathrm{ml} / \mathrm{min}\end{array}$ & $\begin{array}{r}20.11 \\
+/=0.02 \\
n=4\end{array}$ & $\begin{array}{l}18.44 \\
+/-0.01 \\
n=6\end{array}$ & $\begin{array}{c}18.50 \\
+\mid-0.01 \\
n=4\end{array}$ & $\begin{array}{l}11.21 \\
\quad+1-0.008 \\
n=6\end{array}$ & $\begin{array}{l}0.92+1-0.02 \\
\end{array}$ & $\begin{array}{ll}0.61+1-0.02 \\
\end{array}$ & $\begin{array}{l}61 \\
+\mid-3\end{array}$ & $\begin{array}{l}66 \\
+1-8\end{array}$ \\
\hline $\begin{array}{l}\text { CDP850 }(10 \mathrm{mg} / \mathrm{ml})+\text { Peg }+ \text { Mannitol } \\
\text { scCO }-10 \mathrm{ml} / \mathrm{min} \\
\text { solvent }-0.9 \mathrm{~m} 1 / \mathrm{min} \\
\text { CDP850 soln }-0.03 \mathrm{ml} / \mathrm{min}\end{array}$ & $\begin{array}{r}51.2 \\
+1-0.02 \\
n=4\end{array}$ & $\begin{array}{l}49.10 \\
\quad+/-0.008 \\
\quad n=6\end{array}$ & $\begin{array}{c}43.81 \\
+/-0.02 \\
n=4\end{array}$ & $\begin{array}{l}28.88 \\
+/-0.008 \\
n=6\end{array}$ & $\begin{array}{l}0.96+1-0.03 \\
\end{array}$ & $\begin{array}{l}0.66+1-0.03 \\
\end{array}$ & $\begin{array}{l}59 \\
+/-2\end{array}$ & $\begin{array}{l}69 \\
+1-9\end{array}$ \\
\hline
\end{tabular}

Table 4.17 - Results of SEDS processing PEG-4D5Fab and CDP850 with PEG added to antibody solution

This table details the results obtained from the SEDS processing of 4D5PEG Fab and whole antibody CDP850 with PEG-600 added to the starting solution. See Table 4.1 for explanation of presentation of results. 


\section{CHAPTER FIVE}

\section{DISCUSSION AND FUTURE WORK}




\section{Discussion and Future Work}

\subsection{Introduction}

In this chapter the results presented in the Chapters 3 and 4 will be discussed. The overall conclusions drawn from this work will be presented, along with suggestions for future work and investigations.

\subsection{Discussion of Results from Preliminary Stability Studies}

\subsubsection{Temperature Experiments}

The results obtained for the temperature stability experiments carried out on D1.3Fv (Chapter 3) indicated that the effect of temperature on this antibody fragment is dependent on the concentration of antibody present. The lower the concentration of antibody present, the more susceptible it is to thermal damage. This result is consistent with previous studies which have demonstrated that proteins are more stable at high concentrations (Foster, 1994). Wong et al., (1997) found that the degradation kinetics for most proteins and peptides depend on protein concentration. It has also been shown that thermodynamic stability of $\mathrm{Fv}$ fragments is concentration dependent and increases with higher protein concentrations (Jäger et al., 1999). The lower the concentration of Fv the less stable it is. This is thought to be due to the lack of disulphide bonds in Fv fragments. In this type of antibody fragment the two component chains are held together non-covalently by three pairs of hydrophobic patches, therefore the two chains of the antibody are easily separated. The lower the concentration of antibody present the less likely the chains are to re-associate. At low concentrations $(0.1 \mu \mathrm{M})$, the Fv fragment becomes significantly destabilised, leading to domain dissociation prior to significant domain unfolding taking place (Jäger et al., 1999).

At higher concentrations the D1.3Fv was stable up to $60^{\circ} \mathrm{C}$. Therefore, if SEDS runs were carried out below $60^{\circ} \mathrm{C}$ and at high concentrations, the results of these experiments would predict that this antibody fragment would not suffer thermal damage whilst being processed using SEDS.

The 4D5Fab temperature experiments in Chapter 3 suggest that this antibody fragment is more thermally stable than the $\mathrm{D} 1.3 \mathrm{Fv}$ fragment. $4 \mathrm{D} 5 \mathrm{Fab}$ was temperature stable up to $70^{\circ} \mathrm{C}$. At $80^{\circ} \mathrm{C}$ there was loss of activity over time. This loss could be indicative of the antibody fragment reaching its melting point. This again is a predictable result as the secondary and tertiary structures of many proteins begin unfolding at temperatures above $70^{\circ} \mathrm{C}$. During a thermal unfolding process, the temperature at which $50 \%$ of protein molecules are unfolded is defined as the unfolding (or melting/denaturation/transtion) temperature $\left(T_{m}\right)$. 
The $T_{m}$ of many proteins have been determined and are mostly in the range of $40-80^{\circ} \mathrm{C}$ (Wang, 1999). Lysozyme, a particularly stable protein, for example, unfolds at $74 / 5^{\circ} \mathrm{C}$.

\subsubsection{Solvent Experiments}

The initial experiments carried out using different concentrations of methanol and D1.3Fv indicated that solvent did have a damaging effect. However, because these experiments were carried out at $40^{\circ} \mathrm{C}$ and with a low concentration of antibody, the results of these experiments showed a combined temperature/solvent/concentration effect. These effects could be additive. That is the antibody is damaged to some extent by all three effects independently of each other, or synergistic i.e. because the antibody is more susceptible to damage at lower concentrations this means that the temperature will cause damage which will make the antibody fragment susceptible to solvent damage. These results could be a realistic indication of the damage caused during SEDS as both solvent and temperature effects will occur during SEDS runs. These results suggest that there is quite likely to be a considerable amount of damage caused to this antibody fragment during SEDS.

The second set of solvent experiments examined the effect of different solvents on the two antibody fragments (D1.3Fv and 4D5Fab). The solvents were added to the antibody fragment solutions at concentrations calculated to mimic the concentration of solvent present during SEDS. All of the solvents used caused similar levels of damage. These results indicated that at $20^{\circ} \mathrm{C}$ the lower levels of solvent caused little damage to the antibody fragments but the higher levels caused total loss of activity.

These experiments also indicated that the D1.3Fv and 4D5Fab could possibly be damaged in different ways by the solvents. On addition of $96 \%$ solvent to $\mathrm{D} 1.3 \mathrm{Fv}$ it became gel-like in texture after about 10 minutes. As samples could not be taken for analysis on the biosensor it was assumed that this indicated complete loss of antibody activity. The solid gel-like texture is indicative of aggregation of the antibody fragment. The 4D5Fab fragment also lost all of its bioactivity after addition of $96 \%$ solvent. However, there was no change seen in the texture of this sample it remained in liquid form. These results suggest that perhaps there is a different type/level of denaturation occurring for each antibody. It could be that when the D1.3Fv denatures it exposes core hydrophobic regions, which could cause unravelling leading to aggregation whereas with the other protein (4D5Fab) this does not happen. It is possible that as the Fv fragment is just two unlinked polypeptide chains it is more likely to completely unravel than the Fab, which is bigger and whose subunits are covalently attached which probably stops the unravelling to a certain extent. 
It is know that the addition of solvents to a protein solution can cause precipitation of the protein but this is often a reversible loss of activity. Sometimes the protein will regain bioactivity upon re-suspension in aqueous solution. (Rothstein, 1994, Foster, 1994, Banga, 1995). It maybe that precipitation is happening during SEDS, the belief at Bradford Particle Design is that this is not the case and they have evidence from FTIR analysis that protein conformation is retained after SEDS processing. However, this evidence is for small molecules only and may not be true for larger proteins. It is possible that the protein is being precipitated and some of the active protein is regained upon resuspension in aqueous buffer after SEDS processing but the rest maybe irreversibly denatured.

It is perhaps unsurprising that the high levels of solvent had such a damaging effect as it is widely reported in the literature that solvents, particularly when present in high concentrations, can cause damage to proteins (Schubert et al., 1981). Charged polar molecules locate on the surface of a protein to interact with an aqueous solvent. Some water soluble or organic solvents such as alcohol destabilise a protein by interfering with the hydrophobic interactions among the nonpolar residues. Water-miscible organic solvents unfold proteins by changing the dielectric constant of the aqueous medium. This change increases the solubility of the hydrophobic core and decreases the solubility of the charged surface. As a result proteins unfold (Wong et al., 1997). At high alcohol concentrations denaturing effects occur. Depending upon the concentration of the alcohol, and the temperature, the denaturation transition may be either thermally induced or solvent induced

The timescale of the three SEDS feed streams meeting and being dispersed out of the nozzle will be very fast so complete mixing of the streams may not occur. This may mean that the solvent concentration may not reach $96 \%$. Furthermore a significant amount of the solvent will dissolve rapidly in the $\mathrm{CO}_{2}$ and not come in contact with the aqueous environment, as predicted from the phase diagram, so the figure of $96 \%$ may be too high. Solvent may be regarded as a problem and a potential cause of damage to the antibody however, as long as the concentration is below $75 \%$ some recovery of the antibody is potentially possible.

The results of the SEDS experiments suggest that $96 \%$ solvent concentration was not reached, as there was recovery of active antibody. If $96 \%$ solvent concentration had been reached then there would have been no activity recovery. Alternatively it could be that if exposure to the solvent is very brief (as it would be in SEDS) then high levels of solvent maybe tolerable to the antibody fragments.

The solvent experiments were repeated using chilled solvents. Chilling of the solvents prior to the experiments and chilling of the samples during the experiments did reduce the level of damage seen. This result was predicted as previous literature records that chilling solvents reduces their damaging effect to 
proteins. For example, ethanol induced denaturation of ribonuclease has been shown to be a strong function of temperature. At a fixed ethanol concentration $(10 \% \mathrm{v} / \mathrm{v})$ the native conformation was destabilised at $50^{\circ} \mathrm{C}$ but strongly stabilised at $10^{\circ} \mathrm{C}$. This behaviour of low-temperature stabilisation by solvents is a general phenomenon (Schubert et al., 1981). Different solvents have been shown to have individual effects on the final protein conformation. Final conformation of a denatured protein has been shown to be dependent upon both temperature and solvent concentration (Schubert et al., 1981).

A number of water-miscible organic solvents are used to precipitate proteins from low ionic strength solutions (most commonly used are ethanol and acetone, though methanol is also used). However as proteins can be readily denatured in the presence of solvents, precipitation processes have been designed to avoid this. Control of temperature is important and for this reason precipitation is normally carried out close to the freezing point of the solution. For ethanol concentrations of $20 \%$ or greater, processing is generally carried out at $-5^{\circ} \mathrm{C}$ (Foster, 1994). Cold miscible solvents have also been used to concentrate antibody activities from plasma and serum (Rothstein, 1994).

It is hard to foresee how this result could be utilised during SEDS processing without re-designing the equipment quite substantially. SEDS experiments need to be run at temperatures above $31.7^{\circ} \mathrm{C}$ to ensure that the carbon dioxide is supercritical.

\subsubsection{Shear, pH and Freeze Drying}

Proteins can be denatured by shaking or shearing. Shaking creates hydrophobic air/water interface, which results in alignment of protein molecules at the interface, unfolding to maximise exposure of hydrophobic residues to air, and to initiate aggregation. The hydrophobic surfaces causing protein aggregation during shaking can be either gaseous or solid. Similarly, shearing also exposes hydrophobic areas of proteins, initiating aggregation (Wang, 1999).

The effect of shear rate (Chapter 3 ) on the antibody fragments was shown to be dependent on the antibody fragment being investigated. For D1.3Fv shear with an air/liquid interface caused total loss of activity but shear without an air/liquid interface caused very little damage. It would be expected that shear with an air/liquid interface would cause greater damage. Harrison et al., (1997) showed that ScFv lost antigen-binding activity in the presence of air-liquid interfaces at $31^{\circ} \mathrm{C}$. As the Fv fragment being examined in this experiment is known to be less stable than ScFv, it would be reasonable to assume that the Fv fragment would also be susceptible to shear as demonstrated by the results obtained. Harrison et al., (1998) also noted that the deactivation of proteins at a sheared interface is a complex process 
Investigation of Supercritical Fluid Technology to Produce Dry Particulate Formulations of Antibody Fragments

involving a number of steps: rate of adsorption to the interface, conformational changes, unfolding and coagulation, and continual replacement of the interface by mixing. Similarly, protein loss may occur due to irreversible binding at surfaces. Protein concentration, temperature, $\mathrm{pH}$, extent of shear, solution components and presence of oxygen may also be contributory factors to deactivation of some proteins. Denaturation is therefore a function of all, or some, of these for each individual protein solution.

For 4D5Fab the damage from shear without an air/liquid interface was greater than that seen for the Fv fragment and the damage seen from shear with an air/liquid interface less. This may have been the result of aggregation due to shear. Aggregation is not induced by shear itself but by denaturation at an aqueous/hydrophobic surface such as the air/water interface generated upon shaking (Katakam et al., 1995). As proteins adsorb, and then unfold, at the air-water interfaces generated by shaking or shear, thereby exposing the hydrophobic amino acids that are normally located in the interior. The exposed hydrophobic amino acid side chains of one molecule interact with those of another to form aggregates. Shear accelerates the turnover of air-liquid interfaces. Use of excipients can stabilise against shear. Surfactants can be used to protect as they preferentially adsorb at air/water interfaces. (Katakam et al., 1995). The effect of shear varies from protein to protein. For example hGH doesn't aggregate at even the highest shear rates, however it will aggregate readily if a hydrophobic interface is generated. Insulin doesn't aggregate without air-liquid interface but aggregates with an air-liquid interface (Maa et al., 1996, Banga, 1995).

Maa and Hsu, (1996) found that the effect high shear $\left(>10^{7}\right)$ and high shear rate $\left(>10^{5} s^{-1}\right)$ on protein aggregation for rhGH and rhDNase was not significant. However, changes in thermal properties as determined by scanning microcalorimetry suggest that highly sheared rhGH might experience slight conformational changes, this was without the presence of an air/liquid interface.

Shear was applied to the experimental samples for 20 seconds. Time-scale may reduce these effects in the SEDS process, as the streams will be sprayed out from the nozzle tip very quickly. Theoretically mixing in the nozzle should be fast and complete therefore minimising the time-scale where interfaces may occur. Also in theory the surface tension in supercritical carbon dioxide should be zero which would remove/reduce any shear effects. The viscosities of supercritical fluids are very low. Also, if the system is totally miscible then there should be no interface. SEDS experiments are carried out using flow-rates that ensure work is carried out in the miscible region of the phase diagram.

Freeze-drying was found to have little effect on the activity of the antibody fragments. Although this result does not provide any insight into what may happen during SEDS it does lead to a method of testing the conditions inside the SEDS vessel. The antibody fragments could be freeze-dried and the stability of the 
Investigation of Supercritical Fluid Technology to Produce Dry Particulate Formulations of Antibody Fragments Chapter Five - Discussion and Future Work

freeze-dried powder in the SEDS vessel tested (SEDS Stability Tests - Chapter 4).

The acidic nature of supercritical carbon dioxide can also be discounted as a damaging element of the SEDS process as both antibody fragments were found to be stable at $\mathrm{pH} 2.8$.

Overall these preliminary results seem to indicate that the most likely cause of damage during SEDS will be the presence of high levels of solvent. Temperature could also have an effect but this effect will most likely be due to a synergistic effect. Either due to a low concentration of antibody being used making it more susceptible to damage or the solvent will have damaged the antibody fragment, again making it more vulnerable to thermal damage.

\subsection{Discussion of SEDS Experiments Results}

\subsubsection{Temperature and Solvent Effects}

The SEDS experiments were carried out using different temperatures and solvents to study the effect that these parameters had on the activity of SEDS processed antibody fragments (Chapter 4). The three temperatures investigated did not have that great an influence on the activities recovered although $40^{\circ} \mathrm{C}$ was found to give slightly higher recovered activities. The parameter that had the greatest influence on activity recovery was solvent. Three solvents were looked at in this study methanol, ethanol and isopropanol. Methanol had the greatest effect on activity loss. Ethanol and isopropanol had similar effects, though isopropanol was found to be slightly less damaging.

These results fit well with the available literature on proteins and solvents as the tendency for alcoholwater mixtures to denature proteins is well established. Schubert et al., (1981) found that experiments carried out using methanol, ethanol and n-propanol as denaturants at $4{ }^{\circ} \mathrm{C}$ and $25^{\circ} \mathrm{C}$ showed solvent denaturation in a solvent/water mix is independent of temperature. Alcohols are selected for protein precipitation based on number of carbon atoms, as discussed below.

It was interesting that the level of damage caused by the different solvents during the experiments detailed in Chapter 3 and 4 followed the pattern that it did. Much of the literature available on the effects of different solvents in solvent-water mixtures suggests that different solvents have different denaturing effects. Denaturing efficiency tends to follows the series, methanol<ethanol<propanol<butanol. There is a relationship between the increased denaturing effectiveness of longer chain monohydric alcohols to their 
being hydrophobically bound to apolar amino acid residues of the protein and the consequent dehydration of the protein. The greater denaturing effect of alcohols with longer alkyl chains is a results of their enhanced hydrophobic binding to apolar groups and the consequent weakening of intra protein hydrophobic interactions (Rothstein, 1994). Therefore, it would have been expected that methanol would have been the least denaturing solvent during SEDS experiments. However, it has also been reported that methanol used as a precipitating agent inactivates a number of enzymes to a greater degree than other alcohols. This observation is anomalous since methanol has also been reported to be the least denaturing of the alcohols. (Schubert et al., 1981).

\subsubsection{Stability Tests}

As well as carrying out SEDS experiments, stability tests were carried out to examine the effects of the different feed streams on freeze dried antibody fragment and antibody as it sat in the SEDS drying chamber. The powders were exposed to $\mathrm{scCO}_{2}$ alone, $\mathrm{scCO}_{2}$ plus solvent and $\mathrm{scCO}_{2}$ plus solvent and water. There was little or no damage seen when the powders were exposed to $\mathrm{scCO}_{2}$ or $\mathrm{scCO}_{2}$ plus solvent. Upon exposure of the protein powder to solvent it is likely that there will be a gradient from dry, insoluble and hence stable protein to dissolved protein which is free to unfold but still associated with the powder. The rules governing loss of protein function in solution potentially give insights as to what happens to the protein.

The fact that organic solvent alone did not affect the recovered activity is supported by the work of Griebenow et al., (1996). The statement is often made that 'Proteins can be denatured by certain miscible organic solvents such as alcohol or acetone'. Such conclusions, however, rarely come from studies where proteins are actually examined in 'organic solvents such as alcohol or acetone'; instead, miscible organic solvents are usually added to aqueous solutions of proteins. Although it is tempting to presume that if proteins are denatured in aqueous-organic mixtures they will certainly experience that fate, and likely to a greater extent, in pure (neat) organic solvents, this extrapolation may not be correct. There is some direct biophysical evidence that, somewhat counterintuitively, proteins are more denatured in aqueous-organic mixtures than in the corresponding pure organic solvents

However, when the powders were exposed to all three components there was a substantial amount of activity loss. Therefore it is implicated that the major source of damage to the antibody fragments and whole antibody in the SEDS system is the presence of an organic solvent and water.

Once again the results of these experiments fit well with findings documented in the literature that the 
Investigation of Supercritical Fluid Technology to Produce Dry Particulate Formulations of Antibody Fragments

Chapter Five - Discussion and Future Work

presence of an organic solvent/water interface can be damaging to proteins. $A$ folded protein in an aqueous solution has hydrophobic regions sequestered from and hydrophilic areas in contact with, the aqueous environment. When the polarity of an aqueous solvent decreases by adding a non-aqueous solvent, protein hydrophobic cores tend to dissipate in contact with the solvent, and the protein hydration shell may be disrupted, leading to destabilisation and unfolding of the protein. Non-aqueous solventinduced inactivation of proteins by disruption of water residues at the active site may occur without disruption of the tertiary structure (Wang, 1999).

Little research has been carried out on antibody behaviour in organic solvents therefore it is perhaps pertinent to comment on organic phase enzymology since, like antibodies, enzymes are proteins exhibiting biochemical activity. Many enzymes are able to function in organic solvents by retention of an essential hydration shell, effectively a thin film of water that surrounds the enzyme in solution. Strongly hydrophobic solvents will not interact with this film, resulting in retained enzymatic activity. Water-miscible solvents however are able to strip this water layer which can lead to distortion and inactivation of the enzyme molecule. In water-miscible organic solvents, an antibody is in direct contact with the solvent due to hydration shell disruption. Russell et al. cited in Setford (2000) found that a decrease in antiaminobiphenyl antibody-antigen affinity with increasing solvent hydrophobicity. However it has also been demonstrated that binding affinity was more influenced by solvent molecular mass rather than solvent polarity, suggesting that binding inhibition is related to the ability of the solvent to displace water from around the antigen (Setford, 2000).

Due to the increasing interest in the microencapsulation of proteins many studies have been carried out looking at the effect of organic solvent/water interface on the stability of proteins (Sah a,b,c, 1999, van de Weert et al., 2000). During microencapsulation, proteins are exposed to organic solvents, and adsorption onto various interfaces occurs. Sah, $(1999 \mathrm{~b}, \mathrm{c})$ found that protein instability during emulsification could be linked to protein contact with the water/organic solvent interface around emulsion droplets. It was also found that both aqueous protein concentration and the presence of another protein influenced protein aggregation. Aggregation of the protein of interest was reduced by the presence of a second protein. These results suggest that competitive adsorption modes of proteins could be used to stabilise a protein of interest against the denaturing effects of a solvent/water interface. Sah's study showed that protein destabilisation reactions occur primarily over a very short time scale that lasted for only 1 minute. With regard to the effect of protein concentration upon its stability, two hypotheses have been proposed to explain that a smaller fraction of proteins becomes inactivated at high concentrations. The first one takes into consideration that only a limited amount of protein could interact at the interfaces. Under this condition, the protein is suggested to act as a self-protectant at high concentrations, thereby inhibiting its interaction with the interface. The other hypothesis elaborates on the role of the energy barrier on protein 
adsorption. At low protein concentrations, there is no barrier to adsorption and subsequent interfacial reactions. By contrast, at high protein concentrations, an energy barrier comes into play to prohibit further protein adsorption.

The presence of an organic/water interface could enhance any other potentially damaging effects such as shear. It has been found that shearing proteins solutions in the presence of a solvent/water interface produced problematic, undesirable events (compared to water alone). It is probable that shear increases the total surface area of the organic solvent/water interface that serves as a hydrophobic adsorbent and also generates a turbulent flow to transport continuously fresh protein molecules to the interface (Sah, 1999a).

Timed stability tests were carried out using the whole antibody. These involve exposing freeze dried CDP850 to the different components of SEDS for varying lengths of time. It was found that the damage occurred to the antibody during the first 20 minutes of exposure and after this time no further loss of activity was seen. This may be due to only the exposed parts of the powder being in contact with the process streams. As the powder was present as a 'plug' in the chamber, some parts of it may not have been exposed to the process streams. Dooley et al., (1998) found a similar pattern when investigating the effect of DMSO on antibody fragments and intact monoclonal antibody. They found that the antibody fragments showed an initial drop in activity followed by a levelling of the activity curve with little or no further loss of antigen binding activity. This was also found by Johannesson et al., (1997) who demonstrated that the DMSO denaturation of a protein occurs in a sharp transition followed by a deceleration of the unfolding. Retention of the residual activity is due to disulphide bonds. Intact monoclonal antibody was found by Dooley et al., (1998) to be most stable and showed, in general slower dissociation.

Considerable variation has been found in the levels of damage that occur to different proteins due to organic solvent/water interface-induced denaturation. This phenomenon is expected, considering that each protein has different thermodynamic and kinetic stability determined from its own amino acid sequence. The extent of solvent/water induced inactivation during microencapsulation of proteins has been found to be protein specific, concentration dependent, and synergistically facilitated by shearassociated secondary effects (Sah, 1999a). 


\subsubsection{Protein Effect}

Four types of antibody fragment and antibody were used during this study, reported in Chapter 4 - an Fv fragment, two Fab fragments and a whole antibody. The Fv fragment was found to be the least stable replicating previous studies (Dooley et al., 1998, Glockshuber et al., 1990).

The Fab fragments and whole antibody were found to be more stable. It might have been predicted that the whole antibody would have been more stable than the Fab fragment. However, as the Fab antibody fragment and whole antibody were of different species then this prediction might not hold true. Indeed it was found that their recovered specific activities after SEDS processing were very similar.

Generally it has been found that intact antibody molecules are more stable than antibody fragments. Glockshuber et al., (1990) found that intact monoclonal antibody was more stable than any fragment configurations and retained its full antigen binding activity in $40 \%$ methanol. This may be explained by the more complex and dimeric nature of the molecule. The findings of Dooley et al., (1998) confirm that intact monoclonal antibody is the most stable conformation tested, showing greater stability under all test conditions. Unlinked Fv was consistently shown to be the least stable of the fragments tested, dissociating and losing functionality under even the mildest of denaturing conditions.

Previous studies report that Polyethylene glycol (PEG) can be used as a stabilising agent for proteins (Cleland et al., 1992, Morita et al., 2000). PEG is a precipitant and stabilising agent for proteins. Its stabilising effect on the protein structure appears to arise from its steric exclusion from protein molecules. This speculation is based on the observation that the degree of hydration increases with the increase in PEG's molecular weight. Only water, not the high molecular weight PEG, can penetrate the protein structure, thus hydrating and stabilising the protein (Wong et al., 1997). With this fact in mind PEG600 was added to an antibody solution of CDP850. The results obtained from these SEDS runs were no higher than those seen without the addition of PEG were, indeed the recoveries obtained were slightly lower than those obtained without PEG. This was disappointing as all the literature points to PEG being an efficient stabiliser of protein. However, it could be that the temperature of the SEDS runs played a part in the lack of stabilisation. As although PEG is regarded as non-denaturing and is generally believed to stabilise proteins; de-stabilisation of some proteins has been reported (Arakawa et al., 1985, Bhat et al., 1992, Foster, 1994, Mahadevan et al., 1992, Rothstein, 1994). Under normal conditions PEG does not denature proteins, however, protein destabilisation by PEG occurs at temperatures significantly higher that room temperature $\left(>40^{\circ} \mathrm{C}\right.$ ), (Rothstein, 1994). PEGs have been found to destabilise proteins in thermal denaturation although this is not a universal effect (Bhat et al., 1992). It could simply be that PEG 
Investigation of Supercritical Fluid Technology to Produce Dry Particulate Formulations of Antibody Fragments Chapter Five - Discussion and Future Work

does not work as a protecting agent during the SEDS process.

One explanation for this lack of stabilisation comes from the findings of van de Weert et al., (2000) who examined the stabilisation of lysozyme against aggregation in a water/methylene chloride system. Nonionic surfactants such as Tween 20 and Tween 80 were not found to have any stabilising effect. $A$ possible explanation can be found in the chemical structure of the Tweens: their surface activity is based on the presence of hydrophilic PEG chains and a hydrophobic fatty acid chain grafted onto sorbitan. However, it is well known that PEG behaves unusually in a water/methylene chloride system, and preferentially distributes into the methylene chloride phase. Thus, in a water-methylene chloride, system the fatty acid chain and the PEG chains of the Tweens both have affinity for the methylene chloride phase, explaining their low efficacy in preventing lysozyme unfolding at the water-methylene chloride interface.

PEGylation of proteins is of great interest to the pharmaceutical industry as covalent attachment of PEG molecules can increase protein sera half-lives and reduce antigenicity (Heller, 1998). Chemical modification of antibody fragments with PEG results in the production of antibody fragments with longer in vivo half-lives and full retention of antigen-binding properties (Chapman et al., 1999, Peters et al., 1999).

It was thought that the use of PEG-Fab would yield higher recovery after SEDS than the non-peglyated Fab fragments. However, the results obtained indicated that the PEG-Fab was no more stable under SEDS processing than the non-PEGylated Fab. The PEG does not appear to have caused any further destabilisation yet it had no discernible stabilising effect either. These results may not be a true reflection of stability of the PEG-Fab compared to the non-PEGlyated Fab as unsurprisingly PEGylation significantly alters the surface characteristics of a protein. Consequently, its conformational stability during freezing and drying is altered. Therapeutic protein formulations optimised for the non-modified protein may not generally provide adequate protection when formulating PEGylated derivatives (Heller, 1998). PEG will alter the solubility of the protein in water/organic and $\mathrm{CO}_{2}$ solvents, which may result in different findings. Therefore different SEDS conditions from those used for processing the Fab may result in greater recovered activity for the PEG-Fab.

The use of PEG as a stabiliser and the SEDS processing of PEGylated Fab was intended as a brief look at some of the ways in which extra stability could be conferred on the protein during SEDS processing. The stabilisation of proteins is a vast subject and worthy of an entirely separate piece of research 


\subsection{Overall Conclusions}

The work covered in this thesis was designed to assess the suitability of the SEDS process for the production of dry particulate formulations of antibody fragments and whole antibodies. The likely causes of damage during SEDS were identified. The effect of these on the antibody fragments outside of the SEDS environment was assessed as part of preliminary studies carried out prior to beginning SEDS processing. SEDS processing was carried out varying a number of the process parameters.

The results obtained from both the preliminary experiments and the SEDS experiments point to the presence of solvent and water being the major cause of damage during the SEDS process. There could potentially be other causes of damage such as temperature and shear, however these alone are unlikely to have a significant impact on the retained activities of the antibody fragment or antibody and are more likely to act in a synergistic fashion. Any effect they may have will be due to the protein already being damaged by the effect of the solvent/water interface.

Protein choice has a substantial influence on the results obtained from both preliminary experiments and SEDS experiments. The addition of PEG or use of a PEGylated antibody was not found to increase protein activity recovery. However, this maybe due to the optimal processing conditions for these formulations not yet being established.

Much of the work that has been conducted to date using supercritical fluid processing has used lower molecular weight species of proteins $(225 \mathrm{kDa})$. Recovery of full activity has been reported for many of these proteins (Winters et al., 1996). However, these proteins have fewer critical sites that are sensitive to supercritical fluid processing. The result presented in this thesis show that the biological activities of the antibody fragments and whole antibody were compromised as a result of SEDS processing. It is likely that macromolecular species such as antibodies are more sensitive to supercritical fluid processing than the lower molecular weight proteins.

The experiments described in this thesis explored the preliminary underpinning work for the understanding of the effect of SEDS processing antibody fragments and whole antibodies. Although $100 \%$ activity recovery was not established during the this work, the findings did lead to a substantial increase in activity from the initial result of $2 \%$ recovery, to the final maximum recovery of $76 \%$ recovery (CDP850 at $10 \mathrm{mg} / \mathrm{ml})$. The Fab fragment had a maximum recovered activity of $72 \%$. These results comapre favourably to those of Nesta et al., (2000) who processed rlgG at $5 \mathrm{mg} / \mathrm{ml}$ using the SEDS process but using liquid $\mathrm{CO}_{2}$ premixed with ethanol. The retention of biological activity that they achieved was $48.5 \%$. 
The results in this thesis indicate that it is possible to increase activity recovery by adjustment of the process parameters. Therefore, in theory it should be possible to increase the activity recovered to $100 \%$.

\subsection{Future Work}

In order to achieve the aim of $100 \%$ recovery of antibody fragment/whole antibody activity, a number of areas require further investigation. The most obvious would be the problem of the organic/water mix causing the damage. The work carried out in the area of biotransformations and the stability of enzymes in solvent/water mixes may provide some clues to solving this problem. The choice of solvent is probably key and a different solvent maybe required other than the ones investigated in this thesis. In some cases solvents can be used to stabilise protein structure (Timasheff et al., 1983). The difficulty in solvent choice lies in the fact that the solvent must be partially miscible with both water and $\mathrm{scCO}_{2}$.

The other area that requires extrapolation is the use of stabilisers. There is a large amount of literature describing the use of additives for the stabilisation of proteins (Banga, 1995, Katakam, 1995, Schein, 1990, Wang, 1999). There does not however appear to be a generic solution to this problem. Each protein must be treated on an individual basis. Time would have to be invested in examining a number of different stabilisers or combination of stabilisers. It would also be important to consider at this point whether or not the stabilisers are acceptable for pharmaceutical use. Some excipients used as bulking agents in pharmaceutical products can also be used as stabilisers so it would be perhaps prudent when developing a stabilisation strategy to consider the overall formulation of the product being dried.

Some studies detail the use of additives to protect against denaturing effects (Banga, 1995, Carpenter et al., 1997, Glockschuber et al., 1990). The literature that details work on microencapsulation provides information on the use of stabilisers against solvent/water denaturation (Bot et al., 2000, Bustami, et al., 2000, Sah a,b,c, 1999). Van de Weert et al., (2000) looked at the stabilisation of lysozyme against aggregation during microencapsulation. The use of surface-active additives, such as partially hydrolysed PVA, significantly reduced lysozyme aggregation. The application of other surface-active proteins, such as serum albumins, to block interfacial contact with lysozyme, is prohibited, since these proteins are not always pharmaceutically acceptable. Other excipients that preferentially adsorb onto the water/methylene chloride interface such as partially hydrolysed PVA, were found to be promising in stabilising proteins during the encapsulation process.

The influence of protein choice could be investigated further. Antibodies that have been engineered to have greater stability in adverse environments may be one fruitful avenue of enquiry (Dooley et al., 1998). 
One example of this could be use of scFv fragments in the place of the Fv fragment.

In 'single-chain' antibody fragments (scFv) a short hydrophilic peptide chain also covalently links the two chains. This means that even if $V_{H}$ and $V_{L}$ are temporarily dissociated, the linker peptide should keep $V_{H}$ and $V_{L}$ in close proximity thereby enabling reassembly (Berry et al., 1993). The unfolding of the scFv fragment is much slower that the Fv fragment. The higher thermodynamic stability of the scFv is at least partially due to a high-energy transition state for unfolding (Jäger et al., 1999).

It would also be interesting to examine the entire series of antibody fragments and the whole antibody from the same species to try and map and understand where the damage is occurring during the SEDS process.

Once a stable formulation has been developed work would need to begin on assessing the size and shape of the particles being produced during the SEDS processing. This can be done using standard techniques such as scanning electron microscopy and particle sizing equipment. Different sizes and shapes of particles can be achieved by altering the flow-rates used during SEDS. 


\section{CHAPTER SIX}

\section{COMMERCIALISATION OF RESEARCH}




\section{Commercialisation of Research}

\subsection{Introduction/Background}

Identification of potential commercial and patentable aspects of academic scientific research is becoming an increasingly important area. This chapter attempts to briefly look at the potential commercial applications of the work carried out for this thesis and also related work. This chapter in general looks at how Bradford Particle Design could take the work forward rather than from UCL's point of view.

In addition to the SEDS work carried out using antibody fragments work was also conducted at UCL by Dr Markus Tservistas looking at the potential of SEDS processing plasmid DNA (Tservistas et al., 2001). Commercialisation of the antibody and plasmid DNA work would only be possible as part of a collaboration with Bradford Particle Design. Bradford Particle Design (bpd) holds the patents on the SEDS process although there will be Intellectual Property Rights (IPR) sharing agreements in place with regards to the work carried out at UCL using the SEDS equipment.

Over the last few years a number of particle formation techniques have shown considerable promise in their developmental stages only to falter on scale-up studies and in trying to achieve strict cGMP requirements for the process. Increased vigilance is being expressed by the regulatory agencies in facilities used for the preparation of drug substances in particulate form. Also the pharmaceutical industry is looking for a global harmonisation of material preparation and consistency of properties of powdered materials (York, 2000).

Unlike many novel technologies that seem promising in their early stages the SEDS process has been successfully scaled up from bench-scale $(50 \mathrm{ml}$ vessel) to pilot plant size (2 litres) to a production scale facility with a 10 litre particle formation vessel. A small manufacturing facility has been built to comply with current Good Manufacturing Practice (cGMP). This facility has a potential throughput of 1-2 tonnes per annum. This is such that all levels of quantities of clinical trial material composed of engineered particles can be manufactured efficiently and cost effectively. The SEDS process is a fully validatable process, which is essential for commercial viability. As the process is applicable to all bioactive materials, the supercritical fluid SEDS process is finding a place as a platform technology for particle design for drug delivery systems (Palakodoty et al., 2000, York, 2000).

There are a number of potential markets for drugs that can be formed into engineered particles. Inhaleable drugs have a number of appealing features for the treatment of systemic and respiratory 
diseases. Inhaleables would provide a non-invasive method of delivering drugs into the bloodstream for those drugs that can currently only be delivered via injection. These could include peptides and proteins such as insulin, beta interferon for multiple sclerosis, $\alpha-1$ proteinase inhibitor for emphysema and most of the 'bio-pharmaceuticals'. Inhaleables would provide a convenient and pain-free alternative to injections. They also enable effective targeting of the lung for respiratory tract diseases such as emphysema or asthma. Inhaleables provide for very rapid onset, typically faster than is achieved with either oral delivery or subcutaneous injections. This rapid delivery has potential benefits in the treatment of pain, hypertensive crisis, anaphylactic shock, nausea, cardiovascular conditions, Parkinson's "lock-up" and seizures, all conditions where speed of treatment is of the essence (URL: http://www.inhale.com).

Transdermal drug delivery via particle bombardment of the skin is where the physical force of impact overcomes the cell membrane barrier. This technique has potential in the area of gene therapy where studies have already looked at levels of expression of genes following bombardment of the epidermis with DNA-coated gold or tungsten particles. Particle bombardment has also been looked at as part of a vaccination protocol, (Schofield et al, 1995). Antibodies could be used in particulate form in a number of ways; they could be coupled to prodrugs, radiolabels or toxins for imaging and treatment. Needle-free injectables are considered to provide an improvement to more traditional injectors, and several companies are working to improve these devices which have been on the market in various forms for over half a century.

\subsection{Evaluation}

To take the work presented in this thesis to a commercial proposition a substantial amount of further work is required. There would need to be further technical evaluation of the work plus a commercial evaluation.

\subsubsection{Technical Evaluation}

The SEDS work carried out on the plasmid DNA has led to conditions where by $100 \%$ recovery was achieved. This work needs to be expanded into looking at the production of particles of specified size and shape. Also the requirements of plasmid DNA in any potential therapies need to be addressed. What would it be co-formulated with, would it need to be attached to a pro-drug and how would these complexes respond to SEDS processing?

The antibody studies led to recovery approaching $100 \%$ but further work is required to increase this 
Investigation of Supercritical Fluid Technology to Produce Dry Particulate Formulations of Antibody Fragments

Chapter Six - Commercialisation of Research

recovery to $100 \%$. The further work required for a full technical evaluation, with a possible commercial potential, would need to look at the following areas. Throughputs - how much is it possible to produce using the SEDS process, the reproducibility of the products produced with SEDS, the particle properties and also the economics of producing antibody particles using SEDS.

To achieve full technical evaluation would probably require another $2-3$ years work with $2-3$ researchers working on the project. There are two possible routes to achieve this.

Firstly, a company collaboration. bpd already does this for other projects. One would need to find a company that could produce the required materials (i.e. plasmid and/or antibody fragments) and would be interested in the potential for their use in dried particulate form. A deal would have to be structured with regards to IPR, in general developments in the SEDS technology belongs to bpd and compound specific improvements belong to the client. This would be quite an expensive way forward perhaps in range of $£ 1,000,000$ over the three years. In university terms and for a small company this is a great deal of money. However, for a medium to large size company in the pharmaceutical sector, this although not insignificant amount could be considered quite reasonable. One person per year at bpd is usually costed in the region of $£ 250,000$, allowing for equipment design, additional support and materials.

The second option is a further university collaboration. Another $\mathrm{PhD}$ and/or Post Doctoral research project. This option would be far cheaper; potentially it would reduce the costs by a factor of 10 . Less actual money would be involved, as some payment would be 'in kind' i.e. supply of equipment etc.

\subsubsection{Commercial Evaluation}

The drug delivery market is one that is attracting more and more investment. In the pharmaceutical sector the environment is such that there is constant pressure to launch new products onto the market. The cost of investment in drug delivery compares favourably with new drug discovery. Consequently, the market for drug delivery systems is growing faster than the pharmaceutical market overall. Another major opportunity for drug delivery systems is the large amount of 'blockbusters drugs' due to lose patent protection within the next 10 years as product differentiation can significantly prolong a products life (Evers, 2001).

As an example one can consider the insulin market, as this is a drug that is currently injected but is already in Phase III clinical trials as an inhalation drug.

Calculation for cost of manufacture of one kilotonne of product based on material and energy costs give 
Investigation of Supercritical Fluid Technology to Produce Dry Particulate Formulations of Antibody Fragments Chapter Six - Commercialisation of Research

similar figures for the SEDS process compared with the alternative spray drying single stage process. When the processing routes of organic solvent crystallisation followed by micronising, and the SEDS process are compared the elimination of several operating steps is demonstrated, together with reduction in material handling and environmental control and parallel benefits in cost reduction (York et al, 1998).

An equivalent spray drying plant to the SEDS SMP could cost $>10$ times the cost, however the ancillary costs such as buildings, validation, FDA approval, etc. for the SEDS process may overwhelm any cost difference.

The incidence of diabetes is increasing globally; the World Health Organisation predicts the number of diabetics will double by the year 2025 due to the increased number of elderly people and rising obesity. According to the Pharmaceutical World Review 1999, the world-wide market for insulin's was valued at $\$ 2.5$ billion in 1998, showing a $10 \%$ growth in local currency $\$$ terms, over 1997 . The North American market accounts for $39 \%$ of the total. One of the reasons for poor diabetic control is the fact that patients are required to inject themselves every day. Not only does this reduce compliance, it can also lead to complications. The fact that new delivery systems are appearing just as the incidence of diabetes rises means that many diabetics will be spared the inconvenience of injections. Also, non-invasively delivered insulin is likely to generate an expansion in the size of the insulin market as a whole, with type II diabetics switching to insulin therapy more rapidly than has historically been the case.

The main driver of insulin products' increasing market share is their delivery systems. Currently, the invasive nature of insulin injections is recognised as a key cause in preventing diabetics from properly managing their meal time glucose levels (Evers, 2001). Worldwide sales of insulin are currently in the region of $\$ 2.5 \mathrm{bn}$. According to a recent Reuters Business Insight Report 'The Drug Delivery Outlook 2001' (Paul Evers) an effective pulmonary or other non-invasive insulin formulation could expect a $20 \%$ switch from the injectable products within a year. Assuming a moderately high price (30\% up on injectable insulin), this represents potential sales of $\$ 600 \mathrm{~m}$ for the new product a year after launch. Potentially something in the region of $20 \%$ of this value would go to bpd.

It is difficult to start guessing market sizes at this point in time. What is important is to mature the technology as quickly as possible to get products onto the market before any competing technology. Being first to market with a better delivery system will likely win a large chunk of any potential market

Inhale Therapeutic Systems Inc. is developing an insulin inhaler that delivers an insulin powder deep into the lungs where it is easily absorbed into the bloodstream. Inhale Therapeutics is currently carrying out Phase III clinical trials of their inhaler along with Pfizer Inc. and Aventis Pharma in the US. European 
Phase III trials are planned for the future. Inhale Therapeutics expects the results of its Phase III trials in mid-2001 (Evers, 2001).

One problem with this market could be the need for a greatly increased level of insulin production. With pulmonary delivery there are a number of areas where drug losses could occur. These could occur in the packaging, device, mouth, throat, large airways, and enzymatic activity. These losses lead to the consequence that the overall bioavaliability for pulmonary delivered insulin is only $12 \%$. The Inhale device that is in clinical trails at present is relatively efficient and loses in the mouth, throat and airways may not be that great. Currently the estimated global production of insulin is $6-8$ tons. Potentially pulmonary delivered insulin would require 48-65 tons (Hakes, 2001).

Another market possibility is 'needle-less injections'. That is a drug fired across the epidermis in particulate form. This market has a large potential in areas where sterility is a problem as it avoids the need for sterile needles. The 'needle-less' injection market also has the advantage of utilising dried powders, these are inherently more stable than the liquid formulations required for conventional injections. They are also more easily transported and stored. Most dried formulations also remove the need for refrigeration, as they are stable at ambient temperatures. The main areas that this market would cover would be remote, isolated areas of developing countries. However, is this really a realistic market to aim for? How much will it cost to produce suitable particles and equipment? Will cost prohibit its use in this market? These are questions that need to be addressed before entering this area. There are potential sources of funding and backing that specifically fund research into medical applications in the Third World. The World Health Organisation funds projects such as these and they maybe a potential source of funding or perhaps subsidisers of the cost of production. Are there other markets for needle-less injections? Some gene therapies may be administerable via this technique; courses of treatment where multiple injections are involved would be more amenable to patients administered in this way. Depending on the overall cost of particle production and delivery equipment this treatment route may have the potential to take over from conventional injections. The benefits being the added convenience of drug stability and storage, coupled with the common dislike most people have of conventional injections. However, it is likely that the development of an alternative, a completely non-invasive delivery system would squeeze needle-free injectors out of the market.

Realistically it would probably take a minimum of 5 years to complete research work and get to the beginning of the commercialisation stage. In the mean time what other technologies will be developed? There are a number of competing technologies for size reduction for example micronisation and spray drying, but all have unique associated problems (as discussed in Chapter 1). There are other competitors in the supercritical fluid area such as LaviPharm, who bought Separex, the company who made bpd's 
SMP.

\subsubsection{Development Stages}

Three possible stages of development have been identified and considered.

\section{Achieve $100 \%$ activity recovery}

I believe that the work detailed in this thesis points to the fact that this is possible to achieve $100 \%$ activity for SEDS processed antibody fragments and antibodies. However, it requires a substantial amount of further research work. It would still be considered blue-sky research and as such carries an inherent risk of not achieving ones aims. This work could possibly be funded by bpd either as part of another university research project or as part of their own in-house work. It would be important to have access to large quantities of antibody fragments and antibodies; therefore it would be necessary to source such supplies. If this were to be a university collaboration, the university involved may have access to such supplies through other research activities. If bpd were to undertake this work in-house or the university did not have adequate supplies, agreements would have to be reached with the antibody suppliers as to their entitlement to any work carried out using their antibodies. If the antibody is purchased from a company then they have no entitlement to any work that is commercialised. However, if the material was given free of charge then Material Transfer Agreements must be signed. It is unlikely that a university scale project could produce enough material for a complete study including scale-up and clinical trials. Also a university would not have the controls in place for GMP. Therefore a university collaboration would be able to take this stage to only a certain level before a commercial supplier of material would have to be sourced.

bpd and/or a university collaboration would carry out this stage

\section{Establish need and market for powder delivery and risk of acceptability as therapy}

A lot of work has already been done in this area and there are a number of very recent reports out that look at the current state of the drug delivery markets and their potential for growth. To undertake a further study perhaps at a more clinical level rather than on market values might be useful and informative. This would be fairly easy to undertake but time-consuming. It would involve identifying therapeutic areas that may be suitable for treatment via particle delivery. Following this, groups involved in research and clinical treatment in these areas would need to be found and the key people in these groups identified. Preferably these people would be the Drs, nurses or clinicians that have some direct involvement with patients. It 
would then be a case of seeking their opinions/advice on the subject. This is perhaps best done in the form of a standard pre-prepared survey that can be easily sent out to the people involved. In assessing the acceptability of powder delivery as a therapy one would have to look closely at how validatable the processes are and how likely they are to receive regulatory approval.

This stage could be carried out either by bpd alone or in collaboration with any existing clinical research/trials.

\section{$3 \quad$ Need to establish dose size, delivery device etc}

This stage would definitely have to be carried out in collaboration with two partners - the makers of the chosen drug delivery device and the drug manufacturers. For this stage negotiations would have to take place as to who is entitled to what. It is quite likely that the drug supplier is going to be a large pharmaceutical company and they will probably be unwilling to relinquish very much as they will claim that in developing their drug they have incurred the largest $R \& D$ costs. Also, without the drug bpd and the delivery device company do not have a marketable product, therefore the drug company will assert that they bring the greatest value to the partnership. However, bpd and the delivery device company have quite a lot of leverage with the fact that there is a growing market for different drug delivery systems and the drug company needs their technology to enter this market. The best way to go about this negotiation would be for bpd and the Delivery Device Company to form an alliance/partnership before approaching the pharmaceutical company. This is indeed what has happened with the recent acquisition of bpd by Inhale Therapeutics. The SEDS technology offers Inhale an avenue into a wider drug delivery market than just inhalation, expanding to other solid dosage forms for example tablets and intramuscular injections. It must also be considered that a drug company may have its own device and may not want to use the device on offer from $\mathrm{bpd} / \mathrm{Inhale.}$

This stage would have to be carried out in collaboration with two partners. 


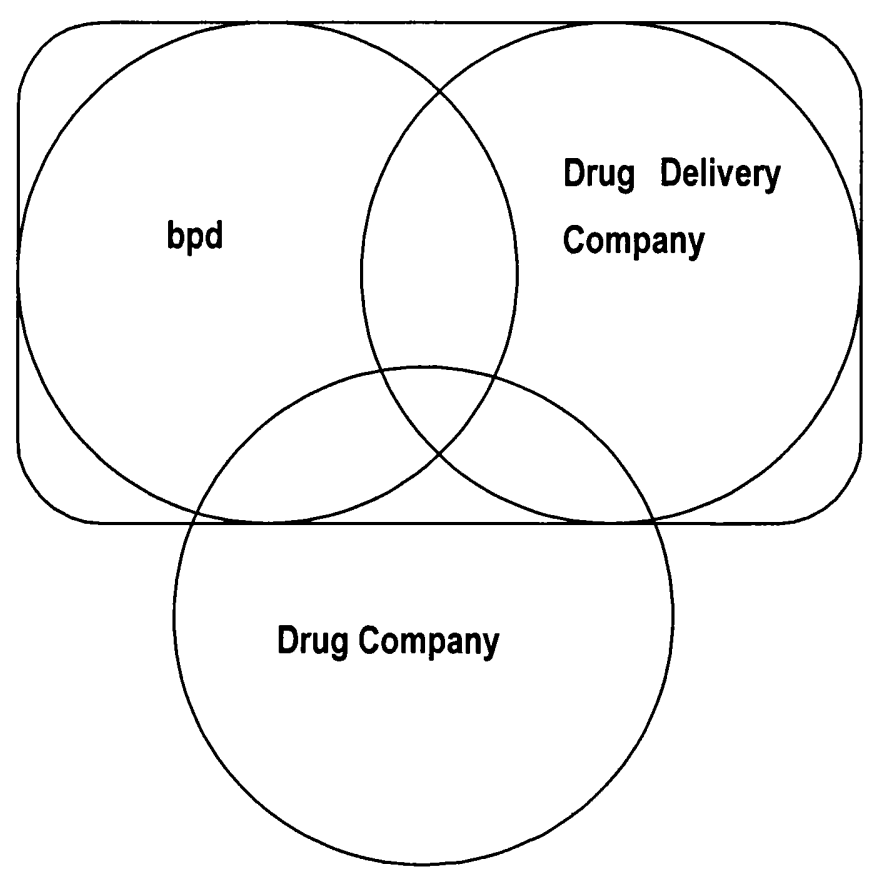

The above diagram illustrates the potential collaborations that would need to take place to satisfy stage 3 of the commercialisation process discussed above. bpd and the delivery device company would be in a stronger position if they formed an alliance before approaching or negotiating with a drug company.

In general protein delivery methods have continued to evolve over the past year; however, a great deal of research and development is still required to make the most of these methods feasible for commercialisation. Noninvasive routes of protein delivery allow for efficient local delivery of proteins to target tissues such as the lungs and skin. Of the non-invasive routes pulmonary delivery has the greatest promise because of the higher protein bioavailability compared to transdermal or oral delivery. Phase III clinical trials of pulmonary insulin delivery will be completed over the next year, yielding valuable insights into commercial feasibility of this delivery method. Finally, research to improve non-invasive routes of protein delivery continues to provide hope that some day (in five or more years) proteins will be taken orally like small-molecule therapeutics (Cleland et al, 2001). 


\section{CHAPTER SEVEN}

\section{REFERENCES}




\section{References}

Ahern, T.J. and Klibanov, A.M. (1985). The mechanisms of irreversible enzyme inactivation at $100^{\circ} \mathrm{C}$. Science 228: 1280-1284.

Andya, J.D., Maa,Y.F., Costantino, H.R., Nguyen, P-A., Dasovich, N., Sweeney, T.D., Hsu, C.C. and Shire, S.J. (1999). The Effect of Formulation Excipients on Protein Stability and Aerosol Performance of Spray-Dried Powders of a Recombinant Humanized Anti-lgE Monoclonal Antibody. Pharmaceutical Research 16(3): 350-358.

Banga, A.K. (1995). Stability of Therapeutic Peptides and Proteins and Formulation of Therapeutic Peptides and Proteins. In "Therapeutic Peptides and Proteins: Formulation, Processing and Delivery Systems". pp61 - 231, Technomic Publishing Company, Inc.

Berry, M.J. and Davies, J. (1991). Use of antibody fragments in immunoaffinity chromatography: Comparison of $\mathrm{Fv}$ fragments, $\mathrm{V}_{H}$ fragments and paralog peptides. Journal of Chromatography 597: 239245.

Berry, M.J. and Pierce, J.J. (1993). Stability of immunoabsorbants comprising antibody fragments. Comparison of Fv fragments and single chain Fv fragments. Journal of Chromatography 692: 161-168.

Bevan, C.D. and Marshall, P.S. (1994). The Use of Supercritical Fluids in the Isolation of Natural Products. Natural Product Reports 1994: 451-466.

Bhat, R. and Timasheff, S.N. (1992). Steric exclusion is the principal source of the preferential hydration of proteins in the presence of polyethylene glycols. Protein Science 1: 1133-1143.

Bhat, T.N., Bentley, G.A., Fischmann, T.O., Boulot, G. and Poljak, R.J. (1990). Small rearrangements in structures of Fv and Fab fragments of antibody D1.3 on antigen binding. Nature 347: 483-485

Birch, M., Schanz, M. and Hartig, A. (1985). Bulk Production of Monoclonal Antibodies in Fermentors. Trends in Biotechnology 3: 162-166.

Bird, R.E., Hardman, K.D., Jacobson, J.W., Johnson, S., Kaufman, B.M., Lee, S., Lee, T., Pope, S., Riordan, G., and Whitlow, M. (1988). Single chain antigen binding proteins. Science 242: 423-426. 
Bird, R.E., and Walker, B.W. (1991). Single chain antibody variable regions. Trends in Biotechnology 9(4): 132-137.

Blanch, H.W. and Clark, D.S. (1996). Product Recovery. In "Biochemical Engineering" (H. W. Blanch and D.S. Clark Eds) pp 435 - 458, Marcel Dekker Inc.

Bleich, J. and Muller, B.W. (1996). Production of drug loaded microparticles by the use of supercritical gases with the Aerosol Solvent Extraction System (ASES) process. Journal of Microencapsulation 13(2): 131-139.

Bot, A.I., Tarara, T.E., Smith, D.J., Bot, S.R., Woods, C.M. and Weers, J.G. (2000). Novel Lipid-Based Hollow-Porous Micorparticles as a Platform for Immunoglobulin Delivery to the Respiratory Tract. Pharmaceutical Research 17(3): 275-283.

Brennecke, J.F. (1996). New Applications of Supercritical Fluids. Chemistry and Industry 12: 831-834.

Broadhead, J., Rouan, S.K.E. and Rhodes, C.T. (1992). The Spray Drying of Pharmaceuticals. Drug Development and Industrial Pharmacy 18(11\&12): 1169-1206

Brown, J.M. (1993). Clinical Use of Monoclonal Antibodies. In: Biotechnology and Pharmacy (John M Pezzuto, Michael E Johnson and Henri R Manasse, Eds) pp227-249. Chapman and Hill.

Burgess, D.J. (1993). Drug Delivery Aspects of Biotechnology Products. In: Biotechnology and Pharmacy (John M Pezzuto, Michael E Johnson and Henri R Manasse, Eds) pp116-151. Chapman and Hill.

Bustami, R.T., Chan, H-K., Dehghani, F. and Foster, N.R. (2000). Generation of Micro-Particles of Proteins for Aerosol Delivery Using High Pressure Modified Carbon Dioxide. Pharmaceutical Research 17(11): 13601366

Carpenter, J.F., Pikal, M.J., Chang, B.S. and Randolph, T.W. (1997). Rational Design of Stable Lyophilized Protein Formulations: Some Practical Advice. Pharmaceutical Research 14(8): 969-975

Chandler J. P. (1987). Factors influencing monoclonal antibody production in mouse ascites fluid. In: 'Commercial production of monoclonal antibodies, A guide to scale-up.' (S. Seaver, Ed), p.75-92. Marcel Dekker, New York 
Chapman, A.P., Anotoniw, P., Spitali, M., West, S., Stephens, S. and King, D.J. (1999). Therapeutic antibody fragments with prolonged half-lives. Nature Biotechnology 17: 780-783.

Chester, K.A. and Hawkins, R.E. (1995). Clinical Issues in antibody design. Trends in Biotechnology 13: 294-300.

Cleland, J.L. and Jones, A.J.S. (1996). Stable Formulations of Recombinant Human Growth Hormone and Interferon-y for Microencapsulation in Biodegradable Microspheres. Pharmaceutical Research 13(10): 1464-1475

Cleland, J.L., Builder, S.E., Swartz, J.R., Winkler, M., Chang, J.Y. and Wang, D.I.C. (1992). Polyethylene-glycol enhanced protein refolding. Biotechnology 10(9): 1013-1019.

Cleland, J.L., Daugherty, A. and Mrsny, R. (2001). Emerging protein delivery methods. Current Opinion in Biotechnology. 12: 212-219.

Colcher, D., Bird, R., Roseiii, M., Hardman, K.D., Johnson, S., Pope, S., Dodd, S.W., Pantoilano, M.W., Milenic, D.E. and Schiom, J. (1990). Invivo tumour targeting of a recombinant single-chain antigen-binding protein. Journal of the National Cancer Institute 82(14): 1191-1197.

Constantino, H.R., Andya, J.D., Nguyen, P-A., Dasovich, N., Sweeney, T.D., Shire, S.J., Hsu, C.C. and Maa, Y-F. (1998). Effect of Mannitol Crystallization on the Stability and Aerosol Performance of a Spray-Dried Pharmaceutical Protein, Recombinant Humanized Anti-IgE Monoclonal Antibody. Journal of Pharmaceutical Sciences 87(11): 1406-1411

Constantino, H.R., Firouzabadian, L., Hogeiand, K., Wu, C., Begabski, C., Carrasquiilo, K.G., Cordova, M., Griebenow, K., Zale, S.E. and Tracy, M.A. (2000). Protein Spray-Freeze Drying. Effect of Atomization Conditions on Particle Size and Stability. Pharmaceutical Research 17(11): 1374-1383

Debenedetti, P.G., Tom, J.W., Yeo, S-D. and Lim, G-B. (1993). Application of supercritical fluids for the production of sustained delivery devices. Journal of Controlled Release 24: 27-44.

Dooley, H., Grant, S.D., Harris, W.J. and Porter, A.J. (1998). Stabilization of antibody fragments in adverse environments. Biotechnology and Applied Biochemistry 28: 77-83

Domingo, C., Berends, E. and van Rosmalen, G.M. (1997). Precipitation of ultrafine organic crystals 
Investigation of Supercritical Fluid Technology to Produce Dry Particulate Formulations of Antibody Fragments

from the rapid expansion of supercritical solutions over a capillary and frit nozzle. Journal of Supercritical Fluids 10: 39-55.

Eckert, C.A., Knutson, B.L. and Debenedettl, P.G. (1996). Supercritical Fluids as solvents for chemical and materials processing. Nature 383: 313-318.

Engle, J.P., Kraus, D.M., Parent, L.S. and Dean Holland, M. (1993). The Pharmacist Practioner's Role in Biotechnology: Clinical Applications of Biotechnology Products. In: Biotechnology and Pharmacy (John M Pezzuto, Michael E Johnson and Henri R Manasse, Eds) pp419-433. Chapman and Hill.

Evers, P. (2001). The Drug Delivery Market by Therapeutic Category. In "Drug Delivery Outlook 2001" pp 93-116, Reuters Business Insight.

Filkova, I. and Mujumdar, A.S. (1987).Industrial Spray Drying. In: "Handbook of Industrial Drying" (Arun S Mujumdar, Ed.) pp 243 - 291, Marcel Dekker Inc.

Flaschel, E. and Friehs, K. (1993). Improvements of Downstream Processing of Recombinant Proteins by Means of Genetic Engineering Methods. Biotechnology Advances 11: 31-78.

Forbes, R.T., Sloan, R., Klbria, I., Hollowood, M.E., Humphreys, G.O. and York, P. (1998). Production of Stable Protein Particles: A Comparison of Freeze, Spray and Supercritical Drying. Presented at the World Congress on Particle Technology 3, Brighton, UK. $7^{\text {th }}-9^{\text {th }}$ July 1998.

Forbes, R.T., Davls, K.G., Hindle, M., Clarke, J.G. and Maas, J. (1998). Water Vapor Sorption Studies on the Physical Stability of a Series of Spray Dried Protein/Sugar Powders for Inhalation. Journal of Pharmaceutical Sciences. 87(11): 1316-1317.

Foster, P.R. (1994). Protein Precipitation. In: "Engineering Processes for Bioseparations" (L.R. Weatherley, Ed.) pp73-108, Butterworth/Heinemann.

Glockschuber, R., Malla, M., Pfitzinger, I. and Pluckthun, A. (1990). A comparison of strategies to stabilize immunoglobin Fv fragments. Biochemistry 29: 1362-1367.

Gölker, C.F.(1991). Final Recovery Steps: Lyophilization, Spray-Drying.

Gray, C.J. (1988). Additives and enzyme stability. Biocatalysis 1:187-196. 
Griebenow, K. and Klibanov, A.M. (1996). On Protein Denaturation in Aqueous-Organic Mixtures but Not in Pure Organic Solvents. Journal of the American Chemical Society 118(47): 11695-11698

Hakes, L.B. (2001). Biological Products: A Vision of the Future? Oral Presentation for MBI Course 'Biological Product Formulation and Delivery', UCL, London.

Hanna, M. and York, P. (1993). Method and apparatus for the formation of particles. European Patent No. 9313642.2 .

Hannay, J.B. and Hogarth, J. (1879). On the solubility of solids in gases. Proceedings of the Royal Society of London. 29: 324-6.

Harris, B. (1991). Magic Bullets. Chemistry and Industry 7: 656-657

Harrlson, J.S., Gill, A. and Hoare, M. (1998). Stability of a Single-Chain Antibody Fragment When Exposed to a High Shear Environment Combined With Air-Liquid Interfaces. Biotechnology and Bioengineering 59(4): 517-519

Hauthal, W.H. (2001). Advances in supercritical fluids (review). Chemosphere 43: 123-135

Heller, M.C., Carpenter, J.F. and Randoloph, T.W. (1998). Conformational Stability of Lyophilized PEGylated Proteins in a Phase-Separating System. Journal of Pharmaceutical Sciences 88(1): 58-64

Hovmand, S. (1987).Fluidised Bed Drying. In: "Handbook of Industrial Drying" (Arun S Mujumdar, Ed.) pp 165 - 221, Marcel Dekker , Inc.

Hudson, P.J. (1999). Recombinant antibody constructs in cancer therapy. Current Opinion in Immunology 11: $548-557$.

Inhale Therapuetics on world wide web URL: http://www.inhale.com

Jäger, M. and Plückthun, A. (1999). Domain interactions in antibody Fv and scFv fragments: effects on unfolding kinetics and equilibria. Federation of European Biochemical Societies 462: 307-312

Jarzebski, A.B. and Mallnowski, J.J. (1995). Potentials and Prospects for Application of Supercritical Fluid Technology in Bioprocessing. Journal of Process Biochemistry 30(4): 343-352. 
Johannessen, H., Denisov, V.P. and Halle, B. (1997). Protein Science 6: 1756-1763

Kamat, S.V., Beckman, E,J. and Russel, A.J. (1995). Enzyme Activity in Supercritical Fluids. Critical Reviews in Biotechnology 15(1): 41-71.

Katakam, M., Bell, L.N. and Banga, A.K. (1995). Effect of Surfactants on the Physical Stability of Recombinant Human Growth Hormone. Journal of Pharmaceutical Sciences. 84(6): 713-716

Khaw, B-A. (1999). Antibodies as delivery systems for diagnostic functions. Advanced Drug Delivery Reviews 37(1-3): 63-80.

Klegerman, M.E. (1993). Background to Monoclonal Antibodies. In: Biotechnology and Pharmacy (John M Pezzuto, Michael E Johnson and Henri R Manasse, Eds) pp39-52. Chapman and Hill.

Kohler, G. and Milstein, C. (1975). Continuous cultures of fused cells secreting antibody of predefined specificity. Nature 256: $52-53$.

Kordikowski, A., York, P. and Latham, D. (1999). Resolution of Ephedrine in Supercritical $\mathrm{CO}_{2}$ : A Novel Technique for the Separation of Chiral Drugs. Journal of Pharmaceutical Sciences 88(8): 786-791

Kordikowski, A. (1999). Introduction into Phase Equilibria: A Beginners Guide. Bradford Particle Design in-house publication.

Krijgsman, J. (1992)a. Downstrean processing in biotechnology. In "Product Recovery in Bioprocess Technology" (DrR.O Jenkins, Ed) pp 1 - 13, Butterworth Heinemann.

Krijgsman, J. (1992)b. Formulation and Application. In "Product Recovery in Bioprocess Technology" (Dr R.O Jenkins, Ed) pp 209 - 229, Butterworth Heinemann.

Li, S., Schöneich, C. and Borchardt, R.T. (1995). Chemical Instability of Protein Pharmaceuticals: Mechanisms of Oxidation and Strategies for Stabilization. Biotechnology and Bioengineering 48: 490 500 .

Liapis, A.I. (1987).Freeze Drying. In: "Handbook of Industrial Drying” (Arun S Mujumdar, Ed.) pp 295 323, Marcel Dekker , Inc. 
Lucas, P., Anderson, K. and Staniforth, J.N. (1998). Protein Deposition from Dry Powder Inhalers: Fine Particle Muliplets as Performance Modifiers. Pharmaceutical Research 15(4): 562-569.

Maa, Y-F. and Hsu, C.C. (1996). Effect of High Shear on Proteins. Biotechnology and Bioengineering 51: $458-465$.

Maa, Y-F., Nguyen, P-A., Andya, J.D., Dasovich, N., Sweeney, T.D., Shire, S.J. and Hsu, C.C (1998). Effect of Spray Drying and Subsequent Processing Conditions on Residual Moisture Content and Physical/Biochemical Stability of Protein Inhalation Powders. Pharmaceutical Research. 15(5): 768-775.

Maa, Y-F., Nguyen, P-A., Sweeney, T.D., Shire, S.J. and Hsu, C.C (1999). Protein Inhalation Powders: Spray Drying vs Spray Freeze Drying. Pharmaceutical Research. 16(2): 249-254.

Mahadevan, H. and Hall, C.K. (1992). Experimental analysis of protein precipitation by polyethylene glycol and comparison with theory. Fluid Phase Equilibria 78: 297-321.

Marr, R. and Gamse, T. (2000). Use of supercritical fluids for different processes including new developments - a review. Chemical Engineering and Processing. 39: 19-28.

Masters, K. (1991). Spray Drying Handbook. Longman

Milliqvist-Fureby, A., Malmsten, M. and Bergenstahl, B. (1999). Spray-drying of trypsin - surface characterisation and activity preservation. International Journal of Pharmaceutics 188(2): 243-253.

Morita, T., Horikiri, Y., Yamahara, H., Suzuki, T. and Yoshino, H. (2000). Formation and Isolation of Spherical Fine Protein Microparticles Through Lyophilization of Protein-Poly(ethylene glycol) Aqueous Mixture. Pharmaceutical Research 17(11): 1367-1373.

Moshashaée, S., Bisrat, M., Forbes. R.T., Nyqvist, H. and York, P. (2000). Supercritical fluid processing of proteins I: Lysozyme preciptitation from organic solution. European Journal of Pharmaceutical Sciences 11: 239-245.

Nesta, D.P., Elliot, J. and Warr, J.P. (2000). Supercritical Fluid Precipitation of Recombinant Human Immunoglobulin from Aqueous Solutions. Biotechnology and Bioengineering 67(4): 457464 
Owens, R., Ball, E., Ganesh, R., Nesbitt., Brown D., Gofton, C., Stephens S., Chaplin, L., Christofidou-Solomidou, M., Blake, S., Howat, D., Buurman, W.A., Albelda, S. and Robinson, M.K. (1997). The in vivo and in vitro characterisation of an engineered human antibody to E-selectin. Immunotechnology 3: 107-116.

Paborji, M., Pochopin, N.L., Coppola, W.P. and Bogardus, J.B. (1994). Chemical and Physical Stability of Chimeric L6, a Mouse-Human Monoclonal Antibody. Pharmaceutical Research 11(5): 764-771

Pakowski, Z. (1987). Drying of Pharmaceutical Products. In: "Handbook of Industrial Drying" (Arun S Mujumdar, Ed.) pp 605 - 641, Marcel Dekker, Inc.

Paiakodaty, S., Walker, S., Townend, G., York, P., and Humphreys, G. (2000). Scale-Up and GMP Design - Particle Process Engineering by the SEDS Process. European Pharmaceutical Contractor. August: $60-63$.

Palakodaty, S., York, P., Hanna, M. and Pritchard J. (1998). Crystallization of Lactose Using Solution Enhanced Dispersion By Supercritical Fluids (SEDS) Technique. In: Proceeding $s$ of the $5^{\text {th }}$ Meeting on Supercritical Fluids, Nice, France, 1998, Tome 1, 275-280.

Paiakodaty, S., York, P. and Pritchard J. (1998). Supercritical Fluid Processing of Materials from Aqueous Solutions: The Application of SEDS to Lactose as a Model Substance. Pharmaceutical Research 15(12): $1835-1843$

Paiakodaty, S., Hanna, M., York, P. and Humphreys, G. (1997). An Experimental Method for the Determination of Solid Solubility in Pure and Modified Supercritical Carbon Dioxide. Pharmaceutical Technology Conference 1997.

Peters, R. and Sikorski, R. (1999). PEG Antibodies. Science 286(5439): 434.

Phillips, E.M. and Stella, V.J. (1993). Rapid Expansion from supercritical solutions: application to pharmaceutical processes. International Journal of Pharmaceutics 94: 1-10.

Pikal, M.J., Dellerman, K.M., Roy, M.L. and Riggin, R.M. (1991). The Effects of Formulation Variables on the Stability of Freeze-Dried Human Growth Hormone. Pharmaceutical Research 8(4): 427-436.

Pisecky, J. (1987). Evaporation and Spray Drying in the Dairy Industry. In: "Handbook of Industrial 
Drying" (Arun S Mujumdar, Ed.) pp 571 - 575, Marcel Dekker, Inc.

Pollack, S.J., Jacobs, J. and Schultz, P.G. (1986). Selective chemical catalysis by an antibody. Science 234: 1570

Rothstein, F. (1994). Differential Precipitation of Proteins. In: "Protein Purification Process Engineering" (R.G. Harrision, Ed) pp 115-207, Marcel Dekker, Inc.

Russell, A.J., Trudel, L.J., Skipper, P.L., Groopman, J.D., Tannenbaum, S.R. and Klibanov, A.M. (1989). Antibody-antigen binding in organic solvents. Biochemical and Biophysical Research Communications 158(1): $80-85$

Sadana, A. (1989). Protein inactivation during downstream separation, part II: the parameters. Biopharmaceuticals 2: 20 - 23.

Sah, H. (1999a). Protein Instability Toward Organic SolventWater Emulsifiation: Implications for Protein Microencapsulation. PDA Journal of Pharmaceutical Science and Technology. 53(1): 3-10

Sah, H. (1999b). Stabilization of proteins against a methylene chloride/water interface-induced denaturation and aggregation. Journal of Controlled Release. 58(2): 143-151

Sah, H. (1999c). Protein Behaviour at the Water/Methylene Chloride Interface. Journal of Pharmaceutical Sciences. 88(12): 1320-1325

Sarup, L., Tservistas, M., Sloan, R., Hoare, M. and Humphreys, G.O. (2000). Investigation of Supercritical Fluid Technology to Produce Dry Particulate Formulations of Antibody Fragments. Transaction of the Institute of Chemical Engineers 78 Part C: 101-104

Sariciaux, J-M., Mansour, S., Hageman, J. and Nail, S. (1999). Effects of Buffer Composition and Processing Conditions on Aggregation of Bovine IgG during Freeze-Drying. Journal of Pharmaceutical Sciences 88(12): 1354-1360.

Setford, S. (2000). Immunosensing in organic and mixed aqueous-organic phase environments. Trends in Analytical Chemistry 19(5): 330-339.

Schein, C.H. (1990). Solubility as a Function of Protein Structure and Solvent Components. 
Bio/Technology 8: 308-317

Schofield, J.P. and Caskey, C.T. (1995). Non-viral approache to gene therapy. British Medical Bulletin 51(1): 56-71.

Schubert, P.F. and Finn, R.K. (1981). Alcohol Precipitation of Proteins: The Relationship of Denaturation and Precipitation for Catalase. Biotechnology and Bioengineering 23: 2569-2509.

Sokhansanj, S. and Jayas, D.S. (1987). Drying of Foodstuffs. In: "Handbook of Industrial Drying" (Arun S Mujumdar, Ed.) pp 517 - 520, Marcel Dekker, Inc.

Skerra, A. and Pluckthun, A. (1993). Bacterial Expression of Immunoglobulin Fragments. Current Opinion in Immunology 5: 256-262.

Skerra, A., Pfitzlnger, I. and Pluckthun, A. (1991). The functional expression of antibody Fv fragments in E.coli: improved vectors and a generally applicable purification technique. Bio/technology 9: 237-278.

Sloan, R., Tservlstas, M., Hollowood, M.E., Sarup, L., Humphreys, G.O., Ashraf, W., York, P. and Hoare, M. (1999) Controlled Particle Formation Of Biological Materials Using Supercritical Fluids.. In: Proceeding $s$ of the $6^{\text {th }}$ Meeting on Supercritical Fluids, Nottingham, U.K, 1999, 169-174.

Sloan, R., Hollowood, M.E., Humphreys, G.O., Ashraf, W. and York, P. (1998) Supercritical Fluid Processing: Preparation of Stable Protein Particles. In: Proceeding $s$ of the $5^{\text {th }}$ Meeting on Supercritical Fluids, Nice, France, 1998, Tome 1, 301-306.

Smlth, T. and Kelly, J. (1998). Formulation of insoluble test substances for long term oral administration in toxicology investigations. Toxicology Letters 95, Supplement 1: 119

Sokhansanj, S. and Jayas, D.S. (1987). Drying of Foodstuffs. In: "Handbook of Industrial Drying" (Arun S Mujumdar, Ed.) pp 517 - 520, Marcel Dekker , Inc

Staniforth, J.N. (1995). Performance-Modifying Influences in Dry Powder Inhalation Systems. Aerosol Science and Technology 22: 346-353

Strandberg, L, Kohler, K. and Enfors, S-O. (1991). Large scale fermentation and purification of a recombinant protein from E.coli. Process Biochemistry 26: 225-234. 
Subramaniam, B., Rajewski, R.A. and Snavely, K. (1997). Pharmaceutical Processing with Supercritical Carbon Dioxide. Journal of Pharmaceutical Sciences 86(8): 885-890.

Thiering, R., Dehghani, F., Dillow, A. and Foster, N.R. (2000a). The influence of operating conditions on the dense gas precipitation of model proteins. Journal of Chemical Technology and Biotechnology 75: $29-41$

Thiering, R., Dehghani, F., Diliow, A. and Foster, N.R. (2000b). Solvent effects on the controlled dense gas precipitation of model proteins. Journal of Chemical Technology and Biotechnology 75: 42-53.

Thomas, C.R. and Dunnhill, P. (1979). Action of shear on enzymes: studies with alcohol dehydrogenase. Biotechnology and Bioengineering 21: 2263 - 2278.

Tijsterman, J.A. (1993). Product Drying, Conditioning and Stabilization: In "Recovery of Bioproducts" (G. Schmidt-Kastner, D. Sell, K. Biederman, M.P. Brocklebank, A. Jungbauer \& J.A. Tijsterman, Eds) pp 59 $65, \mathrm{SCl}$.

Timasheff, S.N. and Arakwa, T. (1988). Stabilization of protein structure by solvents. In: Stabilization of protein structure by solvents (T.E. Creighton Ed) pp: 331-343

Toews, K.L., Shroll, R.M., Wai, C.M and Smart, N.G. (1995). pH-Defining Equilibrium between Water and Supercritical $\mathrm{CO}_{2}$. Influence on SFE of Organics and Metal Chelates. Analytical Chemistry 67(22): 4040-4043.

Tservistas, M., Levy, M.S., Lo-Yim, M.Y.A., O'Kennedy, R.D., York, P., Humphrey, G.O. and Hoare, M. (2001). The formation of Plasmid DNA Loaded Pharmaceutical Powders Using Supercritical Fluid Technology. Biotechnology and Bioengineering 72(1):12-18.

Tramantano, A., Janda, K.D. and Lemur, R.A. (1986). Catalytic Antibodies. Science 234: 1566-1569.

van de Weert, M., Hoechstetter, J., Hennik, W.E. and Crommeiin, D.J.A. (2000). The effect of a water/organic solvent interface on the structural stability of lysozyme. Journal of Controlled Release 68: 351-359. 
Venkat, E. and Kothandaraman, S. (1995). Supercritical Fluid Methods. In: Methods in Biotechnology, Vol 4: Natural Products Isolation (R.J.P. Cannell, Eds). Humana Press Inc.

Verhoeyen, M. and Riechmann, L. (1988). Engineering of antibodies. BioEssays 8(2): 74-78.

Virkar, P.D., Narendranathan, T.J., Hoare, M. and Dunnill, P. (1981). Studies of the effect of shear on globular proteins: Extension to high shear fields and pumps. Biotechnology and Bioengineering 21: 425 429.

Walsh, G. (1998). The Drug Manufacturing Process. In "Biopharmaceuticals: Biochemistry and Biotechnology" pp 103 - 157, John Wiley \& Sons.

Wang, W. (1999). Instability, stabilization, and formulation of liquid protein pharmaceuticals. International Journal of Pharmaceutics 185: 129-188

Wang, W. (2000). Lyophilization and development of solid protein pharmaceuticals. International Journal of Pharmaceutics 203: 1-60

Ward, E.S. (1992). Antibody Engineering Using Escherichia coli as Host. Advances in Pharmacology 24: $1-20$.

Weijers, S.R. and Van't Riet, K. (1992). Enzyme Stability in Downstream Processing, Part 1: Enzyme inactivation, Stability and Stabilization. Biotechnology Advances 10: 237 - 249.

Weijers, S.R. and Van't Riet, K. (1992). Enzyme Stability in Downstream Processing, Part 2: Quantification of Inactivation. Biotechnology Advances 10: 251-273.

Willemer, H. (1999). Experimental Freeze-Drying: Procedures and Equipment. In: FreezeDrying/Lyophilization of Pharmaceutical and Biological Products (Louis Rey and Joan C May, Eds). Pp 79-121. Marcel Dekker Inc.

Winters, M.A., Knutson, B.L, Debendetti, P.G., Przbycien, T.M. and Prestrelski, S.L. (1996). Precipitation of Proteins in Supercritical Carbon Dioxide. Journal of Pharmaceutical Sciences 85(6): 586594.

Winters, M.A., Debenedetti, P.G., Carey, J., Sparks, H.G., Sane, S.U. and Przybycien, T.M. (1997). 
Long term and high temperature storage of supercritically-processed microparticulate protein powders. Pharmaceutical Research 14(10): 1370-1377.

Winters, M.A., Frankel, D.Z., Debenedetti, P.G., Carey, J., Devaney, M. and Przybycien, T.M. (1999). Protein Purification with Vapour-Phase Carbon Dioxide. Biotechnology and Bioengineering 62(3): 247258.

Winters, M.A., Debenedetti, P.G., Carey, J., Sparks, H.G., Sane, S.U. and Przybyclen, T.M. (1997). Long term and high temperature storage of supercritically-processed microparticulate protein powders. Pharmaceutical Research 14(10): 1370-1377.

Winter, G. and Milstein, C. (1991). Man-made antibodies. Nature 349: 293-299.

Wong, D. and Parasrampuria, J. (1997). Pharmaceutical Excipients for the Stabilization of Proteins. Pharmaceutical Technology October 1997: 34-50.

Yeo, S.D., Lim, G.B., Debenedetti, P.G. and Berstein, H. (1993). Formation of Microparticulate Protein Powders Using a Supercritical Fluid Antisolvent. Biotechnology and Bioengineering 41: 341-346.

York, P. and Hanna, M. (1996). Particle Engineering by Supercritical Fluid Technologies for Powder Inhalation Drug Delivery. Respiratory Drug Delivery V: 231-239

York, P., Hanna, M., Shekunov, B.Y. and Humphreys, G.O. (1998). Microfine Particle Formation by SEDS (Solution Enhanced Dispersion by Supercritical Fluids): Scale Up by Design. Respiratory Drug Delivery VI: 169-175

York, P. (1999). Strategies for particle design using supercritical technologies. Pharmaceutical Science and Technology Today 2(11): 430-440.

York, P. (2000). Supercritical fluids ease Drug Delivery. Manufacturing Chemist June 27-29.

Zale, S.E. and Klibanov, A.M. (1986). Why does ribonucleas irreversibly inactivate at high temperatures. Biochemistry 25: 5432-5444. 
Investigation of Supercritical Fluid Technology to Produce Dry Particulate Formulations of Antibody Fragments

Appendices

\section{APPENDICES}




\section{Appendix 1 - Treatment and Propagation of Errors}

When collecting experimental data errors or variations in the data can occur due to a number of reasons. Errors can be generated during the experimental procedure for example during dilutions of samples, particularly if a whole series of dilutions is being performed. Errors can occur during pipetting of samples especially if pipettes are not regularly calibrated.

Having estimated a data population quantity such as the mean, it is desirable to assess the accuracy of this estimate. The customary approach is to construct a confidence interval within which one is sufficiently sure the true population value lies. The standard error of a data population measures the precision with which an estimate from one sample approximates the true data population value, and thus can be used to construct a confidence interval to assess the accuracy of the estimate.

When considering experimental data one can consider the data to be of a normal distribution (an assumption that is entirely reasonable), then this data will have a population mean $(\mu)$, the value of which is of interest when analysing the data.

The observation that the mean of a large sample is, in some sense, going to be closer to the mean of the sample population is the key to the more precise understanding of why the mean of a larger sample is 'better' than the mean of a smaller sample. Means based on larger samples provide more precise estimates of the underlying population mean because the distribution of the sample mean becomes more concentrated about $\mu$ as the sample size increases.

The figure that is used to measure how precisely the sample mean estimates the population mean is called the standard error of the mean, or more simply the standard error. If a variable has a standard deviation of $\delta$ then the standard error of the mean of sample size $n$ is given by the equation:

$s e=\delta /(\sqrt{ } n)$

Standard errors and standard deviations are put to different uses. Standard deviations are descriptive tools that indicate the dispersion in a sample. A standard error is an inferential tool, which measures the precision of estimates of sample population parameters.

It is common to indicate the 'error' in a quantity by quoting the mean value plus or minus the estimated error (mean+/-se). However, strictly speaking for greater accuracy one should quote the mean value plus 
Investigation of Supercritical Fluid Technology to Produce Dry Particulate Formulations of Antibody Fragments Appendices

or minus 2xse. This is due to the fact that for a Normal Distribution most values (approx. 95\% of them) lie between $\mu-2 \delta$ and $\mu+2 \delta$. Therefore, if one is using standard error as a measurement of the accuracy of the mean it is more relevant to quote $\mu+/-2 \delta$ as this amounts to saying that there is a $95 \%$ chance that $\mu$ lies in the interval $\mu+/-2 \delta$.

It should be noted that the standard error decreases as the sample size increases, because the denominator in the ratio $\delta /(\sqrt{ } n)$ gets larger. This is in distinction to the standard deviation, which does not have a tendency to get larger or smaller as $n$ increases.

All the Tables in Chapter Four of this thesis that previously quoted values for standard deviation have now been corrected to state standard error values. 


\section{Appendix 2 - Second Order Rate Equations}

As with many physiochemical principles the rules governing rates of reaction were first established empirically, and later subject to extensive theoretical analysis, leading to present understanding of the controlling factors. The empirical observations centred around establishment of reaction conditions under which the rate could be measured as a function of concentration of reactants. It was found that the rate was related to concentration in a predictable way, leading to the concept of the rate constant, and equations for simple reactions that fell into several classes.

$1 \quad$ 1storder reactions.

Reactions, in which the rate of reaction is directly proportional to the concentration of a single species. The resulting change in concentration with time is exponential, so that a plot of In(concentration) $v$ time is linear.

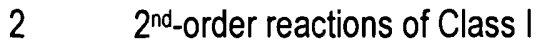

Reactions in which the rate varies with concentration of a single species, but the stoichiometric coefficient is 2 . The result is that a plot of $1 /$ (concentration) $v$ time is linear.

In this appendix the derivation of $2^{\text {nd-order }}$ processes of the Class 1 type will be shown. Derivation of the formal equations describing the reaction shown below follows a similar approach to that for 1 storder reactions.

\section{$A+A \rightarrow P$}

A general reaction: $2 A \rightarrow P$ is described.

rate of reaction $=v=-d[\mathrm{~A}] / d \mathrm{t}=d\left[\mathrm{P} y / d t=k[\mathrm{~A}]^{2}\right.$

Choosing a set of parameters to minimise terms:

$$
v=-d[A] / d t=k[A]^{2}
$$

Re-arranging to group like terms:

$$
-d[A] /[A]^{2}=k d t
$$


Integrating both sides of the equation:

$$
1 /[A]=k t+C
$$

Substituting an appropriate term for the constant of integration, C:

$$
1 /[A]-1 /[A]_{0}=k t
$$

solving for $t_{1 / 2}$ :

$$
\begin{aligned}
& 1 /\left(1 / 2[A]_{0}\right)-1 /[A]_{0}=k t_{1 / 2} \\
& 1 /[A]_{0}=k t_{1 / 2} \\
& t_{1 / 2}=1 / k[A]_{0}
\end{aligned}
$$

The integrated rate equation shows that a plot of $1 /[A]]$ against time will give a straight line for a $2^{\text {ndorder, }}$ Class I reaction, with an intercept at $1[A]$ o. A concentration term for $[A]$ appears in the equation for $t_{1 / 2}$, so the half time depends in initial concentration.

For a first order reaction following the approach shown above we would have:

$$
\begin{aligned}
& d[A] / d t=k[A] \\
& d[A] /[A]=k d t
\end{aligned}
$$

Integrating

$$
\begin{aligned}
& \ln [A]=k t+C \\
& \ln \left[A / A_{0}\right]=k t
\end{aligned}
$$

Initially it was believed that the data collected for the temperature stability tests carried out on 4D5Fab at $80^{\circ} \mathrm{C}$ could be fitted to a second order reaction (see page 89 of thesis for initial plotting of data). However, subsequently this data has been re-plotted (see following figure) and it has been found that the data cannot be fitted to a $2^{\text {nd }}$-order reaction. 


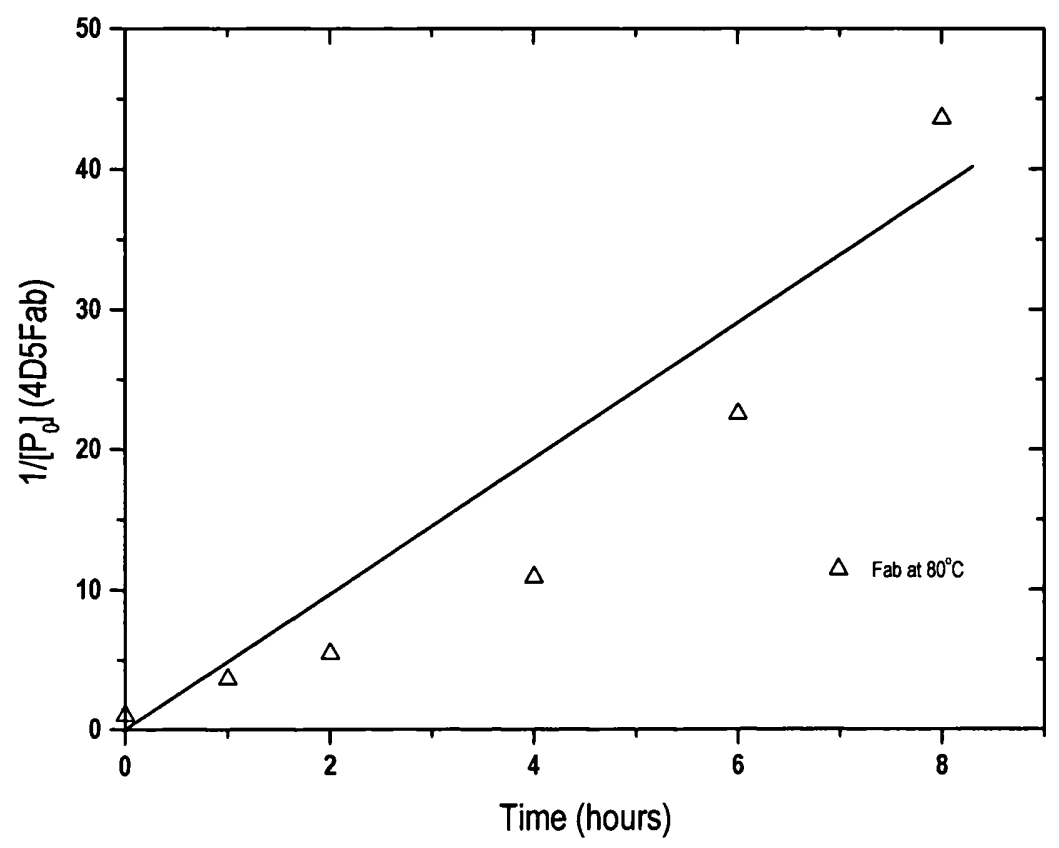

Appendix Figure 1 - Results from 4D5Fab Temperature Stabiiity Experiment at $80^{\circ} \mathrm{C}$ fitted to a $2^{\text {nd. }}$ order reaction. 


\section{Appendix 3 - Activation Energy for Thermal Damage of Proteins}

The activation energy $\left(E_{A}\right)$ is the minimum energy required to convert reactants into products. Or in the case of the example here the minimum energy required for the thermal damage of the proteins being studied (Fab Antibody Fragments). The activation energy enables bonds to stretch and break and rearrangements of atoms, ions and electrons to occur as reactions proceed.

This activation energy can be calculated using the Arrhenius Equation:

$$
k=A \exp \left(-E_{A} / R T\right)
$$

where the rate constant $k$ is the total frequency of collisions between reaction molecules $A$ times the fraction of collision $\exp \left(-E_{A} / R T\right)$ that have an energy that exceeds a threshold activation energy $E_{a}$ at a temperature of $T$ (kelvins). $R$ is the universal gas constant. In this analysis $1^{\text {st }}$ order values of rate constants are used.

If one takes logarithms to the base $e$ in the above equation then:

$$
\ln k=\ln A+\ln e^{-E_{A} / R T}
$$

Which gives

$$
\ln k=\ln A-E_{A} / R T
$$

Comparing this equation to:

$$
y=c+m x
$$

a graph of Ink against $1 / T$ should give a gradient of $-E_{A} / R$. Where $E_{A}$ is the activation energy in $\mathrm{J}$ mole ${ }^{-1}$ and $R$ is the gas constant $\left(R=8.3144 \mathrm{Jmol}^{-1} \mathrm{~K}^{-1}\right)$.

The graphs on the next three pages show the plots of $\ln k v 1 / T$ (in kelvins) for the D1.3Fv temperature experiments detailed in Chapter 3. These plots have been used to calculate the Activation Energy for each of the concentrations of D1.3Fv looked at.

Activation Energies for the 3 D1.3 Fv Concentrations:
Low Conc $(65 \mu \mathrm{g} / \mathrm{ml})$
$E_{A} / R=4200$
$E_{A}=35 \mathrm{~kJ} / \mathrm{mole}$
Med Conc (300 $\mathrm{gg} / \mathrm{ml})$
$E_{A} / R=2950$
$E_{A}=24 \mathrm{~kJ} / \mathrm{mole}$
High Conc $(650 \mu \mathrm{g} / \mathrm{ml})$
$E_{A} / R=9800$
$E_{A}=82 \mathrm{~kJ} / \mathrm{mole}$

These values are really only in the order of magnitude ones and not too much should be read into their relative values. They should only be regarded as rough indicators as to D1.3Fv being a typical molecule where small increases in temperatures can lead to sharp changes in the lability of the molecule. 


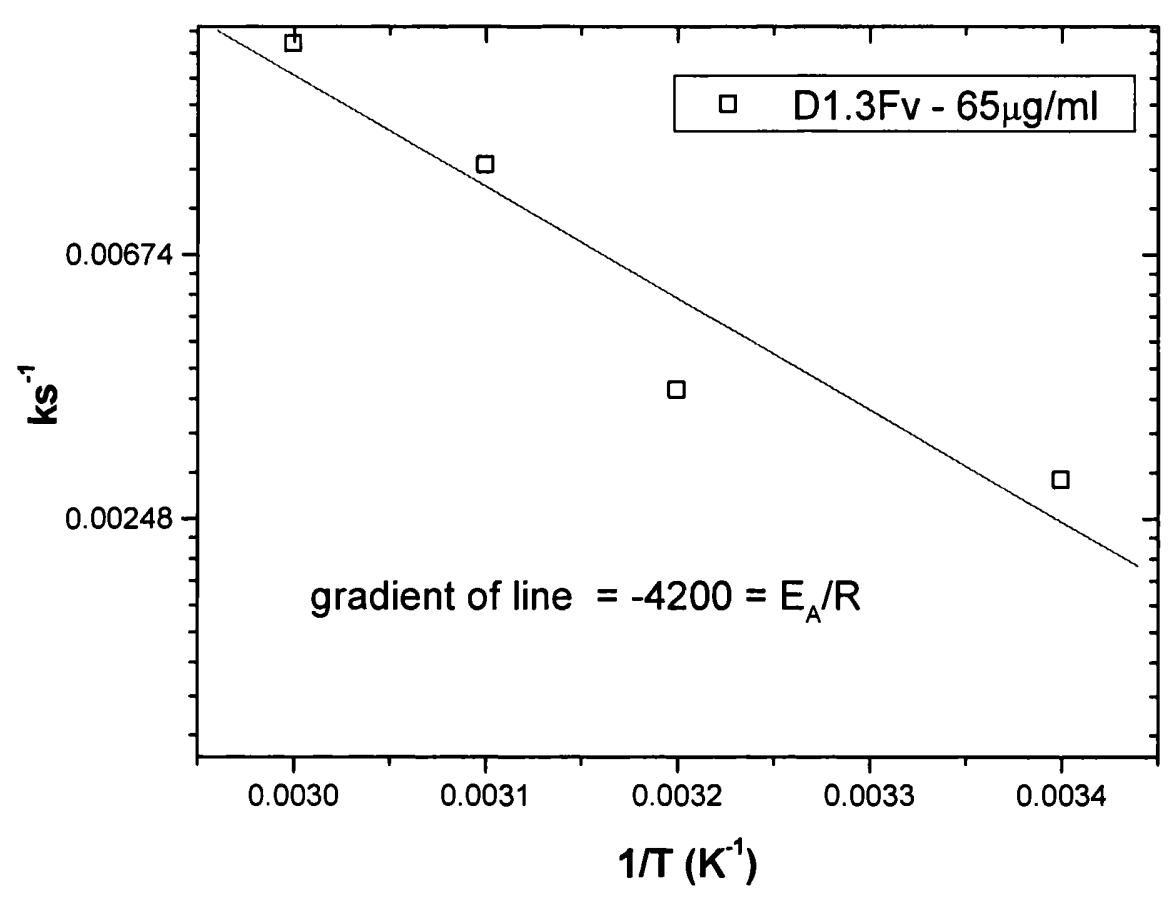

Appendix Figure $2 \quad$ Plot of Ink $v 1 / T$ for low concentration of D1.3Fv.

Gradient of slope $=E_{A} / R$ 
Investigation of Supercritical Fluid Technology to Produce Dry Particulate Formulations of Antibody Fragments Appendices

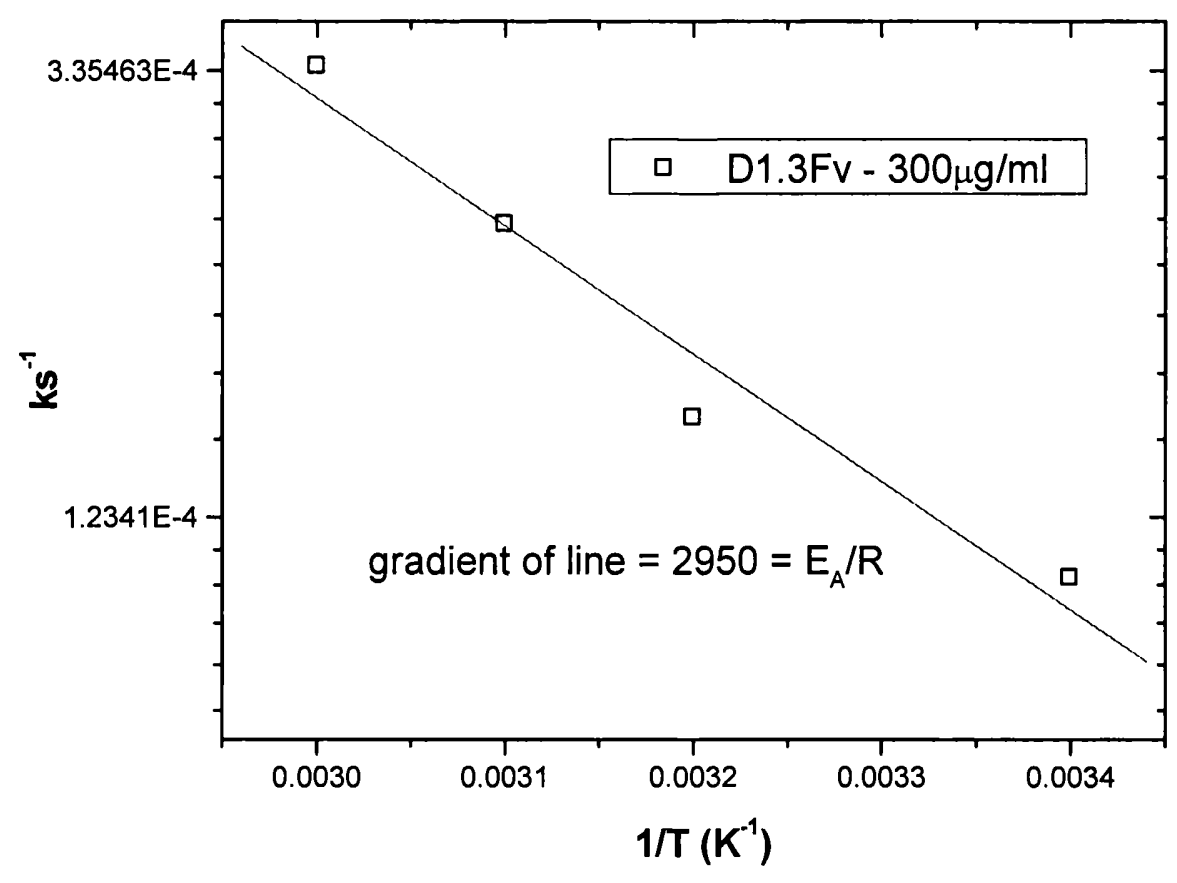

Appendix Figure $3 \quad$ Plot of Ink $v 1 / T$ for medium concentration of D1.3Fv.

Gradient of slope $=-E_{A} / R$ 


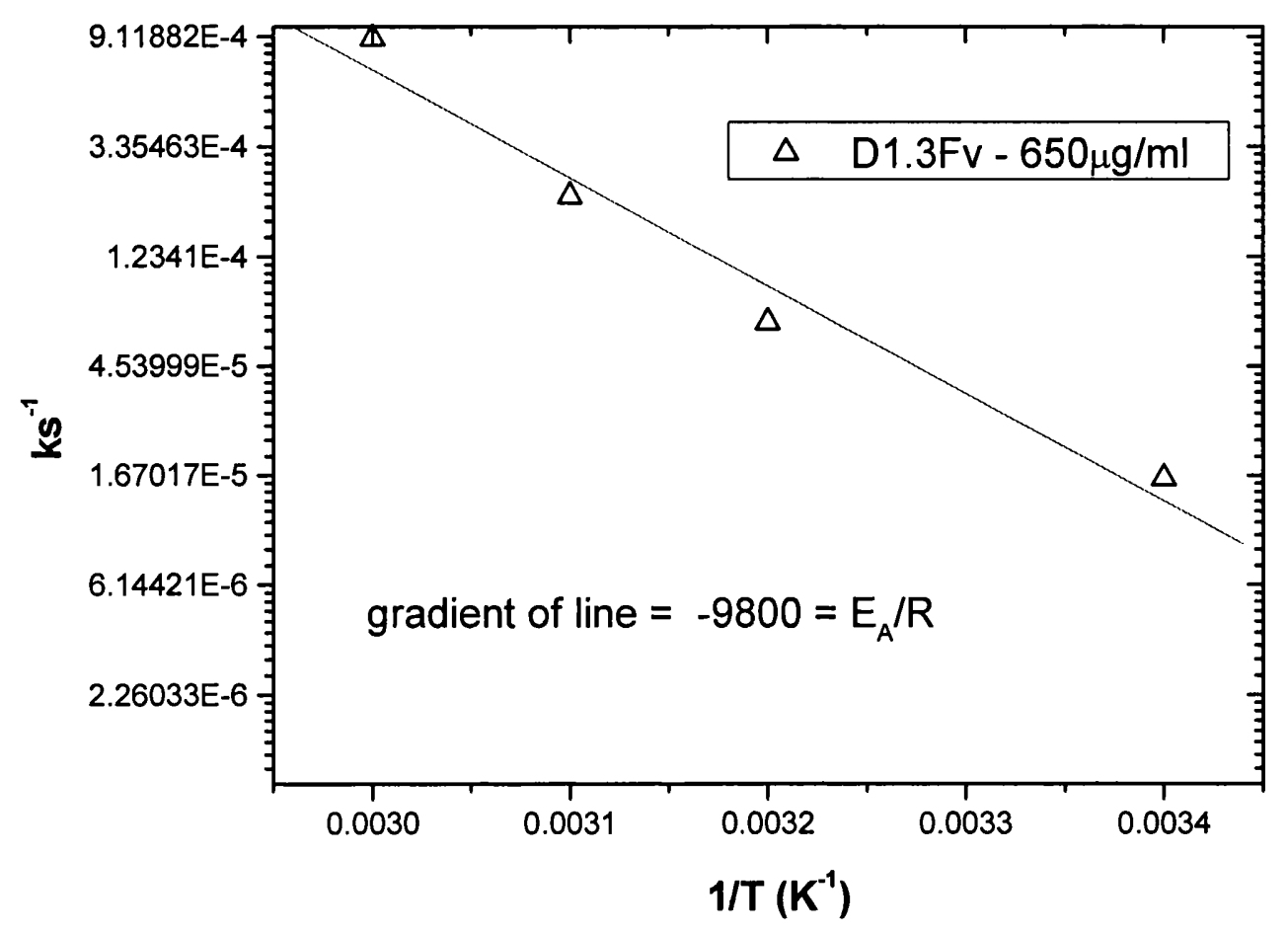

Appendix Figure $4 \quad$ Plot of Ink $v 1 / T$ for high concentration of D1.3Fv.

Gradient of slope $=-E_{A} / R$ 


\section{Appendix 4 - Residence Time in the Nozzle}

Nozzle volume. The volume being considered is the volume of the nozzles mixing chamber. As this is Bradford Particles Designs proprietary data the actual dimensions of the nozzle cannot be given here only the volume of the mixing chamber will be stated.

The volume of the mixing chamber is $3.3 \mathrm{E}-4 \mathrm{~cm}^{3}$ or $3.3 \mathrm{E}-4 \mathrm{ml}$

Flowrates for initial experiments - scCO2 $-18 \mathrm{~m} / \mathrm{min}$

Solvent $-1.5 \mathrm{ml} / \mathrm{min}$

Antibody Solution $-0.06 \mathrm{ml} / \mathrm{min}$

Flowrates for initial experiments - scCO2-10 $\mathrm{ml} / \mathrm{min}$

Solvent $-0.9 \mathrm{ml} / \mathrm{min}$

Antibody Solution $-0.03 \mathrm{ml} / \mathrm{min}$

When the three feed streams mix the most influential flowrate will be the $\mathrm{scCO}_{2}$ flowrate as this is substantially faster than the other flowrates, therefore this flowrate will govern the residence time in the nozzle mixing chamber.

For initial flowrates residence time in the mixing zone:

$\underline{3.3 \times 10^{-4} \mathrm{ml}}=1.8 \times 10^{-5} \mathrm{~min}$ or $1.08 \times 10^{-3}$ secs

$18 \mathrm{ml} / \mathrm{min}$

For second set of flowrates residence time in the mixing zone:

$\frac{3.3 \times 10^{-4} \mathrm{ml}}{10 \mathrm{~m} / \mathrm{min}}=3.3 \times 10^{-5} \mathrm{~min}$ or $1.98 \times 10^{-3}$ secs

$10 \mathrm{ml} / \mathrm{min}$ 
Investigation of Supercritical Fluid Technology to Produce Dry Particulate Formulations of Antibody Fragments Publications arising from and related to this thesis

Publications arising from and related to this thesis. 
Investigation of Supercritical Fluid Technology to Produce Dry Particulate Formulations of Antibody Fragments Publications arising from and related to this thesis

The following list is of publications that have arisen directly from work carried out for this thesis or work connected to this thesis. On the following pages a copy of the first paper can be found and a reproduction of the poster presented at the IchemE Research 2000:Stretching the Boundaries of Chemical Engineering Conference, Bath, January 2000. This poster won the $£ 500$ first prize in the poster competition run by the IChemE Solids Drying Subject Group. An oral presentation was also given at this conference.

Sarup, L., Tservistas, M., Sloan., R., Hollowood, M., Hoare, M., Humphreys, G.O., York, P. and Ashraf, W. (2000). Investigation of Supercritical Fluid Technology to Produce Dry Particulate Formulations of Antibody Fragments. Transactions of the Institute of Chemical Engineers. 78(C): 101-103.

Tservistas, M., Sarup, L., Hoare, M, York, P., Sloan, R. and Humphreys, G.O. (2000). Supercritical fluid technology for the processing of biomaterials. Biotechnology 2000, The World Congress on Biotechnology, 11th International Biotechnology Symposium and Exhibition, 3-8 Sept. Berlin, Book of Abstracts, 1, 505.

Tservistas, M., Sarup, L., Sloan, R., Ashraf, W., Humphreys, G.O. and Hoare, M (1999). Supercritical Fluids for Dry Powder Formualtions of Plasmid DNA. 9th European Congress on Biotechnology, Brussels July 1999. Poster Presentation.

Sloan., R., Tservistas, M., Sarup, L., Hollowood, M., Humphreys, G.O., York, P., Ashraf, W. and Hoare, M. (1999). Controlled Particle Formulations of Biological Material Using Supercritical Fluids. I.S.A.S.F $6^{\text {th }}$ Meeting on Supercritical Fluids, Nottingham. April 1999. Oral Presentation. 


\title{
INVESTIGATION OF SUPERCRITICAL FLUID TECHNOLOGY TO PRODUCE DRY PARTICULATE FORMULATIONS OF ANTIBODY FRAGMENTS
}

\author{
L. SARUP, M. T. SERVISTAS, R. SLOAN*, M. HOARE (FELLOW) and G. O. HUMPHREYS** \\ The Advanced Centre for Biochemical Engineering, University College London, Torrington Place, London UK \\ *Postgraduate Studies in Pharmaceutical Technology, University of Bradford, Bradford, UK \\ **Bradford Particle Design Ltd, Listerhills Science Park, Bradford, UK
}

\begin{abstract}
C. olution Enhanced Dispersion by Supercritical fluids (SEDS) has been used to produce dry particulate formulations of two antibody fragments, D1.3Fv and 4D5Fab. Loss of activity was experienced by both of the antibody fragments, the 4D5Fab was found to be the most robust of the two. Activity loss was reduced by choice of solvent and temperature.
\end{abstract}

Keywords: supercritical carbon dioxide; antibody fragments; particles; SEDS

\section{INTRODUCTION}

Micro, submicrometre and ultrafine particles are increasingly in demand as they have a broad application in pharmaceutical drug delivery especially. in the fields of pulmonary delivery and needle-free powder injection. These delivery methods have advantages over conventional methods, as they are more amenable to patients. Such applications require bioactive particles of well-defined characteristics ${ }^{1}$.

Conventional methods for powder preparation including freeze drying and spray drying have considerable disadvantages for these applications. Freeze-drying produces particles of a broad size range distribution, which require subsequent milling and sieving ${ }^{2-4}$. Spray drying can produce particles of a controlled size, but biological material is exposed to high temperatures during the process, which can result in significant loss of biological activity ${ }^{2,5,6}$.

The use of supercritical fluids for materials' processing is one of the efficient and novel approaches used to achieve high purity micron-sized particles with well-defined morphological structures in a single step. Particle production using supercritical fluids could potentially mean the elimination of harvesting and drying stages and also the reduction of residual solvents ${ }^{7}$.

Methods involving supercritical fluids facilitate controlled particle formation at near ambient temperatures. Four or five main processes have been developed that use supercritical fluids for materials processing: rapid expansion of supercritical solutions $(\mathrm{RESS})^{8}$, the gas anti-solvent (GAS) ${ }^{9}$ method, aerosol solvent extraction system (ASES) ${ }^{10}$, a precipitation with a compressed anti-solvent $(\mathrm{PCA})^{11}$ and solution enhanced dispersion by supercritical fluids (SEDS). The first four of these processes requires the product to be dissolved either in the supercritical fluid itself or in a organic solvent. For biomolecules such as proteins or nucleic acids, this is often not possible or can result in considerable denaturation. The fifth technique (SEDS) overcomes these limitations by maintaining the biomolecules in an aqueous solution prior to particle formation and using modified supercritical $\mathrm{CO}_{2}$ to extract the aqueous phase from the product.

The technique of Solution Enhanced Dispersion by Supercritical fluids (SEDS) involves the rapid dispersion, mixing and extraction of a protein solution and anti-solvent. The successful application of SEDS requires not only a detailed understanding of the phase diagrams involved but also the interaction of the biological material with the process engineering environment ${ }^{12-14}$.

The use of SEDS is described in this paper. Data is presented to show the effects of the SEDS process on the biological activity of two antibody fragments. Results of experiments carried out to characterize the sequence of process events occurring during SEDS are given. These results were used to identify critical aspects of the process which lead to loss of biological activity and to find means by which these aspects can be minimized or eliminated.

\section{SOLUTION ENHANCED DISPERSION BY SUPERCRITICAL FLUIDS}

A schematic diagram of the process is shown in Figure 1. The key component of this technique is the three-channelled coaxial nozzle, designed to use high velocity supercritical carbon dioxide to disperse the aqueous feed and an organic anti-solvent (e.g. isopropanol) into a particle formation vessel. Constant supercritical pressure and temperature are maintained by the means of a back pressure regulator and air oven, respectively. The solutes of the aqueous feed (e.g. biological product and excipients) precipitate by the action 
of the anti-solvent and the particles thus formed are retained in the vessel. The resultant supercritical mixture, comprising water and organic solvent extracted into the supercritical $\mathrm{CO}_{2}$, is vented via the back pressure regulator outlet.

\section{THREE COMPONENT SUPERCRITICAL PHASE BEHAVIOUR}

Four variables (temperature, pressure and two independent mole fractions) according to the Gibbs phase rule are needed to describe the system. Usually ternary phase equilibria are plotted in so-called Gibbs-triangles, where composition is plotted at constant pressure and temperature. Figure 2 shows a typical phase diagram for a three component system of the aqueous, common alcohol (such as ethanol) and $\mathrm{CO}_{2}$ process streams employed in $\mathrm{SEDS}^{15}$.

It can be seen that the region of immiscibility (the area bounded by and below the binodal curve) is large and more than half of all possible mole fractions lie inside it. Above the critical point of the organic and $\mathrm{CO}_{2}$ there is complete miscibility of $\mathrm{CO}_{2} /$ organic and organic/water mixtures. The 'bottom' of the triangle represents the binary system $\mathrm{CO}_{2} / \mathrm{H}_{2} \mathrm{O}$ and it can be seen that only a small amount of either component is miscible with the other, this necessitates the use of an organic anti-solvent.

The aim of the SEDS process is to form dry solute particles in a single equilibrium phase, whilst removing the water and organic anti-solvent from the particle formation vessel. Aqueous, organic and supercritical fluid feeds are introduced into the particle formation vessel through the nozzle at flow rates aimed achieving a single-equilibrium phase within the particle formation vessel. The process path occurring in SEDS is from a two-phase flow (aqueous/ organic and supercritical fluid/organic phases) to the desired single equilibrium phase. This process path follows the equilibrium tie-lines defined by the process conditions. The phase transition and subsequent particle formation comprise concurrent phenomena initiated by a two-way mass transfer between the supercritical fluid/organic and organic/water phases. These phenomena are precipitation of the solute from the aqueous feed by the organic anti-solvent and extraction of water into the supercritical $\mathrm{CO}_{2}$ facilitated by the organic solvent modifier.

Figure 2 shows two different experimental systems, corresponding to points $\mathrm{A}$ and $\mathrm{B}$ on the phase diagram. $\mathrm{L}(\mathrm{A})$ and $\mathrm{L}(\mathrm{B})$ show the composition of the liquid phase where particle formation initiates with points $\mathrm{A}$ and $\mathrm{B}$ representing the finally resulting supercritical mixture. The difference in composition of $\mathrm{A}$ and $\mathrm{B}$ is small but their corresponding liquid phase points, $\mathrm{L}(\mathrm{A})$ and $\mathrm{L}(\mathrm{B})$, differ significantly. $\mathrm{L}(\mathrm{A})$ being an organic rich phase and $\mathrm{L}(\mathrm{B})$ being an aqueous rich one. Thus for two experimental systems the particle formation proceeds from significantly different liquid phases. The make up of the feeds to the nozzle represent an important operating variable defining the chemical environment of particle formation ${ }^{16}$. The role of phase behaviour on derived particle size and morphology has been demonstrated during the SEDS processing of aqueous solutions of small water soluble molecules ${ }^{13}$.

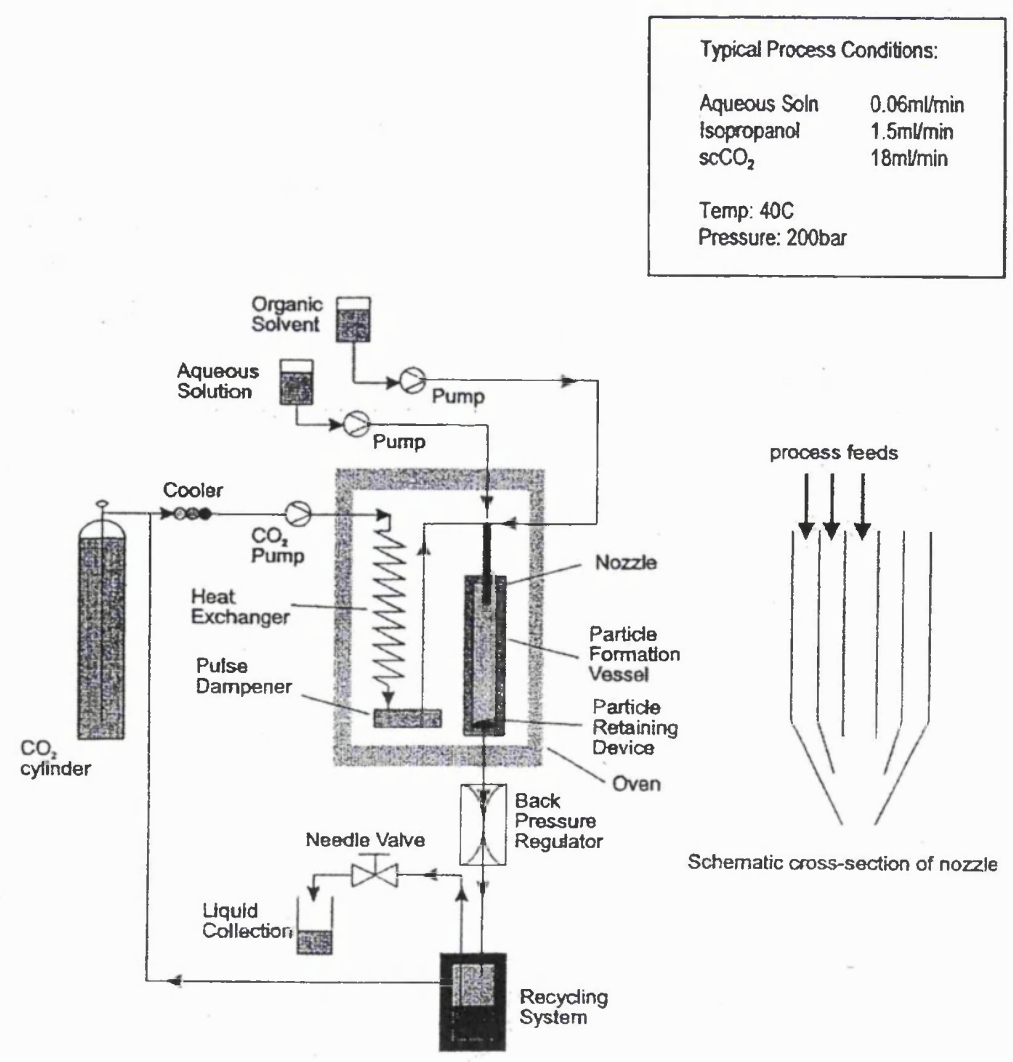

Figure 1. Schematic diagram of the SEDS experimental set-up, including cross-section of nozzle arrangement. 


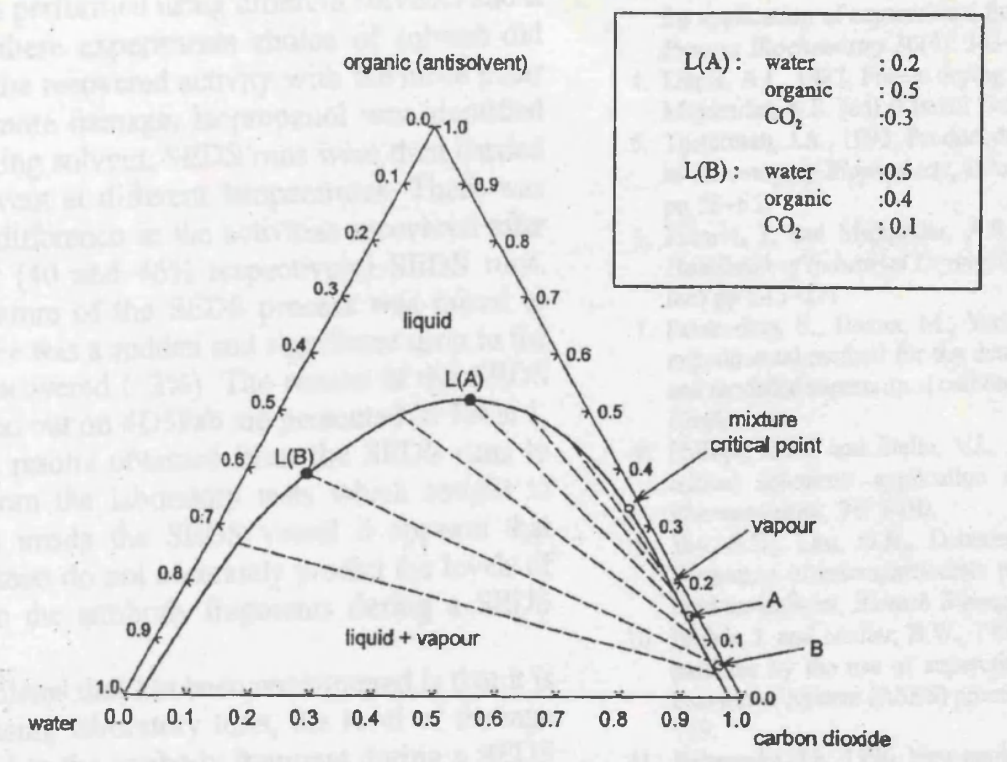

Figure 2. A typical phase diagram for a three component system of the aqueous, common alcohol, such as ethanol, and $\mathrm{CO}_{2}$ process streams employed in SEDS.

\section{SEDS PROCESSED ANTIBODY FRAGMENTS}

To date, two antibody fragments have been processed using SEDS, D1.3Fv and 4D5Fab. Antibody molecules are multi-chain proteins. The antibody molecule, shown in Figure 3, consists of a Y-shaped tetramer of polypeptides composed of two heavy and two light chains. The whole antibody may be cleaved, via digestion with papain, at the hinge region resulting in three approximately equal sized fragments. Two Fab fragments (fragments that retain the ability to bind the-antigen) and an Fc fragment (the part of the antibody that triggers the immune response). Fv fragments are obtained by digestion of Fab fragments with pepsin. Fab fragments contain both variable regions (those regions that form the antigen binding site) and constant domains (areas that are not involved in binding). Fv fragments contain only the variable regions ${ }^{17}$.

\section{RESULTS}

Both of the antibody fragments were freeze-dried to test whether or not they could withstand drying via a conven- tional method. Freeze-drying does have a slight damaging effect on the antibody fragments but the results indicate that both fragments are robust enough to withstand conventional drying and that any loss of activity seen after SEDS processing must be due to some specific feature of the SEDS process. Both antibody fragments were found to be susceptible to considerable damage on exposure to solvent over long time periods.

Both antibody fragments were tested for temperature and $\mathrm{pH}$ stability. D1.3Fv was stable up to 50C and 4D5Fab was stable up to $70 \mathrm{C}$. These results suggested that the SEDS processing temperature of $40 \mathrm{C}$ would be feasible. The stability of the antibody fragments at $\mathrm{pH} 2.7$ (the $\mathrm{pH}$ of supercritical $\mathrm{CO}_{2}$ ) was also tested, there was a slight loss in activity at this $\mathrm{pH}$ but not a significant one.

A series of runs were carried out in the SEDS device for both antibodies varying both temperature and solvent used. A summary of some of these runs is presented in Table 1. After SEDS processing of D1.3Fv little activity was retained whilst for 4D5Fab significant activity was recovered. This reflects the more robust structure of the Fab fragment form (see Figure 3).

Table 1. 4D5Fab antibody fragment.

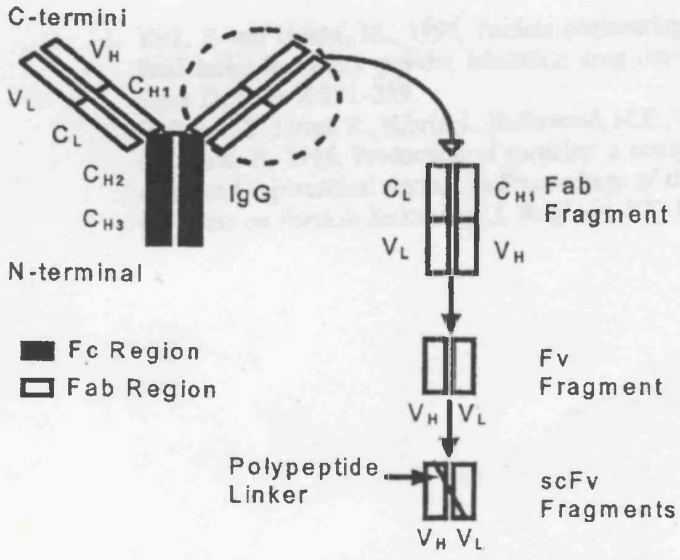

Figure 3. An antibody molecule and its derived fragments.

\begin{tabular}{llcc}
\hline & Solvent & $\begin{array}{c}\text { Temperature } \\
\text { (c) }\end{array}$ & $\begin{array}{c}\text { Recovered specific } \\
\text { activity \% }\end{array}$ \\
\hline Effect of protein & Methanol & 40 & 3 \\
D1.3Fv & Methanol & 40 & 20 \\
4D5Fab & & & \\
Effect of solvent & Methanol & 40 & 20 \\
4D5Fab & Ethanol & 40 & 21 \\
4D5Fab & Isopropanol & 40 & 46 \\
4D5Fab & & & \\
Effect of temperature & Isopropanol & 35 & 40 \\
4D5Fab & Isopropanol & 40 & 46 \\
4D5Fab & Isopropanol & 50 & 12 \\
4D5Fab & & & \\
\hline
\end{tabular}


SEDS runs were performed using different solvents and it was seen that in these experiments choice of solvent did have an effect on the recovered activity with the more polar solvents causing more damage. Isopropanol was identified as the least damaging solvent. SEDS runs were then carried out using this solvent at different temperatures. There was not a siginificant difference in the activities recovered after the $35 \mathrm{C}$ and $40 \mathrm{C}$ (40 and $46 \%$ respectively) SEDS runs. When the temperature of the SEDS process was raised to $50 \mathrm{C}$, however, there was a sudden and significant drop in the level of activity recovered (12\%). The results of the SEDS experiments carried out on 4D5Fab are presented in Table 1.

Comparing the results obtained from the SEDS runs to those obtained from the laboratory tests which sought to mimic conditions inside the SEDS vessel it appears that these small scale tests do not accurately predict the levels of damage caused to the antibody fragments during a SEDS run.

One of the problems that has been encountered is that it is hard to predict, using laboratory tests, the level of damage that will be caused to the antibody fragment during a SEDS run. Promising work is being carried out at present which involves subjecting pre-dried antibody fragments to the conditions inside the vessel. Preliminary results from these experiments indicate that damage caused by the organic solvent is the major issue that needs to be addressed. Results from these experiments will be discussed.

\section{CONCLUSIONS}

The results presented show that of the two antibody fragments tested 4D5Fab is the more robust of the two. This result is not surprising as this antibody fragment is a thought to be a more stable fragment due to its protein engineering. The results of the SEDS experiments indicate that choice of temperature and anti-solvent are critical in reducing the amount of damage suffered by the antibody fragment during SEDS processing. One of the problems that has been found is that it is hard to predict, using laboratory tests, the level of damage that will be caused to the antibody fragment during a SEDS run.

Future work will examine in more detail the losses encountered in processing the antibody fragments. Studies will be made of suitable protectants for processing and stabilisers for long-term storage.

\section{REFERENCES}

1. York, P. and Hanna, M., 1996, Particle engineering by supercritical fluid technologies for powder inhalation drug delivery, Respiratory Drug Delivery V, 231-239.

2. Forbes, R.T., Sloan, R., Kibria, I., Hollowood, M.E., Humphreys, G.O. and York, P., 1998, Production of particles: a comparison of freeze, spray and supercritical drying, In Proceedings of the IChemE World Congress on Particle Technology 3, Brighton, UK, 180.
3. Jarzebski, A.B. and Malinowski, J.J., 1995, Potentials and prospects for application of supercritical fluid technology in bioprocessing, $J$ of Process Biochemistry 30(4): 343-352.

4. Liapis, A.I., 1987, Freeze drying. In: Handbook of Industrial Drying, Mujumdar, A.S. (ed) (Marcel Dekker, Inc) pp 295- 323.

5. Tijsterman, J.A., 1993, Product drying, conditioning and stabilization, in Recovery of Bioproducts, Schmidt-Kastener et al. (eds) (SCI, UK) pp 59-65.

6. Filkova, I. and Mujumdar, A.S., 1987, Industrial spray drying, In Handbook of Industrial Drying, Mujumdar, A.S. (ed) (Marcel Dekker, Inc) pp 243-291.

7. Palakodaty, S., Hanna, M., York, P. and Humphreys, G., 1997, An experimental method for the determination of solid solubility in pure and modified supercritical carbon dioxide, Pharmaceutical Technology Conference.

8. Phillips, E.M. and Stella, V.J., 1993, Rapid expansion from supercritical solutions: application to pharmaceutical processes. Int $J$ Pharmaceutics, 94: 1-10.

9. Yeo, S.D., Lim, G.B., Debenedetti, P.G. and Berstein, H., 1993, Formation of microparticulate protein powders using a supercritical fluid antisolvent, Biotech Bioengi 41: 341-346.

10. Bleich, J. and Muller, B.W., 1996, Production of drug loaded microparticles by the use of supercritical gases with the Aerosol Solvent Extraction System (ASES) process, J Microencapsulation 13(2): 131139.

11. Brennecke, J.F., 1996, New applications of supercritical fluids. Chemistry and Industry 12: 831-834.

12. Hanna, M.H. and York, P., Method and Apparatus for the Formulation of Particles, Patent Application, 1995, published as WO 96/00610.

13. Palakodaty, S., York, P., Hanna, M. and Pritchard J., 1998, Crystallization of lactose using solution enhanced dispersion by supercritical fluids (SEDS) technique, In: Proceedings of the 5th Meeting on Supercritical Fluids, Nice, France, Tome 1, 275-280.

14. Sloan, R., Hollowood, M.E., Humphreys, G.O., Ashraf, W. and York, P., 1998 Supercritical Fluid Processing: Preparation of Stable Protein Particles, In: Proceedings of the 5th Meeting on Supercritical Fluids, Nice, France, Tome 1, 301-306.

15. Levine, I.N., 1995, Multi component phase equilibrium, In: Physical Chemistry 4th edn, pp 311-345, (McGraw-Hill International Editions) pp 311-345.

16. Sloan, R.., Tservistas, M., Hollowood, M.E., Sarup, L., Humphreys, G.O., Ashraf, W., York, P. and Hoare, M., 1999, Controlled particle formation of biological materials using supercritical fluids, In Proceedings of the 6th Meeting on Supercritical Fluids, Nottingham, U.K, pp 169-174.

17. Harris, B., 1991, Magic bullets, Chemistry and Industry, 7: 656-657

\section{ACKNOWLEDGEMENTS}

This work is funded by a BBSRC Industrial CASE studentship with Bradford Particle Design and affiliated with the BBSRC LINK Biochemical Engineering Programme. The authors would like to thank M.E. Hollowood, P. York and W. Ashraf for their help.

\section{ADDRESS}

Correspondence concerning this paper should be addressed to Professor Mike Hoare, Advanced Centre for Biochemical Engineering, University College London, Torrington Place, London WC1E 7JE.

This paper was presented at Research 2000, held at University of Bath 6-7 January 2000. It was received 5 October 1999 and accepted for publication without revision 4 April 2000. 